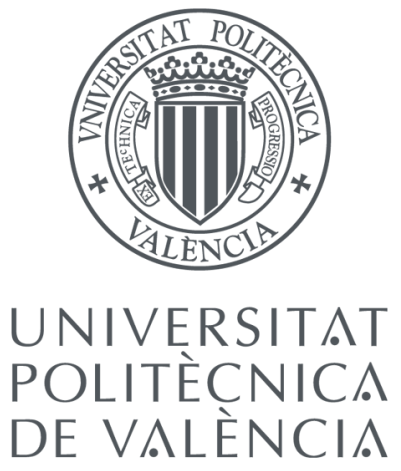

\title{
Proposal of a set of Key Performance Indicators for the environmental assessment of Higher Education Institutions
}

Vanesa G. Lo Iacono Ferreira

Advisors:

Juan Ignacio Torregrosa-López

Salvador F. Capuz-Rizo

June, 2017 

For mom and dad.

A mamá y papá. 



\section{Acknowledgements}

I would like to acknowledge the unconditional support of my advisors Dr. Juan Ignacio Torregrosa López and Dr. Salvador F. Capuz Rizo whose inestimable guidance, dedication and patience made this thesis possible. I would also like to thank Dr. José Vicente Colomer Ferrándiz for his unconditional support and encouragement. I would like to thank Dr. Masami Nakagawa for the guidance and the opportunity of exploring some new paths for this research.

I would like to thank the Universitat Politècnica de València and specially the personnel of the Environmental Office for their full support and collaboration during the development of this project. The collaboration of the staff of the Escuela Politècnica Superior de Alcoy was invaluable as was the support of the Institute for Industrial, Radiophysical and Environmental Safety. I would like to thank all the professors who have guided me along the way. I would also like to express my sincere appreciation to the anonymous reviewers of each of the articles that compose this thesis. Their precious insights helped me improve the quality of each publication.

I would like to thanks my family and friends for being there for me. My friends Lorena and Mayka who always have time and motivating words when I needed them. My friends Kyle, Yu, Pablo, Javier, Agnes, Asun, Vero, Dani, Mon, Cris, Agus, Natalia, Alberto, Laura, Antonio and Toñi who broadened my vision on the environment awareness. I would also like to thank my brothers in law, Juan and Fran and my nephew, Ashton J. just for being there. I would like to specially acknowledge my friend and colleague Dr. Javier Cardona Amengual whose inputs and assistance were invaluable.

I am forever grateful to my parents, Nelly and Duilio, my sister, Yesica, my loving husband, Jose Bernardino, and my awesome son, Alec. Under no circumstances, I would be able to complete this thesis without their wholehearted support.

$$
* * *
$$

Estaré por siempre agradecida a mis padres, Nelly y Duilio, a mi hermana, Yesica, a mi amado esposo, Jose Bernardino, y a mi asombroso hijo Alec. Bajo ninguna circunstancia podría haber completado esta tesis sin su apoyo incondicional. 



\begin{abstract}
Higher Education Institutions (HEIs) should be lighthouses for society. Therefore, they must have an exemplary behavior in all sustainability areas: economy, social and environment. The environmental awareness of the educational community - student, professors, researchers, staff and managers - has increased considerably in the first decades of this century. The Environmental Management Systems (EMS), either ISO certified or EMAS verified, have gained popularity in HEIs seeking for a better disclosure of their environmental behavior and the improvement of their environmental performance.
\end{abstract}

Due to the structure of HEIs, the EMS has difficulties when being incorporated into the overall management system. To respond in real time to the changes that occur as a result of the environmental performance of the HEI, a better integration of the environmental assessment in the overall management system is needed.

In this research, several methodologies and tools have been tested trying to improve the interaction between the environmental behavior and the general management system of the HEI. Reporting tools like the Global Reporting Initiative (GRI) and the Sustainability Tracking, Assessment \& Rating System $^{\text {TM }}$ (STARS ${ }^{\circledR}$ ) have proven to be useful to report sustainable behavior to specialize stakeholder. However, their intricacy make them difficult to used directly in the everyday management or as a disclosure tool.

The aggregated indicators like the ecological footprint have proven to be useful to communicate the environmental performance on a comprehensive way although with restrictions in the assessment. The Life Cycle Assessment (LCA) and its recently launched adaptation of the LCA for Organizations (OLCA) also allows to describe and evaluate the environmental impact of these institutions. However, the complexity of performing this type of assessment and the high requirements of quality data not always available have become a handicap.

This research analyzes the complexity of HEIs and the particularities of these tools and methodologies to propose a set of Key Performance Indicators (KPIs) for the environmental assessment of these organizations. The Universitat Politècnica de València (UPV), specially one of its environmental units (EPSA), is used as a case study.

As a result, a methodology to define the most suitable environmental KPIs for a HEI is presented. The methodology considers a life cycle approach with an operational control as a consolidation method. The environmental management system is used as the main data provider. The information 
managed by the accounting system has been explored and a classification method has been proposed to use the accounting system as a complementary source of quality data.

The methodology has been applied to the case study defining 7 environmental KPIs that assess the most significant environmental impacts of EPSA UPV and can be easily integrated in the current general management system of a HEI. 


\section{Resumen}

Las instituciones de educación superior (IES) deben ser faros para la sociedad. Deben tener un comportamiento ejemplar en todas las áreas de sostenibilidad: economía, sociedad y medio ambiente. La conciencia ambiental de la comunidad educativa - estudiantes, profesores, investigadores, personal y gestores - ha aumentado considerablemente en las primeras décadas de este siglo. Los sistemas de gestión ambiental (SGA), ya sea certificados por ISO o por EMAS, han ganado popularidad en las IES buscando la divulgación de su comportamiento y la mejora de su rendimiento medioambiental.

Debido a la estructura de las IES, el SGA tiene dificultades para incorporarse en su sistema de gestión general. Para responder en tiempo real a los cambios que se produzcan como resultado del desempeño ambiental de la IES, se necesita una mejor integración de la evaluación ambiental en el sistema de gestión general.

En esta investigación se han evaluado varías metodologías y herramientas buscando la mejora de la interacción entre el desempeño ambiental, la sociedad y el sistema de gestión de la IES. Las herramientas de información como la Iniciativa de Informes Globales (GRI, Global Reporting Initiatives) y el Sistema de Seguimiento, Evaluación y Calificación de Sostenibilidad (STARS ${ }^{\circledR)}$ han demostrado ser útiles para reportar un comportamiento sostenible a los actores e interesados especializados. Sin embargo, su complejidad hace que sea difícil de utilizar directamente en la gestión cotidiana y como herramienta de divulgación.

Los indicadores agregados, como la huella ecológica, han demostrado ser útiles para comunicar el desempeño ambiental, aunque presentan restricciones. El Análisis de Ciclo de Vida (ACV) y su adaptación recientemente lanzada del ACV para Organizaciones también permite describir y evaluar el impacto ambiental de estas instituciones salvando las restricciones. Sin embargo, la complejidad de realizar este tipo de estudios se ha convertido en una desventaja.

Los Indicadores Clave de Desempeño (KPI, Key Performance Indicators) surgen como alternativa aunando precisión con flexibilidad para informar sobre la situación ambiental de la organización y servir como herramienta en la toma de decisiones.

El objetivo de este trabajo es definir un conjunto de Indicadores Clave de Desempeño (KPI) que permitan optimizar el desempeño ambiental de las IES. Esta tesis analiza la complejidad de las IES y las particularidades de los indicadores, las herramientas y las metodologías aplicadas en IES. La Universitat Politècnica de València (UPV), en particular una de sus unidades 
medioambientales, la Escuela Politècnica Superior de Alcoy (EPSA), ha sido utiliza como caso de estudio.

Como resultado, se propone una metodología para definir los KPI ambientales más adecuados para una IES. La metodología considera un enfoque de ciclo de vida con un control operativo como método de consolidación o agregación de la información. El SGA se utiliza como principal proveedor de datos. Se explora también la información gestionada por el sistema contable. Se propone una clasificación y un método para utilizar el sistema contable como fuente complementaria de datos de calidad para la evaluación del comportamiento ambiental.

La metodología propuesta se ha aplicado al caso de estudio proporcionando siete KPI ambientales que evalúan los impactos ambientales más significativos de la EPSA UPV y que pueden integrarse fácilmente en el actual sistema de gestión general de una IES. 


\section{Resum}

Les institucions d'educació superior (IES) han de ser fars per a la societat. Han de tindre un comportament exemplar en totes les àrees de sostenibilitat: economia, societat i medi ambient. La consciència ambiental de la comunitat educativa -estudiants, professors, investigadors, personal i gestors- han augmentat considerablement en les primeres dècades d'aquest segle. Els sistemes de gestió ambiental (SGA), ja siguen certificats per ISO o per EMAS, han guanyat popularitat en les IES buscant la divulgació del seu comportament i la millora del seu rendiment mediambiental.

A causa de l'estructura de les IES, el SGA té dificultats per a incorporar-se al seu sistema de gestió general. Per tal de respondre en temps real als canvis que es produïsquen com a resultat de l'acompliment ambiental de l'IES, es necessita una millor integració de l'avaluació ambiental en el sistema de gestió general.

En aquesta recerca s'han avaluat diverses metodologies i eines cercant la millora de la interacció entre l'acompliment ambiental, la societat i el sistema de gestió de l'IES. Les eines d'informació, com ara la Iniciativa d'Informes Globals (GRI, Global Reporting Initiatives) i el Sistema de Seguiment, Avaluació i Qualificació de la sostenibilitat (STARS ${ }^{\circledR}$ ) han demostrat ser útils per a reportar un comportament sostenible als actors $i$ interessats especialitzats. No obstant això, la seua complexitat fa que siga difícil d'utilitzar directament en la gestió quotidiana i com a eina de divulgació.

Els indicadors agregats, com l'empremta ecològica, han demostrat ser útils per a comunicar l'acompliment ambiental, encara que presenten restriccions. L'Anàlisi de Cicle de Vida (ACV) i la seua adaptació llançada recentment de l'ACV per a Organitzacions també permet descriure i avaluar l'impacte ambiental d'aquestes institucions salvant les restriccions. No obstant això, la complexitat de realitzar aquesta mena d'estudis s'ha convertit en un desavantatge.

Els indicadors clau d'acompliment (KPI, Key Performance Indicators) sorgeixen com a alternativa conjuminant precisió amb flexibilitat per a informar sobre la situació ambiental de l'organització i servir com a eina en la presa de decisions.

L'objectiu d'aquest treball és definir un conjunt d'indicadors clau d'acompliment (KPI) que possibiliten optimitzar l'acompliment ambiental de les IES. Aquesta tesi analitza la complexitat de les IES i les particularitats dels indicadors, les eines i les metodologies aplicades en IES. La Universitat Politècnica de València (UPV), particularment una de les seues unitats 
mediambientals, 1'Escola Politècnica Superior d'Alcoi (EPSA), ha estat utilitzada com a cas d'estudi.

Com a resultat, es proposa una metodologia per a de definir els KPI ambientals més adequats per a una IES. La metodologia considera un enfocament de cicle de vida amb un control operatiu com a mètode de consolidació o agregació de la informació. El SGA s'utilitza com a principal proveïdor de dades. S'explora també la informació gestionada pel sistema comptable. Es proposa una classificació i un mètode per a utilitzar el sistema comptable com a font complementària de dades de qualitat per a l'avaluació del comportament ambiental.

La metodologia proposada s'ha aplicat al cas d'estudi proporcionant set KPI ambientals que avaluen els impactes ambientals més significatius de l'EPSA UPV i que poden integrar-se fàcilment en l'actual sistema de gestió general d'una IES. 


\section{TABLE OF CONTENTS}

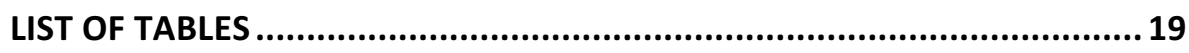

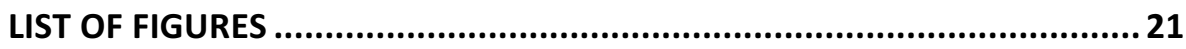

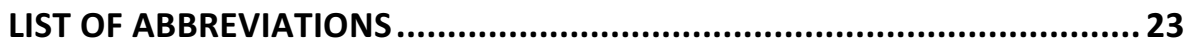

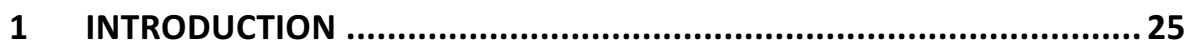

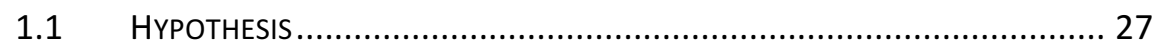

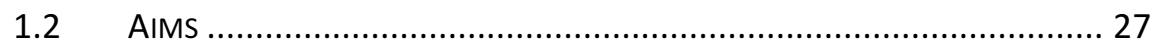

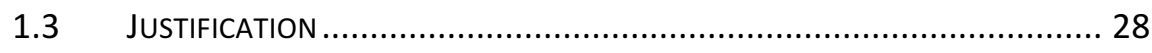

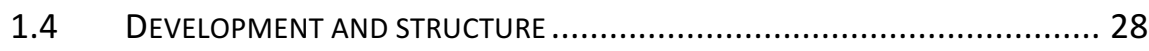

2 THE STRENGTHS OF EMAS AS AN ENVIRONMENTAL MANAGEMENT SYSTEM FOR EUROPEAN UNIVERSITY CAMPUSES ..................................33

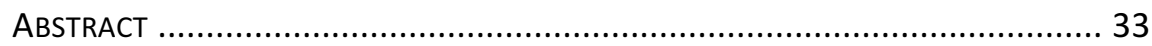

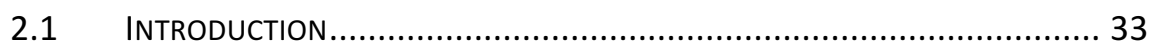

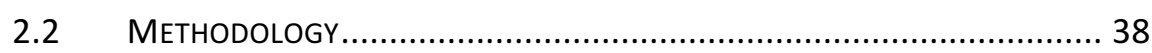

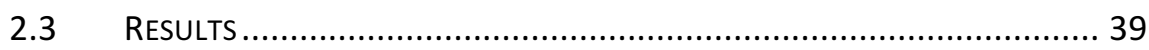

2.3.1 Background and implementation process .......................... 39

2.3.2 An overview of EMAS implementation at UPV .................... 41

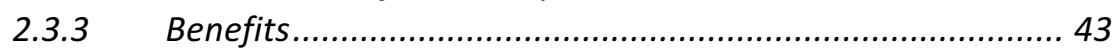

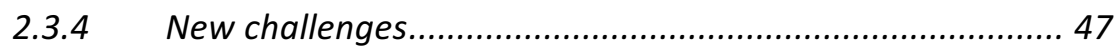

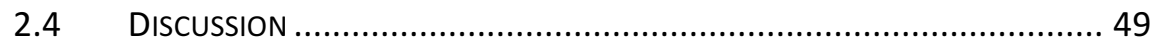

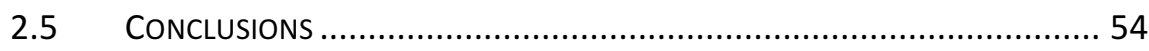

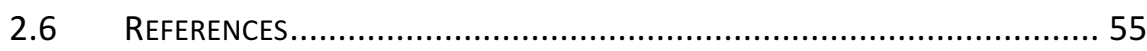

3 ECOLOGICAL FOOTPRINT ASSESSMENT OF HIGHER EDUCATION APPLYING LIFE CYCLE ASSESSMENT FRAMEWORK. CASE STUDY: UNIVERSITAT POLITÈCNICA DE VALÈNCIA .........................................59

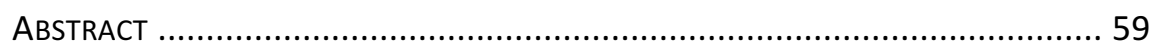

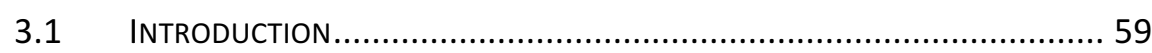

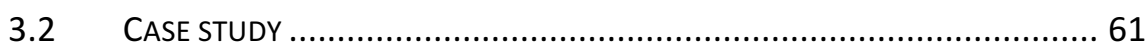

3.2.1 Definition product system, functional unit, system boundaries

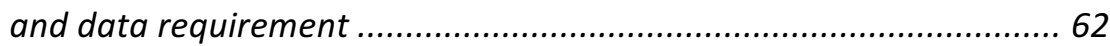

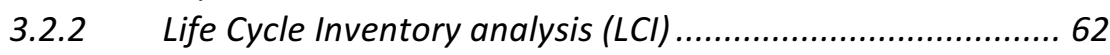

3.2.3 Life Cycle Assessment Inventory (LCAI).............................. 62

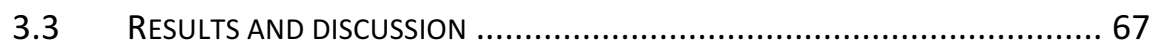

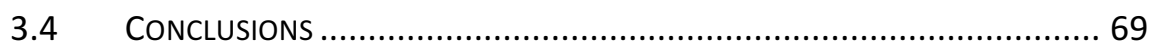

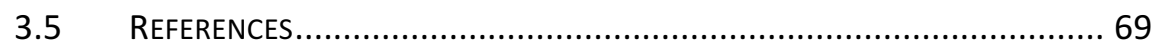


4 STUDY OF THE INCLUSION OF LIFE CYCLE ASSESSMENT IMPACT CATEGORIES IN ECOLOGICAL FOOTPRINT .........................................73

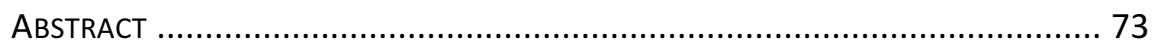

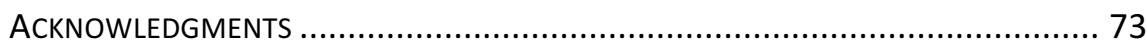

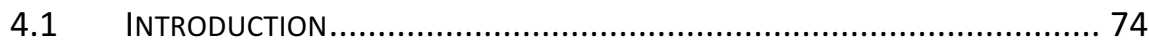

4.1.1 Life Cycle Assessment (LCA) ................................................. 74

4.1.2 Ecological Footprint (EF).................................................. 76

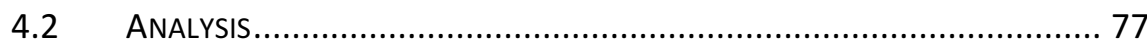

4.2.1 Including Resource category: Minerals and Fossil.............. 78

4.2.2 Introducing Ecosystem quality: Ecotoxicity, Eutrophication

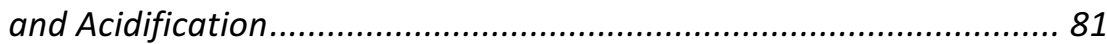

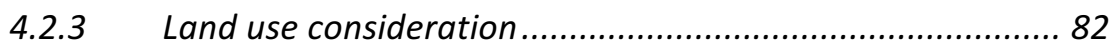

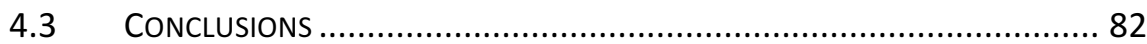

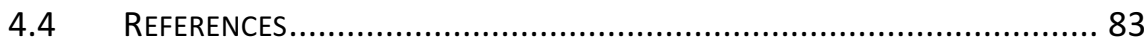

5 USE OF LIFE CYCLE ASSESSMENT METHODOLOGY IN THE ANALYSIS OF ECOLOGICAL FOOTPRINT ASSESSMENT RESULTS TO EVALUATE THE ENVIRONMENTAL PERFORMANCE OF UNIVERSITIES ............................87

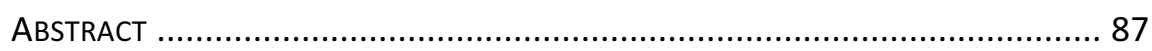

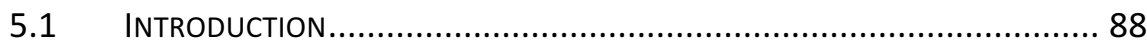

5.2 LITERATURE REVIEW OF LCA AND EFA AS PERFORMANCE TOOLS FOR

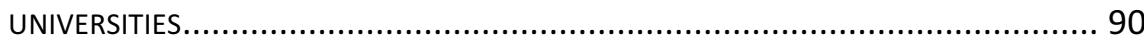

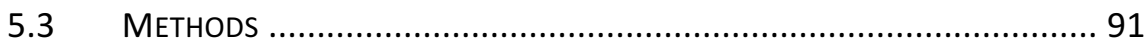

5.4 RESULTS AND DISCUSSION .......................................................... 93

5.4.1 Step 1. Definition of the specific decision to consider in general LCA methodology ............................................................. 93

5.4.2 Step 2. Develop a complete case study............................. 95

5.4.3 Step 3. Analyze other studies of the use of EFA by universities 102

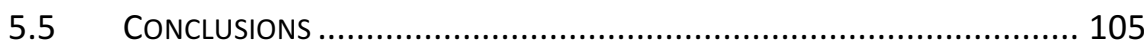

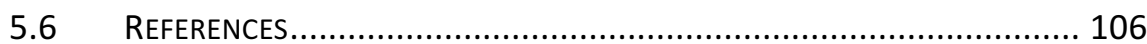

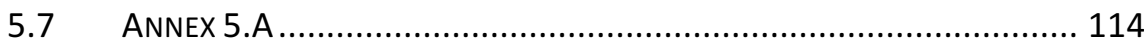

6 ORGANIZATIONAL LIFE CYCLE ASSESSMENT: SUITABILITY AND METHODOLOGICAL PROPOSAL FOR HIGHER EDUCATION INSTITUTIONS. 119

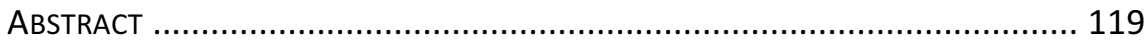

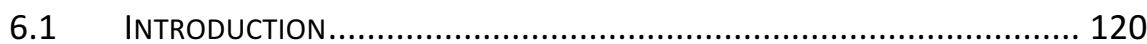

6.1.1 Literature review of O-LCA for organizations ................... 123

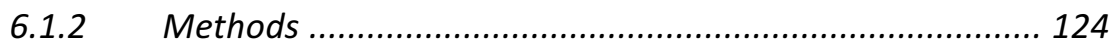

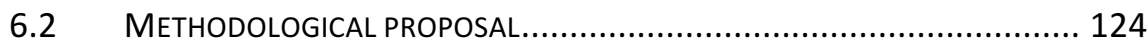




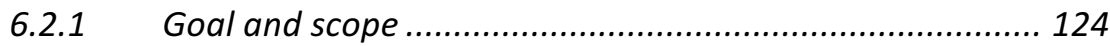

6.2.2 Life Cycle Inventory analysis (LCI) ................................ 127

6.2.3 Life Cycle Impact Assessment (LCIA) and results

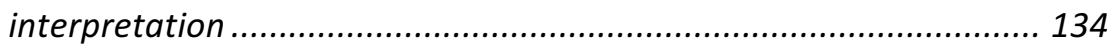

6.3 RESULTS: APPLICATION OF METHODOLOGY TO EPSA CASE STUDY (PILOT EU) 136

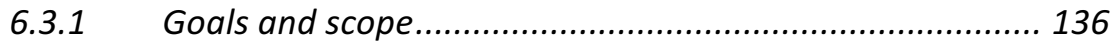

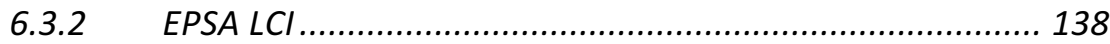

6.3.3 EPSA results interpretation ............................................ 146

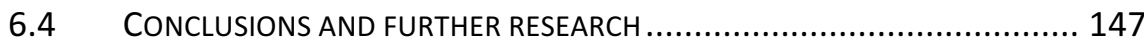

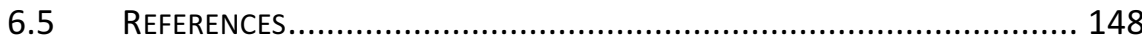

6.6 ANNEX 6.A COMPARISON BETWEEN ISO 14072:2014 AND EMAS

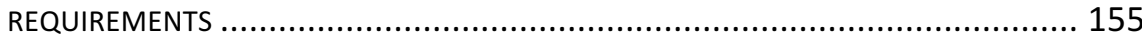

6.7 ANNEX 6.B EPSA AND UPV DETAILS FOR 2015 ................................ 165

6.8 ANNEX 6.C PRIORITIZATION PROCEDURE FOR LCI ANALYSIS OF EPSA ..... 166

7 THE ACCOUNTING SYSTEM AS COMPLEMENTARY DATA SOURCE FOR ORGANIZATIONAL LIFE CYCLE ASSESSMENT OF HIGHER EDUCATION

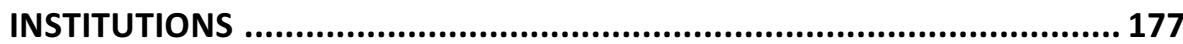

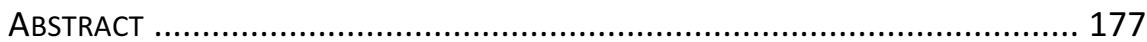

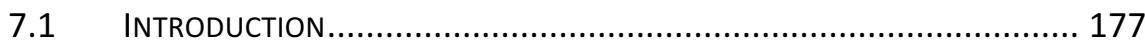

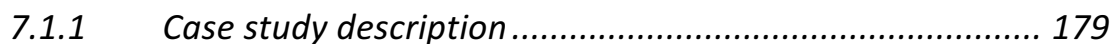

7.2 METHOD: ACCOUNTING SYSTEM AND BUDGET ANALYSIS...................... 180

7.2.1 Registers classification proposal...................................... 183

7.3 RESULTS: EPSA AVAILABLE ENVIRONMENTAL QUALITY DATA ................. 187

7.4 DISCUSSION AND CONCLUSIONS: STRUCTURE, COVERAGE AND QUALITY ... 190

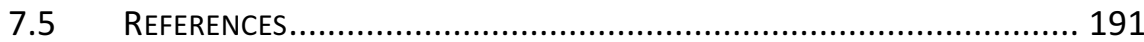

\section{APPLICABILITY OF GLOBAL REPORTING INITIATIVE TO ASSESS THE} ENVIRONMENTAL PERFORMANCE OF HIGHER EDUCATION INSTITUTIONS.

193

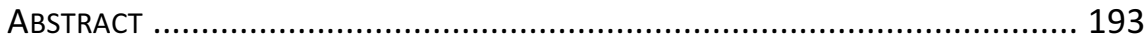

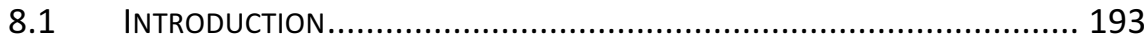

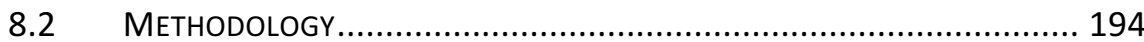

8.2.1 Step 1. Select the most suitable GRI guide for universities 195

8.2.2 Step 2. Extract those indicators related to the environmental aspect 196

8.2.3 Step 3. Case study. Analyze indicators environmentally related 200

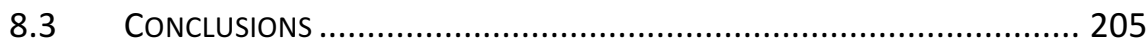

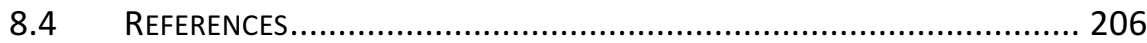


9 KEY PERFORMANCE INDICATORS TO ASSESS ENVIRONMENTAL PERFORMANCE OF HIGHER EDUCATION INSTITUTIONS. CASE STUDY OF UNIVERSITAT POLITÈCNICA DE VALÈNCIA.......................................... 209

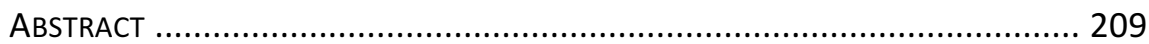

9.1 INTRODUCTION..................................................................... 210

9.1.1 Literature review over environmental indicators relevant to HEls 214

9.1.2 Methods .................................................................. 216

9.2 METHOdOLOGICAL PROPOSAL..................................................... 216

9.2.1 Definition of the reporting organization......................... 217

9.2.2 Identification of relevant environmental aspects............. 219

9.2.3 Definition of KPls ....................................................... 221

9.2.4 Validation method: meta-performance evaluation.......... 222

9.2.5 Continuous improvement cycle and reporting.................. 223

9.3 RESULTS: DEFINITION OF ENVIRONMENTAL KPIS FOR EPSA ................. 223

9.3.1 Definition of the reporting organization: EPSA................ 223

9.3.2 Identification of relevant environmental aspects............. 224

9.3.3 Goals definition.......................................................... 226

9.3.4 KPls definition ....................................................... 226

9.3.5 Assessment of environmental KPIs for EPSA................... 230

9.3.6 Validation ................................................................ 232

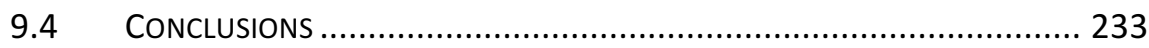

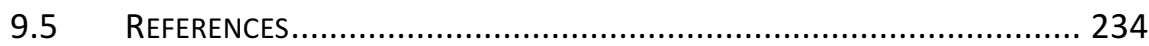

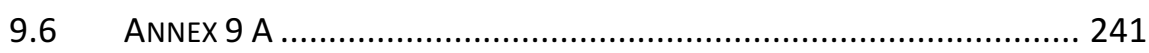

9.7 ANNEX 9 B. VALIDATION METHOD ............................................ 273

10 GENERAL DISCUSSION OF RESULTS, CONCLUSIONS AND FURTHER

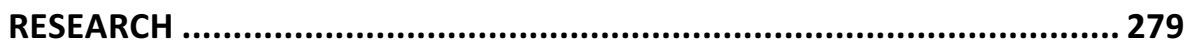

10.1 REGARDING THE STUDY OF ASSESSMENT TOOLS AND METHODOLOGICAL

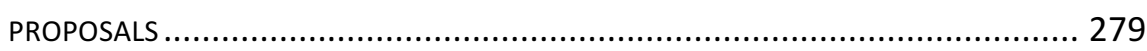

10.2 RESULTS DISCUSSION, CONCLUSIONS FOR THE CASE STUDY, EPSA ......... 283

10.3 SUMMARY ................................................................. 287

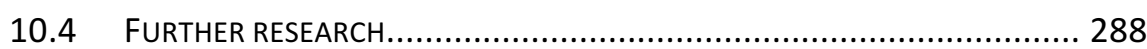

11 REFERENCES ............................................................ 295

12 ANNEX 1: COMPARATIVE ANALYSIS OF THE METHODOLOGY OF CALCULATION OF EF IN DIFFERENT AREAS. .................................... 319

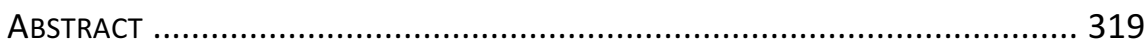

12.1 INTRODUCTION AND GOALS ................................................... 319

12.2 EF METHODOLOGIES AND ITS APPLICATIONS................................ 321 


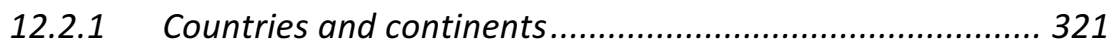

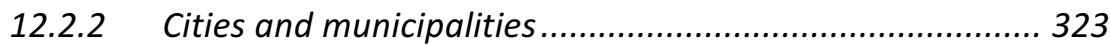

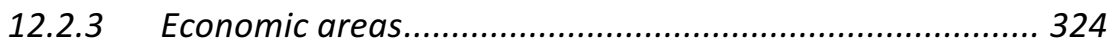

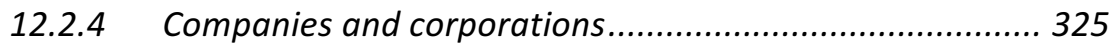

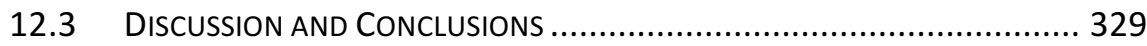

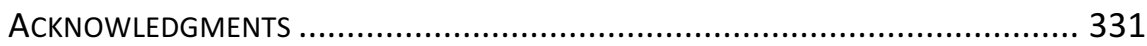

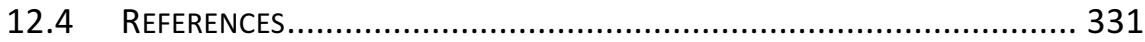





\section{LIST OF TABLES}

TABLE 1-1 SCHEME OF THE DISSERTATION. 30

TABLE 2-1 LIST OF UNIVERSITIES AND HIGHER EDUCATION INSTITUTIONS THAT HAVE REPORTED

EMAS VERIFICATION IN ALL OR A PART OF THE ORGANIZATION IN LAST 12 YEARS .............36

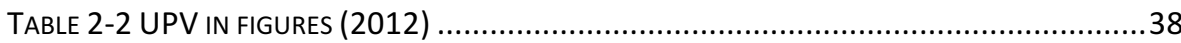

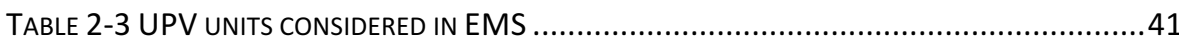

TABLE 2-4 LIST OF ENVIRONMENTAL INTERACTIONS ASSESSED IN NORMAL OPERATING CONDITIONS

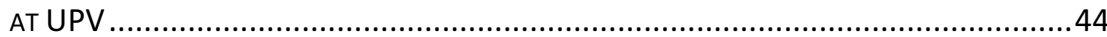

TABLE 2-5 SUMMARY OF EMAS DOCUMENTATION AT UPV ........................................ 46

TABLE 2-6 SUMMARY OF BENEFITS AND CHALLENGES OF THE EMS AT UPV ACCORDING TO STAKEHOLDER'S OPINION COLLECTED WITH QUESTIONNAIRES ....................................4 48

TABLE 2-7 RECOMMENDATIONS OF LOZANO (2006B) FOR IMPLEMENTING SUSTAINABLE DEVELOPMENT (SD) AT UNIVERSITIES AND UPV ACTIONS ACCORDING TO IMPLEMENTATION

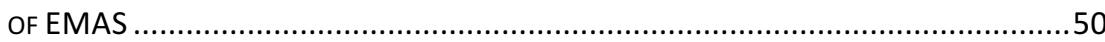

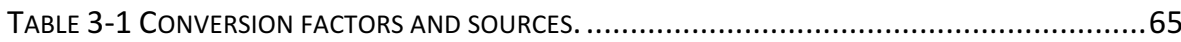

TABLE 3-2 ECOLOGICAL FOOTPRINT BY ASPECTS AND BY FUNCTIONAL UNIT (STUDENTS) IN GHA ....68

TABLE 4-1 ECO-INDICATOR 99 STRUCTURE. (GOEDKOOP \& SPRIENSMA, 2001) .......................77

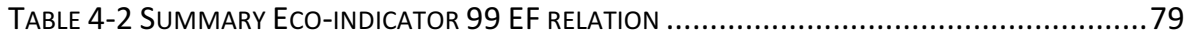

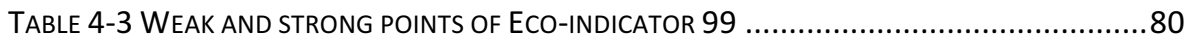

TABLE 4-4 EXERGY LOSS VALUES ACCORDING TO NGUYEN ................................................. 80

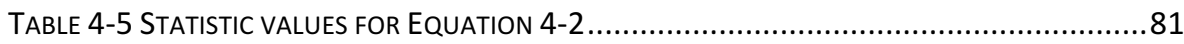

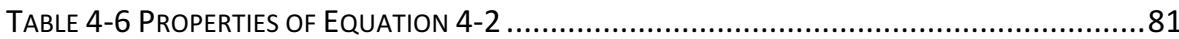

TABLE 4-7 REMOVAL RATES OF AIR POLLUTANTS BY LAND USE ACCORDING TO JIM \& CHEN FOR

GUANGZHOU CITY IN CHINA. ..................................................................... 82

TABLE 5-1 REFERENCES OF CONVERSION FACTORS USED IN THE CASE STUDY ..........................99

TABLE 5-2 CRITICAL DECISIONS OF EFA STUDIES..................................................... 114

TABLE 6-1 SCORE ASSIGNMENT RULE FOR ACTIVITIES AND PROCESSES BASED ON EAS AND CS

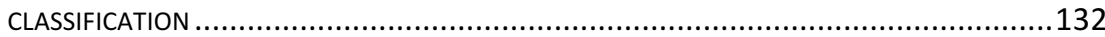

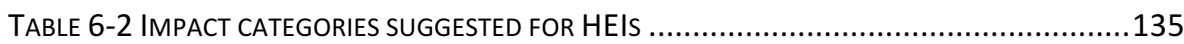

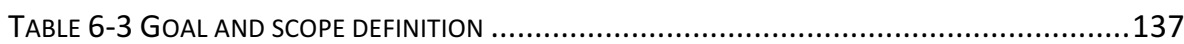

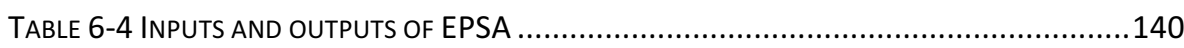

TABLE 6-5 PRIORITIZED LIST OF ACTIVITIES AND PROCESSES FOR EPSA .................................143

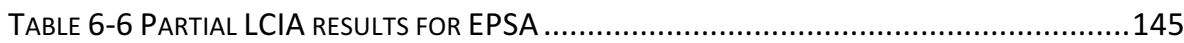

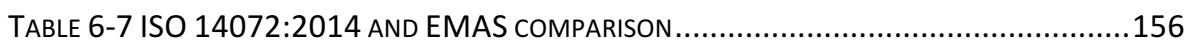

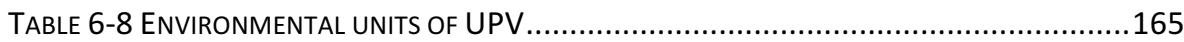

TABLE 6-9 MATRIX OF ACTIVITIES AND PROCESSES FOR SIGNIFICANT (S) EA .........................166

TABLE 6-10 MATRIX OF ACTIVITIES AND PROCESSES FOR INSIGNIFICANT (NS) EA ...................172

TABLE 6-11 SUMMARY MATRIX OF ACTIVITIES AND PROCESSES FOR SIGNIFICANT (S) AND

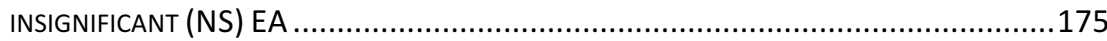

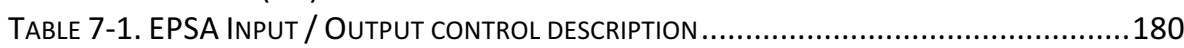

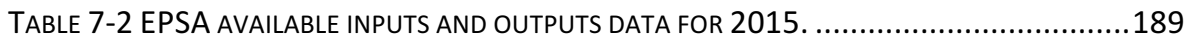

TABLE 8-1 IDENTIFIED MATERIAL ASPECTS AND BOUNDARIES INDICATORS ..............................197 


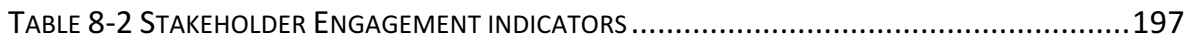

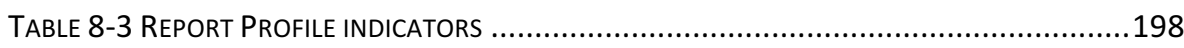

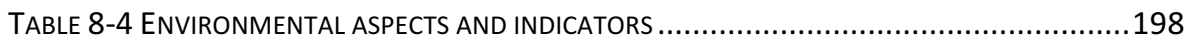

TABLE 8-5 ENVIRONMENTAL INDICATORS APPLICABILITY ASSESSMENT ....................................201

TABLE 9-1 ACTIVITIES AND PROCESSES TAKING PLACE AT EPSA ..........................................22

TABLE 9-2 EA OF EPSA. LIST IN ORDER OF PRIORITY TOP-DOWN (MOST RELEVANT ON TOP)......225

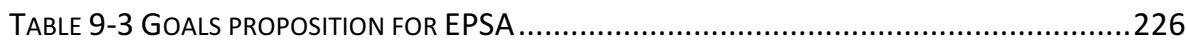

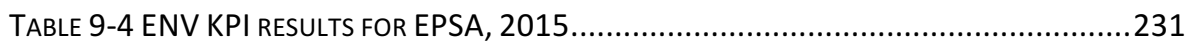

TABLE 9-5 AIR POLLUTION INDICATORS APPLICABLE TO HEIS ..............................................243

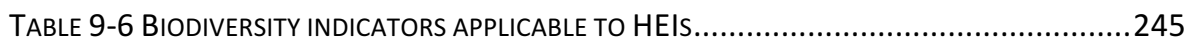

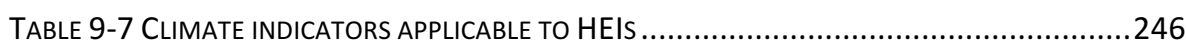

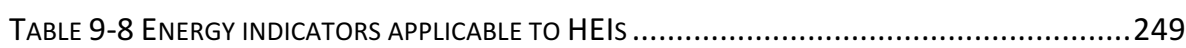

TABLE 9-9 ENVIRONMENTAL SCENARIO INDICATORS APPLICABLE TO HEIS ..............................251

TABLE 9-10 FOOD AND BEVERAGE INDICATORS APPLICABLE TO HEIS ...................................253

TABLE 9-11 GREEN ECONOMY INDICATORS APPLICABLE TO HEIS .........................................254

TABLE 9-12 INFRASTRUCTURE INDICATORS APPLICABLE TO HEIS ........................................256

TABLE 9-13 LAND USE INDICATORS APPLICABLE TO HEIS...............................................258

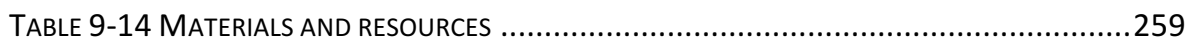

TABLE 9-15 MOBILITY INDICATORS APPLICABLE TO HEIS..................................................262

TABLE 9-16 WASTE AND EFFLUENTS INDICATORS APPLICABLE TO HEIS .................................266

TABLE 9-17 WATER INDICATORS APPLICABLE TO HEIS..................................................270

TABLE 9-18 LEVEL 1 KEY GOOD-PRACTICE FACTORS AND ITS META-PERFORMANCE EVALUATION INDICATORS FOR ENVIRONMENTAL KPIS FOR HEIS ............................................274

TABLE 9-19 LEVEL 2 KEY GOOD-PRACTICE FACTORS AND ITS META-PERFORMANCE EVALUATION INDICATORS FOR ENVIRONMENTAL KPIS FOR HEIS ...........................................276

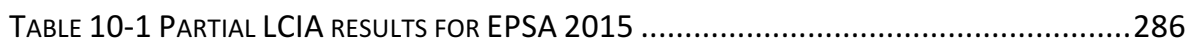

TABLE 10-2 PRIORITIZED LIST OF ACTIVITIES AND PROCESSES FOR EPSA ................................289

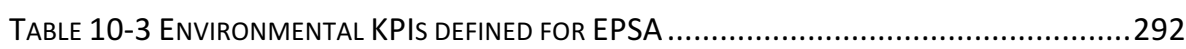

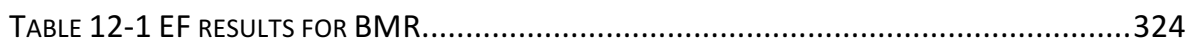

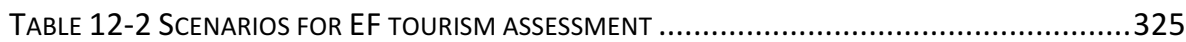

TABLE 12-3 GIJON PORT CORPORATION ECOLOGICAL AND CARBON FOOTPRINT RESULTS. ..........326

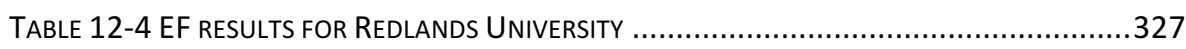

TABLE 12-5 EF RESULTS BY ASPECTS FOR UNIVERSITAT POLITÈCNICA DE VALÈNCIA ....................328

TABLE 12-6 EF RESULTS FOR UNIVERSITAT PolitèCNICA DE VALÈNCIA ...................................329

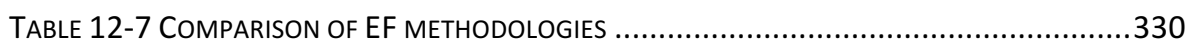




\section{LIST OF FIGURES}

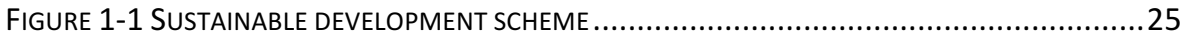

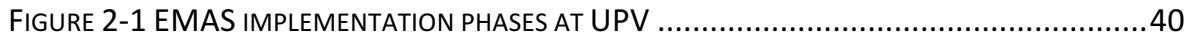

FIGURE 2-2 TYPICAL ORGANIZATION CHART OF PUBLIC UNIVERSITY IN SPAIN ............................43

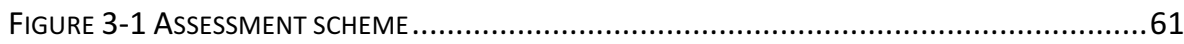

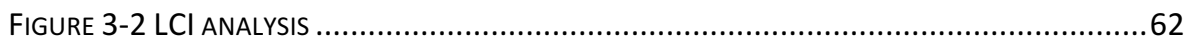

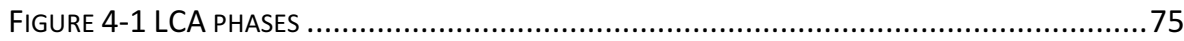

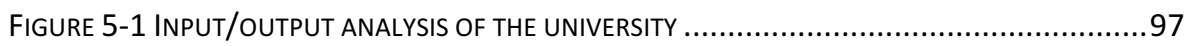

FIGURE 5-2 RESULTS OF UPV'S CASE STUDY: ECOLOGICAL FOOTPRINT. .............................100

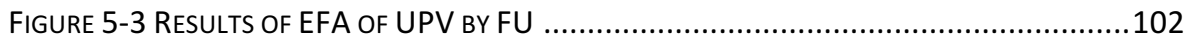

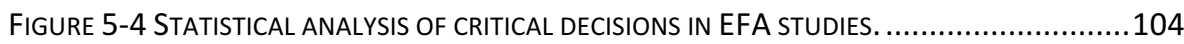

FiguRE 5-5 PERCENTAGE OF STUDIES THAT CONSIDERED EACH ENVIRONMENTAL ASPECT ............105

Figure 6-1 Procedure to analyze EU flows. DeVELOPED by the AUthors .......................128

FIGURE 6-2 PRIORITIZATION OF DATA COLLECTION EFFORTS AND CUT-OFF PROCEDURE. ............131

FIGURE 6-3 TOP-DOWN PRIORITIZATION APPROACH WITH 95\% CUT-OFF CRITERION SCHEME ....133

FIGURE 6-4 RESULTS INTERPRETATION PROCEDURE SUGGESTED FOR HEIS...............................135

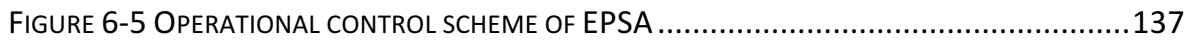

FiguRE 6-6 ACTIVITIES AND PROCESSES OF EPSA. DEVELOPED BY THE AUTHORS ON THE BASIS OF

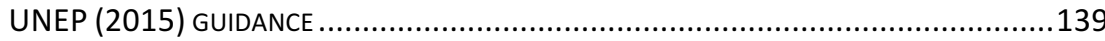

FIGURE 6-7 RESULTS OF THE WASTE GENERATION BY TYPE OF WASTE INVENTORY INDICATOR FOR

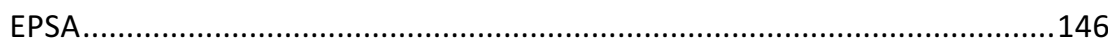

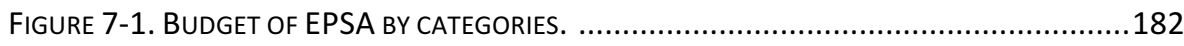

FIGURE 7-2. MONETARY DISTRIBUTION OF EPSA INPUTS FOR 2015 BY CATEGORY. ...................184

FIGURE 7-3. ANALYSIS OF REGISTERS OF THE MATERIAL CATEGORY FOR EPSA 2015 ................185

FIgURE 7-4. ANALYSIS OF EXTRAORDINARY TRAVELLING OF STAFF AND STUDENTS OF EPSA FOR

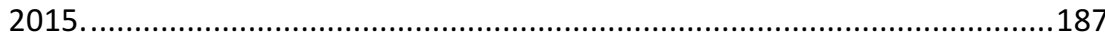

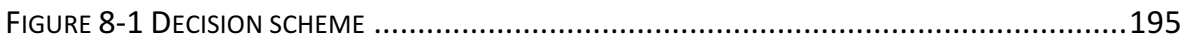

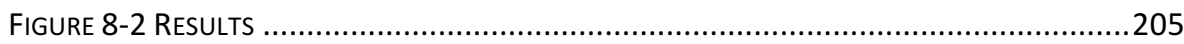

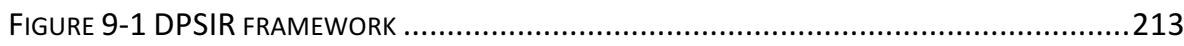

FIGURE 9-2 METHODOLOGICAL PROCEDURE PROPOSAL FOR THE DEFINITIONS OF ENVIRONMENTAL

KPIS FOR HEIS WITH EMS...................................................................217

Figure 9-3 PRIORITIZATION PROCEDURE CROSS-SCORE EAS-CS. FOR MORE DETAILS SEE LO-

IACONO-FERREIRA ET AL. (2017) DEFINITION OF GOALS ......................................220

FIGURE 10-1 RESULTS OF UPV'S CASE STUDY: ECOLOGICAL FOOTPRINT...............................284

FIGURE 10-2. ACTIVITIES AND PROCESSES OF HEIS PREPARED BY THE AUTHORS ON THE BASIS OF

UNEP (2015) GUIDANCE. PUBLISHED IN LO-IACONO-FERREIRA ET AL., (2017).............285

FIGURE 10-3 RESULTS OF THE WASTE GENERATION BY TYPE OF WASTE. INVENTORY INDICATOR FOR

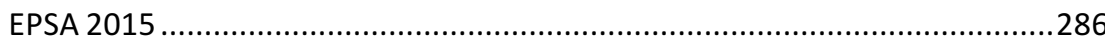





\section{LIST OF ABBREVIATIONS}

BUA: BUILD-UP AREA

CC: COMPLETE CONTROL

CDP: CARBON DISCLOSURE PROJECT

CF: CARBON FOOTPRINT

CO2E: CARBON DIOXIDE EQUIVALENT.

CS: CONTROL STATE

EA: ENVIRONMENTAL ASPECT

EAS: ENVIRONMENTAL ASPECT STATE

EC: EUROPEAN COMMISSION

EF: ECOLOGICAL FOOTPRINT

EFA: ECOLOGICAL FOOTPRINT ASSESSMENT

EMAS: ECO-MANAGEMENT AND AUDIT SCHEME

EMS: ENVIRONMENTAL MANAGEMENT SYSTEM

EPIS: ENVIRONMENTAL PERFORMANCE INDICATORS

EPSA: HIGHER POLYTECHNIC SCHOOL OF ALCOY (ESCUELA POLITÉCNICA SUPERIOR DE ALCOY IN SPANISH)

EO: ENVIRONMENTAL OFFICE

EU: ENVIRONMENTAL UNIT

FTE: FULL-TIME EQUIVALENT

FU: FUNCTIONAL UNIT

GHA: GLOBAL HECTARES

GHG: GREENHOUSE GASES

GRI: GLOBAL REPORTING INITIATIVE

HEI: HIGHER EDUCATION INSTITUTION

ISO: INTERNATIONAL STANDARD ORGANIZATION

KPI: KEY PERFORMANCE INDICATOR

LCA: LIFE CYCLE ASSESSMENT

LCI: LIFE CYCLE INVENTORY

LCIA: LIFE CYCLE IMPACT ASSESSMENT

MPI: MANAGEMENT PERFORMANCE INDICATORS

NS: INSIGNIFICANT

O-LCA: ORGANIZATIONAL LIFE CYCLE ASSESSMENT

OEF: ORGANIZATIONAL ENVIRONMENTAL FOOTPRINT

OPI: OPERATIONAL PERFORMANCE INDICATORS

PC: PARTIAL CONTROL

PIS: PERFORMANCE INDICATORS

S: SIGNIFICANT

SB: SYSTEM BOUNDARIES

SD: SUSTAINABLE DEVELOPMENT

STARS: SUSTAINABILITY TRACKING, ASSESSMENT \& RATING SYSTEM

UC: UNCONTROLLED

UNEP: UNITED NATIONS ENVIRONMENT PROGRAM

UPV: UNIVERSITAT POLITÈCNICA DE VALÈNCIA 



\section{INTRODUCTION}

Since the Rio summit in 1992, most of all organizations, big and small, start gaining awareness over the sustainable development (Brundtland Commission, 1987). The environment is one of the three well-known areas of sustainability (Figure 1-1). An enterprise is only viable if economic impacts are in accordance with the environmental impact. Equity is only possible when society is well represented and attended. Actions are bearable when environment and society are preserved. However, sustainability is only achieved when economy, society and environment are in harmony. This dissertation considers, mainly, the environmental area of the sustainable development scheme.

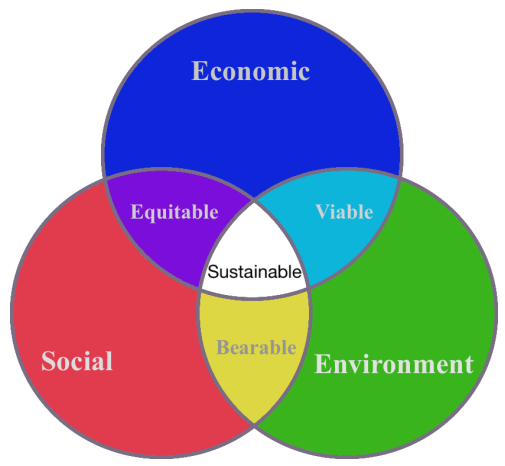

Figure 1-1 Sustainable development scheme

A Higher Education Institution (HEI) is the place where a part of the society is educated and trained to performed and lead all kind of organizations, activities and projects in the real world. The way these projects are performed makes a direct impact in the economy, the society and the environment worldwide; therefore, it contributes or harms the sustainable development.

Benefits of the continuous assessment of environmental performance of a HEI are not under discussion. As lighthouses of society and trainers of future members of the decisions-boards of industries, organizations, local and national governments, etc. giving example of environmental awareness and active action to minimize the environmental impact for the preservation of resources has to be one of the main responsibilities of a HEI (Alonso-Almeida, et al., 2015).

The International Organization for Standardization (ISO) defines the elements of an activity or process of any organization that can interact with the environment as environmental aspects (EA) (International Organization for Standardization, 2015). The relevant EA must be identified by the 
organization based on certain criteria. To identify and monitor the EA as a consequence of the operation of HEIs, Environmental Management System (EMS) has been progressively implemented (Clarke and Kouri, 2009). The degree of commitment and the depth of analysis are different depending on the institutions, their goal and resources (Gustavo de lima et al., 2016; Hancock and Nuttman, 2014; Lozano et al., 2015).

The assessment of these EAs has been carried out with different tools and a wide range of accuracy. Several reviews have been made categorizing the tools available. For example, Singh et al, (2012) analyzes 41 sustainable indexes where 12 are environmental indexes. Braulio-Gonzalo et al. (2015) and Michael et al., (2014) study the 13 most relevant tools to assess urban sustainability where the environment is highly represented. Further in this dissertation, over 120 environmental indicators applicable to HEIs will be analyzed and classified (Chapter 9).

Life Cycle Assessment (LCA), Carbon Footprint (CF) and Ecological Footprint Assessment (EFA) are the most used in HEIs (Alshuwaikhat and Abubakar, 2008). Reporting tools to communicate the performance of the institution are also part of desire to improve environmental performance as a particular area of sustainable development. Global Reporting Initiative (GRI) and Sustainability Tracking, Assessment \& Rating System (STARS) are the preferred (Hespenheide, 2015; Urbanski \& Filho, 2014). However, HEIs have an inherent difficulty to report their environmental behavior due to the complexity of the organization (Lozano, 2011).

Key Performance Indicators (KPIs) are indexes used to evaluate the degree of development of a project or the state of crucial aspects or factors of an organization (Kerzner, 2011; Zaman, 2014). KPIs shall be SMART, meaning that they have to be Specific, Measurable, Achievable, Relevant and Timely. Additionally, they must gather the characteristics of any performance indicator; i.e. intelligible, useful, normalized, sensitive, coherent and representative (Doran, 1981). A detailed definition and analysis is presented in Chapter 9.

Although KPIs were conceived to assess economic performance, the characteristics that defined a key indicator can also be applied to those related to the environment (Doran, 1981, Smeets and Weterings, 1999). Environmental KPIs, due to their nature, are fully embeddable both in an EMS and in the overall decision-making framework of any organization, including HEIs. A set of KPIs that represent the critical factors of a HEI may be a promising decision-making tool. 


\subsection{HYPOTHESIS}

The hypothesis to be proven or rejected in this dissertation is that a set of KPIs environmentally related can be defined according to the specific characteristics of a complex organization as a HEI. The procedure of definition can be normalized in order to be applicable to any HEI.

Special attention is paid to HEIs with robust EMS, either certified in ISO 14001 or verified in EMAS. Universitat Politècnica de València (UPV), a medium-size technical HEI verified in EMAS, is used as a case study.

\subsection{AIMS}

The aim of this study is to define and propose a set of environmental KPIs seeking the optimization of the environmental performance of HEIs. In order to accomplish this purpose, the following goals have been defined:

- Study the environmental assessment methodologies available and their suitability to HEIs.

Several environmental assessment methodologies can be found in the literature. Some of them have already been applied to HEIs. Studying these methodologies and their suitability to HEIs is essential to understand the way how environmental assessments are developed, since the final goal of this work is to assess the environmental performance.

- Analyze the environmental indicators used at HEIs.

The literature and the public reports of institutions, governments and organizations gathered a wide number of indicators related to the environment. Analyzing these indicators is essential to build an overall image of the state of the art. Furthermore, other indicators than environmental indicators related to sustainable development may give valuable information to accomplish the main goal of this research.

- Define a set of KPIs.

Based on the previous research, a list of KPIs is defined and justified. UPV is used as a Case Study.

- Propose a guidance to assess the KPIs defined.

In order to make the results of this work applicable to a wide number of HEIs, a procedure for the election of KPIs is developed and explained. 


\subsection{JUSTIFICATION}

HEIs must be examples of innovation, wisdom and sustainability. The environmental performance of an institution which trains future decisionmakers has to be as good as possible to serve as a lighthouse of environmental responsibility. Assessing and reporting the environmental performance of the institution is essential to be able to include the environmental perspective in the overall management of the institution. The opportunity of a continuous progress minimizing the environmental impact is an opportunity that should not be missed.

There is a large number of environmental indicators and reporting initiatives defined and developed to assess and/or communicate environmental and sustainable performance. Notable among these are: The Ecological Footprint (EF) (Wackernagel \& Rees, 1996), the Carbon Footprint (CF) (International Organization for Standardization, 2013a), the Life Cycle Assessment (LCA) (International Organization for Standardization, 2006a), the Organizational Life Cycle Assessment (O-LCA) (International Organization for Standardization, 2014a), Global Reporting Initiative (GRI) (Global Reporting Initiative, 2013a) and Sustainability Tracking, Assessment \& Rating System (STARS) (The Association for the Advancement of Sustainability in Higher Education, 2016). Except for STARS, none of the previous methods mentioned were developed specifically for HEIs. STARS is a widely applied sustainability reporting tool. However, the complexity of the indicators that compose STARS methods make them difficult to be integrated as elements of the decision-making process of the organization.

In order to extract relevant information for daily decision-making processes toward the improvement of the environmental performance of HEIs, factually measurable, easy-to-use, relevant, achievable and timely indicators are needed. These are some of the characteristics of KPIs. As a result of this research, a methodology to define suitable indicators, KPIs, for HEIs is developed solving the lack of a tool to include environmental performance in the overall management system fully applicable to HEIs. UPV is used as case study due to the accessibility of data and the consolidated EMS verified in EMAS since 2009. A specific set of KPIs for UPV are also proposed.

\subsection{DEVELOPMENT AND STRUCTURE}

This dissertation is presented as a compendium of seven published articles. The document is structured in eleven chapters plus an annex. Seven of the chapters and the annex are the authors' version of works already published. Each chapter stands for a stage of the research. Articles have been published in journals and congress proceedings; in both cases, under peer review 
process. In this section, the history of how the dissertation has been conceived is described as a path to present the structure of the document. A short introduction, full reference and abstracts are provided in the first page of each chapter.

Table 1-1 is presented as a summary scheme of the dissertation where both published articles and complementary content are included accompanied by a short description. The full description of the structure is now presented.

The research started with a first state of the art of the use of EF. This analysis revealed that almost 30 HEIs assessed and published the EF of their organization. As a result, EFA has been highlighted as a possible tool to systematically assess the environmental performance of HEIs.

On a second stage, an analysis over how theses assessments were developed revealed that the methodology of EFA, originally defined for countries, was ambiguous and unclear for its application in this kind of complex organizations. These findings were part of a multidisciplinary project directed by $\mathrm{PhD}$. Salvador F. Capuz-Rizo carried out between 2010 and 2011. An EMS verified in EMAS is expected to be able to meet the requirements of the environmental assessment of the organization; in this case, an EFA. The main goal of the project was identifying the EA of UPV to be assessed and strengthen the connections between the EMS operating at the HEI and the research groups involved promoting synergies. Two published works result from this multidisciplinary project:

- a deep analysis of the EMS in HEIs environments published in the International Journal of Environment and Sustainable Development presented in chapter 2. This article aims to analyze HEIs and their complex structure focusing on the implementation and operation of their EMS. Strengths and weaknesses of EMS verified in EMAS, as the one implemented at UPV, are highlighted.

- a methodological proposal to assess EF at HEIs with special attention to EMAS characteristics. The inability of the basic EF methodology to adapt to the complexity of HEIs suggested a new approach; the inclusion of life cycle concept. In chapter 3, a methodology proposal for assessing EF in HEIs is presented along with the results of its application to the case study. The paper was presented as an oral communication at the XX International Congress on Project Management and Engineering in Cartagena (Spain) and further published in the congress proceedings.

The research continued with the study of the inclusion of life cycle assessment impact categories in EFA as a mechanism to better assess the environmental performance of HEIs. The conclusions of this stage have been presented at the 
XV International Congress on Project Management in Huesca (Spain) as an oral communication. The final article published in the congress proceedings is included in chapter 4 .

The discussion over the suitability of including life cycle impact categories in the EFA developed into the consideration of assessing the EF applying the LCA methodology. Chapter 5 presents the article published in the Journal of Cleaner Production with a wide discussion over the use of LCA methodology to assess EF. A full case study for UPV is included.

Table 1-1 Scheme of the dissertation

\begin{tabular}{l|l|l} 
Chapter & Main goal & Published \\
\hline Chapter 1 & Introduction of the dissertation & No \\
\hline Chapter 2 & $\begin{array}{l}\text { Analysis of HEIs EMS with special attention } \\
\text { to those verified in EMAS. }\end{array}$ & Yes \\
\hline Chapter 3 & $\begin{array}{l}\text { Study of EFA of HEIs from a life cycle point } \\
\text { of view. }\end{array}$ & Yes \\
\hline Chapter 4 & $\begin{array}{l}\text { Study the inclusion of life cycle impact } \\
\text { categories in EFA of HEIs. }\end{array}$ & Yes \\
\hline Chapter 5 & $\begin{array}{l}\text { Analysis of EFA results for HEIs with LCA } \\
\text { methodology. }\end{array}$ & Yes \\
\hline Chapter 6 & $\begin{array}{l}\text { Study of the suitability of OLCA for HEIs. } \\
\text { A methodological proposal is presented. }\end{array}$ & Yes \\
\hline Chapter 7 & $\begin{array}{l}\text { Data source and data quality analysis of } \\
\text { EPSA, an EU of UPV. }\end{array}$ & In press \\
\hline Chapter 8 & Study of the applicability of GRI on HEIs & Yes \\
\hline Chapter 9 & $\begin{array}{l}\text { Methodological proposal to define a set of } \\
\text { environmental KPIs for HEIs. }\end{array}$ & $\begin{array}{l}\text { Under } \\
\text { review }\end{array}$ \\
\hline Chapter 10 & $\begin{array}{l}\text { General discussion of results, conclusions } \\
\text { and further research }\end{array}$ & No \\
\hline Chapter 11 & References & $\begin{array}{l}\text { No } \\
\text { methodologies for different areas }\end{array}$ \\
\hline Annex & Yes \\
\hline
\end{tabular}

Finding over the application of life cycle concepts to EFA of universities along with the launch of a new standard specific to assess life cycle of organizations lead out to the study of the suitability of this new standard for the Life Cycle Assessment of Organizations (O-LCA). The analysis has been published in the International Journal of Life Cycle Assessment and is presented in chapter 6 . 
O-LCA has proven to be a suitable for HEIs and a useful tool to guide strategic plans in a mid or long therm. However, the high amount of resources (human, timing and economics) required highlights the need of an alternative tool appropriate for daily decision making processes.

The availability and quality of environmental data has been a continuous issue in the overall research. Therefore, a deep analysis of one of the colleges of UPV has been carried out. This analysis has been focused on one of the EU of UPV, EPSA, as a pilot. Results has been presented as a congress proceeding for the XXI International Congress on Project Management and Engineering that will take place in Cadiz (Spain) the $12^{\text {th }}$ to $14^{\text {th }}$ of July 2017. The communication state is in press at the time of presenting this thesis. Although it is not published yet, it is considered a relevant contribution to the general outcome. For this reason, the data sources and quality analysis of EPSA are presented in chapter 7.

Meanwhile, the reporting tools available have also been studied. STARS, as a specific reporting tool developed for HEIs and GRI. GRI has been underscored due to the simplicity of its indicators. An applicability analysis of GRI for HEIs has been presented as oral communication and published in the proceedings of the XX International Congress on Project Management and Engineering in Cartagena (Spain); the author's version is presented in chapter 8.

The results of the previous studies developed for this thesis suggested that a set of key indicators with characteristics to assess the environmental performance of the HEI might be eligible as an environmental assessment tool. These indicators must be easy to assess, accurate to report the environmental performance and flexible to be included in the daily decisionmaking progress.

Finally, an intensive analysis of all the environmental indicators published or publicly assessed has been developed. Those indicators applicable to HEIs have been deeply analyzed and classified searching for the most suitable environmental performance indicators with the characteristics of key indicators. A methodological procedure to define and identify these indicators has been developed in accordance to the ordinary operation of the EMS of HEIs. The methodology and its application to the case study is under journal review at the time of presenting this thesis; the author's version can be found in chapter 9 .

The research presented in this dissertation has explored several environmental assessment methodologies and a wide range of environmental indicators seeking for an environmental performance methodology that fits the particularities of HEIs; a set of environmental KPIs. The discussion of overall 
Proposal of a set of Key Performance Indicators for the environmental assessment of Higher Education Institution

results is presented in chapter 10 . Conclusions and further research are also included. Chapter 11 gathers all the references cited in the present dissertation for an easier use although each chapter compose by a paper has a section with its references for a fast enquiry if needed.

Additionally, the Annex located in chapter 12 includes a paper published in XV International Congress of Project Engineering in Huesca (Spain) with a comparative analysis of the methodology of calculation of EF in different areas. 


\title{
2 THE STRENGTHS OF EMAS AS AN ENVIRONMENTAL MANAGEMENT SYSTEM FOR EUROPEAN UNIVERSITY CAMPUSES
}

Torregrosa-López, J.I., Lo Iacono-Ferreira, V.G., Barranco-Martí, C., \& Bellver-Navarro, C.G. (2016) The strengths of EMAS as an environmental management system for European university campuses. International Journal of Environment and Sustainable Development, 15(1), 89-106. http://dx.doi.org/10.1504/IJESD.2016.073339

Notice that this article was published originally in British English due to the requirements of the journal. It has been edited to match the style chosen for this document. Figures and tables have also been edited (only format). Abbreviations have also been homogenized. A complete abbreviation code is provided in page 23.

\begin{abstract}
Universities are unique organizations that have a full range of existing environmental issues. Implementing an environmental management system (EMS) has been proposed as a way for educational organizations to track and improve the management of these environmental issues. Although only a handful of universities have been verified in the European Union EcoManagement Environmental Audit Scheme (EMAS), a large number of institutions and companies all over Europe that have become registered. The complexity of universities has resulted in EMAS implementation barriers that other sector companies do not necessarily face. This study analyses the specific barriers, benefits, and challenges of the implementation process of the EMAS at Universitat Politècnica de València (UPV). As a result, some specific strategies for implementing EMAS are identified. EMAS appears to be a good MES for university campuses due to its adaptability to the complexity of university organizations and their governance structures.
\end{abstract}

\subsection{INTRODUCTION}

Many authors have studied the necessity of sustainable actions in modern universities, the benefits and barriers for their implementation and the methods of assessing, reporting and monitoring these actions (Alshuwaikhat and Abubakar, 2008; Lozano García et al., 2006; Lozano, 2006b, 2010, 2011). With respect to sustainability, the implementation of EMS on campuses is considered not only a way of monitoring and controlling operational aspects but also as a means for creating the necessary setting for sustainable practices in universities (Disterheft et al., 2012; Jones et al., 2012). 
Proposal of a set of Key Performance Indicators for the environmental assessment of Higher Education Institution

The EMAS has been available to companies since 1993, but was originally restricted to companies in industrial sectors. In 2001, EMAS became open to all economic sectors including public and private services. In 2009, EMAS Regulation was newly modified to EMAS III (European Commission, 2009), which became effective on January 11, 2010. The main objective of EMAS III is to provide a management tool for companies and other organizations to evaluate, report, and improve their environmental performance. The aim of EMAS is to recognize and reward those organizations that continuously improve their environmental performance and go beyond minimum legal compliance.

According to the study commissioned by the European Union in 2009 (Vernon et al., 2010) about the cost and benefits of EMAS-registered organizations, the reasons for seeking this registration can be very different. Some firms claim that is essential today to enhance transparency with stakeholders and to follow clients' requirements. Furthermore, firms have reported several benefits of EMS implementation, which are (in order of preference) energy and resource savings, improved stakeholder relationships and reduction of negative incidents. In this European Union's study, there is a consensus among member states that the most important benefits are the increase of efficiency and reduction of costs. However, companies not yet EMS verified do not perceive that these benefits are sufficiently clear.

In recent years, there have been a large number of institutions and companies in Europe that have obtained EMS verification according to EMAS web reports (http://ec.europa.eu/environment/emas/register/reports/reports.do). At the time of writing, 193 educational organizations (under NACE code 85) are verified in EMAS; 56 register the NACE code 85.42 (tertiary education) and only 17 of them are HEIs. A list of institutions compiled from the internet and updated from Disterheft et al. (2012) is available in Table 2-1.

Some strong barriers have been identified in the implementation process that may explain the shortage of EMAS implementation in universities. Some of these barriers are related to personnel shortage and financial restrictions; other barriers are related to institutional organization of public universities, where direct taxation in implementing EMS has proven to be ineffective. Lozano (2006b) also discussed the other difficulties related to institutional change and radical innovation.

Some authors (Clarke and Kouri, 2009) doubt the functionality of EMAS in universities as it was not specifically designed for higher education institutions and these authors therefore see other tools, like the AISHE tool (Roorda and Onderwijs, 2001), the Osnabruck Environmental Model for Universities (Viebahn, 2002) or the Sustainable University Model (Velazquez et al., 2006) as more appropriate. An interesting paper about implementation 
status of EMS in US colleges and universities is presented by Savely et al. (2007); this study concludes that $30 \%$ of colleges and universities have implemented some kind of EMS elements, many of them related to EMAS requirements.

Another major factor to consider is the difficulty in aligning environmental issues with educational and research goals, a challenge very specific of university.

The ambiguity of benefits of implementing EMS in a university is also very closely connected with the organization chart of the public universities and the strong differences with respect to private companies. Although policy directives from the top level must be assumed by all, several academic decisions are only in the hands of faculty, departments and research institutes. A priori, the low separate decision-making structures complicate the EMS implementation (Clarke and Kouri, 2009).

Nevertheless, in a recent study, Disterheft et al. (2012) examined the implementation of EMS in HEIs. The study concludes that EMS implementation aids in reducing environmental impact of operations and in developing competencies which lead to more sustainable practices in research and teaching. The study claims that the combination of a top-down process with participation can improve not only operational aspects but also create the necessary setting for sustainable practices at universities.

When the university organization chart is compared with private companies, it can be seen that senior management and staff roles are similar to those in industries. However, the students and faculty roles are not comparable to any in the private sector: these stakeholders take part in the election of representatives of governance and parts of these organizations are set by quotas.

This paper describes, according with the experience of implementing EMAS at UPV, differences between implementing EMAS at universities and implementation at other organizations, as well as the limitations of EMAS for university campuses, the specific barriers detected in its implementation, and benefits of registration. This study should be useful for universities interested in implementing an EMS and, specifically, according to the EMAS standard. 


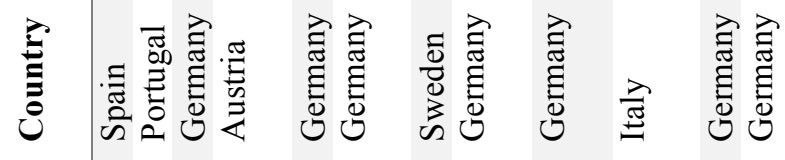

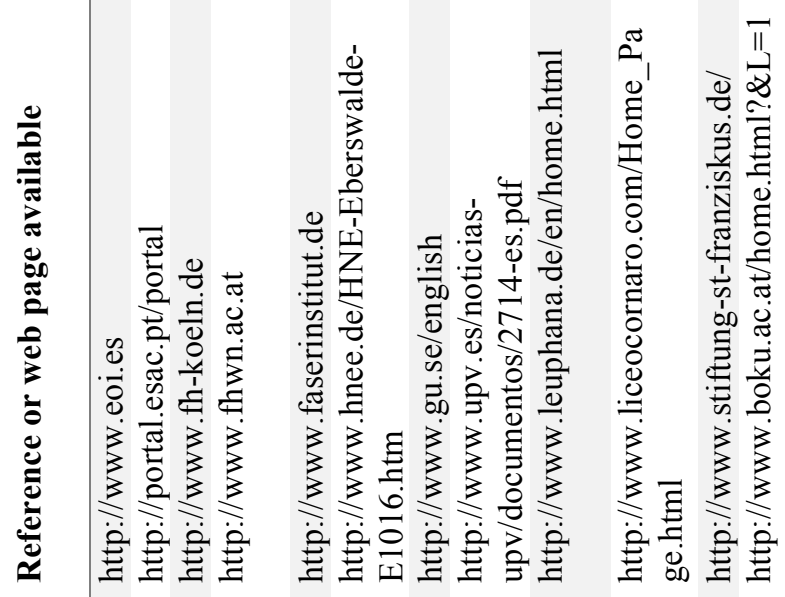

के

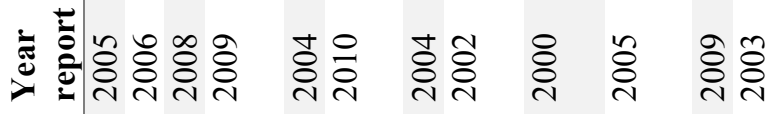

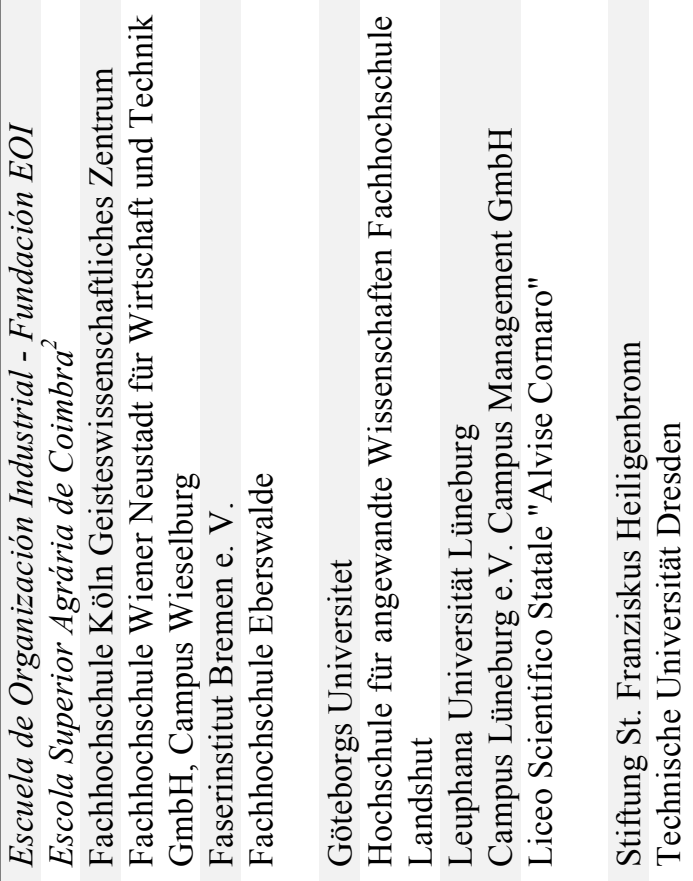

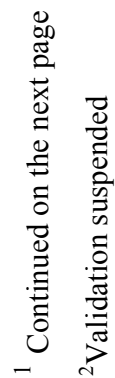




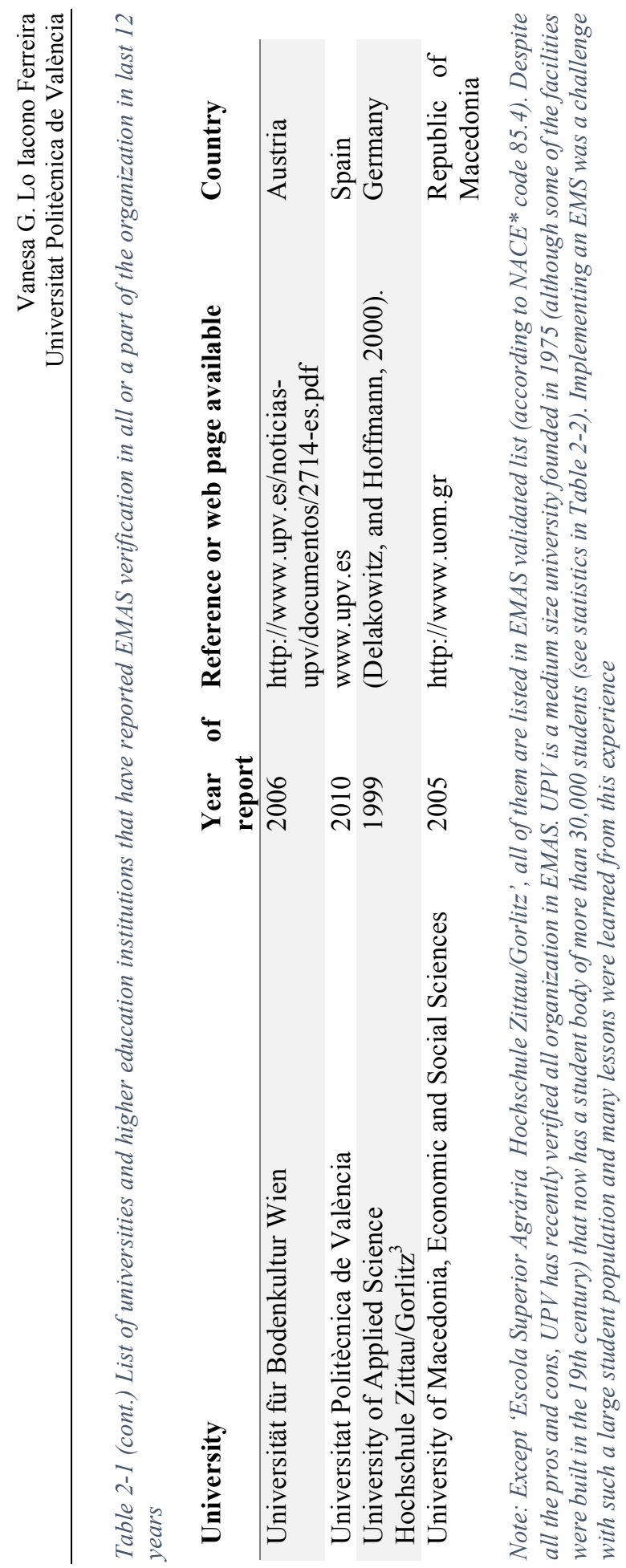

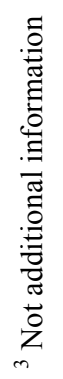


Table 2-2 UPV in figures (2012)

\begin{tabular}{l|lrrrr} 
Campus & $\begin{array}{l}\text { Students } \\
\text { (full-time) }\end{array}$ & Teacher & Others & $\begin{array}{l}\text { Total floor } \\
\text { Area }\left[\mathrm{m}^{2}\right]\end{array}$ & $\begin{array}{l}\text { Landscaping } \\
\text { area }\left[\mathrm{m}^{2}\right]\end{array}$ \\
\hline Valencia $^{4}$ & 31487 & 2401 & 4712 & 624319 & 117,055 \\
Gandía $^{5}$ & 1851 & 167 & 85 & 32,416 & 7,020 \\
Alcoy $^{6}$ & 2271 & 186 & 84 & 23,633 & - \\
UPV & 38196 & 2754 & 4881 & 599,424 & 113,378 \\
\hline
\end{tabular}

\subsection{Methodology}

A literature review was conducted of publications, conference proceedings, university reports, books, website documents, and education for sustainability profiles. The ultimate goal of the literature review was the identification of the diverging strategies and practices undertaken by key players in order to be able to compare the UPV experience in EMS implementation with other university and industrial sector experiences.

Most of the data presented in this paper is based on existing documentation at UPV as a result of the EMAS implementation process. The data was collected from the archives of UPV: environmental audits, environmental policy, environmental planning and environmental statements.

Archival research was complemented with interviews, Google questionnaire and surveys during 2012, which were conducted with different stakeholders: senior management, environmental officers, environmental committee and environmental contacts.

The questionnaire gathered data about the perception of stakeholders of implementing process, its benefits, drivers and internal barriers. In this study, only the part of benefits, from a qualitative point of view is published as Table 26 . Other results regarding to drivers and internal barriers will be published in a separated study.

\footnotetext{
${ }^{4}$ www.upv.es

${ }^{5}$ www.gandia.upv.es

${ }^{6}$ www.epsa.upv.es
} 


\subsection{RESULTS}

\subsubsection{BACKGROUND AND IMPLEMENTATION PROCESS}

At the beginning of 1990s UPV began implementation of compliance and pollution prevention processes as the first seed planted for the eventual full implementation of an EMS. The actions started with the setup of a small group of staff named 'The Green Office' devoted to the control and management of solid and toxic wastes on campuses: it was the first environmental office (EO) in a Spanish university.

During this period, UPV studied the possibility of implementing EMAS as a pilot program for the verification of this system in European universities. The strategy was to certify all facilities in ISO 14001 which was considered a valid model in the 1993 version of the EMAS regulation (European Commission, 1993). In 1999, the first environmental policy statement for all of UPV was approved, and in 2002, three facilities were verified in accordance with ISO 14001 .

These actions were paralleled by the leadership of UPV in a European project about studying a methodology for implementing EMAS at university campuses starting in 1996 (Peris-Mora, 2002). The study revealed that it was possible to improve quality management of universities not only by EMS implementation but also with the verification of the EMS according to EMAS.

During a universal election of the rector in 2005, the electoral program of different opponents included the implementation of EMS in the future vision for UPV. The goal of certifying each unit separately was abandoned in 2006, as a result of detecting duplicities that seriously impeded the implementation process of an EMS throughout the entire university. As a result, and following the advice of the Regional Department of Infrastructures, Land and Environment (http://www.cma.gva.es), which is the competent authority in EMAS verification in Valencia Region, this strategy was replaced by another one based on implementing EMAS incrementally throughout the whole university.

The process was carefully planned in 15 phases to meet the requirements of EMAS (Figure 2 1). For this task, in 2006 the 'Green Office' was renamed as the EO and reinforced with a new full time technician and administrative staff. This office was initially in charge of implementing the EMS, including coordination and control of operations with environmental impact and the internal auditing of EMAS. 
Proposal of a set of Key Performance Indicators for the environmental assessment of Higher Education Institution

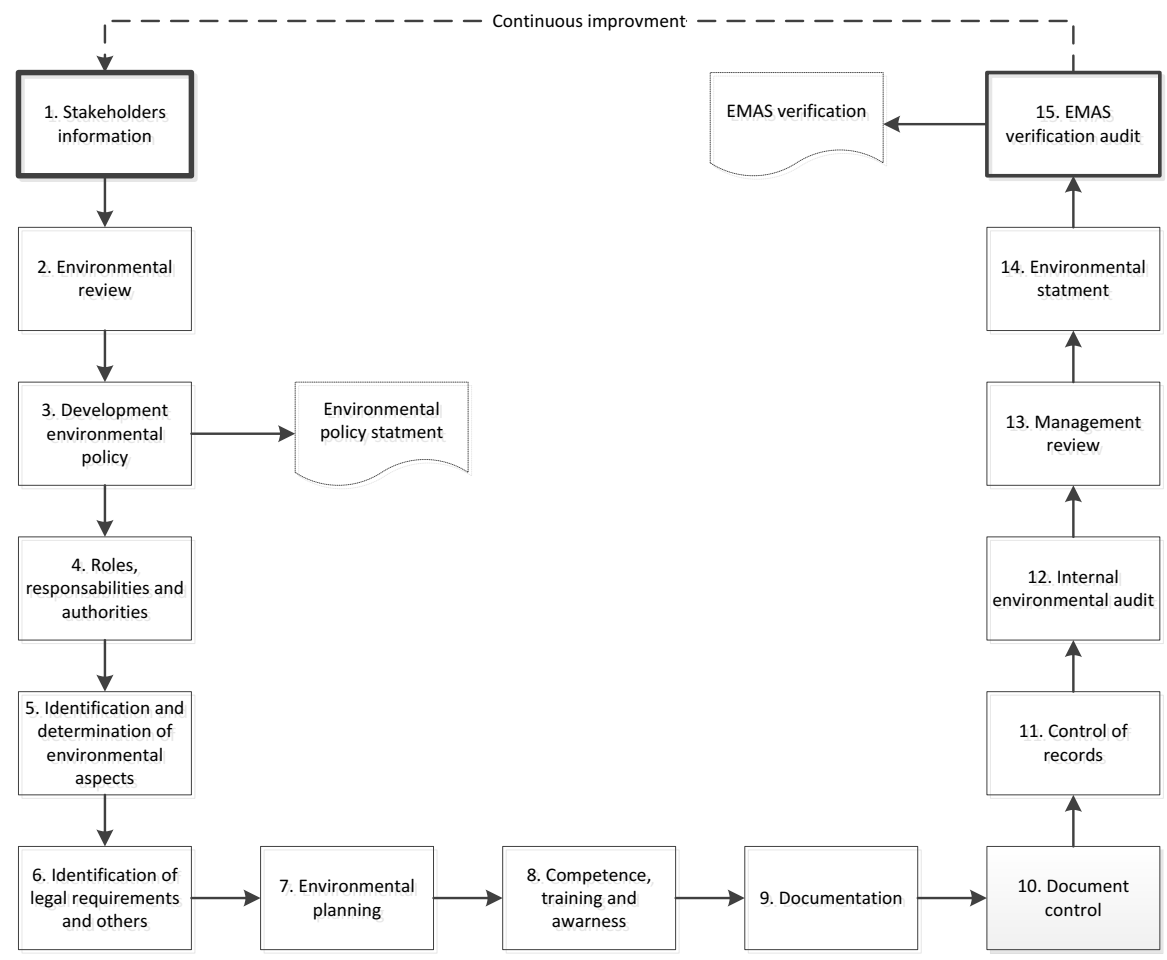

Figure 2-1 EMAS implementation phases at UPV

For a more comprehensive implementation, and taking into consideration the high complexity of the organization, a network consisting of environmental contacts for each unit was created (Table 2-3). The duty of this network was to disseminate information to their community about environmental policies, collaborate in operational control and give feedback to the EO.

Another task of the EO was the performance of an environmental review. As a result of this review, UPV created a new version of its environmental policy statement. The environmental management structure was created and responsibilities were carried out by the environmental committee. This committee was composed of members of the faculty, administrative and technical staff, students and top level management. Many of the faculty members were experts in environmental management and environmental technology.

The step described above was followed by the identification and analysis of environmental aspects of the university and their significance (see Table 2-4). This was the basis for setting an initial proposal for environmental objectives, with the following phases executed in 2007 and 2008. During this period, the 
EO reported regularly to the environmental committee regarding the progress of implementation.

Table 2-3 UPV units considered in EMS

\begin{tabular}{|c|c|c|c|c|c|}
\hline \multicolumn{2}{|l|}{ Activity } & $\begin{array}{l}\text { Alcoy } \\
\text { Campus }\end{array}$ & $\begin{array}{l}\text { Gandía } \\
\text { Campus }\end{array}$ & $\begin{array}{l}\text { Vera } \\
\text { Campus }\end{array}$ & UPV \\
\hline \multirow[b]{3}{*}{ Teaching } & Faculties & 1 & 1 & 12 & 14 \\
\hline & Departments & 1 & 0 & 43 & 44 \\
\hline & $\begin{array}{l}\text { Department } \\
\text { in smaller } \\
\text { campuses }\end{array}$ & 22 & 27 & - & \\
\hline \multicolumn{2}{|c|}{ Research Facilities } & 0 & 0 & 35 & 35 \\
\hline \multicolumn{2}{|c|}{ University services } & & Common & 91 & 91 \\
\hline \multicolumn{2}{|c|}{ Third party facilities } & 2 & 2 & 23 & 27 \\
\hline \multicolumn{2}{|c|}{ Total UPV } & & & & 211 \\
\hline
\end{tabular}

Notes: Alcoy and Gandia are cities of Valencia region where UPV is present. Vera is a suburb of Valencia City where the main campus of UPV is based.

In 2009, EMAS was verified and in early 2010 the system was validated. After verification, the organization was nominated in 2009 and 2010 for the EMAS European awards. From 2010 until now, UPV is still the largest University with EMAS verification (information available at http://ec.europa.eu/environment/emas/register/ reports/reports.do).

\subsubsection{AN OVERVIEW OF EMAS IMPLEMENTATION AT UPV}

For implementing EMAS at UPV three new organizational structures were created: the EO, the environmental committee, and the network of environmental unit contacts (Figure 2-1).

The environmental committee sets the priorities of the EMS and guides its implementation. It remains under the Board of Governors $(\mathrm{BoG})$ and champions the EMS. The president of environmental committee is the rector, and the secretary is the senior technician of the EO. The other members of the staff are student leaders, members of university trade union, faculty, administration and senior management, and other experts in EMS, biology, ecology and engineering. This diverse team is able to troubleshoot problems arising from different management styles and operational structures. Some of the members are working within their job descriptions and others are taking on extra work or are volunteers. One of the most important roles of the EO is to help define corrective actions as a result of assessment reports and to aid in policy review. At present, several units (faculty and departments) involved with the EO have 
created their own committees to advise unit staff and the University environmental committee.

This office is in charge of implementing and maintaining the EMS. This office develops the network of environmental contacts in all units that collaborate in the implementation of EMS in departments, faculties, and research institutes. The EO also executes the actions approved by the environmental committee and is dependent, from the hierarchical point of view, on the vice rector for facilities.

The environmental policy statement includes the institution's commitment to reduce the environmental impact of its operations, including the areas of teaching and research. This has led and continues to lead one of the most important tasks of EMAS at UPV, prioritizing and determining the significance of the elements that influence the environment.

UPV has many specific environmental interactions, which have either benefits or risks through their operations, finances, community service, education and research (see Table 2-4). All environmental interactions are identified, monitored, assessed and recorded systematically.

UPV has also implemented a communication and transparency policy to keep employees, students and the social environment informed about the environmental performance of the university and involved in its management.

The documents of the system and their importance are usual for this kind of EMS. The continuous improvement policy makes it necessary to adopt an annual environmental plan to reduce the environmental impact of the interactions. This plan is proposed with a budget by the environmental committee and approved by the BoG; it contains objectives and goals specifically designed to mitigate the environmental aspects with greatest significance.

Written procedures, documents and records are uploaded onto a server and disseminated to university members (including students) through the intranet according to their specific profiles. A summary of the documentation of the EMS is given in Table 2-5.

Every year, an updated environmental statement report is published according to EMAS requirements. This document is published at the web page of the University and disseminated according to the university's policy of transparency in environmental communication of the University. The 2012 version of this document is available at http://riunet.upv.es/bitstream/handle/10251/29137/UPV.AMA-DA.2012maquetada.pdf? sequence $=1$. The report includes a complete update of the status of the university with regard to environmental performance, the objectives and the goals achieved and new challenges that are being faced. This document is verified and approved by a competent authority of the European Union. 


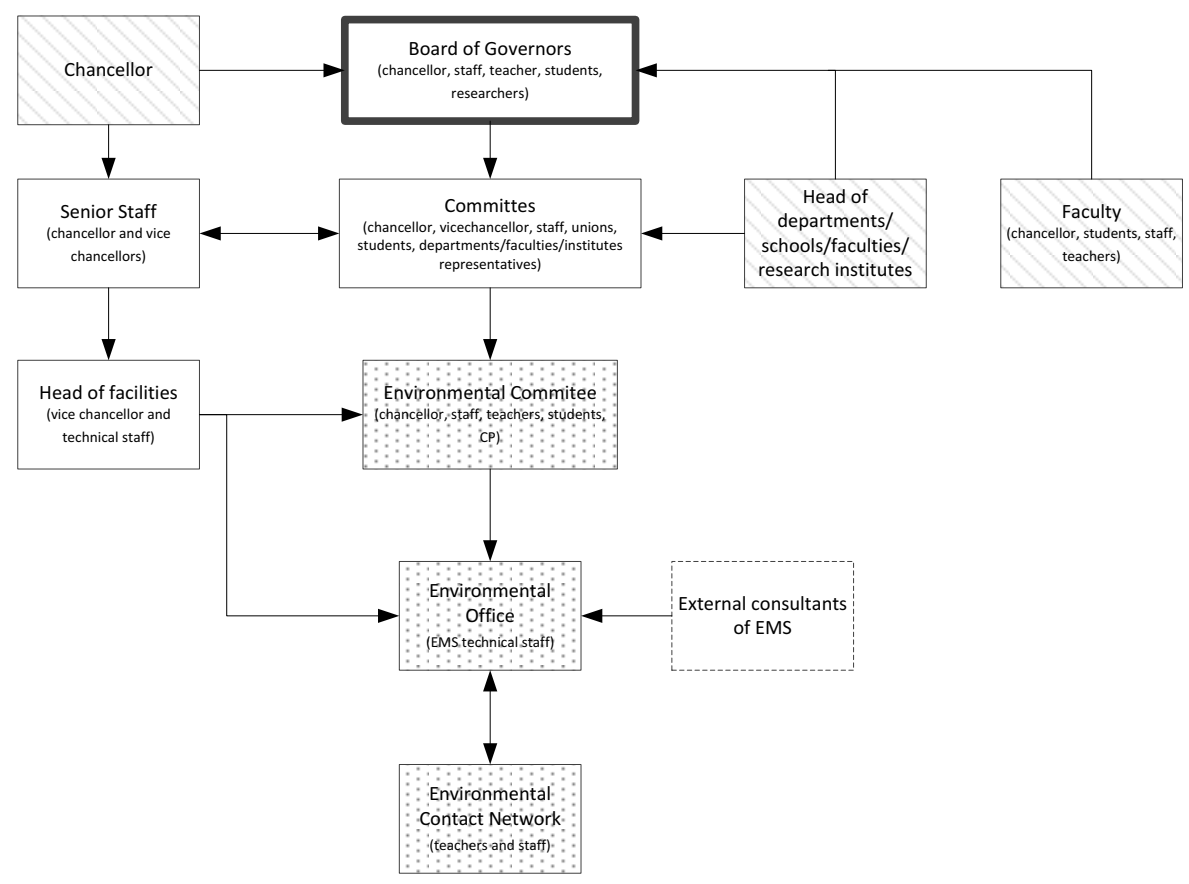

Figure 2-2 Typical organization chart of public university in Spain

Notes: Slashes show elected representatives; dots show new functional organization structures that arose as consequence of implementation of EMAS at UPV. For further information about public Spanish university organization see: http://www.crue.org/legislacion/lou.html.

The environmental vision and mission of UPV was included in the strategic plan 2007-2014 (available at http://www.upv.es/noticias-upv/documentos/2714es.pdf) and described in Goal III: social commitment and values. In this document, the vision of UPV stated that it is an 'efficient institution, with a strong social and environmental commitment'. Benefits

Table 2-6 shows benefits of implementing EMAS. These are typical benefits of implementing an EMS (improved operational control; an organization structured that fits the EMS challenges; higher levels of formation and information; etc.) (Delakowitz and Hoffmann, 2000).

A summary of environmental performance of the university is available in the Environmental Statement of UPV 2012:

http://riunet.upv.es/bitstream/handle/10251/29137/UPV.AMA-DA.2012maquetada.pdf?sequence $=1$ 
Proposal of a set of Key Performance Indicators for the environmental assessment of Higher Education Institution

Table 2-4 List of environmental interactions assessed in normal operating conditions at UPV

\begin{tabular}{|c|c|c|}
\hline Category & Environmental interaction & $\begin{array}{l}\text { Potential } \\
\text { Environmental Impact }\end{array}$ \\
\hline \multirow[t]{30}{*}{ Wastes } & Paper and cardboard & Pollution of soils and \\
\hline & Plastic Packaging & water resources \\
\hline & Glass Packaging & \\
\hline & Other wastes & \\
\hline & Toners & \\
\hline & Compaq discs & \\
\hline & Biohazardous and medical & \\
\hline & Cytotoxic & \\
\hline & Chemical (solid) & \\
\hline & Inorganic acids & \\
\hline & Organic acids, salts and peroxides & \\
\hline & Cyanide substances & \\
\hline & Unknown products with high toxicity & \\
\hline & Halogen solvents & \\
\hline & Non-halogen solvents & \\
\hline & Substances that increase COD & \\
\hline & Packaging of dangerous products & \\
\hline & Phenols and phenolic compounds & \\
\hline & Photographic liquids & \\
\hline & Heavy metals and compounds of $\mathrm{Hg}$ and & \\
\hline & $\mathrm{Cr}(\mathrm{VI})$ & \\
\hline & Organ halogen compounds & \\
\hline & Alkalis and inorganic salts & \\
\hline & Electric and electronic & \\
\hline & Cells and batteries & \\
\hline & Mineral and other oils & \\
\hline & Vegetable oils and fats & \\
\hline & Manure & \\
\hline & Sewage sludge & \\
\hline & Carcasses & \\
\hline
\end{tabular}

${ }^{7}$ Continued on the next page 
Table 2-4 (cont.) List of environmental interactions assessed in normal operating conditions at $U P V$

\begin{tabular}{|c|c|c|}
\hline Category & Environmental interaction & $\begin{array}{l}\text { Potential } \\
\text { Environmental } \\
\text { Impact }\end{array}$ \\
\hline Third party activities & $\begin{array}{l}\text { Environmental behavior of third } \\
\text { party firms }\end{array}$ & All \\
\hline Effluents & Wastewaters & $\begin{array}{l}\text { Pollution of water } \\
\text { resources }\end{array}$ \\
\hline Noise & Noise & Noise pollution \\
\hline Transport & Mobility & All \\
\hline Teaching & Greening curricula & $\begin{array}{ll}\text { Lack } & \text { of } \\
\text { environmental } \\
\text { training }\end{array}$ \\
\hline Research & Greening research & $\begin{array}{l}\text { Unsustainability } \\
\text { practice }\end{array}$ \\
\hline $\begin{array}{l}\text { Material resource } \\
\text { consumption }\end{array}$ & $\begin{array}{l}\text { Toners } \\
\text { Paper } \\
\text { Chemical Products }\end{array}$ & $\begin{array}{lr}\text { Material } & \text { resource } \\
\text { depletion } & \text { and } \\
\text { pollution } & \end{array}$ \\
\hline $\begin{array}{l}\text { Natural resource } \\
\text { consumption }\end{array}$ & $\begin{array}{l}\text { Tap water } \\
\text { Well water } \\
\text { Energy } \\
\text { Fuels }\end{array}$ & $\begin{array}{l}\text { Natural resource } \\
\text { depletion } \\
\text { Natural resource } \\
\text { depletion } \\
\text { Climate change }\end{array}$ \\
\hline
\end{tabular}

Note: The quantitative measure of the interaction was calculated as result of multiplying four parameters: scale (flux or concentration), how closer is to legal limits, dangerousness and extent (quantity of people affected). 
Proposal of a set of Key Performance Indicators for the environmental assessment of Higher Education Institution

Table 2-5 Summary of EMAS documentation at UPV

\begin{tabular}{|c|c|c|}
\hline EMAS requirements & $\begin{array}{l}\text { UPV } \\
\text { Documents }\end{array}$ & Observation \\
\hline $\begin{array}{l}\text { The environmental policy, } \\
\text { objectives and targets }\end{array}$ & $\begin{array}{l}\text { Environmental } \\
\text { Policy }\end{array}$ & Current version in force since 2007 \\
\hline $\begin{array}{l}\text { Description of the scope of } \\
\text { the environmental } \\
\text { management system }\end{array}$ & Manual of EMS & $\begin{array}{l}\text { Current version is in force since } \\
\text { October } 2011\end{array}$ \\
\hline $\begin{array}{l}\text { Description of the main } \\
\text { elements of the } \\
\text { environmental } \\
\text { management system and } \\
\text { their interaction, and } \\
\text { reference to related } \\
\text { documents. }\end{array}$ & Manual of EMS & $\begin{array}{l}\text { Current version is in force since } \\
\text { October } 2011\end{array}$ \\
\hline $\begin{array}{l}\text { Documents, } \quad \text { including } \\
\text { records, } \quad \text { required by } \\
\text { EMAS. }\end{array}$ & $\begin{array}{l}\text { Structural } \\
\text { procedures }\end{array}$ & $\begin{array}{l}17 \text { procedures comprise this section of } \\
\text { documents required specifically by } \\
\text { EMAS. }\end{array}$ \\
\hline $\begin{array}{l}\text { Documents, including } \\
\text { records, determined by the } \\
\text { organization to be } \\
\text { necessary to ensure the } \\
\text { effective planning, } \\
\text { operation and control of } \\
\text { processes that relate to its } \\
\text { significant environmental } \\
\text { aspects }\end{array}$ & $\begin{array}{l}\text { Operational } \\
\text { control } \\
\text { procedures } \\
\text { Technical } \\
\text { Instructions }\end{array}$ & $\begin{array}{l}25 \text { Operational Procedures that covers } \\
\text { all environmental aspects of the } \\
\text { university. } \\
\text { Currently, there are } 4 \text { "Technical } \\
\text { Instructions" available that support } \\
\text { technical instructions for several } \\
\text { procedures as energy data conversion } \\
\text { and materials calculation, between } \\
\text { others. }\end{array}$ \\
\hline
\end{tabular}

Notes: According to Annex II of "No, R.;1221/2009 of the European Parliament and of the Council of 25 November 2009 on the voluntary participation by organizations in a Community eco-management and audit scheme (EMAS), repealing Regulation (EC) No 761/2001 and Commission Decisions 2001/681/EC and 2006/193". 


\subsubsection{NEW CHALLENGES}

Most of the challenges for improving the EMS at a university campus are the specific to a management system based on continuous improvement that is under the control provided by internal and external audit (Table 2-6). It is interesting to point out some of the challenges that are closed related to the university's idiosyncrasies (research and educational greening) and the reduction of the environmental impact of key interactions.

For educational purposes, the EMAS at UPV provides an indicator that measures the performance of the core competencies in environmental matters developed in all subjects taught. In the case of research greening, there is another indicator that measures the impact reduction of the research activities in the improvement of the environment and society (see Table 2-4). As of yet, there are no objectives and actions plans for mainstreaming environmental issues in teaching and research yet. Nevertheless, the use of these indicators is considered a first step prior to the definition and execution of an action plan for mainstreaming environmental issues in curricula and research activities.

The role of UPV in reducing the environmental impact caused by consumption, as well as how to use green procurement to stimulate innovation in environmental technologies, products and services, in accordance with Green Procurement European Unit Policy is an outstanding issue (European Commission, 2008). Green procurement is only provided at UPV in two procedures for the purchase of recycled paper and toners. Decentralized procurement makes it difficult to implement other measures. The lack of information about environmentally sustainable products and services makes the implementation of correction measures especially difficult for this problem.

In accordance with EMAS, direct and indirect environmental aspects at UPV are assessed by considering environmental impacts produced in situ. Thus, the actions of reducing environmental impact and resulting assessments, do not consider the entire life cycle impact. The main difficulty in implementing a life cycle assessment is related to the lack of quality information about life cycle costing of products and services. This is a common problem for all kinds of organizations whose interactions are similar to those at UPV.

Another challenge that requires special attention is the necessity of the reduction of energy consumption, which not only reduces direct and indirect emissions of greenhouse gases and other pollutants, but also may result in a financial cost saving if the energy savings offset any additional costs of implementing an energy efficient technology. Improved energy efficiency in buildings, university processes and transportation is one of the most important goals planned in the EMS. 
Proposal of a set of Key Performance Indicators for the environmental assessment of Higher Education Institution

Table 2-6 Summary of benefits and challenges of the EMS at UPV according to stakeholder's opinion collected with questionnaires

\begin{tabular}{|c|c|c|}
\hline \multirow{5}{*}{ Benefits } & Operational control & $\begin{array}{l}\text { Control and assessment of all environmental } \\
\text { interactions } \\
\text { Increase in quantity of waste that are managed } \\
\text { Reduction in energy consumption in several } \\
\text { units } \\
\text { Control and assessment of environmental law } \\
\text { accomplishment } \\
\text { External audit }\end{array}$ \\
\hline & $\begin{array}{l}\text { Organizational } \\
\text { Structure }\end{array}$ & $\begin{array}{l}\text { A consolidated group of specialist staff in EMS } \\
\text { Organizationally environmental structure fully } \\
\text { integrated in university management and in the } \\
\text { decisions making structure of university }\end{array}$ \\
\hline & Formation & $\begin{array}{l}\text { Improvement of the training of member and } \\
\text { senior staff involved directly in EMS }\end{array}$ \\
\hline & $\begin{array}{l}\text { Communication } \\
\text { and Information }\end{array}$ & $\begin{array}{l}\text { Higher level of sensitizing in the university } \\
\text { members, especially for the case of teachers and } \\
\text { staff } \\
\text { A better corporate image of the university }\end{array}$ \\
\hline & Operational control & $\begin{array}{l}\text { Action plan for greening the curricula and the } \\
\text { research } \\
\text { Mainstreaming green procurement } \\
\text { Extend the use of Life Cycle Thinking in } \\
\text { environmental assessment of all interactions } \\
\text { Reduce energy and material consumption } \\
\text { Increase the efficiency in wastewater, wastes } \\
\text { and emissions management }\end{array}$ \\
\hline \multirow[t]{3}{*}{ Challenges } & $\begin{array}{l}\text { Organizational } \\
\text { Structure }\end{array}$ & $\begin{array}{l}\text { Open new ways to achieve greater participation } \\
\text { of members of the university in EMS }\end{array}$ \\
\hline & Formation & $\begin{array}{l}\text { Increase the training in EMS of university } \\
\text { members and senior staff } \\
\text { Increase the environmental sensitizing of } \\
\text { stakeholder, specially of students }\end{array}$ \\
\hline & $\begin{array}{l}\text { Communication } \\
\text { and Information }\end{array}$ & $\begin{array}{l}\text { Increase the level of internal and external } \\
\text { information and it effectiveness. } \\
\text { Increase the level of sensitizing in the students }\end{array}$ \\
\hline
\end{tabular}




\subsection{DisCUSSION}

This section discusses how UPV has dealt with the implementation of the EMAS and overcome some of the barriers identified as being typical of the public university. From the analysis of the actions carried out by UPV, it is possible to identify many of the recommendations proposed by Lozano (2006b) for implementing innovative actions in universities and overcoming typical individual barriers (Table 2-7). The strategies used for this have been largely motivated by the idiosyncrasies of the university itself and adapted to it. As a result, some milestones have been reached which can be considered measurable benefits of implementation. Finally, certain challenges have been detected and it is assumed that can be addressed using the environmental management system itself.

The implementation of EMAS at a university is a unique experience-a special case of EMAS implementation in an education and research center setting due to the differences of a university with other organizations as industries. Although due to this fact some studies request a specific EMS for universities (Clarke and Kouri, 2009), the experience at UPV shows that EMAS is also adequate for a university campus. This fact is only possible if barriers in the implementation are identified and specific strategies are adopted.

UPV, as medium size university, is composed of a great number of different units that must be coordinated (Table 2-3). These units, in many aspects and from the functional standpoint, act independently and interact with each other in a highly complex fashion. This fact complicates the control, coordination and necessary feedback process between unit operations and the EO. It was necessary to create a new functional structure with new responsibilities and integrate them in the general structure of UPV.

According to Peris-Mora (2002) a successful EMS brought together the skills and expertise of all four stakeholder groups (teachers, researchers, administrative personnel and students) and bridged their varied decisionmaking and communication structures, ranging from horizontal, autonomous, and democratic to vertical and hierarchical. This does not resemble the structure of companies for which the EMAS was designed. These problems were bypassed by giving authority to the EO to coordinate a network of environmental contacts, one for each unit. This network has made it possible to disseminate information, train and give operational instructions to every corner of the organization. At the same time, the EO has received important feedback regarding the implementation and maintenance process to feed the system and achieve the goal of continuous improvement. This fact has made possible a high level of involvement among different stakeholders in the EMS, breaking one of the most important barriers identified by Lozano (2006b) 
Proposal of a set of Key Performance Indicators for the environmental assessment of Higher Education Institution

Table 2-7 Recommendations of Lozano (2006b) for implementing sustainable development (SD) at universities and UPV actions according to implementation of $E M A S^{8}$

\section{Recommendations of Lozano UPV actions (2006b)}

The universities' leaders must During a universal election of the recognize that working towards SD is a necessity in the current world, rector in 2005, the electoral where economic processes are program of different opponents included the implementation of rapidly degrading the natural and EMS in the future vision for UPV. human resources upon which societies are totally and mutually interdependent

The individual(s) that are willing to become SD champion(s) must be identified, engaged and supported with official authority and financial means. This champion or champions must receive a proper SD education and be highly motivated and skilled in educating and motivating others to also become engaged in the SD journey. Establish a high-level SD Environmental committee and EO coordinator position which is included in organizational empowered and funded to ensure structure (see Figure 2-2). SD continuity.

Verify that SD is included in the All dimensions are included in five dimensions (curricula, EMS although curricula and research, campus operations, research are still to be developed outreach, and assessment and fully reporting).

\footnotetext{
${ }^{8}$ Continued on the next page
} 
Table 2-7 (cont.) Recommendations of Lozano (2006b) for implementing sustainable development (SD) at universities and UPV actions according to implementation of EMAS

\section{Recommendations of Lozano UPV actions}

(2006b)

The university policies and strategies must be designed to holistically integrate $\mathrm{SD}$ as the golden thread throughout the university system. After this, the process of

(a) operational control;

(b) and (c) effort in mainstreaming environmental issues in teaching and research; implementation in the five (d) environmental statement; dimensions must be started with real involvement at all levels. The following steps may be among the first ones to be started:

(a) implement resource savings, recycling and green procurement via the campus operations, since this will provide quick and visible results rapidly;

(b) make course and curricular changes after educating educators on the concepts, tools and approaches in $\mathrm{SD}$;

(c) work with research coordinators and the individual researches to help them to incorporate SD into their disciplinary, interdisciplinary and trans-disciplinary research;

(d) incorporate SD into all outreach activities;

(e) establish clear goals, objectives, indicators and methods for easy assessment, reporting, analysis and comparison and

(f) use the reports and related information to accelerate the incorporation of SD among all

university stakeholders.

(e) environmental plans;

(f) internal formation and sensitizing actions

\footnotetext{
${ }^{9}$ Continued on the next page
} 
Proposal of a set of Key Performance Indicators for the environmental assessment of Higher Education Institution

Table 2-7 (cont.) Recommendations of Lozano (2006b) for implementing sustainable development (SD) at universities and UPV actions according to implementation of EMAS ${ }^{10}$

\section{Recommendations of Lozano UPV actions (2006b) \\ The university should ensure Environmental policy statement. continuity within a clear and transparent framework and a long- term plan for institutionalization of SD. \\ Perform thorough and regular assessment on where your university stands on the five dimensions and compare with your plan's goals. By detecting the individuals, departments and centers that}

(a) are the most eager to work with SD, and

(b) the most reluctant will help to detect the innovators and laggards. The first ones can be used as multipliers by educating the educators, and the last to be able to detect the highest change level and take the appropriate measures.

Plan and implement regular Environmental statement repots reporting of campus SD EMS at university yearly. Online achievements. WEB and intranet communication assure continuous flux of information with stakeholders

Stakeholders develop, plan, implement, check and review the university environmental policy statement. For this reason, the roles and responsibilities of the different members of university organization have also been reviewed and adapted to the new structure of the network of environmental contacts under the coordination of the EO.

${ }^{10}$ Continued on the next page 
In the case of UPV, the decision of implementing EMAS was adopted by the rector during the process of a universal election in 2005, motivated by the previous experience in implementing EMS at UPV. The decision of the implementation of EMAS was ratified by electors in a democratic and direct way which made the process more participatory, most common approach in European universities certified in EMAS (Disterheft et al., 2012). This is a substantial difference when compared with private companies, where these decisions are not necessarily endorsed by the collective, which will be the ones to make them work and will benefit from them later.

The environmental committee composition is also quite different in universities compared to other organizations (Delakowitz and Hoffmann, 2000). In industrial companies the environmental committee is made up of members of the operational units, quality department staff and the chief executive officer. In UPV, this committee represents all stakeholders (staff, students, faculty and senior management) which ensure democratic participation in decision-making. Many faculty members are part of the committee because of their expertise in environmental management, ecology, biology and environmental engineering, making the environmental committee a group with high level knowledge in environmental issues. This variety of expertise internal to the organization at the disposal of the same for the implementation and maintenance of the system is somewhat unusual for a private company. This participatory approach complements the necessary topdown approach mentioned above, a good strategy of implementing and EMS according with the results of Disterheft et al. (2012).

Furthermore, there is a great quantity of environmental aspects to monitor (Table 2-4). Almost all potential environmental aspects are present at UPV, something unusual in a private company where the environmental aspects are very closely related to some specific operations (Delakowitz and Hoffmann, 2000). Once more, the network of environmental contacts is the keystone which controls the environmental aspects and feedback to the system of the information received under the coordination and supervision of the EO.

Control of environmental legislation applicable to UPV is, likewise, more complex than in a private company, because of the variety and huge number of environmental issues. This requires maintaining a constant focus on keeping the information updated and available to all units involved in the EMS. With EMAS, UPV now has a verified method that allows for the monitoring and control of environmental interactions and legal requirements.

The strategy of abandoning the original plan of certifying each unit separately came as a result of detecting duplicities that hindered the implementation process throughout the entire university. These duplicities were the result of the high level of interdependence among the various units which caused the 
duplication of procedures and functions, and made it impossible to define procedures and a clear and operational organization chart. UPV was ultimately verified as a unique organization wherein some operations are linked specifically to units and require special treatment. This decision reduced the complexity of organization and operational control procedures, and resulted in a better adaptation of EMAS to the UPV structure.

It is assumed that the success of the results and implementation process are achieved when the investment in resources and personnel is sufficient to undertake the project (Vernon et al., 2010). In the case of UPV, corporate and senior management commitment was crucial, especially from the rector, who was entirely engaged from the beginning of the process. Considering that the election of the rector is held every four years and that the BoG is refreshed every new election of representatives of stakeholders, the strong will of top management must be maintained and reinforced by the political changes over the institution's own university. In the case of UPV, the implementation process lasted more than three years and it was necessary to have a strong investment in a full-time staff of technicians to coordinate and execute all requirements of EMAS. The will and the stability of senior management provided the necessary institutional framework to ensure the continuity in the project.

Analysis of the actions carried out by UPV for overcoming typical individual barriers are listed in Table 2-6.

\subsection{CONCLUSIONS}

For the implementation of EMAS at a university campus it is necessary to overcome some specific barriers which are typical of the public university. The strategies used for this have been largely motivated by the unique environment of the university itself and adapted to it. As a result, some milestones have been reached which can be considered measurable benefits of implementation.

Certain challenges, as mainstreaming environmental issues in teaching and research and green procurement, have been detected and it is assumed that can be addressed using the EMS itself.

The benefits achieved are related both to the improvement in operational control, and on the organizational level. Also notable is the improvement of environmental awareness, training, and information on the EMAS to members of the university, as well as an improvement of the image of the institution in the social, business and political arenas. 
At the same time, along with EMAS implementation, internal and the external environmental communication and transparency strategies are included in the policy of UPV.

In conclusion, EMAS can be considered a good environmental management system for university campuses, due to its adaptability to the complexity of university organization, and a very satisfactory model of governance of these institutions. EMAS constitutes an important tool among university sustainability initiatives.

\subsection{REFERENCES}

Alshuwaikhat, H.M., Abubakar, I., (2008) An integrated approach to achieving campus sustainability: assessment of the current campus environmental management practices. Journal of Cleaner Production, 16(16), 1777-1785. $\quad$ http://dx.doi.org/ 10.1016/j.jclepro.2007.12.002

Clarke, A., Kouri, R., (2009) Choosing an appropriate university or college environ- mental management system. Journal of Cleaner Production, 17(11), 971-984. http://dx.doi.org/ 10.1016/j.jclepro.2009.02.019

Delakowitz, B. and Hoffmann, A. (2000) The HochschuleZittau/Görlitz: Germany's first registered environmental management (EMAS) at an institution of higher education, International Journal of Sustainability in Higher Education, 1(1), 35-47. http://dx.doi.org/10.1108/1467630010307084

Disterheft, A., da Silva Caeiro, S.S.F., Ramos, M.R. and de Miranda Azeiteiro, U.M. (2012) 'Environmental management systems (EMS) implementation processes and practices in European higher education institutions - top-down versus participatory approaches', Journal of Cleaner Production, 31, 80-90. http://doi.org/ 10.1016/j.jclepro.2012.02.034

European Commission (1993) Council Regulation (EEC) No 1836/93 of 29 June 1993 Allowing Voluntary Participation by Companies in the Industrial Sector in a Community Eco-management and Audit Scheme, Official Journal L. 10/07, 0001-0018 Retrieved on December $\quad 16^{\text {th }} \quad 2012$ from http://eurlex.europa.eu/LexUriServ/LexUriServ.do?uri=OJ:L:2001:114:0001: 0029:EN:PDF 
European Commission (2008) Public Procurement for a Better Environment. Communication from the Commission to the European Parliament, The Council, The European Economic and Social Committee and the Committee of the Regions. Retrieved on December $16^{\text {th }} 2012$ from http://eur-lex.europa. eu/LexUriServ/LexUriServ.do?uri=COM:2008:0400:FIN:EN:HTM $\underline{\mathrm{L}}$

European Commission (2009) No, R.;1221/2009 of the European Parliament and of the Council of 25 November 2009 on the Voluntary Participation by Organisations in a Community Eco-management and Audit Scheme (EMAS), Repealing Regulation (EC) No 761/2001 and Commission Decisions 2001/681/EC and 2006/193 Retrieved on December $\quad 16^{\text {th }} \quad 2012$ from $\underline{\text { http://eur-lex.europa.eu/ }}$ LexUriServ/LexUriServ.do?uri=OJ:L:2009:342:0001:01:EN:HTML

Jones, N., Panoriou, E., Thiveou, K., Roumeliotis, S., Allan, S., Clark, J.R.A. and Evangelinos, K. (2012) Investigating benefits from the implementation of environmental management systems in a Greek university, Clean Technologies and Environmental Policy, 4(4), 669676. http://doi.org/ 10.1007/s10098-011-0431-8

Lozano García, F.J., Kevany, K. and Huisingh, D. (2006) Sustainability in higher education: what is happening?, Journal of Cleaner Production, 14(9), 757-760. http://dx.doi.org/10.1016/j.jclepro.2005.12.006

Lozano, R. (2006b) Incorporation and institutionalization of SD into universities: breaking through barriers to change, Journal of Cleaner Production, $\quad$ 14(9),

787-796.

http://doi.org/10.1016/j.jclepro.2005.12.010

Lozano, R. (2010) Diffusion of sustainable development in universities' curricula: an empirical example from Cardiff University, Journal of Cleaner Production, 18(7), 637-644. http://dx.doi.org/10.1016/j.jclepro.2009.07.005

Lozano, R. (2011) The state of sustainability reporting in universities, International Journal of Sustainability in Higher Education, 12(1), 67-78. http://doi.org/10.1108/14676371111098311

Peris-Mora, E. (2002) Environmental responsibility of universities. The environmental management systems, Environmental Management Systems for Sustainable Universities Conference 2002, 339-346. 
Roorda, N. and Onderwijs, S.D.H. (2001) AISHE Auditing Instrument for Sustainability in Higher Education Retrieved on December $16^{\text {th }} 2012$ from

http://www.eauc.org.uk/audit instrument for sustainability in hig her educ

Savely, S.M., Carson, A.I. \& Delclos, G.L. (2007) A survey of the implementation status of environmental management systems in US colleges and universities, Journal of Cleaner Production, 15(7), 650 659. http://dx.doi.org/10.1016/j.jclepro.2006.01.014

Velazquez, L., Munguia, N., Platt, A. and Taddei, J. (2006) Sustainable university: what can be the matter? Journal of Cleaner Production, 14(9), 810-819. http://dx.doi.org/10.1016/j.jclepro.2005.12.008

Vernon, J., Peacock, M., Belin, A., Ganzleben, C. and Candell, M. (2010) Study on the Costs and Benefits of EMAS to Registered Organizations Retrieved on January $1^{\text {st }} 2011$ from http://ec.europa.eu/environment/emas/

$\mathrm{pdf} /$ news/costs and benefits of emas.pdf Accessed $16^{\text {th }}$ December 2012

Viebahn, P. (2002) An environmental management model for universities: from environmental guidelines to staff involvement, Journal of Cleaner Production, 10(1), 3-12. http://dx.doi.org/10.1016/S09596526(01)00017-8 



\title{
3 ECOLOGICAL FOOTPRINT ASSESSMENT OF HIGHER EDUCATION APPLYING LIFE CYCLE ASSESSMENT FRAMEWORK. CASE STUDY: UNIVERSITAT POLITÈCNICA DE VALÈNCIA
}

\begin{abstract}
Lo-Iacono-Ferreira, V.G., Capuz-Rizo, S.F., Torregrosa-López, J.I. (2016) Ecological Footprint Assessment of Higher Education applying Life Cycle Assessment framework. Case study: Universitat Politència de València. XX International Congress on Project Management and Engineering. Cartagena. $1423-1432$. ISBN:

978-84-617-4180-9

http://www.aeipro.com/aplic/tree congresos/detalle remository aeipro.php? file $=4636$
\end{abstract}

Notice that this paper has been edited to match the style chosen for this document. Figures and tables have also been edited (only format). Abbreviations have also been homogenized. A complete abbreviation code is provided in page 23.

\begin{abstract}
Universities from all over the world has recently developed Ecological Footprint to assess their environmental impact. The methodologies applied are variations of the original methodology designed for territories. The analysis of these studies highlight the lack of standardization of the methodology and the lack of comparability with in results. Seeking for a standardized methodology that provides comparable results, an Ecological Footprint Assessment (EFA) methodology based on Life Cycle Assessment (LCA) is proposed. The assessment is applied to case study Universitat Politècnica de València (UPV). Results brings out the high impact of the emission component of the EFA - Carbon Footprint - that represents the 85\% of EFA. Weaknesses of the methodology are also discussed and the usefulness of a verified Environmental Management System is proven.
\end{abstract}

\subsection{INTRODUCTION}

The EFA is an environmental indicator defined as 'the ecologically productive territory needed to produce the resources used and to assimilate the waste and emissions produced by a population with a specific life mode indefinitely' by Wackernagel and Rees (1996). Over last years, it has been applied to different land areas as countries, regions, etc. (Lo Iacono-Ferreira, et al., 2011a). Moreover, EFA methodology has been adapted to assess companies and 
Proposal of a set of Key Performance Indicators for the environmental assessment of Higher Education Institution

different types of organizations; HEI are not an exception (Lozano et al., 2014).

EFA provides a result in global hectares (gha). A gha represents the average productivity of all biologically productive areas (measured in hectares) on earth in a given year (Wackernagel \& Rees, 1996). It is a manageable measure to report as the community target can visualize the dimension of a hectare easily.

The responsibility of HEI to be a benchmark of good practices made analysts, researchers and stakeholders search for tools to assess and report the results of their efforts to reduce the environmental impact of their activities. Several HEI adapted EFA methodology to their organization and published their results (Lo-Iacono-Ferreira et al., 2016c).

However, not standardize methodology, add uncertainty to the assessment. Studies have been made in order to detect weaknesses and strengths of EFA by its comparison with a well-known and standard assessment tool, the Life Cycle Assessment (LCA) (Lo Iacono-Ferreira, et al, 2011b).

LCA (International Organization for Standardization, 2006a) is a tool developed to evaluate impacts associated to a product or services. Four objectives can be distinguished in LCA application:

- Identify opportunities to improve productive cycle of the product.

- Detect as much information as possible to assist in decision making.

- Select pertinent environmental indicators and it measure technics.

- Produce marketing.

LCA goal is to analyzed potential environmental impacts and environmental aspects along the entire life cycle of the product or service. A material and energy flow analysis has to be made (International Organization for Standardization, 2006b).

Universitat Politècnica de València is a HEI located in Valencia region, Spain. It has an EMS that has been verified in EMAS (Torregrosa-López, et al., 2016). Both staff and researchers are engaged with the system in order to better manage the environmental impact of the institution.

This work is based on first author master's final project where EFA of universities has been analyzed. Further, main characteristics of LCA has also been studied in relationship with those EFA methodologies applied to universities. As a result, the following methodology is proposed and assessed for case study of UPV with data of 2014. 


\subsection{CASE STUDY}

UPV was founded in 1971, although some of it' s schools date back to nineteenth century. It is located in Valencian region and has three main campuses: Alcoy, Gandía y Vera with more than 38000 students, over 8000 staff members and 51 ha.

To assess EFA of UPV, LCA framework is used through the following steps according to LCA standard (International Organization for Standardization, 2006b):

- Definition of goals, scope, functional unit, system boundaries and data requirement

- Life Cycle Inventory analysis (LCI)

- Life Cycle Impact Assessment (LCIA)

- Interpretations of results (in section 3.3)

Figure 3-1 shows the assessment scheme where data sources are identified.

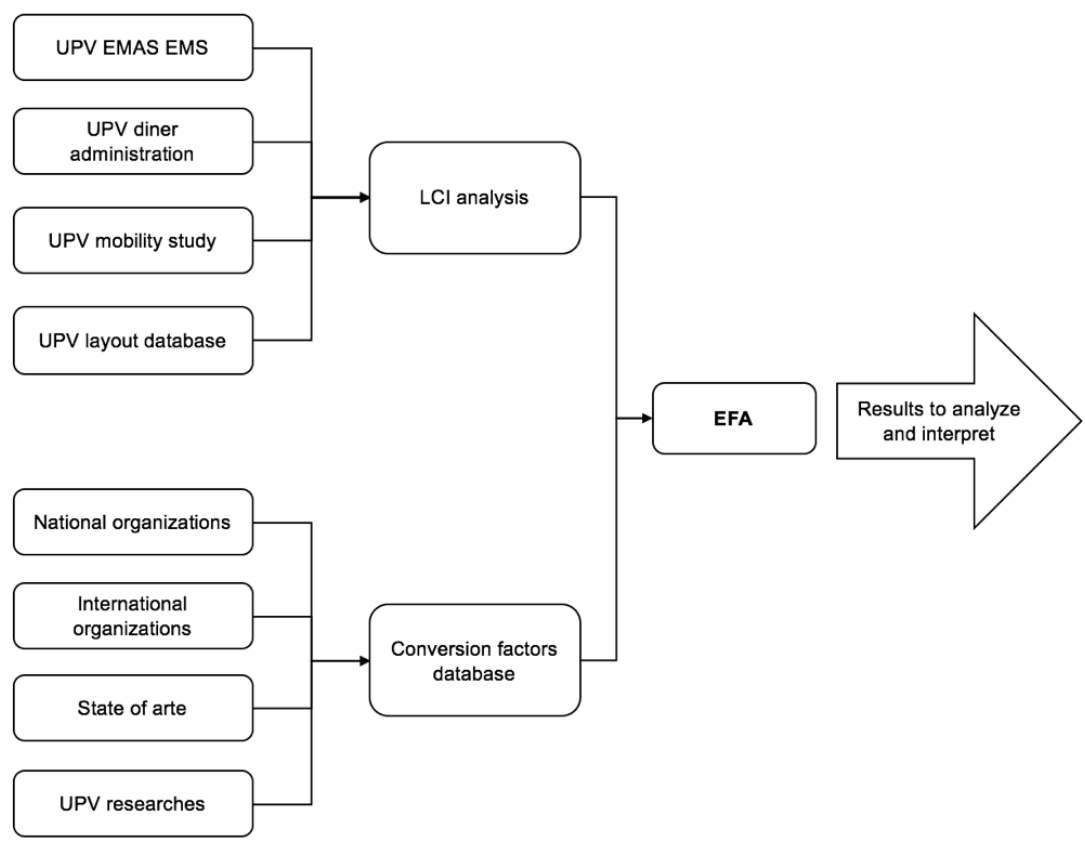

Figure 3-1 Assessment scheme 


\subsubsection{DEFINITION PRODUCT SYSTEM, FUNCTIONAL UNIT, SYSTEM BOUNDARIES AND DATA REQUIREMENT}

The product system has been defined as The University, including all three campuses and it community. The functional unit chosen is students. System boundaries has been defined on geographical basis.

About data requirement, whenever is possible, direct measures are preferred. Estimations are used if no direct measures are available but estimation methodology must be clearly reported. Regarding conversion factors, only reliable sources are used and consistent geolocation is pursued.

\subsubsection{LIFE CYCLE INVENTORY ANALYSIS (LCI)}

The LCI is defined considering the university as a whole, including all its activities. In this point, attention need to be paid as mobility from / to the university is a linked activity. Although the activity does not take place entirely inside geographical limits, it is considered as an interesting aspect that deserves to be assessed. Figure 3-2 shows the flow analysis for UPV. Aspects under consideration for UPV EFA are energy and water consumption, procurements, food \& drinks consumption, waste and wastewater generation, infrastructure and mobility.

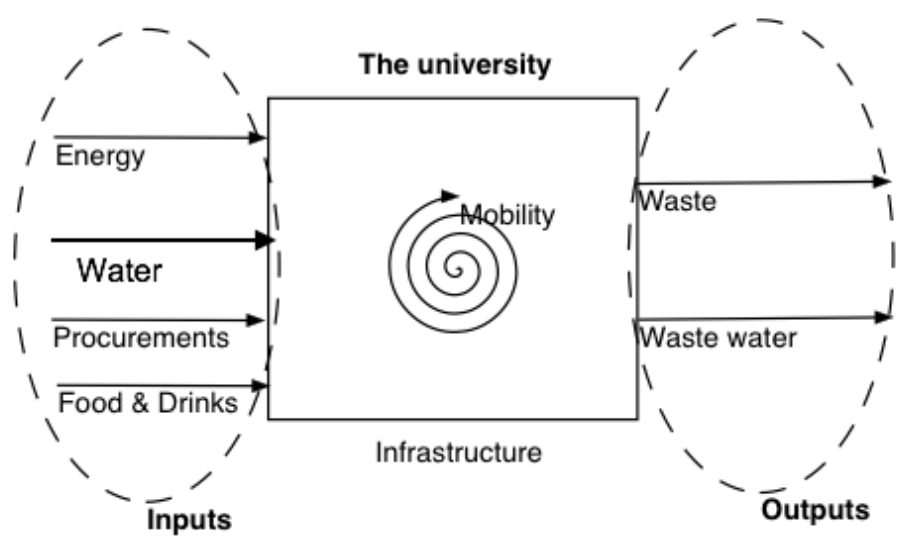

Figure 3-2 LCI analysis

\subsubsection{LifE CyCLE ASSESSMENT InVENTORY (LCAI)}

In this section, three characteristics of aspects are developed: how data is gathered, where does conversion factors come from and how the impact of the aspect is assessed. 
Energy consumption gathers five types of energy: electricity, gasoil, natural gas, gasoline and propane. Data over these aspects is obtained from invoices details and considered as direct measures. Same procedure is applied to water consumption and transferred to wastewater treatment as all incoming water needs to be treated as output somehow. Water consumption includes well and main water.

UPV has no centralized purchasing system. Each department manage their own budget as schools and general services. For this aspect, the only item available to assess is paper (virgin and recycled) used in the copy service. Direct data was obtained from Alcoy's copy service. Data for Valencia and Gandía Campus was inferred by a simple rule of three. A similar process was applied with food $\&$ drinks consumption as the manager of Alcoy coffee shop and dinner provided the number of menus sold during the year.

Waste aspect includes paper \& paperboard, electrical waste, light packaging, debris, manure, glass, municipal solid wastes (MSW) and batteries. EMS weight electrical waste, debris, manure, batteries and the glass of Valencia and Gandía campuses. The glass of Alcoy is estimated by the same EMS as well as MSW, light packaging and paper \& paperboard. The method applied to estimate the amount of glass in Alcoy and MSW is similar; a reference value that describe the rate generation of waste for each city $(R G)$ is multiplied by the number of people associated to each campus $(\mathrm{P})$ and the number of working days (D) as shown in Equation 3-1.

Equation 3-1

$$
\text { Data }=R G \cdot P \cdot D
$$

When no RG is available, a different estimation method is used. The waste collecting system is structured in sectors within cities. The collecting company weight the material collected by sectors (W). Light packaging and paper \& paperboard estimation is based on the relationship between the numbers of containers installed at the university (UC) and the total number of containers (TC) of the sector. This ratio gives the proportion of weight attribute to the university as shown in Equation 3-2.

Equation 3-2

$$
\text { Data }=\frac{W \cdot U C}{T C}
$$

EMS carried out a mobility study for 2014 where emissions associated to the mobility of all UPV community are calculated. The detail procedure can be seen in (Universitat Politècnica de València, 2015). 
Proposal of a set of Key Performance Indicators for the environmental assessment of Higher Education Institution

UPV layout database served as source for infrastructural data to include the constructed area for each year. The impact of constructed area is considered in equal proportions along its useful time life set at 50 years.

The data of each aspect considered is convert to impact units (gha) by a simple equation (Equation 3-3) where di represents the data of each aspect, CF the conversion factor and EF the Ecological Footprint.

\section{Equation 3-3}

$$
E F=\sum_{i=1}^{n} d_{i}[\text { units }] \cdot C F\left[\frac{g h a}{\text { units }}\right]
$$

The world average forest factor, the ratio that assess the land needed, in gha, to absorb certain amount of $\mathrm{CO}_{2} \mathrm{e}$, in $\mathrm{kg}$, used is $4400 \mathrm{kgCO}_{2} \mathrm{e} /$ gha (Escuela Politécnica Universitaria de Valladolid, 2009). Table 3-1 gather all conversion factors used to convert data into global hectares. 

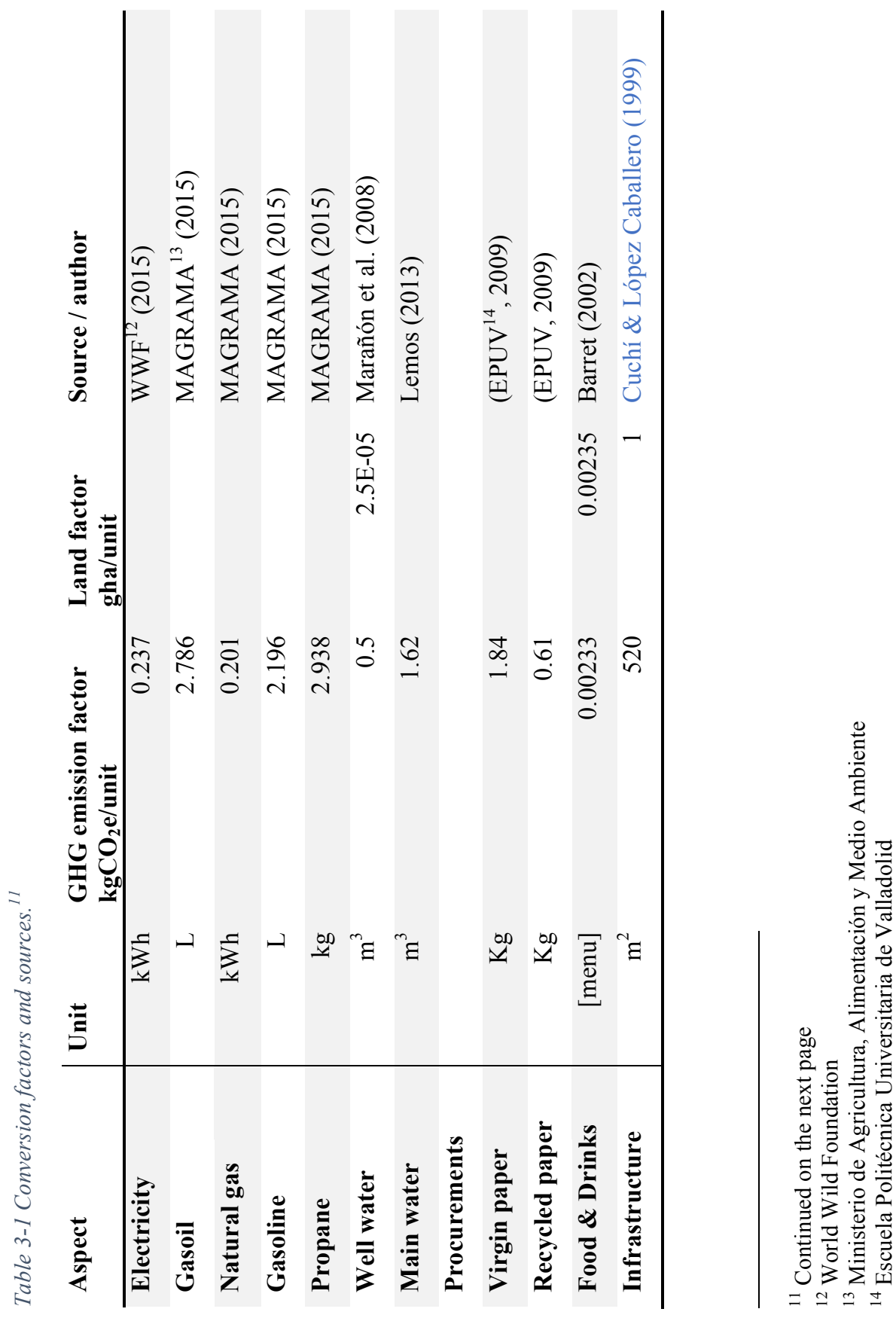


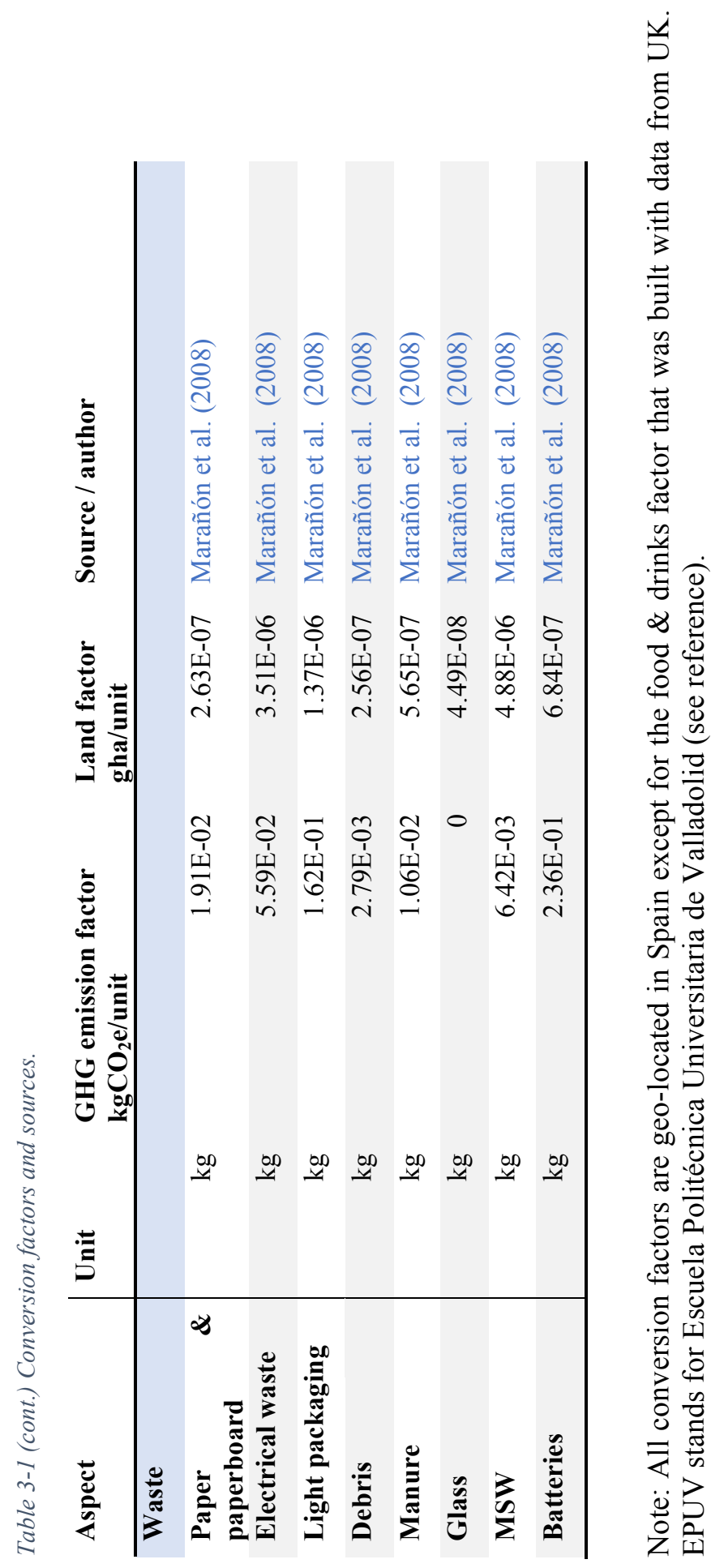




\subsection{RESULTS AND DISCUSSION}

EFA of UPV for 2014 is 7690 gha. The composition of EFA is presented in de following figure.

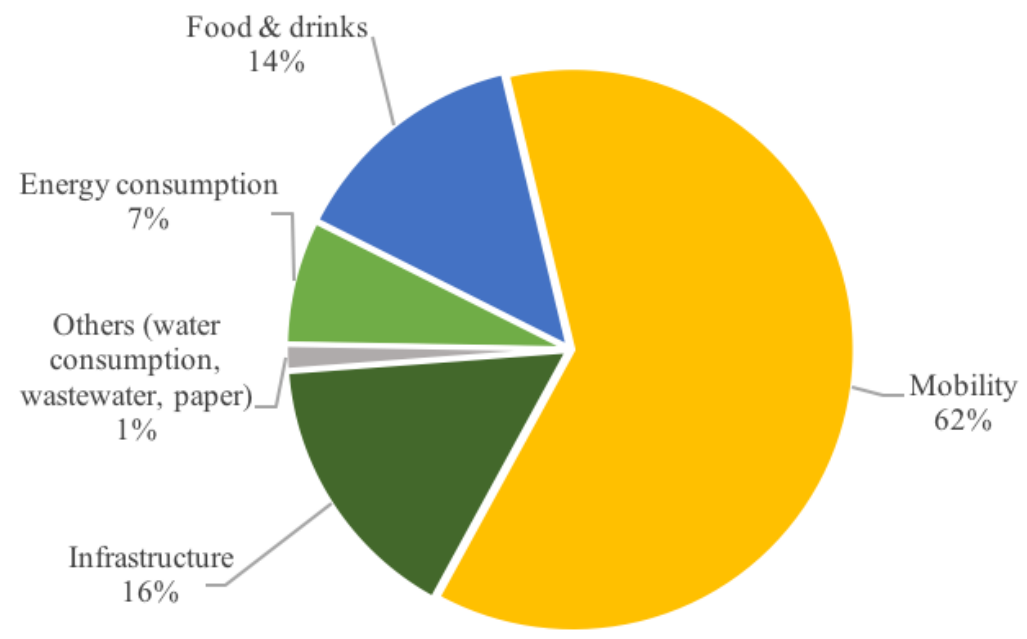

Figure 3-3 EFA UPV results for 2014

Four aspects stand out of the figure: Energy with a 7\%, infrastructure with a $16 \%$, mobility with $62 \%$ and food \& drinks with $14 \%$. Other aspects are grouped in an insignificant category.

Paper, a concept associated with education, it happens to have an insignificant impact. However, by not being able to assess purchases fully, some relevant impacts are being excluded: computers, lab equipment, electronics, chemical substances, office furniture, etc. All items that might have a significant impact. As infrastructure, long life devices would need a special consideration to allocate their impact along all its useful life. Water consumption and wastewater treatment are not relevant aspect of the environmental impact of this HEI.

The minimization consumption of energy is one of the main goals of the environmental office. Several actions have been taken to make a more efficient use of fuel and electricity. All energy sub-aspects are fully included in the EMS giving results relevance and transparency.

Food and drinks is an aspect based on estimations from real data of a small part of the community (Alcoy campus). It is the believe of the authors that the 
assessment of food can be improved by it direct inclusion in the regular monitoring of the EMS.

Mobility has been the subject of EMS in 2014 where the most recent mobility diagnosis took place. Regular information is gather during each course with the objective on knowing and understanding the way UPV community moves. As a public and recognized institution, UPV might have certain influence to negotiate changes on public transport to encourage it used minimizing the impact of mobility. This will impact not only on EFA results for UPV but on the area where its placed. Results by functional unit are shown in Table 3-2.

Table 3-2 Ecological footprint by aspects and by functional unit (students) in gha

\begin{tabular}{l|ll} 
Aspect & EF [gha by student] & UPV EF [gha] \\
\hline Energy & & \\
Electricity & 2.16 & $5.88 \mathrm{E}-05$ \\
Gasoil & 32.34 & $8.79 \mathrm{E}-04$ \\
Natural gas & 498.50 & $1.36 \mathrm{E}-02$ \\
Gasoline & 4.23 & $1.15 \mathrm{E}-04$ \\
Propane & 11.60 & $3.15 \mathrm{E}-04$ \\
Water & & \\
Well water & 23.46 & $6.38 \mathrm{E}-04$ \\
Main water & 67.69 & $1.84 \mathrm{E}-03$ \\
Procurements & & \\
Virgin paper & 7.95 & $2.16 \mathrm{E}-04$ \\
Recycled paper & 3.26 & $8.86 \mathrm{E}-05$ \\
Food \& Drinks & $1,064.28$ & $2.89 \mathrm{E}-02$ \\
Infrastructure & $1,219.81$ & $3.31 \mathrm{E}-02$ \\
Mobility & $4,745.77$ & $1.29 \mathrm{E}-01$ \\
Waste & & \\
Paper \& & 0.92 & $2.51 \mathrm{E}-05$ \\
paperboard & & \\
Electrical waste & 0.37 & $1.01 \mathrm{E}-05$ \\
Light packaging & 5.36 & $1.46 \mathrm{E}-04$ \\
Debris & 0.44 & $1.19 \mathrm{E}-05$ \\
Manure & 1.01 & $2.74 \mathrm{E}-05$ \\
Glass & 0.01 & $2.99 \mathrm{E}-07$ \\
MSW & 2.14 & $5.81 \mathrm{E}-05$ \\
Batteries & 0.01 & $2.23 \mathrm{E}-07$ \\
\hline
\end{tabular}

The Carbon Footprint can be assessed directly from the EFA by extracting the category of GHG emissions. For 2014, is $28.9 \mathrm{t} \mathrm{CO}_{2} \mathrm{e}$ and represents the $85 \%$ of EFA results. 


\subsection{CONCLUSIONS}

LCA methodology help to developed a clear EFA. Except for 1, all conversion factors have the same geographical root than the object of study, UPV. However, the origin of these factors it is not always clear. Moreover, improvements need to be accomplish in order to have more accurate data of some aspects like procurement and food consumption.

The Ecological Footprint of UPV shows that the main impact is due to the mobility of the community. However, the lack of a full assessment of the procurement aspect has to be taken under consideration. UPV is already focusing efforts in the reduction of this impact as can be seen in the mobility plan recently published. Furthermore, alternatives to gather procurement information to improve the assessment are being considered.

Results presented by functional unit, students, could constitute a useful tool to inform and engage higher education institution community in direction of a better environmental performance. Further research may shed light on the best way to use this information and how to measure the influence towards a behavioral change to achieve necessary environmental impact reductions.

\subsection{REFERENCES}

Cuchí i Burgos, A., \& López Cabeallero, I. (2005) Informe MIES: Una proximació a l'impacte ambiental de l'Escola d'Artquitectura del Vallès. Universitat Politècnica de Catalunya. ISBN: 84-7653-870-7

Escuela Politécnica Universitaria de Valladolid (2009) Emisiones CO2. Retrieved on June $15^{\text {th }} 2013$ from http://www.eup.uva.es/emisionesco2

International Organization for Standardization (2006a) Environmental management - life cycle assessment - principles and framework. ISO 14040:2006.

International Organization for Standardization (2006b) Environmental management - life cycle assessment - requirements and guidelines. ISO 14044:2006(E).

Lo Iacono Ferreira, V.G., Torregrosa-López, J.I., López Pérez, F., PachecoBlanco, B., Viñoles-Cebolla, R. (2011a) Comparative Analysis of the methodology of calculation of EF in different areas. XV International Congress on Project Management. Huesca. AEIPRO ISBN: 978-84615-4543-8

http://www.aeipro.com/aplic/tree congresos/detalle remository aei pro.php?file $=3331$ 
Lo-Iacono-Ferreira, V.G. Torregrosa-López, J.I Lora-García, J., BastanteCeca, M.J. \& Capuz-Rizo, S. F. (2011b) Study of the inclusion of life cycle assessment impact categories in ecological footprint calculation. XV International Congress of Project Engineering. Huesca. $\quad$ AEIPRO ISBN: 978-84-615-4543-8 http://www.aeipro.com/aplic/tree congresos/detalle remository aei pro.php?file $=3329$

Lo-Iacono-Ferreira, V.G., Torregrosa-López, J.I., \& Capuz-Rizo, S.F. (2016c) Use of Life Cycle Assessment methodology in the analysis of Ecological Footprint Assessment results to evaluate the environmental performance of universities. Journal of Cleaner Production, 133, 43-53. http://doi.org/10.1016/j.jclepro.2016.05.046

Lozano, R., Ceulemans, K., Alonso-Almeida, M., Huisingh, D., Lozano, F. J., Waas, T., Lambrechts, W., Lukman, R., Hugé, J. (2014) A review of commitment and implementation of sustainable development in higher education: results from a worldwide survey. Journal of Cleaner Production, 108, 1-18. http://doi.org/10.1016/j.jclepro.2014.09.048

Ministerio de Agricultura, Alimentación y Medio Ambiente (2015) Ministerio de Agricultura, Alimentación y Medio Ambiente. Cambio Climático. Retrieved on May $3^{\text {rd }} 2015$ from http://www.magrama.gob.es/es/cambio-climatico/temas/mitigacionpoliticas-y-medidas/Registro-Huella-Carbono.aspx

Torregrosa-López, J. I., Lo Iacono-Ferreira, V. G., Barranco-Martí, C., \& Bellver-Navarro, C. G. (2016) The strengths of EMAS as an environmental management system for European university campuses. International Journal of Environment and Sustainable Development, 15(1), 89-106. http://dx.doi.org/10.1504/IJESD.2016.073339

Universitat Politècnica de València (2015) Plan de movilidad sostenible. Diagnóstico de situación inicial. Unidad de Medio Ambiente. Retrieved on January $2^{\text {nd }} 2015$ from https://www.upv.es/entidades/AMAPUOC/infoweb/ov/info/887195 normalc.html

Wackernagel, M., \& Rees, W. (1996) Our ecological footprint: reducing human impact on the earth. Gabriola Island, Canada: New Society Publishers 0-86571- 312-X. 
World Wild Foundation (2015) Observatorio de la electricidad. Retrieved on June $15^{\text {th }}$ 2013 from http://www.wwf.es/que hacemos/cambio climatico/nuestras soluci ones/energias renovables/observatorio de la electricidad/ 



\section{STUdy OF THE INCLUSION OF LIFE CYCLE ASSESSMENT IMPACT CATEGORIES IN ECOLOGICAL FOOTPRINT}

Lo-Iacono-Ferreira, V.G. Torregrosa-López, J.I Lora-García, J., Bastante-
Ceca, M.J. \& Capuz-Rizo, S. F. (2011) Study of the inclusion of life cycle
assessment impact categories in ecological footprint calculation. XV
International Congress of Project Engineering. Huesca. AEIPRO ISBN: 978-
84-615-4543-8
http://www.aeipro.com/aplic/tree_congresos/detalle_remository aeipro.php?
file=3329

Notice that this paper has been edited to match the style chosen for this document. Figures and tables have also been edited (only format). Abbreviations have also been homogenized. A complete abbreviation code is provided in page 23.

\section{ABSTRACT}

The Ecological Footprint (EF) has been compared to a simplified version of a Life Cycle Assessment (LCA) (Finkbeiner, 2009) (Weideman et al., 2008). This simplification allows a simpler calculation method and a more intuitive result, at the expense of rigor in the calculation. This loss of rigor has been criticized by many experts.

To improve these shortcomings, EF could pick up either in the calculation of productive land needed for the activity, either by calculating the land required to absorb the environmental impact, the effect of inclusion of the different impact categories of GWP.

In this paper, the way of including others impact categories of LCA in EF calculation will be study, especially its influence on:

- The calculation of the productive footprint.

- The calculation of land area needed to absorb global impact activity.

\section{ACKNOWLEDGMENTS}

The results of this study are a part of the project titled: "Proposal of a Methodology for the assessment of environmental footprint and carbon footprint at the university: a case study of Universitat Politècnica de València", financial supported by the "Program of Support to the Research and Development 2010-2011 (PAID-05-10)." of the Universitat Politècnica de València. 


\subsection{INTRODUCTION}

LCA is a high-level mechanism, strongly based, that helps humanity understand and analyses products and activity impacts for health and environment.

To consider EF as a simplified version of LCA (Finkbeiner, 2009) (Weideman et al., 2008) benefit interpretation of LCA results. Although rigor might be lost, understandable and measurable are the two essential characteristics of EF. Including LCA categories in EF analyses can improve rigor results and enrich this instructive indicator.

To analyze how LCA impact categories influence EF, a review of each tool is made.

\subsubsection{Life CyCle AsSESSMENT (LCA)}

As is defined in UNE-EN ISO 14040 (Asociación Española de Normalización y Certificación, 2006a), LCA is a technic developed to evaluate impacts associated to a product. Four objectives can be distinguished in LCA application:

- Identify opportunities to improve productive cycle of the product.

- Detect as much information as possible to assist in decision making.

- Select pertinent environmental indicators and it measure technics.

- Produce marketing.

LCA goal is to analyzed potential environmental impacts and environmental aspects along the entire life cycle of the product. A material and energy flow analysis has to be made.

Four phases are needed to define LCA methodology, although they are closely related as can be seen in Figure 4-1.

Phase I: Objectives and scope definition.

Phase II: Life cycle inventory analysis (LCI).

Phase III: Life cycle impact assessment (LCIA).

Phase IV: Life cycle results interpretation.

Requirements and guidelines for LCA analysis are defined by standard (Asociación Española de Normalización y Certificación, 2006b).

Phase I, objectives and scope definition, allows defining information and specifications required for LCA study. 


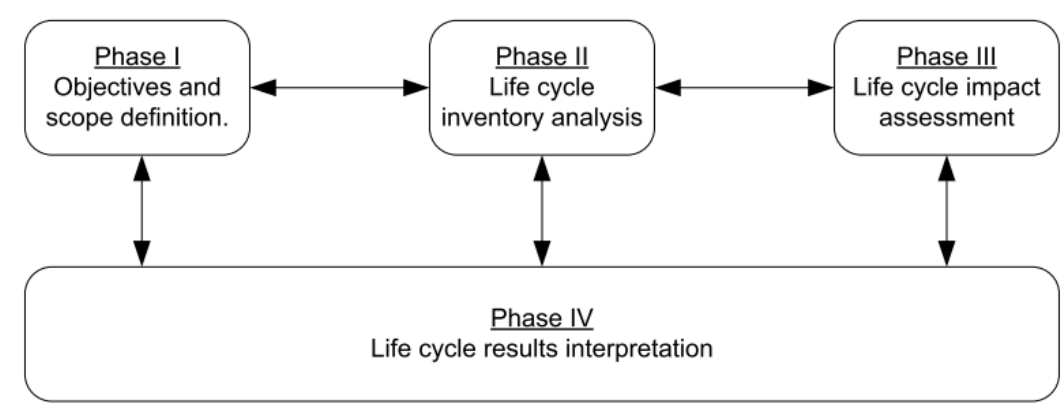

Figure 4-1 LCA phases

Environmental effects generated by the product are analyzed in LCI, phase II. All environmental loads and effects generated by the activity or product analyzed must be take into account. The amount of substances, radiation, noises or vibrations emitted to or removed from the surroundings must be considered. Parameters identify must be quantifiable. Raw materials, energy consumption, air emissions, waste, water emissions, etc. can be included. As said before, a material flow analysis is essential to perform phase II.

Completed LCI, LCIA can be executed, the quantification of impacts associated to each aspect defined at phase II. Different kind of impacts might be taken into account, but there is no standard that rules how to establish impact categories and its indicators, just suggestions and examples (Udo de Haes et al., 1999).

Different methodologies have been design to carry on with LCIA and can be grouped by Weighting methods - single index approaches - and Damage oriented method.

Single index approaches can be in three lines: monetary methods, sustainability and target methods and social and expert method; Eco-indicator 95 is an example.

Eco-indicator 99 (Goedkoop \& Spriensma, 2001), a damage oriented method is analyzed in order to carry out the goal of this paper. Descriptions of other methodologies can be found in Sonnemman (2004).

A critical review must be included in LCA report, as well as the relationship between different phases and the terms of use of value judgments and optional elements. Limitations of study must be described over the critical review. Non-indications are given in standard procedures about measurement units for LCA. 


\subsubsection{ECOLOGICAL FOOTPRINT (EF)}

EF was defined by Wackernagel \& Rees (Wackernagel \& Rees, 1996) as "the area of ecologically productive land needed to produce the resources used and assimilate the waste produce by a given population with a specific lifestyle indefinitely". Main goal of it development was to evaluate how dependent is the objective analyzed on resources and territory.

Global hectares (gha) are used to measure EF, the average bioproductivity of productive world hectares.

EF methodology, design by The Global Footprint Network (Ewing et al., 2010) an organization founded by Wackernagel \& Rees, considerate 6 different categories or items:

- Carbon Footprint

- Built-up land

- Forest land

- Cropland

- Grazing land

- Fishing grounds

Carbon Footprint (CF) evaluates greenhouse gas emissions (GHG) as equivalent $\mathrm{CO}_{2}$ emissions by the activity or organization analyzed, although exact reach depends on factor. Energy used emissions within the process are considered.

Using global average absorption factor, emissions are converted to land needed to absorb them. Standard PAS 2050 (British Standard Institute, 2008) specify how to assess life cycle GHG of goods and services.

Built-up land, Forest land, Cropland, Grazing land and Fishing grounds represents land needed, Productive Footprint (PF), to obtain necessary resources to carry out with the activity of the organization evaluated.

Results are obtained in hectares; a unit easily interpreted as the land occupied by a football camp: a hectare.

Sustainability degree can be evaluated comparing land on property by the organization with EF. Although conclusions have to be taken with care, considering activities performed by the organization.

Improve sustainability is main objectives when EF is analyzed. Process and sub-process most relevant for EF are distinguished and weak and strong points are established for the sake of reducing EF and it components. Even though neutralization has to be last option, neutralization mechanisms are developed and standardized; standard PAS 2060 (British Standard Institute, 2010) specify how to neutralize impact associated to CF. 


\subsection{ANALYSIS}

Although LCA was designed for product analysis, nowadays is applied also for activity analyses.

As seen before, categories identify in LCA analyses depend on LCIA definition and the methodology used in it. For this study, Eco-indicator 99 (Goedkoop \& Spriensma, 2001) is used as LCIA tool.

Eco-indicator 99 distinguishes three main categories that contained 11 different aspects as shown in Table 4-1.

Table 4-1 Eco-indicator 99 structure. (Goedkoop \& Spriensma, 2001)

\begin{tabular}{l|l} 
Category & Aspects \\
\hline \multirow{2}{*}{ Mineral and fossil resources } & Mineral \\
& Fossil \\
\hline \multirow{3}{*}{ Ecosystem quality } & Ecotoxicity \\
& Eutrophication \\
& Acidification \\
& Land use \\
\hline \multirow{4}{*}{ Human Health } & Climate change \\
& Ozone layer depletion \\
& Carcinogenesis \\
& Ionising radiation \\
& Respiratory effects
\end{tabular}

Table 4-2 summarize an analysis of each Eco-indicator 99 aspect and it consideration in EF traditional methodology conducted by authors of this paper. EF aspect is related with an Eco-indicator 99 aspect.

Those Eco-indicator 99 aspects that are included, in a certain way, in traditional EF methodology are identified with Wackernagel \& Rees reference.

- In grey, Eco-indicator 99 aspects that are not included but exists studies that gives a clue to introduce them, or an alternative methodology to evaluate them in an EF compatible way. References are assigned.

- With an X, aspects that have no sense in EF assessment.

- In white, relations that are no needed.

A LCA Human Health category aspect is represented in EF, Climate Change. Indeed, a valid alternative to evaluate $\mathrm{CF}$ is by LCA Climate Change category. Ozone layer depletion, carcinogenesis, ionizing radiation and respiratory effects are not contemplated in EF. 
Proposal of a set of Key Performance Indicators for the environmental assessment of Higher Education Institution

Land use, an aspect of Ecosystem quality is represented by Built-up land, Forest land, cropland, Grazing land and Fishing ground EF aspects.

Ecotoxicity, Eutrophication or Acidification are not considered categories in current EF methodology.

Fossil impact is also partial considered, by the fraction of fossil fuels that are involved in energy use inside CF calculation.

No mineral impact is considered in EF, but other resources as cropland, forest, grazing land and fishing grounds needed to perform activity organization are considered as part of PF.

\subsubsection{InCLUding RESOURCE CATEGORY: MinerALS AND FossiL}

Eco-indicator 99 resource categories emphasize impact in quality of ores and fossil material sources, taking into account long-term trends of lowering resource quality. Proposed methodology assumes that effort to extract remaining resources increases when resource quality is reduced. Depending if damage to mineral or to fossil is being analyzed, concentration and effort to extract varies it relevance. In case of mineral source, concentration is the most relevant parameter; reducing concentration implicates a grate increase in effort to extract. However, for fossil fuels, concentration is not considered significant as the effort needed to extract the resource.

Weak and strong points of Eco-indicator 99 method proposal are mentioned by its authors (Goedkoop \& Spriensma, 2001) (see a summary at Table 4-3). Model establishes de decrease of concentration as a result of the extraction.

Surplus Energy is the unit applied to measure resource damage by this methodology. Surplus energy represents the difference between energy needed to extract a resource in the present and energy that will be needed to extract it in the future, assuming a possible link between depletion of abiotic resources and Human Health category (Nguyen et al, 2005). This attribution does not represent a problem for LCA but can introduce more laxity into EF.

Nguyen (2005) propose an alternative methodology to quantify abiotic resources as to include it in $\mathrm{EF}$ analysis, exergy loss parameter $\Delta \mathrm{E}_{\mathrm{x}}$. Exergy evolves as world entropy increased, is not conserved as mass or energy and does not depend on Human health or eco-system quality directly. Math development of this parameter can be seen in Nguyen's paper.

Exergy loss considered mining, milling and smelting process of ore. Nguyen provides complete equations for analysis and a study of exergy loss for seven materials in a period of 50 years from now on (Table 4-4). 


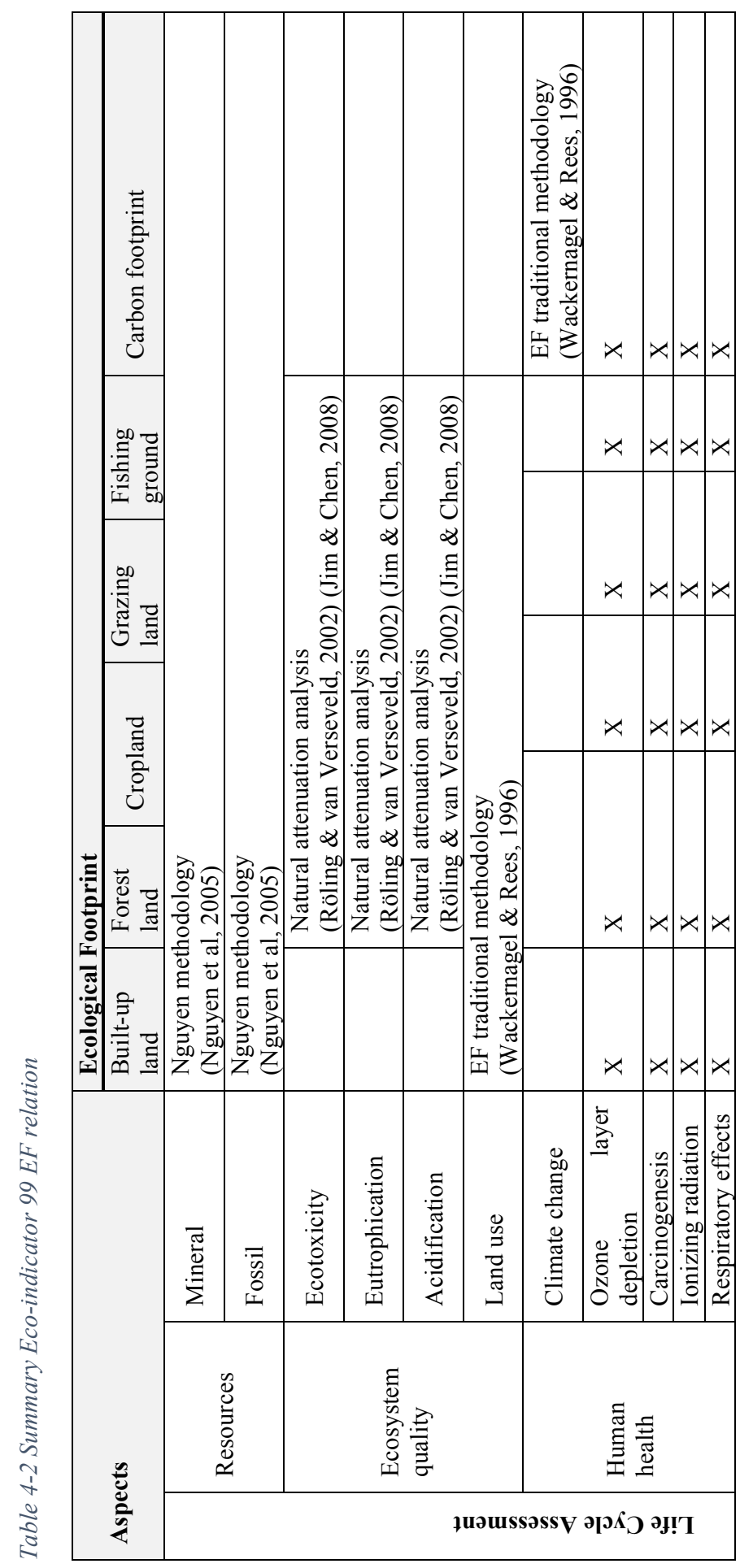


Proposal of a set of Key Performance Indicators for the environmental assessment of Higher Education Institution

Table 4-3 Weak and strong points of Eco-indicator 99

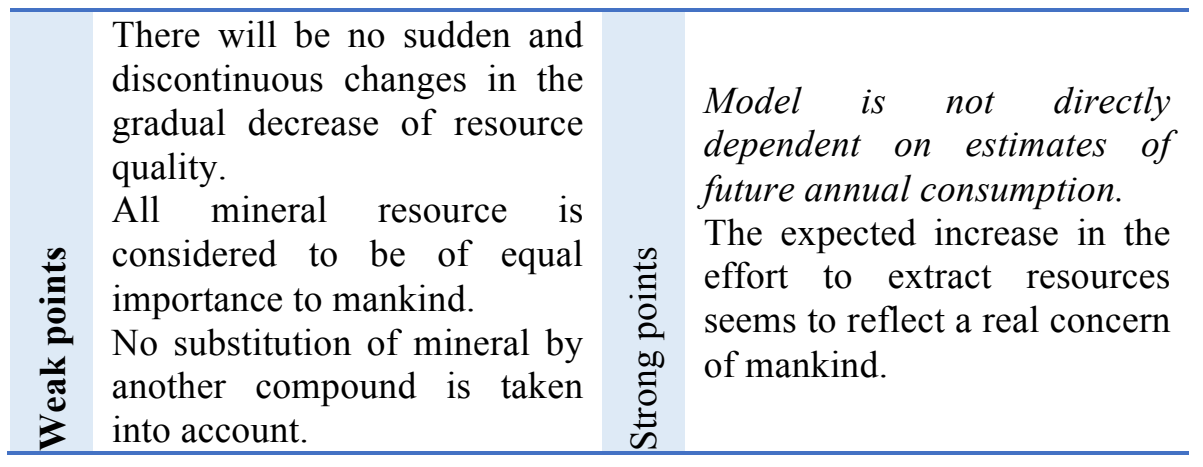

Table 4-4 Exergy loss values according to Nguyen

\begin{tabular}{l|ll} 
Material & $\begin{array}{l}\Delta E_{x} \\
{[M J / \text { ton }]}\end{array}$ & $\begin{array}{l}\text { Abiotic factor }(A f) \\
\text { [gha/ton] }\end{array}$ \\
\hline Aluminum & $3.94 \mathrm{E}+03$ & 2.12 \\
Chromium & $2.73 \mathrm{E}+02$ & 0.15 \\
Copper & $1.65 \mathrm{E}+05$ & 88.72 \\
Iron & $2.88 \mathrm{E}+01$ & 0.02 \\
Molybdenum & $4.26 \mathrm{E}+04$ & 22.98 \\
Nickel & $3.43 \mathrm{E}+04$ & 18.51 \\
Zinc & $3.19 \mathrm{E}+03$ & 1.72
\end{tabular}

When converting exergy loss in gha units, temporal period has to be taken into account; abiotic factor analysis presented in Table 4-4 are evaluated for 50 years and was estimated using the exergy loss of the material and the vegetation area needed to absorbed equivalent solar exergy. Equation 4-1 express Required Abiotic Area (AAR) in gha, where Afi represents de Abiotic factor for (i) material and Mi quantity of M material consumption.

Equation 4-1

$$
A A_{R}=\sum_{i}^{n} A f_{i} \cdot M_{i}
$$

A linear relationship between traditional methods was found by Nguyen. Equation 4-2 represents the relationship with Table 4-5 statistic values and Table 4-6 properties. Equation 4-2 application has to be meditated considering is a regression of countries EF values.

Equation 4-2

$$
E F_{\text {Nguyen }}=0.79 \cdot E F_{\text {traditional }}+0.25
$$


Table 4-5 Statistic values for Equation 4-2

\begin{tabular}{ll}
\hline $\mathrm{R}$ & 0.977 \\
$\mathrm{R}$-sqr & 0.955 \\
Standard Error of Estimate & 1.261 \\
\hline
\end{tabular}

Table 4-6 Properties of Equation 4-2

\begin{tabular}{r|ll} 
Coefficient & $y_{O}$ & $a$ \\
\cline { 2 - 3 } $\mathrm{t}$ & 0.2515 & 0.7923 \\
$\mathrm{P}$ & 0.441 & 8.494 \\
& 0.6820 & 0.0011
\end{tabular}

Although this methodology is developed for traditional EF goals, countries, it can be applied to every kind of organization or product knowing it material consumption.

\subsubsection{INTRODUCING ECOSYSTEM QUALITY: ECOTOXICITY, EUTROPHICATION AND ACIDIFICATION}

Processes as dilution, dispersion, ion exchange, sorption, transformation and degradation are included in Natural Attenuation concept (Röling \& van Verseveld, 2002). Forest, water mass, soil and all natural structure can assimilate, depending on its characteristics, pollutants and balance ecotoxicity, eutrophication and acidification process.

Although no specific investigation reports have been found about land and type of land required to assimilate those impacts, some researcher has already provided knowledge to address conclusive investigations about these aspects.

Röling \& van Verseveld (2002) evaluate the capacity for intrinsic bioremediation of subsurface were microorganisms can attenuate pollutants as organic molecules metals, and inorganic nitrogen compounds based on Subsurface Specimen Banking concept. An insight in the natural attenuation of many compounds in a wide variety of subsurface geochemical settings wants to be given but, as it authors express, current knowledge of natural attenuation has to be improved. However, bases and methodologies for research are developed.

Ecosystem services assessments can contribute to ecosystem quality evaluation by natural attenuation concept (Jim \& Chen, 2008). This parameter can be evaluated in area units to be included in EF assessment. Jim \& Chen (2008) contribute to this cause by investigation urban trees capacity to remove air pollutant. SO2, NOx, and Total Suspended Particulates (TSP) are considered as main pollutants in under study region Guangzhou in China. 
Proposal of a set of Key Performance Indicators for the environmental assessment of Higher Education Institution

Parameters and methodology considered to quantify air pollutant removal can be seen in Equation 4-3.

Equation 4-3

$$
F=\sum_{i} V d_{i} \cdot C_{i} \cdot A \cdot T
$$

Where $\mathrm{F}$ is the amount of air pollutants (i) removed by urban trees, Vdi [cm/s] represents deposition velocity, $\mathrm{Ci}[\mathrm{g} / \mathrm{cm} 3]$ is the concentration of air pollutant $\mathrm{I}, \mathrm{A}[\mathrm{cm} 2]$ is de tree cover in under study region and $\mathrm{T}[\mathrm{s}]$ is time period considered.

Different situations as emissions of volatile organic compounds, transfer process, flower seasons, dry and wet season where included in Jim \& Chen (Jim \& Chen, 2008) analysis.

Removals rates obtain by Jim \& Chen (2008) are presented in Table 4-7.

Table 4-7 Removal rates of air pollutants by land use according to Jim \& Chen for Guangzhou city in China.

\begin{tabular}{l|llll} 
Land use & $\begin{array}{l}\mathbf{S O}_{2} \text { removal } \\
\text { rate } \\
\text { [kg/ha.year] }\end{array}$ & $\begin{array}{l}\mathbf{N O}_{\mathbf{x}} \\
\text { removal rate } \\
\text { [kg/ha.year] }\end{array}$ & $\begin{array}{l}\text { TSP } \\
\text { removal rate } \\
{[\mathbf{k g} / \mathbf{h a} \text {.year] }}\end{array}$ & $\begin{array}{l}\text { Total } \\
\text { removal rate } \\
\text { [kg/ha.year] }\end{array}$ \\
\hline Recreational & 23.87 & 24.29 & 88.79 & 136.90 \\
Institutional & 28.13 & 24.89 & 115.18 & 168.21 \\
Residential & 30.55 & 25.30 & 99.31 & 155.16 \\
Transportation & 21.18 & 28.86 & 110.50 & 160.55 \\
Industrial & 32.74 & 28.90 & 132.78 & 194.42 \\
\hline
\end{tabular}

\subsubsection{LAND USE CONSIDERATION}

Although land use is included in EF traditional methodology, Lenzen \& Murray (Lenzen \& Murray, 2001, Lenzen et al., 2007) make a contribution that deserves to be considered. Deserts and ice caps are included in land use assessment by evaluating its usefulness to area productivity when regions are EF object. In particular, arid and semi-arid lands are included in Australian EF assessment.

\subsection{CONCLUSIONS}

In opinion of the authors, several categories of Ecoindicator 99 can be transformed into land needed to produce the resources used and assimilate the waste produce by a given population with a specific lifestyle indefinitely:

- Abiotic resources can be transformed into gha through the concept of exergy loss. 
- Natural attenuation capacity of the ecosystems could be considered in order to estimate the gha of ecosystems necessary to absorb impacts related to Ecotoxiciy, Eurtrofication and Acidification.

Methodologies analyzed has specific mathematical method that contributes on rigor to EF. Uncertainty analyses can be performed over these methodologies.

Including Resource and Ecosystem quality LCA categories enrich EF methodology with rigor and comparative capacities between understudy organizations.

Developing methodologies to include Resource and Ecosystem quality categories gives EF indicator the capacity to include quality and biodiversity concepts besides actual view focus on production consumer goods. Whereas, the possibility of evaluates the loss of land that provokes acidification, etherification and ecotoxicity.

Further studies are necessary to evaluate quantitative influence of these new categories on EF assessment. Nowadays, authors are analyzing this influence in the EF assessment in Universitat Politècnica de València for the years 2009 and 2010.

\subsection{REFERENCES}

Asociación Española de Normalización y Certificación (2006a) UNE-EN ISO 14040. Gestión Ambiental. Análisis del ciclo de vida. Principios y marco de referencia. AENOR. Madrid, España

Asociación Española de Normalización y Certificación (2006b) UNE-EN ISO 14044 Gestión ambiental. Análisis del ciclo de vida. Requisitos y directrices. Madrid, España

British Standard Institute (2008) Specifications for the assessment of the life cycle greenhouse gas emissions of goods and services. PAS 2050.

British Standard Institute (2010) PAS 2060. Specification for the demonstration of carbon neutrality.

Ewing B., D. Moore, S. Goldnger, A. Oursler, A. Reed, and M. Wackernagel. (2010) The Ecological Footprint Atlas 2010. Oakland: Global Footprint Network. Retrieved on January $3^{\text {rd }} 2011$ from http://www.footprintnetwork.org/images/uploads/Ecological Footpr int Atlas 2010.pdf

Finkbeiner, M. (2009) Carbon footprinting. Opportunities and threats. International Journal of Life Cycle Assessment, (14), 91-94. http://doi.org/ 10.1007/s11367-009-0064-X 
Proposal of a set of Key Performance Indicators for the environmental assessment of Higher Education Institution

Goedkoop, M., \& Spriensma, R. (2001) The Eco-indicator 99. A damage oriented method for Life Cycle Impact Assessment. Amersfoort: PRé Consultants B.V. Retrieved on June $1^{\text {st }} 2012$ from https://www.presustainability.com/download/EI99 annexe v3.pdf

Jim, C., \& Chen, W. (2008) Assessing the ecosystem service of air pollutant removal by urban trees in Guangzhou (China). Journal of Environmental Management, 88, 665-676. http://dx.doi.org/10.1016/j.jenvman.2007.03.035

Lenzen, M., \& Murray, S. (2001) A modified ecological footprint method and its application to Australia. Ecological Economics, 37, 229-255. http://dx.doi.org/10.1016/S0921-8009(00)00275-5

Lenzen, M., Hansson, C. B., \& Bond, S. (2007) On the bioproductivity and land-disturbance metrics of the Ecological Footprint. Ecological Economics, 61(1), 6-10. Retrieved on January $3^{\text {rd }} 2011$ from http://www.isa.org.usyd.edu.au/publications/documents/ISA\&WWF Bioproductivity\&LandDisturbance.pdf

Nguyen, H. X., Wang, Y., Morimoto, K., \& Yamamoto, R. (2005, December). Modified Ecological Footprint Evaluation to include Resource Depletion. In 2005 4th International Symposium on Environmentally Conscious Design and Inverse Manufacturing, 785-790. http://doi.org/ 10.1109/ECODIM.2005.1619350

Röling, W., \& van Verseveld, H. (2002) Natural attenuation: What does the subsurface have in store? Biodegradation, 13, 53-64. http://doi.org/10.1023/A:1016310519957

Sonnemann, G., Castells, F., Schuhmacher, M., \& Hauschild, M. (2004) Integrated life-cycle and risk assessment for industrial processes. The International Journal of Life Cycle Assessment, 9(3), 206-207. http://doi.org/ 10.1007/BF02994195

Udo de Haes, H. A., Jolliet, O., Finnveden, G., Hauschild, M., Krewitt, W., Müller-Wenk, R. (1999) Best available practice regarding impact categories and category indicators in Life-Cycle Impact Assessment. SETAC-Europe: Second Working Group on LCIA (WIA-2). The International Journal of Life Cycle Assessment, 4, 66-74. http://doi.org/10.1007/BF02979403 
Wackernagel, M., \& Rees, W. (1996) Our ecological footprint: reducing human impact on the earth. Gabriola Island, Canada: New Society Publishers 0-86571- 312-X.

Weideman et al. (2008) Carbon footprint, a catalyst for LCA. Journal of Industrial Ecology, 12(1), 3-6. http://doi.org/10.1111/j.15309290.2008.00005.x 

5 USE OF LIFE CYCLE ASSESSMENT METHODOLOGY IN THE ANALYSIS OF ECOLOGICAL FOOTPRINT ASSESSMENT RESULTS TO EVALUATE THE ENVIRONMENTAL PERFORMANCE OF UNIVERSITIES

Lo-Iacono-Ferreira, V.G., Torregrosa-López, J.I., \& Capuz-Rizo, S.F. (2016) Use of Life Cycle Assessment methodology in the analysis of Ecological Footprint Assessment results to evaluate the environmental performance of universities. Journal of Cleaner Production, 133, 43-53. http://doi.org/10.1016/j.jclepro.2016.05.046

Notice that this paper has been edited to match the style chosen for this document. Figures and tables have also been edited (only format). Abbreviations have also been homogenized. A complete abbreviation code is provided in page 23.

\begin{abstract}
The assessment of the environmental performance of an organization is an essential part of the decision- making process of an Environmental Management System. Having robust indicators enables a reliable assessment. The Ecological Footprint Assessment is used in different types of organizations, including universities. Its ability to clearly communicate over-consumption by using a landbase unit is an advantage when involving the university community in achieving better environmental performance. However, its lack of standardization makes it difficult to use as an indicator. It is believed that Life Cycle Assessment offers a framework with which to standardize the Ecological Footprint Assessment. In this paper, an Ecological Footprint Assessment considering Life Cycle Assessment methodology is developed as a case study for Universitat Politécnica de Valéncia. Findings regarding the critical decisions of the methodology are compared with 23 Ecological Footprint Assessments of universities using a Life Cycle Assessment framework. Only $26 \%$ of the studies analyzed reference the Life Cycle Assessment methodology. Critical decisions such as defining a Functional Unit were relevant but not standardized, while the definition of the product system was the most standardized and homogeneous decision. The difficulty of gathering information when Environmental Management Systems are not available makes the Ecological Footprint Assessment a weak indicator. Nevertheless, results show that Life Cycle Assessment can guide an Ecological Footprint Assessment methodology where comparability and reliability is possible.
\end{abstract}




\subsection{INTRODUCTION}

Sustainability is receiving increasing attention (Disterheft et al., 2012). Since the Rio Summit (United Nations Environment Programme, 1992), governments of many countries have agreed on the importance of improving their activities to attain a sustainable future that satisfies our current needs without compromising future generations (Brundtland Commission, 1987). The scope is clearly global and aims towards a sustainable society with regards to environmental, economic and social systems. It is necessary to integrate environmental and social aspects into economic aspects to overcome resistance to change (Lozano, 2006b). Just as important is the need to improve and report the status of sustainability (Joseph, 2012). The reporting of sustainability actions taken by universities is well studied, and its relevance is established (Lozano et al., 2013; Alonso-Almeida et al.,2015; Ceulemans et al., 2015). Strategies to improve sustainability have also been discussed. The signing of declarations, charters and initiatives are strongly related to institutional efforts to contribute to sustainable development (Lozano, 2015).

Nevertheless, some tools are needed to help management improve sustainability. At a regional level, sustainable development can be incorporated into the planning framework (Roseland, 2000). At a smaller scale, such as in organizations, buildings, small areas and processes, the solution could be linked to a management system. The scope of this study is a complex organization, the university.

To manage organizations in a sustainable way, it is necessary to know how well these systems are performing. Monitoring interactions between system agents is also important. Many parameters, including emissions, resource and energy consumption and usage patterns, must be measured. These facts have motivated the development of systems that gather such information, i.e., EMS. An EMS is a set of systematic, planned and documented processes that manage the environmental aspects of an organization (Klassen \& McLaughlin, 1996; Seiffert $\&$ Loch, 2005). An EMS can be the decision-making tool with which to guide an organization towards sustainable development.

To be rigorous in this decision-making process, it is necessary to assess the performance of institutional efforts towards sustainability. These efforts need to be assessed and analyzed individually and together to view their synergies (Azqueta \& Delacamara, 2006). Considering up and down streams, as well as the use phase, is as important as having a global view of the organization's performance. Although all three areas of sustainability - environmental, economic and social - are equally important, this work focuses on the environmental aspects of sustainability.

The environmental impact of universities is significant considering that universities have been compared to small cities or large commercial areas due to 
their energy and resource consumption (Alshuwaikhat \& Abubakar, 2008; Viebahn, 2002). The complexity of universities has been established (Denman, 2009). Universities have an ethical responsibility to societal development; therefore, they have a responsibility to lead the way towards a more sustainable society (Viebahn, 2002). Improving the assessment of campuses' environmental performance can foster action in other public or private institutions and turn universities into role models or lighthouses.

EMS has been progressively adopted as a management tool for the improvement of campuses' environmental performance (Clarke \& Kouri, 2009). To assess universities' environmental strategies at different scales, tools such as LCA, Carbon Footprint and EFA have been adopted (Alshuwaikhat \& Abubakar, 2008).

In recent years, some studies have used the EFA to assess several areas and functional units of universities. Some EFAs have been performed at universities around the world with the following three main goals: (1) to assess the university's ecological impact, (2) to support policy planning and (3) to raise awareness among the university community (Lambrechts \& Van Liedekerke, 2014). Studies of different aspects of EFA models have also been published. Nunes et al. (2013) analyzed the influence of uncertainty in the EFA with regards to university campuses.

According to the definition of LCA, there is a very close relationship between EFA and LCA, and some authors explicitly defend the necessity of standardized and detailed LCA studies to support the calculation of specific impacts accounted for in EFA (Castellani \& Sala, 2012). From a methodological point of view, LCA offers an opportunity to analyze and eliminate many of the drawbacks of EFA. LCA can also define the functional unit and scope. In LCA, the Global Warming Potential Category can be considered differently by assessing absorbing waste flows in a given year for a defined population (Finkbeiner, 2009). This paper explores the possibility of using EFA as an aggregated indicator where the objectives and scope have been defined according to LCA philosophy.

The purpose of this work is to analyze some of the most significant EFAs of universities published from an LCA point of view and to reach informed decisions in the use of this indicator to assess universities' environmental aspects. A total of 23 EFA studies published between 2001 and 2014 were analyzed. The aim of this study is (1) to study the differences among methodologies that practitioners are likely to use with the EFA at universities; and (2) identify, from a methodological point of view based on LCA, critical points and specific drawbacks. 


\subsection{LiTERATURE REVIEW OF LCA AND EFA AS PERFORMANCE TOOLS FOR UNIVERSITIES}

Different ways of assessing environmental performance have been developed (Herva et al., 2008, 2011). The LCA technique was developed to better understand and address environmental impacts associated with products and services (International Organization for Standardization, 2006a). Due to its strict definition, LCA is one of the most accepted tools for the study and measurement of environmental impacts associated with products and services.

It might be considered applying LCA directly on universities. Life cycle concept has a temporal and geographical variability. Organizations, as universities, are time dependent but its geographical variability usually it is not significant. This kind of issues had recently led to the development of an OLCA procedure. According Finkbeiner et al. (2014) LCA may be the key with which to assess the environmental performance standards of an organization. As evidenced by the development of ISO 14072, consensus is needed to apply LCA at organizations as, for example, universities. ISO 14072 is a norm with which to develop an OLCA as a procedure to compile and evaluate inputs, outputs and potential environmental impacts of an organization. Principles and requirements for ISO 14072 are extremely similar to ISO 14040 and 14044 . It must be noted that OLCA is not recommended for comparison purposes (Martínez-Blanco et al., 2015a; United Nations Environment Programme, 2015). Issues related to comparison purposes will be discussed further in this paper.

EFA has been proposed as a measure of ecological impact (Herva et al., 2008; Rees \& Wackernagel, 1996; Wackernagel \& Rees, 1997). The EFA is an aggregated measure that expresses results in terms of the biophysical limits of the resources used. The EFA acts as a strong statement in reports to identify and communicate potential sources of unsustainability to society and to political and corporate decision-makers (Wiedmann \& Barrett, 2010).

The EFA results represent the amount of biologically productive land and water area required to provide resources and assimilate waste produced by a given entity (Conway et al, 2008; Wiedmann \& Barrett, 2010). It is measured in global hectares (gha). A gha represents a hectare of land with productivity equal to that of world average. A hectare is a dimension that is easy to understand and compare. The original EFA methodology was intended for use in land areas such as continents or countries. Modifications of this methodology have been applied to other systems such as cities, companies, associations and universities (Galli et al., 2012; Herva et al., 2008; Wiedmann \& Barrett, 2010). When the EFA is applied to these types of systems, the study highlights consumption, energy use and waste generation. However, when countries or regions are studied, the EFA takes a different approach by comparing land activity with land biocapacity. 
Several studies highlight strengths and weaknesses of EFA as an indicator. According to Wiedmann \& Barrett (2010), weaknesses include a lack of scientific rigor in the assessment. Other weaknesses include its inadequacy to make conclusions about environmental policies and its limitation of assessing only issues related to global warming or biocapacity. The ability to communicate urgency of required actions is a strength of the EFA (Wiedmann \& Barrett, 2010). Lambrechts \& Van Liedekerke (2014) considered the EFA as a method to translate the complexity of ecological pressure into an understandable framework, although their results should be carefully interpreted to take into account estimations and critical reflections.

From the point of view of some authors such as Van den Bergh (2010), the EFA does not include all relevant human impacts on the environment, including emissions of toxic substances, water pollution, noise, acid rain, ozone layer depletion, fragmentation of ecosystems due to infrastructure and biodiversity loss. Along the same lines, Herva et al. (2011) questioned the use of the biocapacity concept when EFA is applied to an industry and the difficulty of defining the administrative boundaries of a company. Herva et al. (2010) also criticized EFA for not taking into consideration toxic and hazardous pollutant wastes.

Several studies have shown the usefulness of LCA in assessing the environmental performance of products and services (Hertwich, 2005). The three main components of LCA that contribute to the integrity of the analysis are (1) the determination of processes involved in the life cycle of a product, (2) the determination of environmental pressures (e.g., emissions, use of resources) produced in each process and (3) the assessment of environmental impacts and aggregation of the impact indicators. The ISO 14040 standard for LCA defines the first two steps as inventory analysis and the third step as impact assessment. ISO defines two additional procedural steps, which are goal and scope definition (i.e., planning the LCA) and interpretation (i.e., discussion and conclusions) (Hertwich, 2005).

\subsection{METHODS}

The purpose of this study is to obtain a better understanding of the results of EFA at universities by applying an LCA framework. We are also interested in comparing studies and the reason why each university decided to use the EFA.

In this study, the EFA of universities was rigorously compared with LCA foundations and standards. As a consolidated methodology, due to its path, ISO 14040 and 14044 are considered the references for this study for LCA concepts. ISO 14072 particularities are also considered as much as possible. 
This research analyzes whether different critical decisions are highlighted and how those decisions affect the final result and comparability. In addition, an EFA case study has been compared with a range of diverse studies that have assessed the critical decision parameters required of practitioners.

Given the strengths and weaknesses of EFA, a deep analysis using an LCA framework has shed light on the difficulties in its use as an environmental indicator at universities. We believe that a rigorous study of the use of EFA at universities will ensure transparency and comparability of results.

The analysis can be summarized in the following steps:

1) Definition of the critical decision in general LCA methodology is based on LCA documentation and publications and, in particular, on ISO14040 and ISO14044.

2) Development of a complete case study that is as comprehensive as possible. This case study has been developed for Universitat Politècnica de Valènica (UPV) in Spain. UPV EMAS EMS inspired this research due to its large volume of data that has been used in this step. Data are regularly published in the annual environmental memory of UPV and was extracted and organized prior to assessment. Full details of UPV's structure and UPV EMAS EMS implementation can be found in "EMAS as environmental management system for university campuses" (Torregrosa-López et al., 2016). High-quality data are essential for a robust EFA.

The EFA of UPV has been developed using classical methodologies with some underlying principles of LCA. The following FUs were considered in light of UPV statutes and the UPV mission:

- Students, who are part of the UPV's teaching mission

- Articles published, which is a component of UPV's research mission

- Patents developed, which is part of UPV's knowledge transfer mission

- The university community, which represents a more general FU

This process has been thoroughly documented, the data have been exhaustively analyzed, and critical points have been listed.

3) Studies assessing the use of EFA by universities has been analyzed. Studies of the use of EFA of universities published between 2001 and 2014 were gathered and assessed. When available, journal articles were preferred. Other sources such as web pages were considered when the information was relevant due to the type of institution or scope of the study. All Spanish universities with available data were included in the study to obtain an additional local comparison for our UPV case study. Information was obtained from the results 
and methods of each study document. The analysis was performed using comparative tables. Special attention was given to highlighted decisions detected in Step 1. If more than one study was available for a particular university and all decisions were the same in all studies, only the last study was considered.

In section 5.4, differences between the case study and the literature were assessed, as well as their omissions and the effect on the final results. The most critical have been highlighted and matched with the critical points found in the case study.

Throughout the study, the relationship between the motivations for the use of EFA in the functional unit and scopes considered in the assessment was sought.

\subsection{RESULTS AND DISCUSSION}

The results of each step of the proposed research approach are presented and discussed below.

\subsubsection{STEP 1. DEFINITION OF THE SPECIFIC DECISION TO CONSIDER IN GENERAL LCA METHODOLOGY}

One of the most mature and robust methodologies for environmental assessment is that proposed for LCA. The maturity of this methodology is evidenced by its use in widely known ISO standards (International Organization for Standardization, 2006a, 2006b). Based on this, the definition of the specific decision to consider in general LCA methodology (Step 1) was developed.

In the initial stage of an environmental assessment, practitioners must define a set of elements that will configure the way the LCA is developed. These elements will decide how the results are interpreted. Documenting this information is critical for evaluating the adequacy of the assessment and for comparability purposes. Despite the new standards developed for assessing organizations with ISO 14072 mentioned above, they are not recommended for comparability purposes, and we believe it is important in the future to evaluate the possibility of using ISO 14040 and ISO 14044 or ISO 14072. Comparing organizational assessments of environmental actions may be extremely useful, as stakeholders can learn not only from their own experience but also from the experience of similar organizations. Requirements and guidelines of ISO 14044:2006 (International Organization for Standardization, 2006b) highlight the characteristics needed to perform such an analysis. In particular, section 4.2.3.7 of ISO 14044:2006 specifies which decisions can be critical. The main critical decision points that have been detected are (a) the product system to be studied, (b) the functional unit (FU), (c) the system boundary (SB), (d) allocation procedures, (e) Life Cycle Impact Assessment 
(LCIA) methodology and types of impacts and (f) data quality requirements. All other decisions are either case-study specific or do not impact the final result as much as its communication.

The product system is the first piece to be defined. The definition of product system includes all processes that compose the object of study, which in this case is the university.

The FU is defined by ISO 14044:2006 as the parameter that quantifies performance of a product system for use as a reference. ISO 14072 replaces the concept of FU with the concept of reporting unit (RU). The RU is defined as the parameter that quantifies performance expression of the organization to be used as a reference. The main difference between FU and RU is the product system or organization instead of the product or service. As ISO 14072 had not yet been published when the studies included in this research were published, for practical purposes, FU is used as the parameter that quantifies performance expression to be used as a reference.

The SB depends on the subject and the intended use of the study according to the ISO 14044:2006 definition. The SB defines those unit processes as part of the product system that is considered for the study. ISO 14072:2014 suggests a definition of SB considering a process-based approach and the additional operations of the organization. As a complex organization, university processes are diverse, and some might not be easy to define in terms of in/out balance, i.e., teaching. However, processes such as teaching and research should be considered because they represent the mission of the organization.

Allocation is the process by which inputs and outputs are assigned to the product system under study. When the product system is the university as a whole, no allocation procedure is required. However, if, for example, one wants to assess the environmental impact of teaching separately from other university processes, an allocation procedure must be defined.

LCIA methodology aims to understand the significance and magnitude of the environmental impacts of the product system according to ISO 14044:2006. When analyzing the EFA in this study, special attention has been paid to references to a LCIA methodology or a definition of types of impacts considered.

Data quality requirements shall be specified according to ISO 14044:2006, and there were no changes in ISO 14072:2014. Requirements to consider include the following: (a) time-related coverage, (b) geographical coverage, (c) technological coverage, (d) precision, (e) completeness, (f) representativeness, (g) consistency, (h) reproducibility, (i) source of the data and (j) uncertainty of the information. For a detailed definition of each requirement, see section 4.2.3.6 of ISO 14044:2006. 


\subsubsection{STEP 2. DEVELOP A COMPLETE CASE STUDY}

A complete EFA was developed for UPV that paid particular attention to the critical decisions detected (Step 2) that helped structure the assessment and provide a framework for the study. In this section, each critical decision is described following ISO steps.

\subsubsection{DEFINITION OF GOALS, SCOPE, FU, SB AND DATA REQUIREMENTS}

In this step, a complete EFA was performed for UPV. The definition of the product system as the university was clear from the beginning of the study, as mentioned in Step 1.

Defining an FU was one of the first problems to be solved. The FU must reflect the mission or function of the university, according to the ISO 14040 definition, and quantify the university's performance. UPV's mission is defined in the University Statements and contains the following three main processes: teaching, research and knowledge transfer. Although it may be logical to assume that the missions of most universities include these three concepts, there are endless details that must be considered to build an algorithm to reflect them. Integrating these three functions in only one parameter seems arbitrary. Considering that the FU definition will affect comparability with other studies and that all universities have students, the teaching mission is important. Students differ in the amount of time they dedicate to their studies. To obtain homogeneity of the FU, an equivalent student (eqst) unit was defined as a student with full dedication to the university in terms of the academic calendar. The results are biased by this choice and have to be carefully analyzed when compared.

The first approach to the case study used main processes mentioned above to define the SB of the study. Although they are difficult to define in terms of input/output, the analysis of sub-processes such as "teacher offering a certain class" was considered in building the assessment. However, the complexity of the analysis due to this process itself, i.e., for each class, the professor takes a different route between the office and the classroom, made us reconsider the definition of the SB. This route can differ by the day of the week and the professor's previous activity each day. The same is true for each student in the class. For a university with more than 30 undergraduate programs, more than 70 graduate programs and 13 schools or faculties, assessing each class's particularities seems nearly impossible without a full-time team dedicated to gathering complete information using a specific structure. SB was ultimately established from an infrastructure point of view considering three campuses.

The data requirement was also a challenge, and two considerations were made. When considering the data represented by each environmental aspect, quality requirements were easy to define due to the EMS verified by UPV's EMAS. The 
EMS collects yearly environmental information for all environmental aspects except procurement. The selection of the environmental aspect is discussed below in the LCI section.

The main quality requirement becomes evident when the study requires conversion factors to assess the EFA. The conversion factors needed to convert consumption and generation information, infrastructure data and mobility data to environmental impact units in terms of either emissions or global hectares (gha) is of inadequate quality. Relations between the selected sources are shown in Table 1 in the LCIA sub-section. For example, there is a detailed study of the environmental impact of yearly electric energy generation in Spain that can be used to assign a value to this environmental aspect (World Wild Foundation, 2015). It is important that the energy impact is assessed considering the local energetic mix and the technologies that produce this energy. Data requirements, including geographical, technological and time coverage, are applied to the electricity use impact assessment. Other aspects, such as food and drinks, were not locally studied. Information available to convert this consumption into environmental impact units was obtained from studies that consider technologies, production rates and availability of other countries or regions, such as the UK, for the environmental aspect of food and drinks (Defra/DECC, 2014). This means that significant requirements, such as geographical and technological coverage, could not be considered, which limits the interpretation of the assessment results.

Because the university is considered as the product system and no differentiation among processes or products of the university is made, according to the ISO definition of allocation no allocation procedure is needed.

\subsubsection{LIFE CYCLE INVENTORY ANALYSIS (LCI)}

Once the product system, the FU and the SB have been defined, the LCI is easy to develop. The inventory of environmental aspects was defined considering all of the university's organizational activities. The set of campuses that compose the university can be considered as a small city where people live, eat, move and generate waste. Figure 5-1 shows the input/output analysis of the university. As inputs, energy and materials are identified, materials are considered in two categories (procurements and food and drinks) with practical purposes. Food and drinks are used and served inside the university but managed by external stakeholders. As they are not purchased by the university itself, the process for considering this aspect is different, which is why this aspect is considered separately. Energy aspects include electricity and fuels. Outputs are separated into waste and waste water. Waste includes recyclable wastes such as paper and cardboard, glass, packaging and organic wastes. Two extra items, mobility and infrastructure, are considered inherent to the university as they are neither inputs nor outputs. Although they are not formal environmental aspects, UPV's EMS 
identified them as relevant items that require monitoring. Infrastructure can be considered an input (energy and materials), but it is not a yearly input, and its impact is considered on an amortized basis due to its life cycle. Mobility is not a regular input or output aspect, but it is a relevant environmental impact that must be considered due to its inherent emissions. The scope of the impact of mobility is restricted to the usage phase of vehicles after considering the followings:

- The usage phase of vehicles represents between the $46 \%$ and $76 \%$ of total energy consumed during its life cycle (Viñoles-Cebolla et al, 2015).

- Climate Change category, the most significant for EFA, represents between $67 \%$ and $74 \%$ of GHG emissions (Burnham et al, 2006).

- Private vehicles have multiple uses; they are not used exclusively with academic purposes except for UPV fleet.

- Public vehicles (local trains, urban and inter urban buses) have even more uses due to its nature. Therefore, only the phase use is considered in accordance of previous statements.

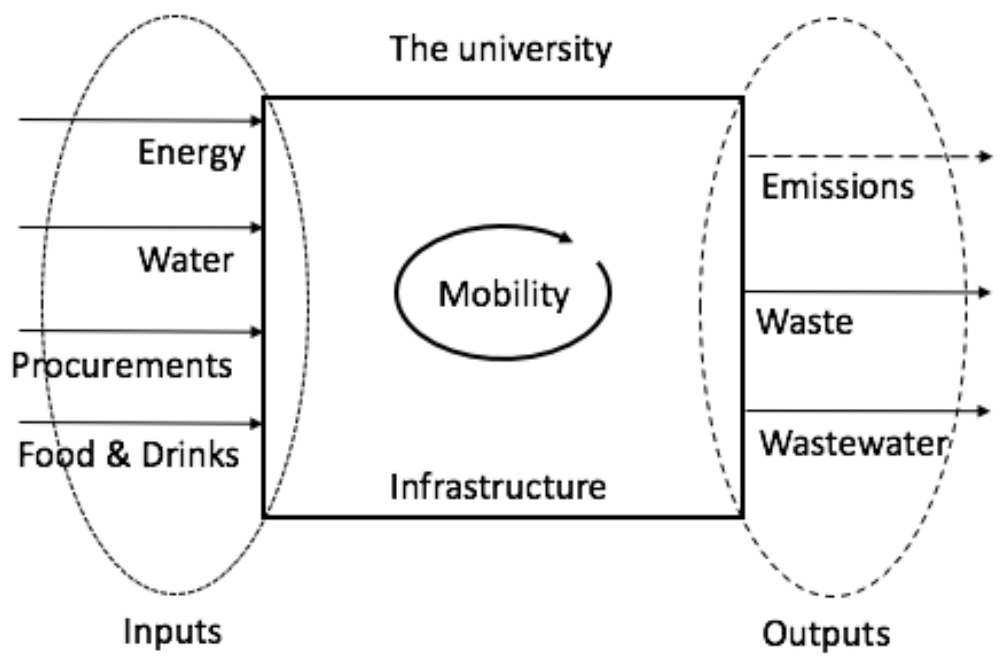

Figure 5-1 Input/output analysis of the university

In performing this analysis, the following seven environmental aspects were considered:

- Infrastructure

- Food and drinks consumption

- Energy consumption 
- Mobility

- Water consumption and treatment

- Procurements/paper consumption

- Waste generation

The EMS verified by UPV's EMAS already collects data relevant to these aspects. Special attention has been paid to the definition of the aspects to avoid the temptation to skew the study towards available information instead of considering real environmental aspects. However, the difficulty of assessing a decentralized system such as UPV's procurements system made it impossible to evaluate this item properly. To continue with the study, this environmental aspect was simplified to paper consumption, which was considered to be a relevant part of the procurement system. Paper purchasing at UPV is centralized. While results may show otherwise, paper is a socially internalized environmental issue at educational institutions.

The difficulty of gathering procurement information biased the LCI criteria, as other goods such as computers, lab equipment and office equipment were not assessed. A deeper analysis can be performed in further studies to estimate procurement information and consider its life cycle to assign a reasonable environmental impact. When the results are interpreted, the limitations associated with procurement must be considered. This particular point helped the EMS coordination to recognize the need for improvements to include procurement information in the system.

\subsubsection{LIFE CYCLE IMPACT ASSESSMENT (LCIA)}

To assess the environmental impact of each environmental aspect defined in the LCI, conversion factors are needed. As a result of an exhaustive search and analysis, the sources shown in Table 5-1 were selected for this study.

Although not all of the conversion factors meet data requirements, they are the most suitable factors available. All limitations of the assessment due to data requirements such as geographical and technological coverage are considered in the section focused on the interpretation of results.

Despite its difficulties, LCIA methodology and types of impacts were defined by taking LCI criteria under consideration. In accordance with one of the goals of this study - developing an EFA case study - the following two indicators were assessed: carbon footprint and productive footprint. Carbon footprint represents the land - global hectare unit (gha) - required to absorb greenhouse gas (GHG) emissions and represents approximately $85 \%$ of the EFA. The productive footprint is obtained from the land required to produce goods and services and assimilate generated waste. 
Results obtained for UPV's case study are shown in absolute value (gha) in Figure 5-2. The left axis represents the impact of each environmental aspect considered (in \%), while the right axis represents the absolute value in global hectares (gha) for each year studied. Notice that the scale of the right axis is between 0.20 and 0.50 gha/eqs.

Table 5-1 References of conversion factors used in the case study

\begin{tabular}{|c|c|c|}
\hline Aspects & $\begin{array}{l}\text { sub-aspects (when } \\
\text { needed) }\end{array}$ & Reference \\
\hline $\begin{array}{l}\text { Food \& Drinks } \\
\text { consumption }\end{array}$ & - & Barret et al., 2002 \\
\hline \multirow{4}{*}{$\begin{array}{l}\text { Energy } \\
\text { consumption }\end{array}$} & Natural Gas & Defra/DECC, 2014 \\
\hline & Gasoil & Defra/DECC, 2014 \\
\hline & Gasoline & Defra/DECC, 2014 \\
\hline & Electricity & World Wild Foundation, 2015 \\
\hline \multirow{4}{*}{ Mobility } & Private transport & $\begin{array}{l}\text { Universitat Politècnica de } \\
\text { València, } 2015\end{array}$ \\
\hline & Public transport & $\begin{array}{l}\text { Universitat Politècnica de } \\
\text { València, } 2015\end{array}$ \\
\hline & $\begin{array}{l}\text { UPV's fleet of light } \\
\text { vehicles }\end{array}$ & $\begin{array}{l}\text { Universitat Politècnica de } \\
\text { València, } 2015\end{array}$ \\
\hline & $\begin{array}{l}\text { UPV's fleet of heavy } \\
\text { vehicles }\end{array}$ & $\begin{array}{l}\text { Universitat Politècnica de } \\
\text { València, } 2015\end{array}$ \\
\hline \multirow{2}{*}{$\begin{array}{l}\text { Water and } \\
\text { wastewater } \\
\text { treatment }\end{array}$} & Well water & Marañón et al, 2008 \\
\hline & Main water & Lemos et al, 2013 \\
\hline \multirow{2}{*}{$\begin{array}{l}\text { Paper } \\
\text { consumption }\end{array}$} & Recycled paper & Hernández Gallego, 2015 \\
\hline & Virgin paper & Hernández Gallego, 2015 \\
\hline Infrastructure & - & $\begin{array}{l}\text { Cuchí i Burgos \& López Caballero, } \\
2005\end{array}$ \\
\hline \multirow{11}{*}{$\begin{array}{l}\text { Waste } \\
\text { generation }\end{array}$} & Paper waste & Marañón et al, 2008 \\
\hline & Electronic waste & Marañón et al, 2008 \\
\hline & Metallic waste & Marañón et al, 2008 \\
\hline & Light packaging & Marañón et al, 2008 \\
\hline & Debris & Marañón et al, 2008 \\
\hline & Manure & Marañón et al, 2008 \\
\hline & Vegetable waste & Marañón et al, 2008 \\
\hline & Glass & Marañón et al, 2008 \\
\hline & Municipal solid waste & Marañón et al, 2008 \\
\hline & Batteries & Marañón et al, 2008 \\
\hline & Ink \& Toner & Marañón et al, 2008 \\
\hline
\end{tabular}

Although the main objective of this study is not to deeply analyze the results of the EFA of UPV (Figure 5-2), it is important to notice a significant reduction between 
2007 and 2009. This is due to a significant net reduction in electricity consumption due to specific actions taken by the staff that operates EMS.

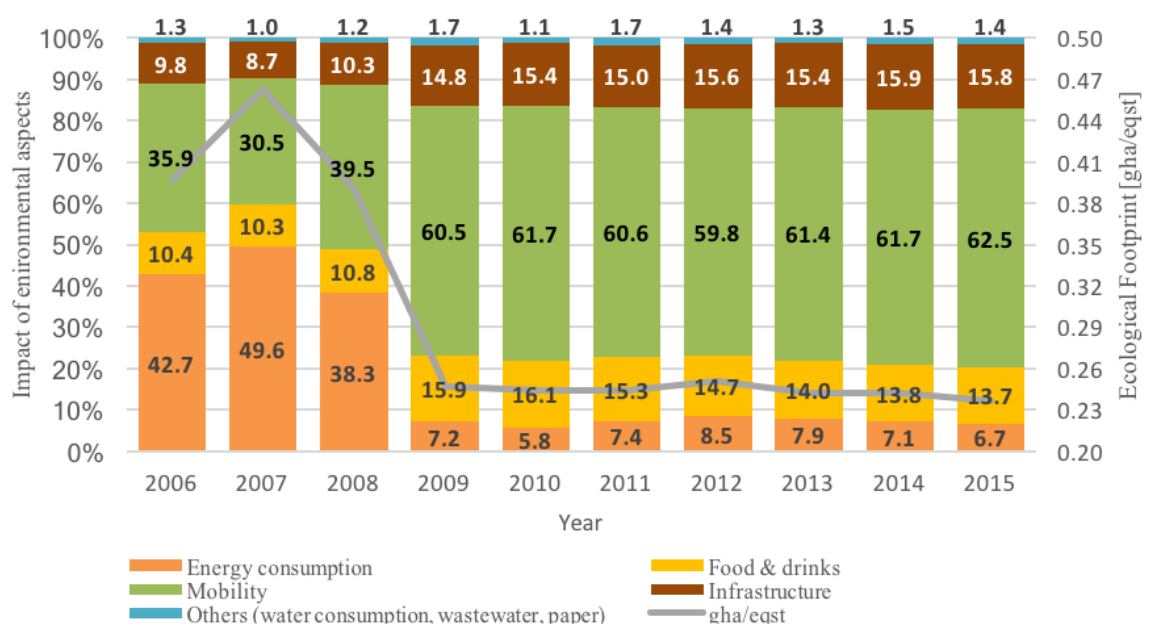

Figure 5-2 Results of UPV's case study: ecological footprint. Interpretation of results

Comparative results for different FUs are presented here for the purposes of evaluating differences. The descriptions of the other FUs are presented below.

- Licenses over results: number of licenses registered over research results. This unit attempts to assess the university's mission of knowledge transfer.

- Journal articles published: number of research articles published in index journals could represent a relevant aspect of the university's research mission.

- $€ \mathrm{R}+\mathrm{D}+\mathrm{I}$ : investment in research, development and innovation activities in euros.

- Enrolled credits: number of total credits in which students are enrolled.

- Equivalent people: the group of people (students, professors and staff) who are part of the university on a full-time basis according to the academic calendar.

To analyze the influence of FUs, Figure 5-3 shows results for UPV's FUs. The bars and the left axis show the EFA of the university without considering FUs as a representation of the university's organizational performance including all activities needed to achieve its missions. The results of the different FUs are shown on the right axis.

Each result shows a different trend depending on the FU. Assuming that the EFA result using the university as a unit without defining an FU represents the real trend 
of the environmental impact of the university as all aspects - with exceptions (inputs, outputs, mobility and infrastructure) - are assessed, the following interpretations can be made:

- The trend of results using enrolled credits and licenses over results as FUs looks contradictory from 2009 to 2015 . When using licenses over results, enrolled credits and $€ \mathrm{R}+\mathrm{D}+\mathrm{I}$ as an $\mathrm{FU}$, an irregularity is obtained. None of the three results have a strict relationship with what we considered a real trend (in bars).

- These results stress the similarity in the trend of the results in gha (bars) considering the university as a unit and the results considering equivalent students and equivalent person as the FU. The same interpretation is valid when journal articles published is the FU.

The choice of equivalent student as an FU is supported by a similar trend for the clear environmental impact. Equivalent people could also be a valid alternative. Although journal articles published does not seem to have a direct relationship with the teaching mission, it is related to the research and knowledge transfer missions. Due to its similarity with what it is consider as the clear environmental impact, journal articles published is an FU that deserves a deeper analysis in further studies.

In any case, the results of the EFA of UPV can only be considered as an approximation useful to assess tendency and magnitude. The following limitations must be considered:

- Data requirements both for UPV data and for conversion factors are not always adequate, i.e., the geographical coverage for some types of energy

- The LCI has not been completely assessed due to the lack of information on procurements

A deeper analysis calculating an estimate can provide a better approach.

The results can also be analyzed by comparing campuses' impacts according to the definition of the SB. As the environmental policy of the university is unique for all campuses, and actions are taken for the university as a whole, it is not considered relevant for this first approach, even though it can be useful in the future to promote more ambitious actions. 


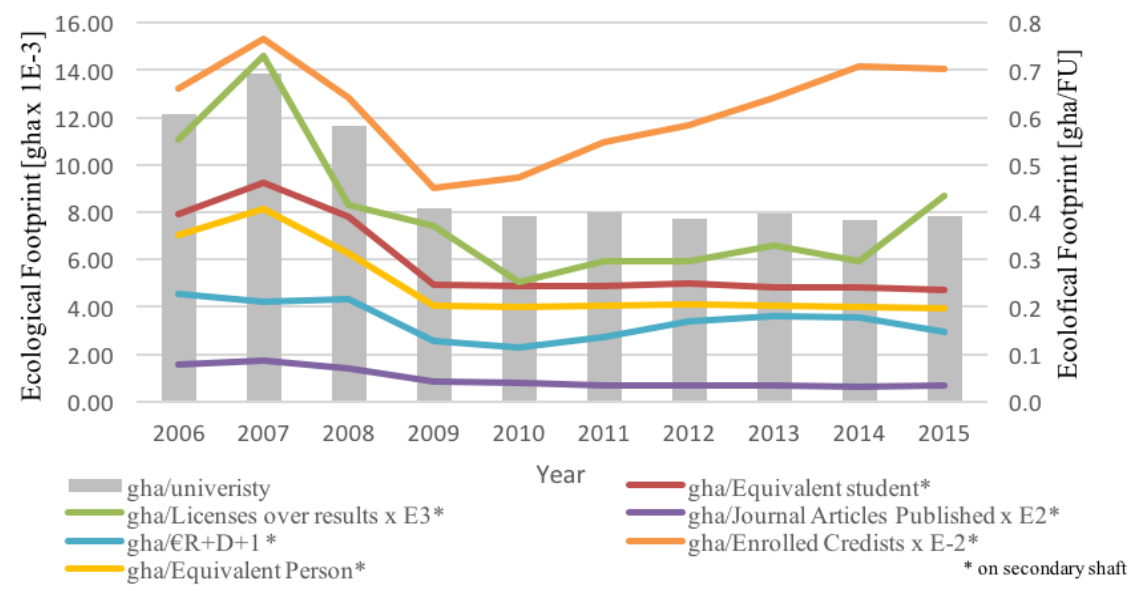

Figure 5-3 Results of EFA of UPV by FU

\subsubsection{SteP 3. ANALYZE OTHER STUdies OF THE USE OF EFA BY UNIVERSITIES}

Developing UPV's case study highlighted both critical decisions defined by ISO and developmental challenges. The experience of developing the UPV case study has been applied in the analysis of other universities' EFA studies. Table 5-2 summarizes critical decisions for 23 universities all over the world that published their experience with EFA. Figure 5-3 shows the analysis of the information contained in this table. References for each publication can be found in Table 5-2. These decisions affect the way the assessment was developed. Therefore, its scope and comparability are conditioned.

Allocation procedures and LCIA methodology and types of impact are analyzed in each assessment. Although allocation procedures are not necessary in cases where the university is the product system, this is not mentioned or justified in most studies. The bibliography is the most commonly used source with which to establish LCIA methodology and types of impacts.

Data and quality requirements and product system identification are also shown in Table 5-2 (see Annex 5.A at the end of this chapter). The university is considered the product system in most cases, but data and quality requirements are commonly unspecified. The lack of requirement specifications for data and data quality may be driven by a lack of management systems that provide quality information.

Although the reference to LCA has been included in the study, it is not considered a critical decision but rather a statement of how the study was developed. Only 
$26 \%$ of studies referenced LCA as a tool with which to frame the assessment, while the other $74 \%$ did not make any reference to LCA. An important number of these studies were not designed as scientific research but rather as management and transparency exercises, and it should be noted that only $47.8 \%$ of the sources are journals. Data from two of these studies $(8.7 \%)$ are published on institutional websites, while the remaining studies (a $43.5 \%$ ) are various publications such as monographs, theses and reports. Although $30.4 \%$ of these studies are published in a language other than English, the information contained in them is considered relevant, and they were included in the study.

Unfortunately, 'unspecified' is a common value in some of the decisions. The percentage of universities that specified their decision for each item and the percentage of coincidence with the most common approach are used as an indicator of homogeneity or disparity (Figure 5-3).

Analyzing Figure 5-3, critical decisions can be classified into the following three concepts:

- Standardized: a high level of specification and homogeneity considering the definition of the product system.

- Relevant but not standardized: a high level of specification with disparity in the criteria followed for the LCI definition and in the definitions of the FU and LCIA methodologies.

- Non-standardized: a low level of specification with disparity when considering allocation procedures and the definition of data and quality requirements.

Non-standardized decisions require a deep analysis. Critical decisions in this category were taken under consideration in only 2 of the 23 studies analyzed, and very different choices were made. In most cases, the allocation procedure was not mentioned, and the factors applied to assess each environmental aspect were not justified or - in the best cases - were cited from other studies without considering discrepancies in criteria. Data and quality requirements were often set in terms of availability and not as a previous requirement. In both cases, the same problem of data availability was reflected in the UPV case study.

Data availability is a critical issue. There is a lack of research on conversion factors for EFA. Although research on conversion factors can be performed by universities with a research mission, due to the complexity of the assessment, it does not seem feasible to do this in a short period of time or for internal use only. The data and data quality for making a critical decision can be easily accessed using an EMS. The case study at UPV was developed with high quality data thanks to the EMS 
that was verified by EMAS, notwithstanding the exceptions mentioned. The time to implement and adjust the EMS has to be taken into consideration.

Data and quality requirements have a direct impact on LCIA methodology, LCI definitions and the criteria followed; these three critical decisions were highly specified but had a low degree of homogeneity.

The complete analysis of environmental aspects is shown in Figure 5-4.

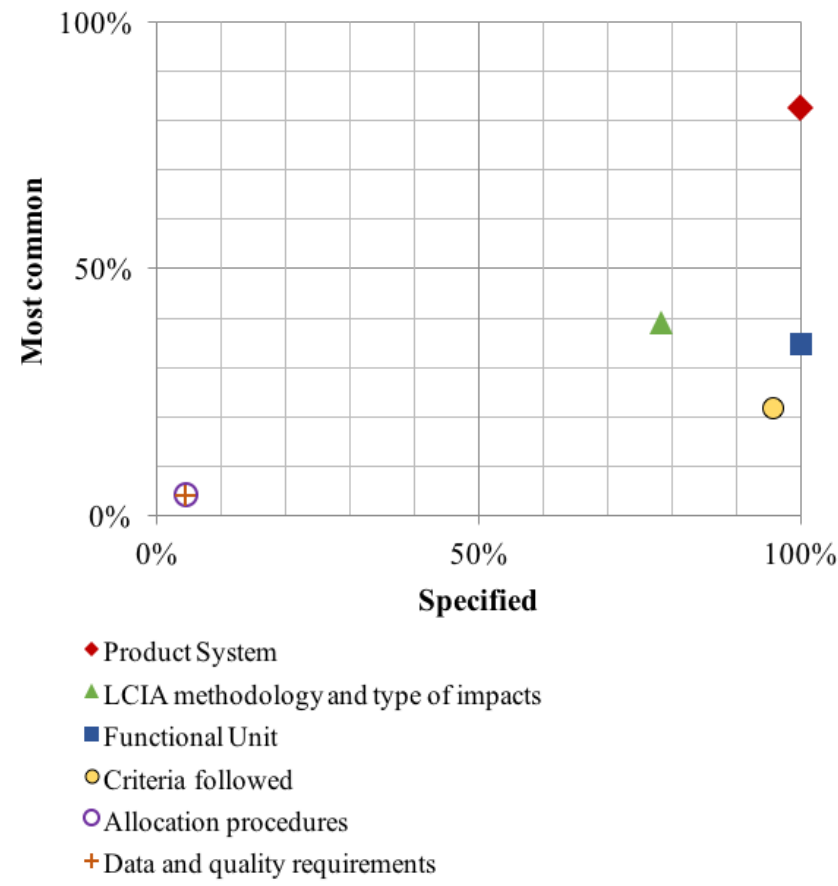

Figure 5-4 Statistical analysis of critical decisions in EFA studies. Note that Allocation Procedures and Data and quality requirements overlap.

Some environmental aspects are commonly considered in almost all studies; mobility, electric and fossil fuel consumption, infrastructure, food and drinks and waste generation were considered in over $50 \%$ of the studies. Goods and services were considered in $27 \%$ of studies, and this diverse aspect includes both hazardous materials and office equipment. Only one study considered equipment, but it did not specify how was considered. Environmental aspects that are particular to a study - i.e., degraded land at Holme Lancy College (Dawe et al., 2004) - are classified as 'other'.

The university and the campus were considered as options for the definition of the product system. A thorough study has to be made to ensure that there is a 
significant difference between these two options. A campus may be understood as a physical barrier over the land that the organization owns, while a university might consider not only the land they own but also the territory affected by its activities.

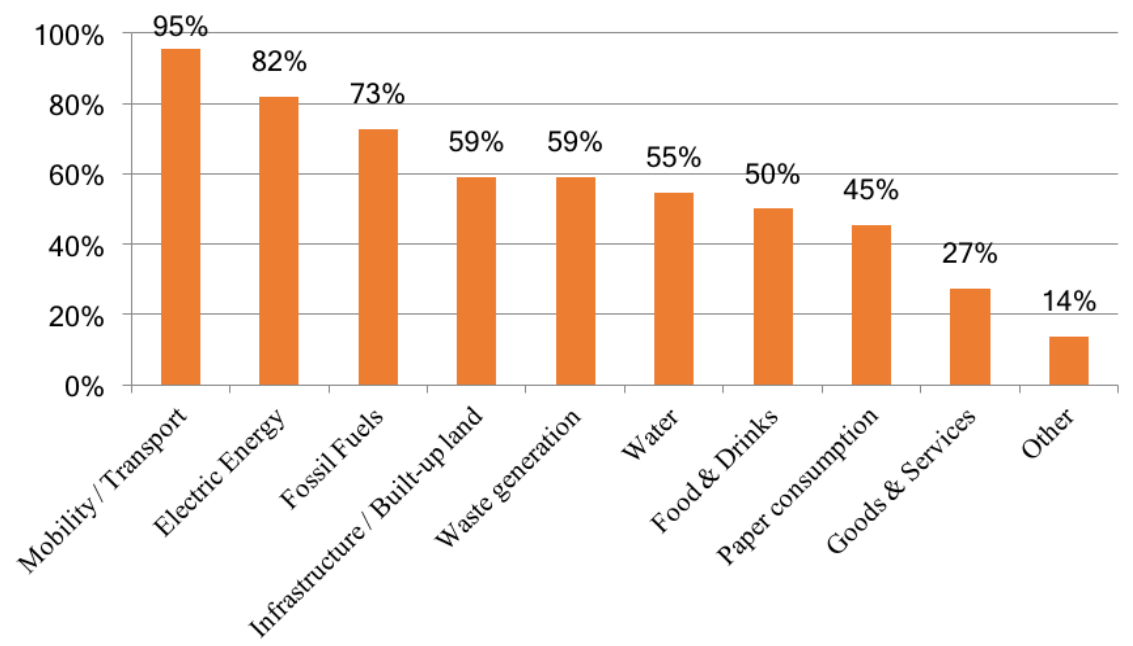

Figure 5-5 Percentage of studies that considered each environmental aspect

\subsection{CONCLUSIONS}

Using a methodology based on LCA has proven to be adequate for detecting critical points and specific drawbacks of EFA as used by universities. UPV's case study was useful for understanding the application of the LCA concept and defining the framework in which to study the use of EFA by universities.

These results show that there are some important methodological deficiencies that make it difficult to compare studies among campuses and standardize EFA methodology. Some important elements that affect the final outcome, such as data and quality requirements, are inadequate in most cases. In addition, the LCIA methodology or the criteria for the LCI definition is based on data availability, and in most cases, it is not further justified. The analysis of the use of EFA by universities demonstrates the difficulty of gathering information in cases where no EMS operates. Interviewing the developers of each study is essential for performing a deeper analysis of the decisions made when developing their EFA.

There is an inherent difficulty in defining the function of a university that goes beyond the domain of LCA or any other tool. Thus, universities are one of the most complex organizations to define in these terms. Any simplistic approach that limits a university to only lecturing, research, technology transfer or other missions may provide a valid unit in terms of purposed equivalent student units, but it will 
ultimately be incomplete. It is important to consider all functions - also sometimes called missions - as stated in the introduction of this article. Defining the function of a university is vital to unambiguously establish the FUs and SB and to define the framework of the assessment. Comparability without well-defined FUs and SB is not possible.

Although some authors believe that EFA has the potential to become a good indicator of environmental performance with which to promote ecological sustainability, the results of this study show that universities follow diverse approaches, which does not allow for comparison of criteria, scope or essence. However, the EFA methodology can be improved with LCA principles.

Future studies may define a taxonomy that ensures that different assessments can be rendered comparable. Although foundations that have proved useful for LCA seem to be appropriate for EFA, this field still needs considerable research. The assessment of OLCA for Universitat Politècnica de València according to ISO 14072:2015 could provide relevant information and knowledge with which to define a standard methodology for EFA.

Regarding the case study, different estimations can be applied; a better assessment of procurement environmental aspect is pending. A deeper analysis comparing impacts by campuses can also be made.

\subsection{REFERENCES}

Alonso-Almeida, M.D.M., Marimon, F., Casani, F., \& Rodriguez-Pomeda, J. (2015) Diffusion of sustainability reporting in universities: current situation and future perspectives. Journal of Cleaner Production, 106, 144-154. http://doi.org/10.1016/j.jclepro.2014.02.008

Alshuwaikhat, H.M., Abubakar, I., (2008) An integrated approach to achieving campus sustainability: assessment of the current campus environmental management practices. Journal of Cleaner Production, 16(16), 17771785. http://dx.doi.org/ 10.1016/j.jclepro.2007.12.002

Álvares, N.L., \& Rodriguez, R.L. (2007) Estimación da pegada ecolóxica en dous centros da universidade de santiago de compostela. Posibles implicacións educativas. Ambientalmente sustentable. 99-117.

Arroyo, P. (2009) Ecological footprint of the campus de Vegazana, León university; a calculation approach. Implications for the sustainability of the university community. MAPFRE, 1-20.

Azqueta, D., \& Delacamara, G. (2006) Ethics, economics and environmental management. Ecological Economics, 56(4), 524-533. http://doi:10.1016/j.ecolecon.2005.03.003 
Barrett, J., Vallack, H., Jones, A., and Haq, G. (2002) A material flow analysis and ecological footprint of York. Stockholm, 129. Retrieved on June $15^{\text {th }} 2013$ from

http://seiinternational.org/mediamanager/documents/Publications/Future/Material Flow_Analysis york.pdf/npapers2://publication/uuid/9F1C847A-09B847F5-BAF8-892555E87ACE

Brundtland Commission. (1987) Our common future: Report of the World Commission on Environment and Development. UN Documents Gatheringa Body of Global Agreements. A/RES/42/187

Burgess, B., \& Lai, J. (2006) How much land is used by Kwantlen University College? Retrieved on June $15^{\text {th }} 2013$ from http://www.kpu.ca/ shared/assets/KUC Ecological Footprint Report2 $\underline{114 . p d f}$

Burnham, A., Wang, M., Wu, Y. (2006) Development and applications of GREET 2.7-The transportation vehicle-cycle model. Argonne: Argonne National Laboratory (ANL), U.S. Department of Energy. http://doi.org/10.2172/898530

Castellani, V., \& Sala, S. (2012) Ecological footprint and life cycle assessment in the sustainability assessment of tourism activities. Ecological Indicators, 16, 135-147. http://doi.org/10.1016/j.ecolind.2011.08.002

Ceulemans, K., Lozano, R., and Alonso-Almeida, M. (2015) Sustainability Reporting in Higher Education: Interconnecting the Reporting Process and Organizational Change Management for Sustainability. Sustainability, 7, 8881-8903. http://doi.org/10.3390/su7078881

Clarke, A., Kouri, R., (2009) Choosing an appropriate university or college environ- mental management system. Journal of Cleaner Production, 17(11), 971-984. http://dx.doi.org/ 10.1016/j.jclepro.2009.02.019

Conway, T. M., Dalton, C., Loo, J., \& Benakoun, L. (2008) Developing ecological footprint scenarios on university campuses: A case study of the University of Toronto at Mississauga. International Journal of Sustainability in Higher Education, $\quad 9(1)$, 20. http://doi.org/10.1108/14676370810842157

Cuchí i Burgos, A., \& López Cabeallero, I. (2005) Informe MIES: Una proximació a l'impacte ambiental de l'Escola d'Artquitectura del Vallès. Universitat Politècnica de Catalunya. ISBN: 84-7653-870-7 
Dawe, G.F.M., Vetter, A., \& Martin, S. (2004) An overview of ecological footprint and other tools and their application to the development of sustainability process: Audit and methodology at Holme Lacy College, UK. International Journal of Sustainability in Higher Education, 5(4), 340371.

http://doi.org/10.1108/14676370410561063

de Miguel, J.J. (2012) Emisiones de CO2 en la EUP. Escuela Politécnica Universitaria de Valladolid. Retrieved on June $15^{\text {th }} 2013$ from http://www.eup.uva.es/emisionesco2/

Defra/DECC (2014) Government conversion factors for company reporting Retrieved June $15^{\text {th }} 2013$ from http://www.ukconversionfactorscarbonsmart.co.uk/

Disterheft, A., da Silva Caeiro, S.S.F., Ramos, M.R. and de Miranda Azeiteiro, U.M. (2012) 'Environmental management systems (EMS) implementation processes and practices in European higher education institutions - top-down versus participatory approaches', Journal of Cleaner Production, 31, 80-90. http://doi.org/ 10.1016/j.jclepro.2012.02.034

Finkbeiner, M., Ackermann, R., Bach, V., Berger, M., Brankatschk, G., Chang, Y.-J., Grinberg, M., Lehmann, A., Martínez-Blanco, J., Minkov, N. (2014) Background and Future Prospects in Life Cycle Assessment. In Background and Future Prospects in Life Cycle Assessment, W. Klöpffer, 207. http://doi.org/10.1007/978-94-017-8697-3

Finkbeiner, M. (2009) Carbon footprinting. Opportunities and threats. International Journal of Life Cycle Assessment, (14), 91-94. http://doi.org/ 10.1007/s11367-009-0064-x

Flint, K. (2001) Institutional ecological footprint analysis. A case study of the University of Newcastle, Australia. International Journal of Sustainability in Higher Education, 2(1), 48-62. http://dx.doi.org/10.1108/1467630110380299

Galli, A., Kitzes, J., Niccolucci, V., Wackernagel, M., Wada, Y., \& Marchettini, N. (2012) Assessing the global environmental consequences of economic growth through the ecological footprint: A focus on china and India. Ecological Indicators, $17, \quad 99-107$. http://doi.org/10.1016/j.ecolind.2011.04.022 
Giménez, A., Pérez, I., Montesions, P., Vera, V., \& Bordonado, S. (2009) Transporte y sostenibilidad. Pautas de movilidad y alternativas de reducción de la huella ecológica en centros de trabajo. La universidad Miguel Hernández como caso de estudio. Seguridad y Medio Ambiente, 40-51.

Hernández Gallego, E., Cano Herrador, C., Correoa Guimaraes, A. (2015) La Huella Ecológica de la Universidad de Valladolid Retrieved on January $1^{\text {st }}$ 2016 from http://www.uva.es/export/sites/uva/7.com

Hertwich, E.G. (2005) Life cycle approaches to sustainable consumption: A critical review. Environmental Science \& Technology, 39(13), 4673-4684. http://doi.org/10.1021/es0497375

Herva, M., Franco, A., Ferreiro, S., Alvarez, A., \& Roca, E. (2008) An approach for the application of the ecological footprint as environmental indicator in the textile sector. Journal of Hazardous Materials, 156(1-3), 478-487. http://doi.org/10.1016/j.jhazmat.2007.12.077

Herva, M., Hernando, M., R., Carrasco, E. F., \& Roca, E. (2010) Development of a methodology to assess the footprint of wastes. Journal of Hazardous Materials, 180(1), 264-273. http://doi.org/10.1016/j.jhazmat.2010.04.026

Herva, M., Franco, A., Carrasco, E. F., \& Roca, E. (2011) Review of corporate environmental indicators. Journal of Cleaner Production, 19(15), 16871699. http://doi.org/10.1016/j.jclepro.2011.05.019

International Organization for Standardization (2006a) Environmental management - life cycle assessment - principles and framework. ISO 14040:2006.

International Organization for Standardization (2006b) Environmental management - life cycle assessment - requirements and guidelines. ISO 14044:2006(E).

Janis, J. (2007) Quantifying the ecological footprint of the Ohio State University Ohio State University. Retrieved June $15^{\text {th }} 2013$ from http://hdl.handle.net/1811/28365

Jorge, J., \& Busquets, P. (2000) La petjada ecologica de l'EUPM. Universitat Politecnica de Catalunya. Retrieved on June $15^{\text {th }} 2013$ from http://www.upc.edu/mediambient

Joseph, G. (2012) Ambiguous but tethered: An accounting basis for sustainability reporting. Critical Perspectives on Accounting, 23(2), 93-106. http://doi.org/10.1016/j.cpa.2011.11.011 
Klassen, R.D., \& McLaughlin, C.P. (1996) The impact of environmental management on firm performance. Management Science, 42(8), 11991214. http://doi.org/0.1287/mnsc.42.8.1199

Klein-Banai, C., \& Theis, T.L. (2011) An urban university's ecological footprint and the effect of climate change. Ecological Indicators, 11(3), 857-860. http://doi.org/10.1016/j.ecolind.2010.11.002

Lambrechts, W., \& Van Liedekerke, L. (2014) Using ecological footprint analysis in higher education: Campus operations, policy development and educational purposes. Ecological Indicators, 45, 402-406. http://doi.org/10.1016/j.ecolind.2014.04.043

Lemos, D., Dias, A., Gararrell, X. \& Arroja, L. (2013) Environmental assessment of an urban water system. Journal of Cleaner Production, 54, 157-165. http://doi.org/10.1016/j.jclepro.2013.04.029

Lenzen, M., Lundie, S., Bransgrove, G., Charet, L., \& Sack, R. (2002) A novel ecological footprint and an example application. ISA Research Paper, 0202 .

Letete, T. C., Mungwe, N. W., Guma, M., \& Marquard, A. (2011) Carbon footprint of the University of Cape Town. Journal of Energy in Southern Africa, 22(2), 2-12.

Li, G., Wang, Q., Gu, X., Liu, J., Ding, Y., \& Liang, G. (2008) Application of the componential method for ecological footprint calculation of a Chinese university campus. Ecological Indicators, 8(1), 75-78. http://doi.org/10.1016/j.ecolind.2007.01.007

Lozano, R., Lozano, F. J., Mulder, K., Huisingh, D., \& Waas, T. (2013) Advancing higher education for sustainable development: International insights and critical reflections. Journal of Cleaner Production, 48, 3-9. http://doi.org/10.1016/j.jclepro.2013.03.034

Lozano, R. (2006b) Incorporation and institutionalization of SD into universities: breaking through barriers to change, Journal of Cleaner Production, 14(9), 787-796. http://doi.org/10.1016/j.jclepro.2005.12.010

Marañón, E., Iregui, G., Doménech, J.L., Fernández-Nava, Y. \& González, M. (2008) Propuesta de índices de conversion para la obtención de la huella de los residuos y vertidos. Observatorio Iberoamericano del Desarrollo Local y la Economía Social, 4. ISSN: 1988-2483.

Nunes, L., Catarino, A., Teixeira, M. R., \& Cuesta, E. (2013) Framework for the inter-comparison of ecological footprint of universities. Ecological Indicators, 32, 276-284. http://doi.org/10.1016/j.ecolind.2013.04.007 
Olalla-Tárraga, M. A. (2003) Indicadores de sostenibilidad y huella ecológica aplicada a la UAM. Retrieved on June $1^{\text {st }} 2012$ from https://www.uam.es/servicios/ecocampus/especifica/descargas/investigac ion/Resumen PFC Indicadores.pdf

Paulson, K. (1997) The transport footprint of Oxford Brookes University. Oxford Brookes University. Technical Report.

Rees, W., \& Wackernagel, M. (1996) Urban ecological footprints: Why cities cannot be sustainable - and why they are a key to sustainability. Environmental Impact Assessment Review, 16(4-6), 223-248. http://dx.doi.org/10.1016/S0195-9255(96)00022-4

Roseland, M. (2000) Sustainable community development: Integrating environmental, economic, and social objectives. Progress in Planning, 54(2), 73-132. http://doi.org/10.1016/S0305-9006(00)00003-9

Seiffert, M. E. B., \& Loch, C. (2005) Systemic thinking in environmental management: Support for sustainable development. Journal of Cleaner Production, 13(12),

1197-1202. http://doi.org/10.1016/j.jclepro.2004.07.004

Soto, M., \& Pérez, M. (2010) A pegada ecolóxica da Universidade da Coruña Vicerrectoría da Infraesttuturas e Xerstión Ambiental - Universidade da Coruña.

Torregrosa-López, J. I., Lo Iacono-Ferreira, V. G., Barranco-Martí, C., \& BellverNavarro, C. G. (2016) The strengths of EMAS as an environmental management system for European university campuses. International Journal of Environment and Sustainable Development, 15(1), 89-106. http://dx.doi.org/10.1504/IJESD.2016.073339

United Nations Environment Programme (UNEP) (1992) Rio declaration on environment and development. United Nations Environment Program (UNEP). Retrieved on September $15^{\text {th }} 2015$ from http://www.unep.org/Documents.Multilingual/Default.asp?documentid= 78\&articleid $=1163$

United Nations Environment Programme (2015) Guidance on Organizational Life Cycle Assessment. Life-Cycle Initiative, United Nations Environment Program and Society for Environmental Toxicology and Chemistry, Paris, France. Retrieved on June $1^{\text {st }} 2016$ from: http://www.lifecycleinitiative.org/wp- content/uploads/2015/04/olca 24.4.15-web.pdf 
Universitat de Girona (2013) Petjada ecològica de la UdG - càlcul de la petjada ecològica derivada dels consums energètics dels edificis universitaris, 1999 - 2008. Retrieved June $15^{\text {th }} 2013$ from http://www3.udg.edu/ov/recursos/petjada.htm

Universitat Politècnica de València (2015) Plan de movilidad sostenible. Diagnóstico de situación inicial. Unidad de Medio Ambiente. Retrieved on January $\quad 2^{\text {nd }} \quad 2015$ from https://www.upv.es/entidades/AMAPUOC/infoweb/ov/info/887195norm $\underline{\text { alc.html }}$

Van den Bergh, J.C.J.M. (2010) Externality or sustainability economics? Ecological Economics, 69(11), 2047-2052 http://dx.doi.org/10.1016/j.ecolecon.2010.02.009

Venetoulis, J. (2001) Assessing the ecological impact of a University. The ecological footprint for the University of Redlands. International Journal of Sustainability in Higher Education, 180-196. http://doi.org/10.1108/14676370110388381

Viebahn, P. (2002) An environmental management model for universities: from environmental guidelines to staff involvement, Journal of Cleaner Production, 10(1), 3-12. $\quad$ http://dx.doi.org/10.1016/S0959$\underline{6526(01) 00017-8}$

Viñoles-Cebolla, R., Bastante-Ceca, M., Capuz-Rizo, S.F. (2015) An integrated method to calculate an automobile's emissions throughout its life cycle. Energy, 83, 125-136. http://doi.org/10.1016/j.energy.2015.02.006

Wackernagel, M., \& Rees, W. E. (1997) Perceptual and structural barriers to investing in natural capital: Economics from an ecological footprint perspective. Ecological Economics, 20(1), 3-24. http://doi.org/10.1016/S0921-8009(96)00077-8

Weideman, B.P., Thrane, M., Christensen, P., Schmidt, J., Lokke, S. (2008) Carbon footprint, a catalyst for LCA. Journal of Industrial Ecology, 12(1), 3-6. http://doi.org/10.1111/j.1530-9290.2008.00005.x

Wiedmann, T., \& Barrett, J. (2010) A review of the ecological footprint indicator-perceptions and methods. Sustainability, 2(6), 1645-1693. http://doi.org/10.3390/su2061645

Willamette University Sustainability Council. (2008) 2007-2008 sustainability indicators report. Willamette University 
Wright, E. P., \& Drossman, H. (2002) The ecological footprint of the Colorado College: An examination of sustainability. Environmental Science, 5(1), 23.

Wright, E., Gill, B., Wallin, P., Hutchison, K., \& Prebble, M. (2009) The ecological footprint of UEA.

World Wild Foundation (2015) Observatorio de la electricidad. Retrieved on June $15^{\text {th }}$ 2013 from http://www.wwf.es/que hacemos/cambio climatico/nuestras soluciones/ energias renovables/observatorio de la electricidad/ 


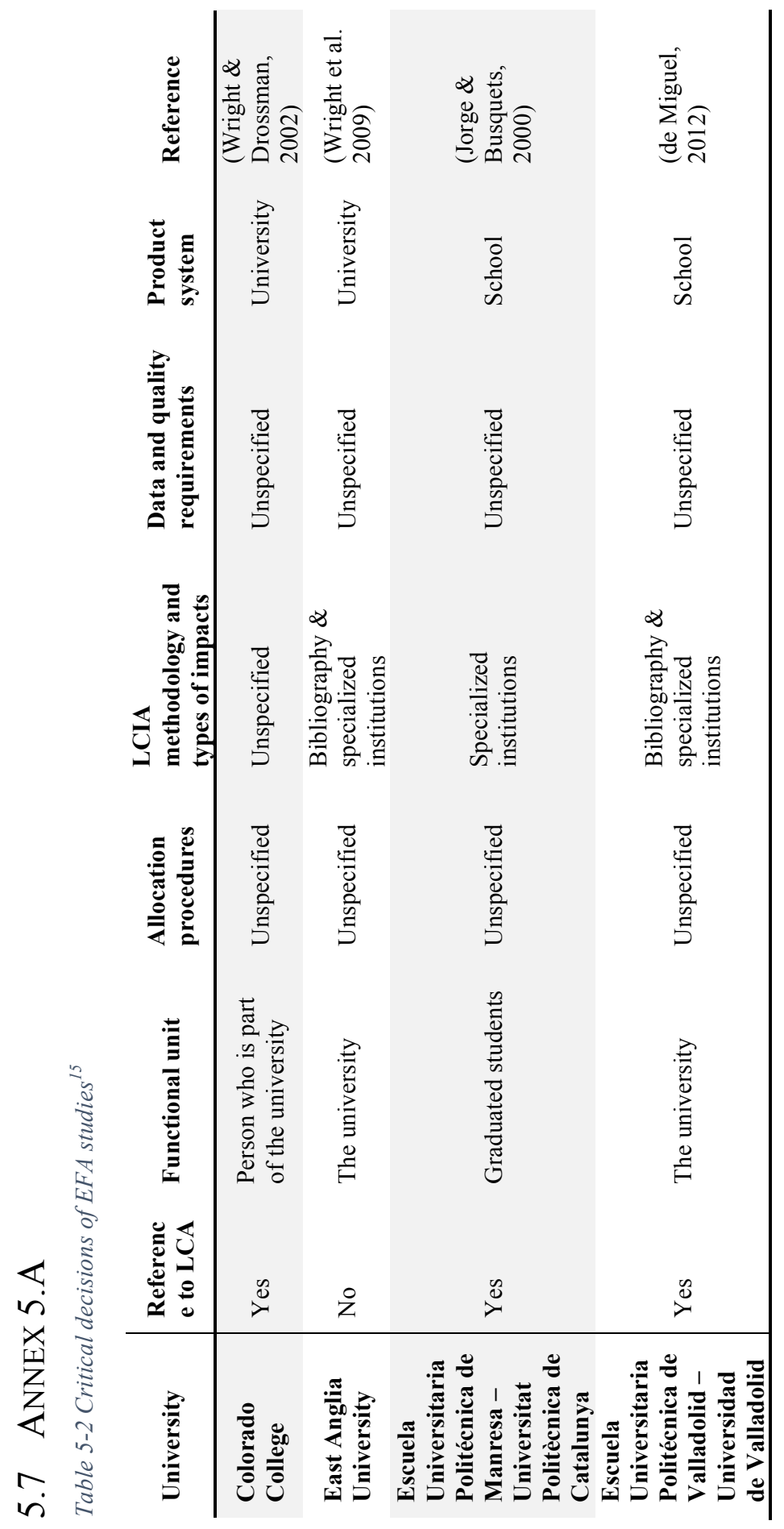

$\dot{0}$
o
0
0
0
0
0
0
\pm
0
0
0
0
0
0
0
0 


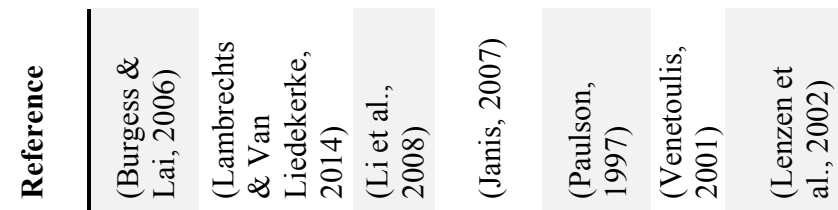

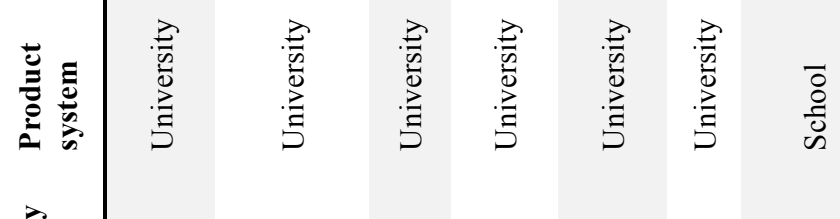

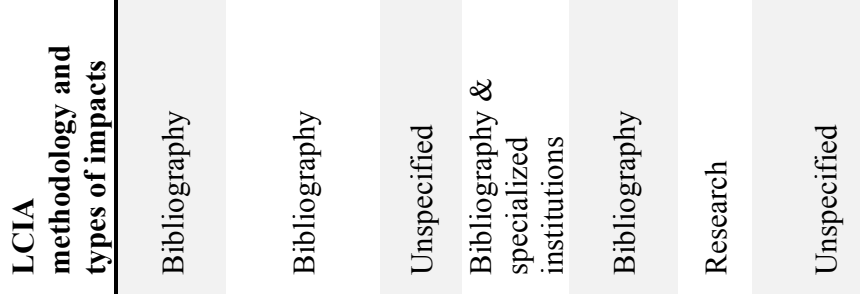

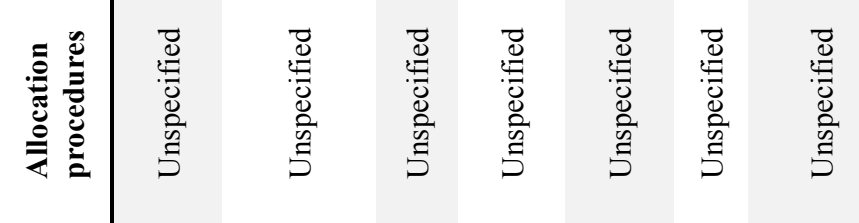

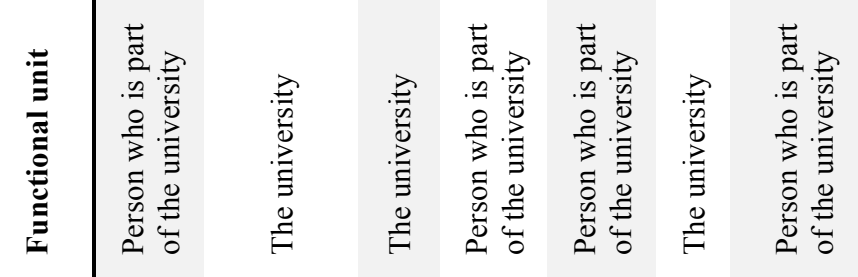

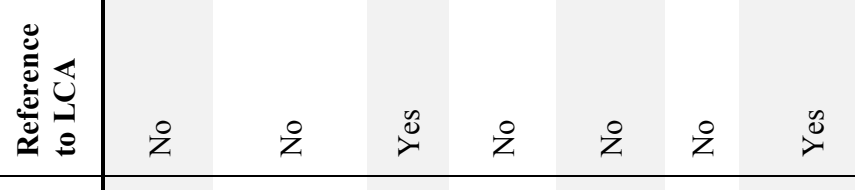

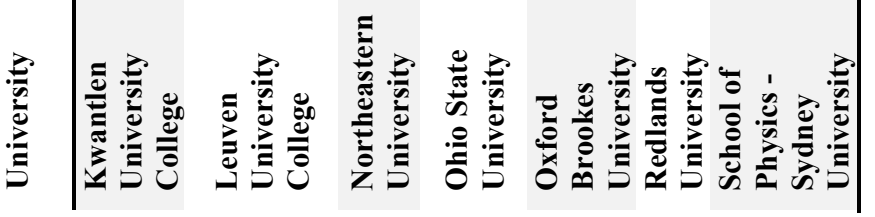




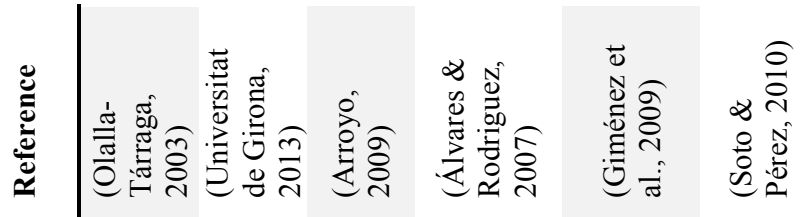

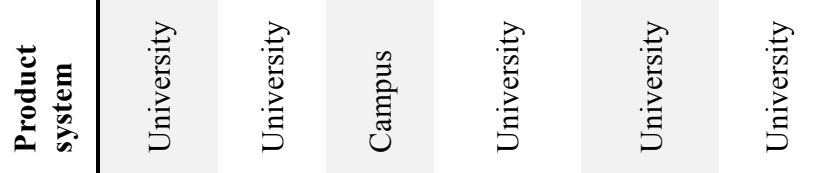

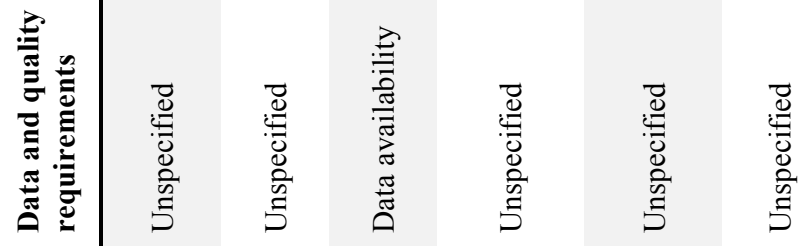

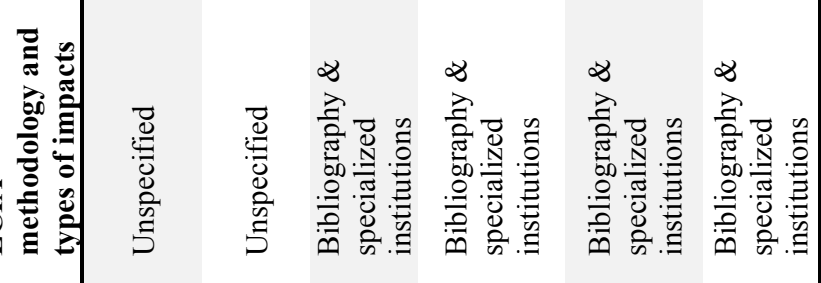

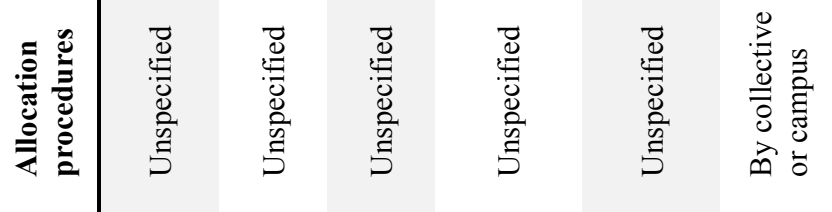

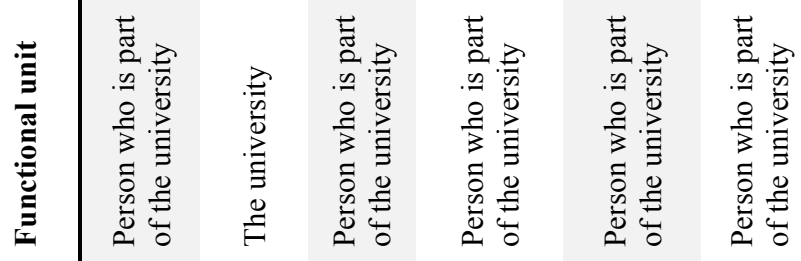

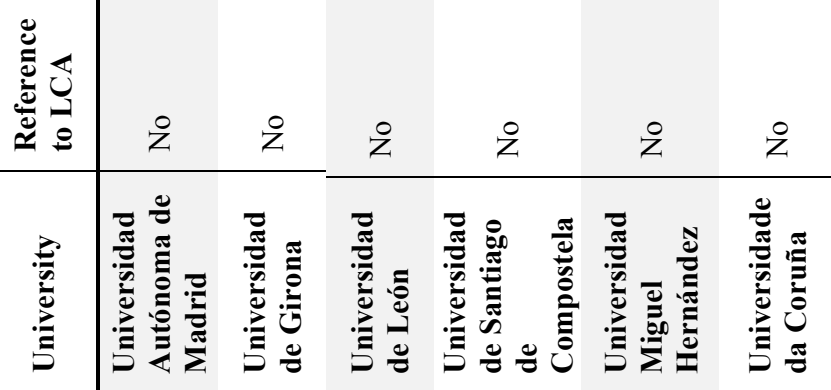




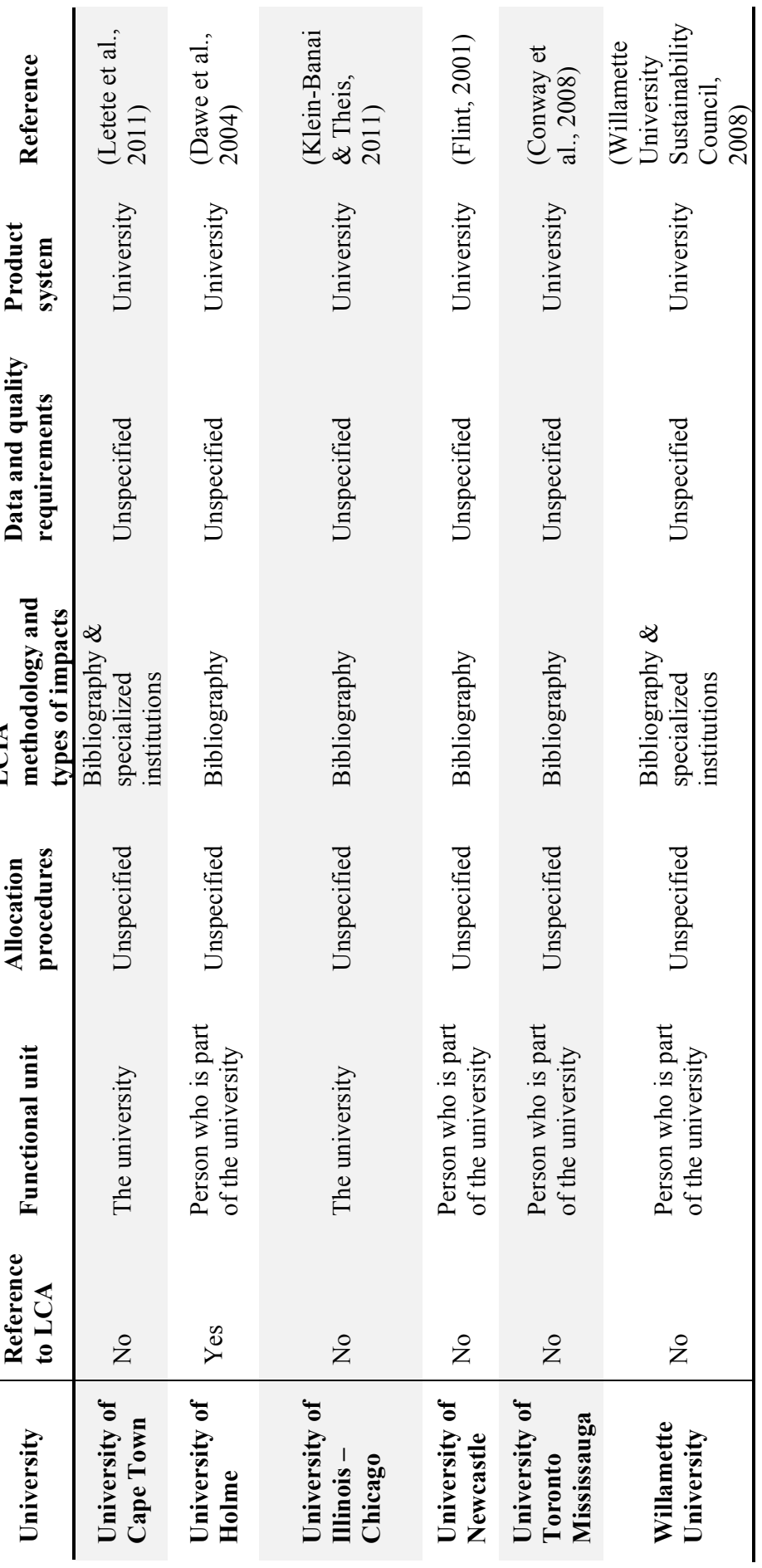





\section{ORgANIZATIONAL LIFE CYCLE ASSESSMENT: SUITABILITY AND METHODOLOGICAL PROPOSAL FOR HIGHER EDUCATION INSTITUTIONS.}

Lo-Iacono-Ferreira, V.G., Torreogrsa-López, J.I., Capuz-Rizo, S.F. (2017) Organizational Life Cycle Assessment: suitability for Higher Education Institutions with Environmental Management System. International Journal of Life Cycle Assessment. 1-6 http://doi.org/10.1007/s11367-017-1289-8

Notice that this paper has been edited to match the style chosen for this document. Figures and tables have also been edited (only format). Abbreviations have also been homogenized. A complete abbreviation code is provided in page 23.

\section{ABSTRACT}

\section{Purpose}

The purpose of this study is to analyze the suitability of organizational life cycle assessments (O-LCAs) for higher education institutions (HEIs) with special attention to the benefits and particularities of those adopting environmental management systems (EMSs) verified according to EMAS.

\section{Methods}

A thorough analysis following ISO/TS 14072 and UNEP Guidance was carried out using the Universitat Politècnica de València (UPV) EMS verified by the EMAS for guiding principles to develop the methodological proposal. The selfsufficiency of UPV EMS for developing an O-LCA was tested at the university pilot unit. The four steps of the O-LCA were applied to the pilot.

Results and discussion

A reporting organization, the organization to be studied (boundaries and scope), was defined in consideration of the environmental units (EU) of the EMS. Operational control was selected as a consolidation method. Reporting flows and system boundaries are also discussed. A three-scope scheme of the GHG protocol is introduced and combined with the ISO 14072 boundary definition to support better alignment with the HEI structure.

For the life cycle inventory analysis, a mechanism for identifying activities and processes as well as their material and energy flows is proposed in consideration of the particularities of HEIs. A procedure for the prioritization of data collection efforts and cut-offs was developed. The procedure integrates current EMAS actions based on the significance of environmental aspects combined with the 
influence of reporting organizations under their control.

Impact categories focus on midpoint indicators along with an additional inventory level indicator as part of the life cycle impact assessment (LCIA). Unfortunately, due to a lack of quality data available, LCIA can only be assessed in part with little interest in outcomes. Partial results are presented.

\section{Conclusions}

An EMS verified by EMAS is proven to be useful in the assessment of O-LCA for HEIs. However, EMAS requirements do not ensure the availability of all data needed to develop an O-LCA. An accounting system should complement a lack of data if it is properly structured. Considerable efforts are required to obtain an accurate result. EMS and the accounting system may be able to provide information that supports an O-LCA approach based on a coherent prioritization of data collection efforts and cut-off procedures along with a set of justified impact category indicators. Overall, organization managers must be in favor of such an assessment to meet the requirements of successful implementation.

\subsection{INTRODUCTION}

The launch of the Technical Specifications (TS) of the International Standards Organization (ISO), ISO/TS 14072 (International Organization for Standardization 2014a) aims to address a gap in the standard methodology for assessing the impacts of the activities of organizations along their life cycles. An organization, according to ISO/TS 14072, is defined as a group of people who have their own functions with the responsibility, authority and relationships needed to achieve the group's objectives. Assessing the life cycle of organizations has been more difficult than the traditional life cycle assessment (LCA) of products or services because some definitions can be challenging to formulate (e.g., functional units or system boundaries).

Some initiatives that have preceded organizational life cycle assessment (O-LCA) include the GHG Protocol Corporate, Bilan Carbone, Carbon Disclosure Project (CDP), Organizational Environmental Footprint (OEF) recommendations of the European Commission (EC) and ISO 14046. An in-depth comparison can be reviewed in Pelletier et al. (2014). The benefits of a life cycle perspective for organizations have also been discussed and proven (Hellweg and Milà i Canals 2014); it can be highlighted that it:

- gives a complete and accurate account of the impact of what is being assessed,

- allows for a better management of resources while providing key information on the needs of the object of study and, 
- encourages fruitful communication with suppliers, clients and stakeholders in general.

O-LCA is a life cycle approach for addressing the environmental footprint of organizations (United Nations Environment Programme, 2015). The scope definition and inventory assessment of O-LCA, in requiring a solid definition of the reporting organization and reporting flows, differ significantly from those used under a traditional LCA procedure. The strong recommendation to not use O-LCA for comparative purposes constitutes its other significant difference from LCA (Martínez-Blanco et al. 2015a). The O-LCA approach provides organizations with a guide for identifying and quantifying environmental aspects within and beyond the boundaries of an organization while considering stakeholders' interests. It is considered a multi-impact environmental approach, as it analyzes environmental issues relevant to an organization while providing a potential environmental impact profile of its activities. Environmental impact profiles provide relevant information needed to disclose environmental insights on an organization's decision-making process. O-LCA can also be used to forecast scenarios and to stimulate data collection efforts (United Nations Environment Programme 2015; Martínez-Blanco et al. 2015b). In particular, ISO/TS 14072 highlights the identification, evaluation and interpretation of the significance of environmental aspects (EA) related to the management systems of organizations as defined under ISO 14001 (International Organization for Standardization, 2004). As another relevant benefit, O-LCA can be used to track the environmental performance of an organization and benefits linked to decision-making processes, as the method can be used to generate relevant information. The delivery of reporting guidance and transparent policies are no less relevant benefits that come with O-LCA implementation.

In this paper, we study HEIs, particularly those with an environmental management system (EMS) verified under the EMAS referred to as the EcoManagement and Audit Scheme (European Commission 2016a). As the EMAS is based on ISO 14001, this certification does not guarantee compliance with O-LCA requirements. In particular, three exclusive features of the EMAS can be highlighted, providing a framework for the identification of significant aspects, for the identification of opportunities for improvement and for the reporting process:

- a commitment to continual improvement,

- the involvement of organization managers through manager reviews and,

- openness and transparency and the periodic delivery of environmental information to interested parties. 
HEIs have a strong effect on the future managers of our industries and countries (Disterheft et al. 2012, Lozano-García et al. 2006, Lozano 2011). As lighthouses of future society, leading by example is their duty (Cortese 2003, Watkins and Glover 2016). HEIs with EMSs verified under EMAS have shown an advantage over organizations that lack EMSs when conducting environmental assessments. The EMAS has proven to be a robust guide to the HEI EMS due to its adaptability to the inner complexities of these types of organizations. However, EMSs focus on the on-site activities of organizations, resulting in incomplete study from an LCA point of view. The authors believe that the O-LCA approach and its relationship to a robust EMS deserves special attention, as this may provide valuable information and a strong case for including a life cycle approach in the daily environmental assessment of HEIs.

Universitat Politècnica de València (UPV) is one of the largest HEIs that has verified its EMS through the EMAS. For a description of EMAS implementation at UPV, see Torregrosa-López et al. (2016). The existence of an EMS might create enough structure to address O-LCA through what UNEP defines as pathway 2, a scenario in which an organization already employs a gate-to-gate environmental approach (see the section entitled "Specific situations for the implementation of O-LCA" in (United Nations Environment Programme 2015) for more details). Although UPV uses a system that assesses its environmental performance to some degree, O-LCAs should provide additional improvements that complement the existing EMS. Another possible pathway is number 4, which was developed for organizations that assess their environmental performance based on environmental indicators. UPV assesses its carbon and ecological footprint yearly. However, the authors note that for an initial approach through which there is no full understanding of where the most significant impacts are, using these indicators and reports as bases of an O-LCA increases bias risks. Although the EMS is the data source for these studies, the scope does not need to be the same as that of an O-LCA as proposed by UNEP. Therefore, under a first approach, we consider pathway 2 to be more appropriate. With further iterations of O-LCA to be developed in future years, the integration of reports and environmental indicators may prove valuable.

The aim of this study is to analyze the applicability of O-LCA to particular organizations (HEIs) that employ robust EMSs verified under the EMAS that generate a defined flow of information on environmental performance. The UPV EMS verified according to the EMAS is used as an example as it has been used for more than 7 years, proving its verification. Critical decisions regarding O-LCA application are suggested as part of a methodological proposal. The methodology is applied to one environmental unit (EU) of UPV (described further in this paper), and it represents a pilot method highlighting the strengths and weaknesses of 
UPV's EMS while answering the following question: is an EMS verified under the EMAS guaranteed success in O-LCA development?

A literature review of O-LCA for organizations and a description of the method used in this study are provided below.

\subsubsection{LITERATURE REVIEW OF O-LCA FOR ORGANIZATIONS}

As the O-LCA approach is relatively new, the related literature is not abundant. Aside from ISO standard ISO/TS 14072 (ISO, 2014a) Requirements and guidelines for Organizational Life Cycle Assessment, the UNEP Guidance on Organizational Life Cycle Assessment (United Nations Environment Programme 2015) is a publication focused on O-LCA. Life Cycle Initiative (2016) is the organization that coordinates all O-LCA flagship initiatives. Martínez-Blanco $(2015 \mathrm{~b}, 2015 \mathrm{c})$ reports on the progress of this project and discussed O-LCA. Jolliet et al. (2014) delves into a definition of life cycle impact categories with particular attention to organizations. Although there are no relevant publications focused on O-LCAs for HEIs, some approaches related to industrial sectors have been published, e.g., an exploration of system boundaries for the O-LCA of beverage-packaging companies by Manzardo et al. (2016) and a decision-making process based on O-LCA methodologies for the textile sector by Resta et al. (2016).

Even though O-LCA is not yet a widely used concept, for some time now researchers and organization managers have been using an LCA point of view to assess the environmental performance of organizations (Finkbeinar et al. 1998), e.g., the Overall Business Impact Assessment applied to Unilever (Tayler and Postethwaite 1996; Clift and Wright 2000) and Input-Output Analysis (Lave et al. 1995; Huang et al. 2009). UNEP guidance on O-LCA considers all of these approaches. One study of HEIs concerns the university examined in this paper, UPV, as described by Lo-Iacono-Ferreira et al. (2011b; 2016c).

By contrast, the implementation of EMSs in HEIs has been widely studied, e.g., ISO 14001 and the EMAS (Disterhelft et al. 2012; Tlapa et al. 2009; TorregrosaLópez et al. 2016).

In light of this review, an analysis of the suitability of O-LCA for HEIs has not yet been conducted. In addition, a robust EMS operated within a complex organization as an HEI promises advantages for the development of environmental assessments such as O-LCA that deserve to be explored. 


\subsubsection{Methods}

To study the suitability of O-LCA for HEIs, an in-depth analysis of ISO 14072 and UNEP Guidance has been performed. The results are presented according to ISO methodology, with the following sections:

1. Goals and scope.

1.1. Reporting organization.

1.2. Reporting flows and system boundaries.

2. Life Cycle Inventory analysis (LCI).

3. Life Cycle Impact Assessment (LCIA).

4. Results interpretation.

Each point is discussed within the HEIs framework. Proposed guidance for application is provided as a methodological proposal. The application of the proposed methodology to an EU of UPV as a pilot is described, applied as far as possible, and discussed. Special attention is paid to synergies between O-LCA and the EMAS verified EMS of UPV.

\subsection{METHODOLOGICAL PROPOSAL}

In this section, each step of O-LCA is analyzed, defined and discussed as comprehensively as possible.

A thorough analysis of both O-LCA and EMAS requirements and operations serves as basis of the hypothesis of this study: HEIs with an EMS verified under the EMAS possess a solid structure for addressing an O-LCA. Most O-LCA requirements outline a direct solution through the EMAS. However, some issues such as data quality requirements and the selection of impact categories are not explicitly referenced in the EMAS and may constitute an issue. A detailed comparison between both tools can be found in Annex 1 .

The methodological proposal is based on the particularities of HEIs and in consideration of the functioning of an EMS and particularly of an EMAS.

\subsubsection{GOAL AND SCOPE}

To define the goal and scope of an assessment, UNEP suggests answering the following questions. "What do you want to assess?" "Who will use the results?" "What questions are you trying to answer?" The objective is to identify organization to be studied; the reporting organization concerned; the consolidation method used; considered operations, facilities and sites of the studied organization; reporting flows; allocation procedures (if needed); impact assessment methodologies; and impact and data quality requirements while making all limitations of the assessment clear. 


\subsubsection{REPORTING ORGANIZATION}

As the functional unit of LCA, the reporting organization represents the unit to be assessed. Limits must be identified and held consistent throughout the entire process. Units that may disaggregate the reporting organization can be explored by examining the HEI EMS concerned, i.e., departments or environmental units (EU).

An EU is an area that is physically localized, that has well-defined functions, and that controls at least one budget item related to material or energy flows. Any HEI can be divided into EUs. Each EU should have an environmental interlocutor and should be internally and externally audited periodically through the given EMS. Faculties, departments and research services are examples of EUs. When initially conducting an O-LCA, it is suggested that one EU is used as a pilot, as EUs have clear limits and can remain consistent throughout an assessment. An HEI could be assessed as a reporting organization divided into EUs. The sum value of the OLCA for all EUs should represent the O-LCA of the HEI as a whole. By integrating the assessment method with the EMAS structure, scaling up should be easy to carry out once all sources of information are correctly managed.

The use of EUs constitutes a benefit that the EMAS can offer when carrying out an O-LCA of an HEI. Of course, any HEI can define its EUs; however, the EMAS ensures the structure needed for definition, as the whole organization can be systematically reviewed. The EU is a concept that was developed by UPV during the execution of its EMS. Although it is not described under EMAS rules, it was validated by the EMAS during the verification of the UPV EMS in 2009 (Registration Code: ES-CV-000030).

An alternative to assessments based on EUs involves considering a whole HEI as a reporting organization - a black box - and not going into detail on internal flows. This is a valid alternative approach when no EMS is available, but when a robust system can provide detailed information through consideration of an EU, it seems to be good practice to take advantage of this. Disaggregated information adds value to the interpretation of results and therefore to the decision-making processes in which this information takes part. In further iterations of the assessment, some feasible simplifications might come to light.

It is important to not forget that an O-LCA study must follow a clear consolidation method and reference period. If any changes between two consecutive studies occur, they must be reported, detailed and analyzed to avoid misunderstandings and to generate an assessment that reflects reality. As an EMS is based on an operational control scheme and works on annual reporting basis, the consolidation method suggested is the operational control and the reference period covers one year. 


\subsubsection{REPORTING FLOWS}

According to EC (2013), reporting flows should answer questions concerning 'what,' 'how much,' and 'how well?' HEIs perform a social function and provide services as part of their mission; they do not produce a formal product. As observed by UNEP (2015), it is particularly challenging for these types of organizations to answer such questions.

The mission of HEIs, or the final goal of these organizations, is dependent on the nature of the institution (public, private, research and/or technology transferoriented, etc.). In any case, this is not within the scope of the present analysis. Functional units for HEIs were discussed in the literature prior to the launch of the O-LCA method: students in regards to education; articles published on research and profits for technology transfer (Lo-Iacono-Ferreira et al., 2016c). According to these findings, the number of equivalent students is recommended as the reporting flow for HEIs. The equivalent student unit is defined as a full-time student, and it is somehow already part of an EMS verified under the EMAS. On one hand, the EMAS requires the normalization of environmental indicators based on the number of full-time equivalent employees. Therefore, the procedure used to assess full-time equivalent persons is already incorporated within the system. On the other hand, the EMAS requires the description of activities, processes and services; the number of students involved is a basic measure that must be reported when the organization concerned is an educational institution.

Lo-Iacono-Ferreira et al. (2016c) found a direct relationship between equivalent students and environmental indicators (the ecological footprint) for universities. Moreover, this unit expresses the main goal of HEIs: to teach and train students. This is why the number of equivalent students is considered to be a good source of reporting flow. However, consistency analyses and results of the first approach to O-LCA must verify that the selection of equivalent students in reporting flows is appropriate.

\subsubsection{SYSTEM BOUNDARIES}

System boundaries must be clearly defined to avoid double-counting impacts. For a successful identification of activities and processes, what is and is not included in an EU must be made clear. Are other EUs related to the one under analysis? How do they interact? The structure of an HEI as a whole must be carefully defined. For example, UPV runs 14 faculties and schools, 44 departments, 35 research facilities, more than 90 university services and almost 30 facilities operated by third parties (full details can be found in Torregrosa-López et al. 2016). Departments are physically located within faculties. The energy consumption and waste generation of these facilities is managed by faculties with operational control. However, each department purchases its own supplies (office 
materials, computers, lab equipment and supplies, etc.). Faculties have no control over these supplies.

System boundaries shall reflect the consolidation approach used when assessing organizations (ISO 2006b). Therefore, an operational control boundary is recommended to taking advantage of the scope of an EMS verified under the EMAS. The EMS shall establish objectives and targets that allow for the identification and monitoring of all EAs related to the operations (activities, processes and services) of the organization.

For a more complete definition of the system boundaries, an extension of the three scopes considered by the GHG Protocol Corporate Standard to other environmental issues apart from GHG emissions is proposed for HEIs and is used for the pilot as suggested by Draucker (2013) and Braunschweig (2014):

(1) Direct resource use, emissions and waste are included under Scope 1,

(2) Upstream indirect factors are divided into two scopes:

Scope 2: indirect emissions and resources associated with infrastructure usage, i.e., power production,

Scope 3: all other indirect emissions and forms of resource use, i.e., emissions associated with waste and waste water treatment,

(3) Downstream indirect factors are not considered, as HEIs are service providers.

\subsubsection{LIFE CYCLE INVENTORY ANALYSIS (LCI)}

The application of a robust EMS with ISO 14001 certification or EMAS periodic verification (or both as is the case for UPV) supports valuable expertise needed to define an LCI. The following procedure is recommended as a way to ensure the consideration of all flows once the reporting organization's goals and scope are well defined. Figure 6-1 shows the scheme of this procedure.

An iterative loop is included under the procedure, as data collection, data validation and consistency analyses can reveal deficiencies in the identification of activities or flows. 
Proposal of a set of Key Performance Indicators for the environmental assessment of Higher Education Institution

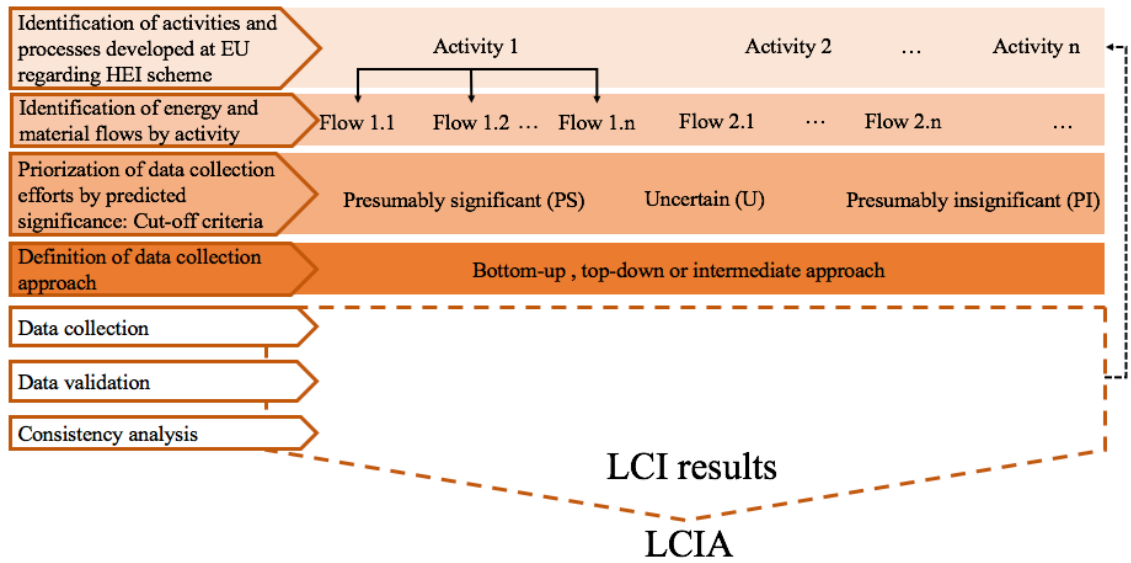

Figure 6-1 Procedure to analyze EU flows. Developed by the authors

\subsubsection{IDENTIFICATION OF ACTIVITIES AND PROCESSES}

EUs and scopes are defined at the Goals and Scope definition stage. Regarding the scopes used, a careful analysis must be conducted to determine which activities and processes are direct activities and which are indirect-upstream or downstream-activities. Additionally, extra care must be taken to avoid double counting EUs that may have shared input or output flows.

Activity and process identification is an EMAS requirement, and therefore an EMS shall employ tools used to update the list of operations annually. The most common tools used include internal surveys, expert advice and facilitated workshops. It is suggested that activities and processes mentioned during identification that are allocated outside of the EU remain clearly identified at the final study reporting stage, as such information can prove valuable for subsequent studies of the same EU. A broader O-LCA can be developed from EU assessments if integration carefully avoids double counting and omissions.

As HEIs do not have a product, there are no easily recognized downstream activities. The role of graduates' professional activities has been broadly debated. This is a relevant issue for the analysis of green curricula, as the result of a good environmental education can be reflected in good professional practices. It may be interesting to consider this aspect when assessing an EU that involves teaching activities. If HEIs are assessed as a whole, other interesting aspects become involved in relation to downstream activities other than curricula, e.g., environmental aspects of research results. These aspects require extensive analysis and debates between experts on these subjects. 


\subsubsection{IDENTIFICATION OF ENERGY AND MATERIAL FLOWS BY ACTIVITY}

The individual identification of flows is needed for a rigorously defined LCI. Although data are obtained from an accounting system or EMS and no allocation procedure is applied, as EUs are treated as a whole, identifying flows for each activity can help ensure that all material and energy flows are considered.

Primary data are required to measure direct emissions and resources and are suggested as the most appropriate for studying indirect emissions and resources. Sources include emissions measurements and waste composition analyses inherent to the EMS and other sources such as invoices of purchases and stock inventories that may be part of an EMS or not. Whenever possible, the source should be the EMS, as it works with material units $(\mathrm{kg}, \mathrm{kW}$, etc.) rather than budgets that register monetary units. When an EMS integrates supplier and service registration, this source gains relevance during assessment. Budgets may be used as a consistency check tool or as a secondary source of information, as they require a conversion of units that adds uncertainty to the assessment.

Regarding general sources, at the time of publishing this study, no scientific papers with generic data on LCA for HEIs have been published. However, other HEI environmental assessments related to carbon, water and ecological footprints can be used as alternative sources, although such data must be handled with care in regards to reliability and coherency (scope, method, geolocation, etc.). Some government statistics for the educational sector may also be useful.

The use of databases such as Ecoinvent, EPLCA, etc. is foreseen as they can complement information given by the EMAS. Energy and basic materials (e.g., water) can be studied in consideration of their complete life cycles. Other materials such as the raw materials needed to produce office supplies might only be considered through an initial O-LCA if existing and accessible databases include such information. Otherwise, risks of assessment failure increase significantly. A simplification can prevent analysis paralysis. It must also be considered that cut-off criteria might exclude some inputs affected by such weaknesses. A prioritization and cut-off methodology is proposed and discussed further in this section. However, every full or partial omission must be reported on and justified. The use of simplifications does not mean that an assessment is not valid if it is properly explained and transparently reported. Higher levels of quality and greater specificity should be expected in a next iteration of this $\mathrm{O}$ LCA. 


\subsubsection{DEFINITION OF DATA COLLECTION APPROACH}

ISO/TS 14072 can involve three different approaches:

- Bottom-up, where LCA involves adding and weighing products together with supporting activities.

- Top-down, where the reporting organization is considered as a whole and where inputs and outputs are added.

- Hybrid approach that combines bottom-up and top-down models to compose a data collection scheme.

No products have been designed for HEIs. Therefore, gathering existing LCAs through a bottom-up approach is not possible. A top-down approach seems the most reasonable option for HEIs.

\subsubsection{PRIORITIZATION OF DATA COLLECTION EFFORTS BY PREDICTING SIGNIFICANCE: CUT-OFF CRITERIA}

The proposed prioritization and cut-off criteria aim to consider activities, processes and EAs based on relevance. The upgraded prioritization procedure considers both the quantitative relevance of EAs and the influence of an EU on the control of activities or related processes. Prioritization procedures are designed to optimize human and economic resources. Activities and processes generating higher scores require fewer resources to obtain a better outcome than activities or processes generating lower scores.

On one hand, activities and processes can be prioritized while bearing in mind an EU's capacity to influence resource use and emissions according to GRI (2005) and WRI and WBCSD (2011). For HEIs, a scoring procedure is proposed. This proposal responds to experience gained through the implementation and management of EMSs. On the other hand, the EMAS encourages EMSs to categorize all organization EAs as (S) significant or (NS) insignificant. At UPV, this latter procedure is referred to as the Environmental Aspect State (EAS). However, the potential influence of an organization on its operational control over activities or processes related to EAs is not considered as suggested by GRI (2005) and WRI and WBCSD (2011). This is why an upgraded prioritization procedure is proposed. The complete prioritization procedure is outlined in Figure 6-2 and is described below.

As a first step, EAs are defined and classified according to the EAS of an organization as S or NS. Alongside this, activities and processes detected through LCI analysis are also classified by the degree of control that an EU has over them, generating an activity property referred to as the Control State (CS). The CS has three possible definitions: complete control (CC), partial control (PC) and uncontrollable (UC). CC denotes complete control where an EU has operational 
control over an activity or process. PC denotes a certain level of uncertainty regarding an activity due to partial operational control, i.e., outsourcing. UC refers to those activities over which an EU has no influence. When any UC activities are detected, they must be thoroughly analyzed and reported on while considering that the chosen consolidation method involves operational control.

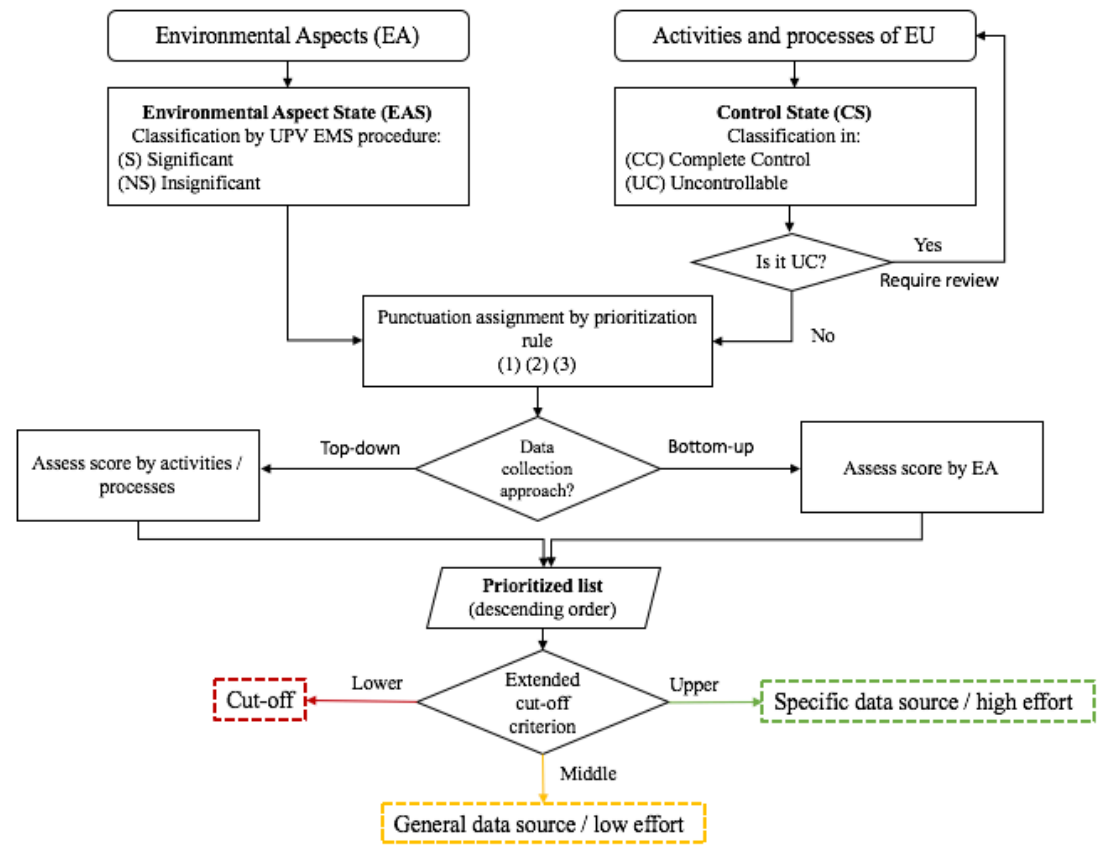

Figure 6-2 Prioritization of data collection efforts and cut-off procedure. Developed by the authors

The iterative loop of LCI procedure (Figure 6-1) can highlight flows and activities not considered in the initial analysis stage. The UC state also works as a consistency mechanism for the entire LCI analysis. When a UC is detected, the identification of activities and of its flows must be reviewed. These uncontrollable activities may be significant and require action in order to become controllable.

Once the EAS and CS are assessed, a crosscheck assigns a score to each EA for each activity and process. The total score by activity and process generates a prioritized list (in descending order; highest first) that can be used to assign resources and efforts for assessment. This method is compatible to a top-down data collection approach. The data collection approach involved is discussed further in this section. Table 6-1 shows the rules for the crosscheck score assignment. 


\begin{tabular}{|l|l|c|}
\hline EAS & CS & Score \\
\hline S & CC & 3 \\
\hline S & PC & 2 \\
\hline NS & CC & 2 \\
\hline NS & PC & 1 \\
\hline
\end{tabular}

Once the prioritized list is fixed, the cut-off criterion is applied. For HEI assessment, an extended cut-off criterion is proposed as a way to facilitate the development of initial approaches to O-LCA. The extended cut-off criterion involves addressing the accumulated percentage score for each subject of study: activities and processes as top-down approaches used. When a subject of study (activity, process or EA) exhibits a high level of control, actions taken by an EU to address improvements in its environmental performance would be more efficient. Similarly, when the subject of study is S, any improvements would reflect a broader difference in the environmental performance of an EU than when an NS subject is considered. Therefore, there is a direct relationship between the score obtained when considering significance and control levels and the impact of a certain subject of study.

A cut-off of between $90 \%$ and $95 \%$ of the score accumulated under a first O-LCA approach is recommended. The cut-off sets aside the lower $10 \%$ or $5 \%$ of the subjects' studies. This proposal is based on the various simplifications typically applied in product-based LCAs (Fleischer et al. 2001; Hochschorner and Finnveden 2003; Vivancos Bono, J.L. 2005).

The remaining subjects must be divided into other two sections (see Figure 6-3). As a standard, equal partitioning is recommended. However, other personalized divisions can be made if considered appropriate. Once all three parts are defined, the following criteria can be applied: (a) allocate resources for a large data collection effort to the upper section to collect as much specific data as possible; (b) carry out balanced effort regarding the middle section of the list, as general data sources can be accepted and (c) remove the lower section of the list unless data collection procedures developed for the upper and middle sections can provide necessary data without additional resources, i.e., data can be easily obtained from the EMS. Figure 6-3 shows the scheme of a top-down approach with a cut-off criterion of $95 \%$ of the score. 


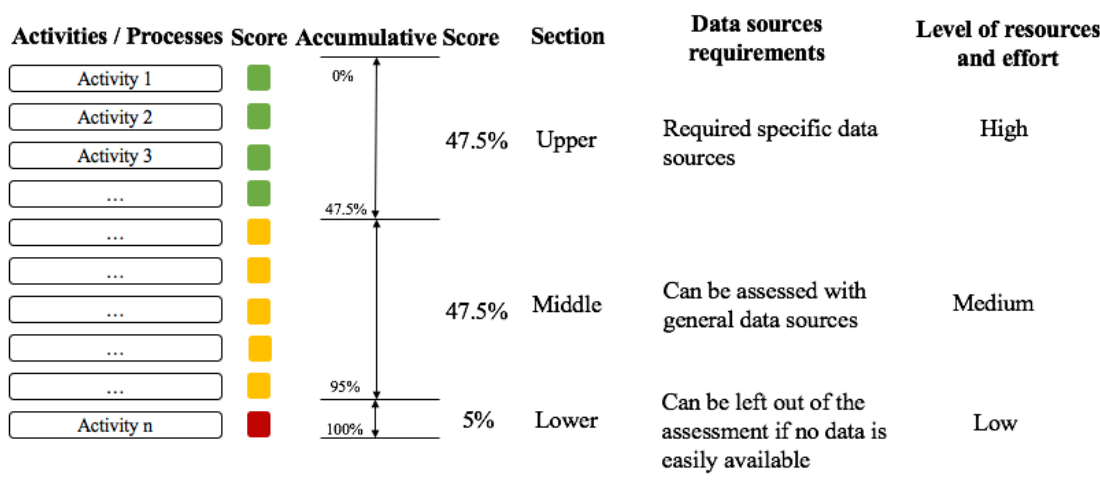

Figure 6-3 Top-down prioritization approach with 95\% cut-off criterion scheme

The cut-off criterion is enriched through each O-LCA iteration based on previous experience. Many different criteria can be applied provided that they clearly serve to prioritize the collection of data on activities, processes or EAs that are expected to have the most significant environmental impacts.

\subsubsection{DATA COLLECTION, VALIDATION AND CONSISTENCY ANALYSIS}

The EMS plays a relevant role by providing a good supply of information on inputs and outputs. An accounting system can serve as an alternative to a data collection process. Both sources can generate data with temporal, geographic and technological representativeness; precision; completeness; reproducibility and reliability, fulfilling the quality requirements.

All documentation used during LCI should be registered as a source, as it may be needed to validate data used. External and internal experts can carry out the validation process. The consistency analysis procedure is an additional step proposed for future iterations of O-LCA whereby once data are collected and validated, they can be compared to previous study data to detect any significant discrepancies and to provide necessary additional reviews and justifications. Matching data from different studies on the same reporting organization can highlight issues that might require further analysis as a consistency test. When significant differences are found (e.g., in the amount of energy consumption from one year to another), checking actions that could have affected this consumption may ensure the consistency of data involved. 


\subsubsection{Life Cycle Impact Assessment (LCIA) AND Results INTERPRETATION}

Regarding LCIA, corresponding requirements are mainly the same as those established for the LCA of products (International Organization for Standardization 2006a, 2006b). The translation of inputs and outputs (LCI) into environmental impacts should be conducted using an existing impact assessment method, i.e., ReCiPE, CML2002, EDIP, etc. (United Nations Environment Programme 2015). The determination of impacts to be assessed constitutes a challenge for such organizations.

Impact categories were selected in consideration of stakeholders, lessons learned from the EMAS, recommendations from the literature (Jolliet et al. 2014) and characteristics of the reporting organization analyzed. Previous case studies on environmental performance (Torregrosa et. al, 2016; Lo-Iacono-Ferreira et al. 2011b, 2016a, 2016b) validate the results of a survey carried out between a representative group of stakeholders. Although the opinions of experienced practitioners are not alone sufficient for the definition of impact categories (Curran, M.A., 2017), such know-how is useful for election; therefore, members of HEIs with recognized experience in LCA were also consulted. O-LCA issues proposed include: climate change, land uses, water footprints, abiotic resource use and acidification based on a midpoint approach. These categories reflect environmental issues related to HEIs identified in previous studies and are defined in accordance with the goals and scopes defined. A midpoint method defines a category from an intervention point of view (i.e., problem oriented) while endpoint methods focus on recognizing societal value (i.e., damage oriented, such as human health) (Hauschild and Huijbregts 2015).

An additional inventory level indicator for HEIs is proposed: waste generated by waste type. This indicator might help communicate impacts and spur community commitment to defined actions needed to improve the environmental performance of the reporting organization. The selection of waste types to report on can be based on the significance of such impacts. Table 6-2 presents the impact categories recommended for HEIs. Other indicators can be included either as midpoint or endpoint indicators. Endpoint indicators can be useful for life cycle interpretation when a broad list of midpoint indicators is also assessed. Endpoint indicators can add valuable information for interpretation. Consistency between the goals and scope of an analysis and impact category indicators must be verified.

There are no significant differences between O-LCA and product LCA in the interpretation of results either. Figure 6-4 describes the five-step procedure proposed by the authors for this analysis. 
Table 6-2 Impact categories suggested for HEIs

\begin{tabular}{|l|l|}
\hline Impact category & Type of indicator \\
\hline Climate change & Midpoint \\
\hline Land use & Midpoint \\
\hline Water footprint & Midpoint \\
\hline Energy resources use & Midpoint \\
\hline Abiotic resources use & Midpoint \\
\hline Acidification & Midpoint \\
\hline Waste generation by types & Inventory level \\
\hline
\end{tabular}

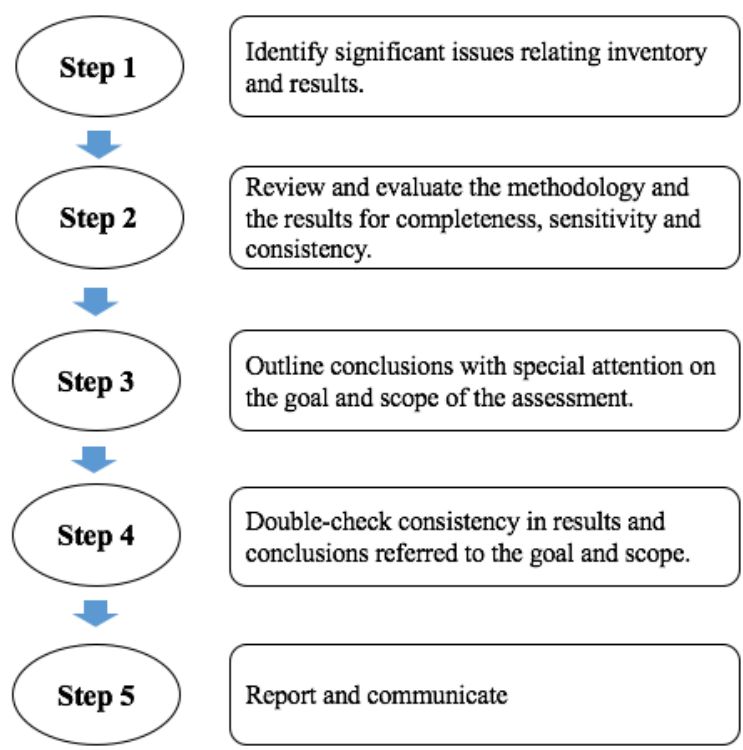

Figure 6-4 Results interpretation procedure suggested for HEIs. Prepared by the authors

Sensitivity and uncertainty analyses constitute part of the result interpretation stage. All limitations, assumptions, data quality requirements and sources must be clearly described and considered. Weak points detected during the assessment must be gathered and evaluated for further study.

Regarding communications, it is desirable to follow a systematic procedure. OLCA results can be easily included through the EMS communication system that the EMAS requires. Different footprints could be used complementarily to communicate results as inventory-level indicators (Jolliet et al. 2014). 


\subsection{Results: APPLiCATION OF METhODOLOGY TO EPSA CASE STUDY (PILOT EU)}

An initial O-LCA approach based on the proposed methodology is presented. Even though the UPV EMS does not exhibit the level of performance needed to address this O-LCA, the results are presented in this section.

The complexity of an organization lies mainly in the decentralization of management and operational control. Although the EMS centralizes the monitoring of EAs identified under the EMAS, other activities and processes considered relevant for O-LCA are not yet supported with qualitative data, i.e., supplies purchases. Assessing UPV as a whole implies accessing and coordinating different areas that are not always open to this. For this reason, through our initial approach, an EU - EPSA - is used as a pilot.

Limitations and barriers related to the assessment are identified and discussed in this section. The procedure is organized based on O-LCA steps.

\subsubsection{GOALS AND SCOPE}

A set of definitions is shown in Table 6-3. Each definition is described, discussed and justified below.

The EPSA is the UPV EU chosen as a pilot for this assessment. It is defined under the EMS and it is physically located in the city of Alcoy. The EPSA consists of 3 buildings managed by staff and headed by a director. The unit also manages one vehicle, a van, for transport of goods and personnel. More details on the EPSA can be observed in Annex 6.B.

The director coordinates several vice-directors (appointed by the director) who are in charge of different subareas and who manage operations as illustrated in Figure 6-5. 
Table 6-3 Goal and scope definition

\begin{tabular}{|l|l|}
\hline Organization to be studied & Universitat Politècnica de València \\
\hline Reporting organization & $\begin{array}{l}\text { Higher Polytechnic School of Alcoy (EPSA) - } \\
\text { UPV }\end{array}$ \\
\hline Period considered & 2015 \\
\hline Consolidation method & $\begin{array}{l}\text { Operational control (see description in section } \\
4.1 .1 \text { ). }\end{array}$ \\
\hline $\begin{array}{l}\text { Reporting flows and system } \\
\text { boundaries }\end{array}$ & $\begin{array}{l}\text { Will be described in Reporting flows and system } \\
\text { boundaries section (4.1.2). }\end{array}$ \\
\hline $\begin{array}{l}\text { Operations, facilities and } \\
\text { sites of the organization } \\
\text { included }\end{array}$ & Will be described in LCI analysis section (4.2) \\
\hline $\begin{array}{l}\text { Impact assessment } \\
\text { methodology and types of } \\
\text { impact }\end{array}$ & Will be described in LCIA section (4.3). \\
\hline Allocation procedures & $\begin{array}{l}\text { No allocation procedures will be needed as the } \\
\text { product/service to be considered is unique; } \\
\text { results do not need to be split. }\end{array}$ \\
\hline Data quality requirements & $\begin{array}{l}\text { Criteria such as temporal, geographical and } \\
\text { technological representativeness, precision, } \\
\text { completeness, reproducibility and reliability will } \\
\text { be described for each reporting flow assessed }\end{array}$ \\
\hline Limitations & $\begin{array}{l}\text { Results are not intended to be used in } \\
\text { comparative assessments intended to be } \\
\text { disclosed to the public. The results will be } \\
\text { limited by the quality of the data. }\end{array}$ \\
\hline
\end{tabular}

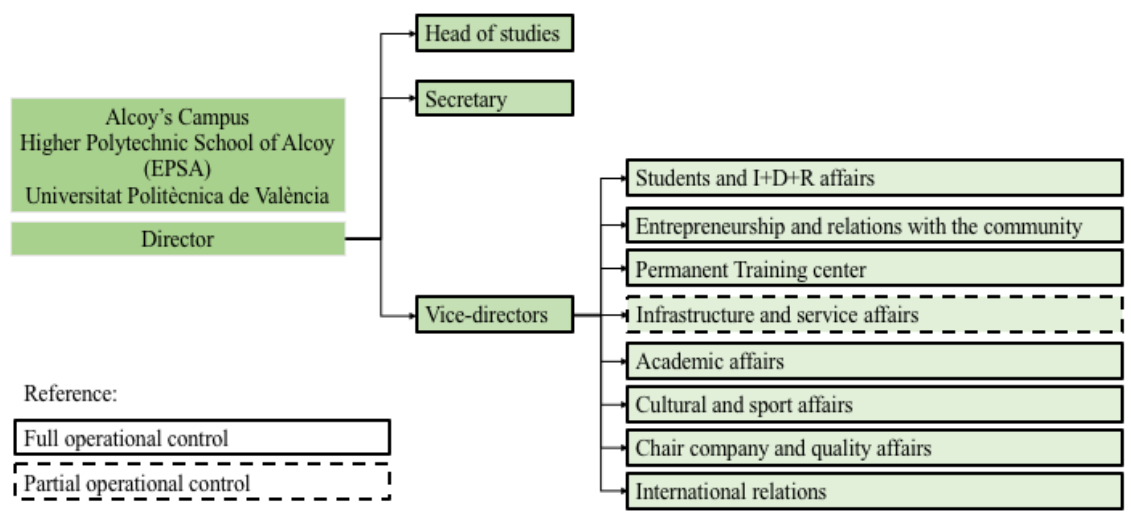


Independent of the general regulation of a public university and of the specific regulation of UPV, the EPSA has full operational control over all of its governed areas with the exception of from some facility issues: the maximum and minimum temperatures of the air conditioning system are fixed by the UPV infrastructure and maintenance office. However, air conditioning system on/off functions are still controlled by the EPSA, giving the EU partial but significant control. The air conditioning system can be turned off or on depending on whether a room is being used or not, but the intensity cannot be freely regulated, thereby preventing extreme usage. This is an energy efficiency measure used by the highest management offices of UPV. The EPSA is a UPV school. Several departments operate through its facilities. The EU only covers activities under its operational control, e.g., the management and maintenance of facilities (electricity, maintenance, waste management, etc.) is managed by the EPSA while each department manages independent accounting on office supplies and other purchases (no control). Something similar occurs in laboratories, where supplies and additional services are bought through department or research institute accounts falling outside of the defined reporting organization. The impacts of these other activities and processes may be assessed when EUs related to them (e.g., departments) are analyzed through individual O-LCAs. All activities and processes falling within the EPSA's system boundaries are identified in the following section.

\subsubsection{EPSA LCI}

The iterative procedure proposed in the LCI section (6.2.2) was applied to the EPSA, with EUs chosen during the previous step. EPSA activities and processes identified by experts are shown in Figure 6-6.

Although the EMS Office has developed a procedure for assessing the green aspects of curricula through the analysis of study plans, the development of study plans is not managed by the EPSA but by the degree committee, a different EU. As no teaching or research activities guide the EU selected for this pilot study, no further considerations are in regards to downstream activities as suggested in the LCI methodology description section.

Flow assignments for each activity and process identified for the EPSA are included in Annex 6.C as part of the prioritization procedure. Table 6-4 presents all inputs and outputs of the EPSA. 


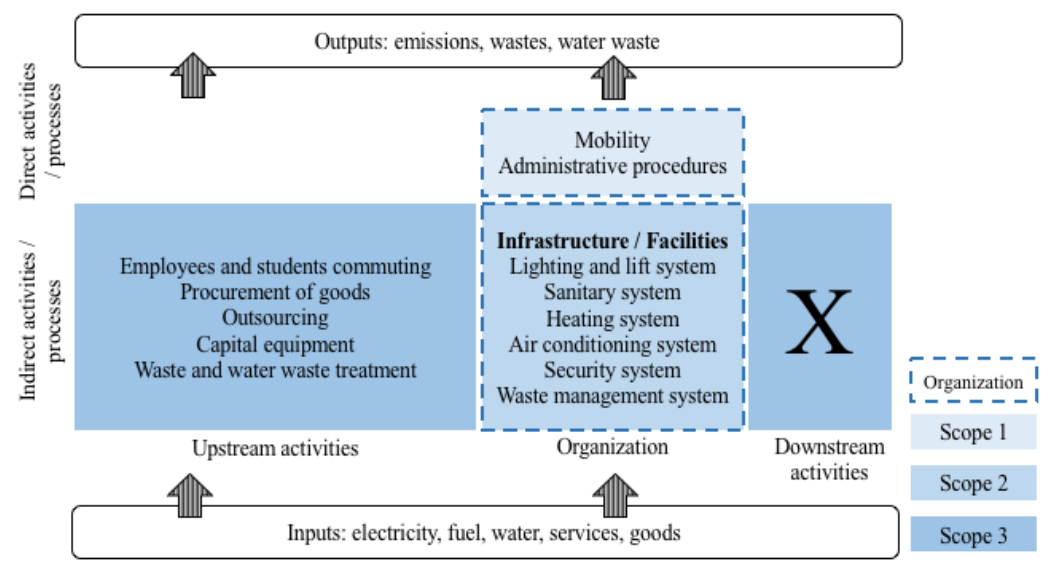

Figure 6-6 Activities and processes of EPSA. Developed by the authors on the basis of UNEP (2015) guidance

Basic infrastructural inputs such as electricity, water, gas, oil for mobility and natural gas for heating are considered. "Office supplies" refer to consumablesfrom paper and pens to toner-while "supplies" refer to consumables other than office supplies. "Technology assets" refer to electronics such as computers, interactive boards, projectors, screens, accessories, etc. "Movable assets" refer to all other movable assets other than automobiles and those considered under the technology category. Although all of these are movable, due to the relevance of their impacts, it is interesting to consider them separately. However, the amortization period should be considered for all of them when their impacts are assessed. Services refer to outsourced services, e.g., the operation of the cafeteria; see Annex 6.C for a detailed description of outsourcing considerations. $\mathrm{CO}_{2}, \mathrm{SO}_{2}$, $\mathrm{NOx}, \mathrm{CO}$ and $\mathrm{HFC}$ from fossil fuel combustion and refrigeration systems are the direct emissions considered. Waste water and different types of solid and liquid waste are also included, completing the output inventory.

EAS is the specific procedure used for the identification and classification of EAs via UPV's EMS. The assessment method is quantitative and based on algorithms for each EA. The method is defined through specific technical instructions developed by the environmental office. All EMS procedures and technical instructions of the EMS are available to stakeholders with access to the Internet, meaning that the organizational community is aware of how the system works and why. The classification objectively considers the relevance of a certain EA based on previously defined parameters such as the relationship between the consumption of a resource and the number of individuals employed under an EU. 
Table 6-4 Inputs and outputs of EPSA

\begin{tabular}{|l|}
\hline Inputs \\
\hline Electricity \\
\hline Water \\
\hline Gasoil \\
\hline Natural gas \\
\hline Office supplies \\
\hline Supplies \\
\hline Automobiles \\
\hline Technology assets \\
\hline Movable assets \\
\hline Services \\
\hline Other supplies \\
\hline
\end{tabular}

\begin{tabular}{|l|}
\hline Outputs \\
\hline $\mathrm{SO}_{2}, \mathrm{NOx}, \mathrm{CO}, \mathrm{HFC}, \mathrm{CO}_{2}$ emissions \\
\hline Debris \\
\hline Electric and electronic waste \\
\hline Oil, fuel and hydrocarbon waste \\
\hline Paper and cardboard waste \\
\hline Light packaging waste \\
\hline Ink and toner waste \\
\hline Municipal solid waste \\
\hline CD waste \\
\hline Waste water \\
\hline
\end{tabular}

Under Annex 6.C, the matrix of activities and processes vs. EA is shown with the corresponding designation for the EPSA based on a $47.5 \%, 47.5 \%$ and $5 \%$ division. As a result, 3 activities or processes are eligible for cut-off; 7 can be assessed through general data sources and 4 require additional efforts and resources to obtain as much specific data as possible.

Two weak points must be highlighted:

- data source assignment regarding specific data quality levels. The EMS does not include the tracking of purchases as a requirement. This lack of specific sources directly concerns an activity with higher priority: administrative procedures.

- the structure of the current EMS does not include enough information to allocate input and output flows to different activities and processes involved in assessment. This limitation affected the rest of the assessment. 
Table 6-5 shows the results obtained along with the associations of each activity or process to impact categories recommended in the methodological proposal. Note that between the upper items, there are scope 1,2 and 3 activities. As scope 3 activities and processes are more difficult to assess because third party collaboration is required, this may create difficulties. However, the proposed methodology is designed to highlight those subjects of study that should be assessed in detail as potential impacts that actions could have on overall environmental performance. For example, electricity consumption is classified as significant under the EMAS; however, the EPSA assume partial operational control, giving this EA a score of 2 in regards to air conditioning that requires electricity. Additionally, emissions from electricity consumption are classified by the EMAS as insignificant, and adding partial control gives this EA a score of 1 . The same classification is applied for emissions from HFCs. As a result, while both aspects (direct emissions and electricity) are considered, air conditioning is given a low score on the prioritization list. Nevertheless, all items merit attention; the extended cut-off procedure is designed to be a tool that complements the knowledge and expertise of practitioners. The criterion fulfills the control approach recommended as an impact consolidation method, and ISO LCI and LCIA requirements as the most significant environmental impacts are considered. The procedure is also easy to document and understand while fulfilling documentation requirements of the standard.

As suggested in the methodology proposal section, a top-down approach is used in this pilot study. Regarding data sources, the EMS approach is used for specific data, as the aim of this study is to determine whether an EMS verified according to the EMAS provides enough structure to complete a reliable O-LCA.

Regarding data collection measures used, emissions of $\mathrm{GHG}, \mathrm{SO}_{2}, \mathrm{NOx}$ and $\mathrm{CO}$ (climate change and acidification causes) related to fossil fuel combustion form part of the EMS based on primary data. They can easily be disaggregated for a specific EU such as the EPSA, as the EMS is already structured by EUs. Land use, water and abiotic resource use are strongly linked to infrastructure services and facilities. Waste generated based on types of waste also forms part of the EMS register. Data concerning these flows of materials are directly available from EMS registers.

Although using a robust EMAS-verified EMS generates specific data on environmental aspects such as natural resource consumption and waste generation, other resources - manufactured ones- might not form part of the EMAS system, as this restricted standard does not require their consideration. The EMS does not yet handle specific information regarding purchases. 
The accounting system based on yearly budgets for supplies, office supplies and service invoices and asset registers could serve as needed information. However, the existing accounting system does not require the disclosure of details on products and services purchased required to complete an accurate assessment, e.g., when buying 10 pencils for an office, the invoice can list ' 10 pencils' or 'office supplies.' Purchase requests should provide more accurate information. It is unlikely that a significant number is created orally; the system is not based on enough information to address the estimation process.

Two weak points must be highlighted:

- data source assignment regarding specific data quality levels. The EMS does not include the tracking of purchases as a requirement. This lack of specific sources directly concerns an activity with higher priority: administrative procedures.

- the structure of the current EMS does not include enough information to allocate input and output flows to different activities and processes involved in assessment. This limitation affected the rest of the assessment. 


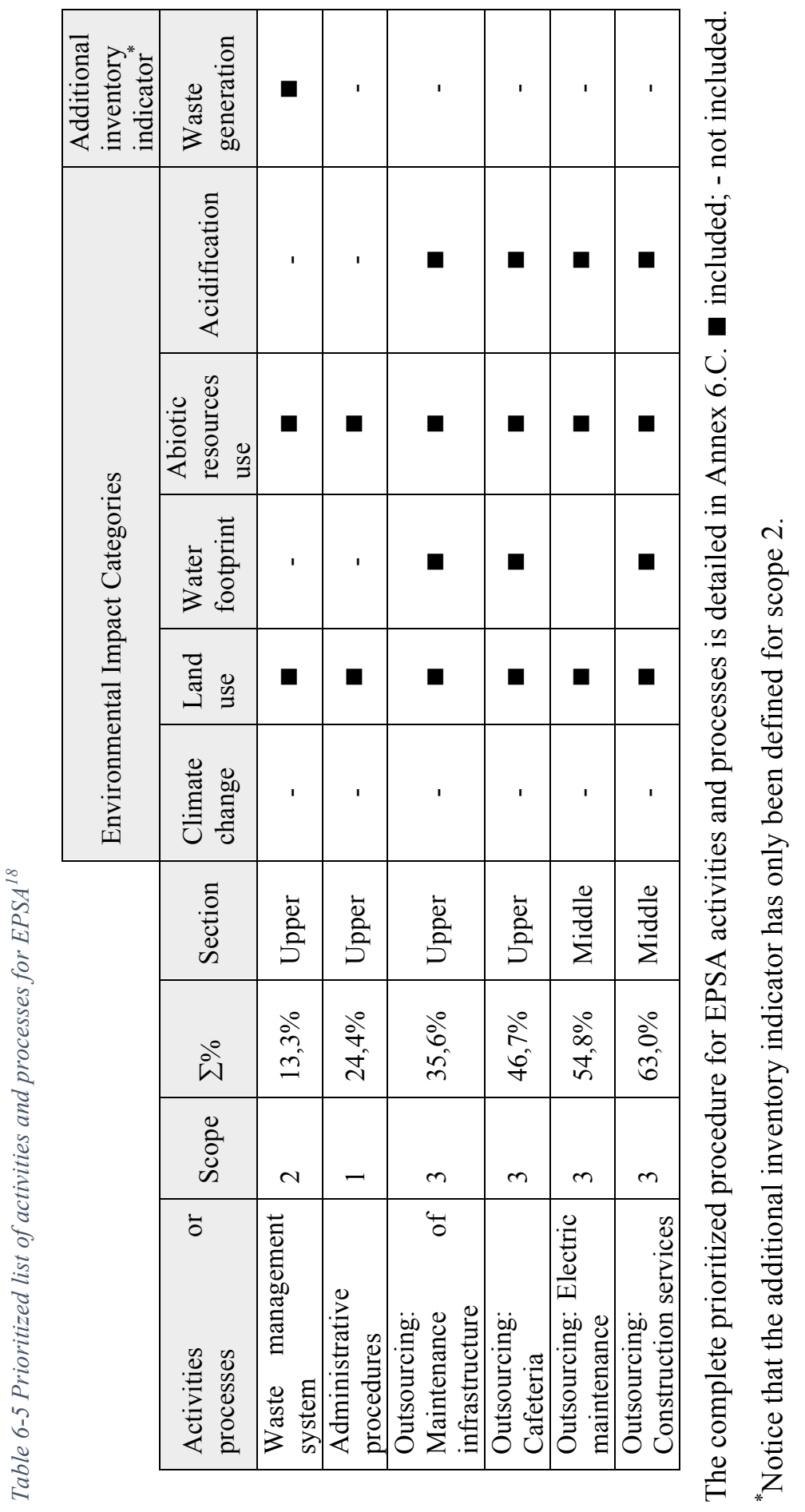

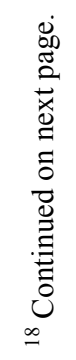




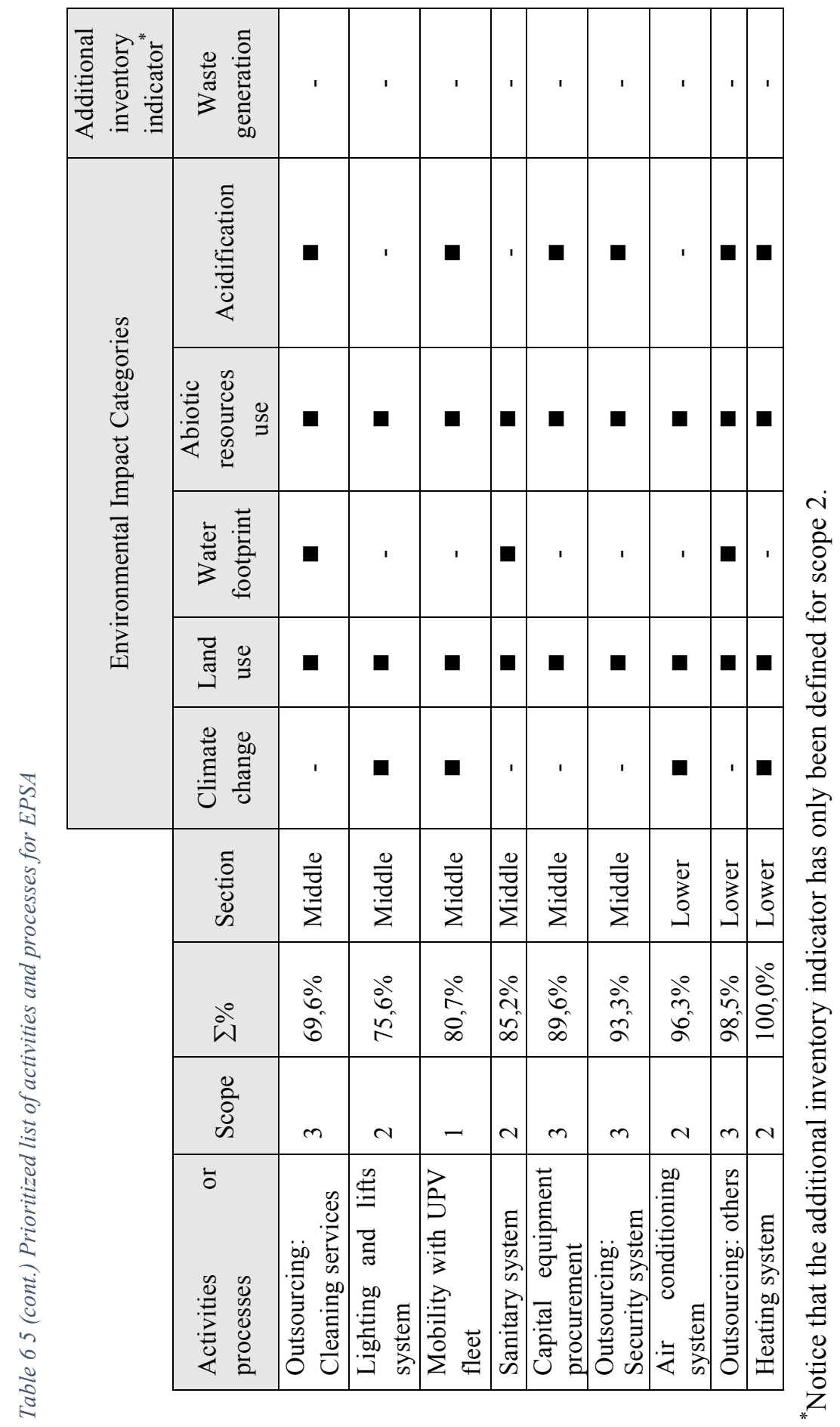


LCIA for the EPSA cannot be assessed without approaching structural modifications in the EMS and/or in the accounting system in obtaining quality data related to supplies. However, some quality data are available, allowing for the partial assessment of some categories. Furthermore, the additional inventory level indicator proposed, waste generated by waste type, is fully accessible as the monitoring of waste generation is a basic function of the EPSA EMS. In this section, the partial results obtained are presented. The implications of these results are discussed in the results interpretation section of this paper.

Table 6-6 shows the partial results for each impact category including a symbol code that identifies the scope of each assessment. Climate change was assessed completely for scopes 1 and 2, as the EMS gathers information on all direct and indirect emissions related to infrastructure. However, scope 3 could not be assessed. Part of the information required for this indicator was obtained from the accounting system, as it was not registered under the EMS, i.e., volume of fuel consumed by the EPSA fleet. The use of land was only fully assessed under scope 1 (direct); scopes 2 and 3 present no information. Acidification and water footprints revealed a similar outcome while abiotic resource use could not be assessed due to a lack of data. This category is directly linked to supplies, technology assets, movable assets and office supply inputs, which the EPSA EMS only monitors qualitatively; quantitative data included in the accounting system are not detailed enough.

Table 6-6 Partial LCIA results for EPSA

\begin{tabular}{|l|r|l|c|c|c|}
\hline Impact Categories & \multicolumn{1}{|c|}{ value } & unit & Scope 1 & Scope 2 & Scope 3 \\
\hline Climate change & 677.90 & $\mathrm{t} \mathrm{CO}_{2} \mathrm{e}$ & $\mathbf{\square}$ & $\mathbf{0}$ & $\square$ \\
\hline Land use & 2.87 & $\mathrm{ha}$ & $\mathbf{\square}$ & - & - \\
\hline Water footprint & 6661 & $\mathrm{~m} 3$ & $\mathbf{\square}$ & - & - \\
\hline Abiotic resources use & - & - & - & - & - \\
\hline Acidification & 0.17 & $\mathrm{t} \mathrm{SO}_{2} \mathrm{e}$ & $\mathbf{\square}$ & - & - \\
\hline
\end{tabular}

- assessed; $\square$ assessed partially; - not assessed;

Figure 6-7 shows the additional inventory indicator and waste generation patterns by waste type defined only for scope 2 . The information required for this indicator was obtained directly from the EMS. 


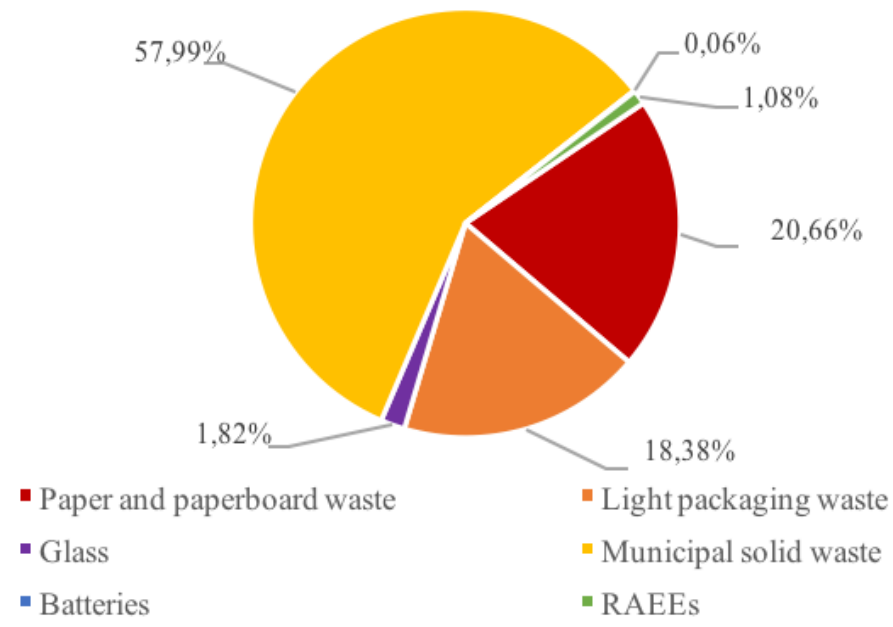

Figure 6-7 Results of the waste generation by type of waste inventory indicator for EPSA

\subsubsection{EPSA RESULTS INTERPRETATION}

Without a complete LCIA, result interpretation can be only partially discussed.

Even though the scopes of some of the impact category indicators are assessed in full, i.e., climate change for scopes 1 and 2, the EMS offers limited information on the allocation of certain flows; therefore, a more comprehensive analysis was not possible.

The additional inventory indicator defined shows that the main type of waste generated is municipal solid waste, representing almost a $60 \%$ of all waste generated. The generation of RAEEs, batteries and glass is almost insignificant according this analysis. However, the environmental impacts of at least two of these types of waste may be high. As already established, the role of this indicator is only informative.

It is interesting to note that the EMAS EMS does require the development of a communication plan. UPV creates yearly environmental reports and supports various environmental training and awareness actions in its regular activities for all of its EUs that can serve as communication platforms for O-LCA results.

Regarding the suitability of the EMAS as a framework for an O-LCA, the hypothesis of this research was founded on the experience of EMAS application at UPV and on its capacity to provide relevant and accurate environmental information for assessments and indicators. A comparison between O-LCA and EMAS requirements (Annex 6.A) and previous studies on LCA standards 
suggests that the EMAS might provide valuable information and a strong framework for addressing an EPSA O-LCA. The goal of this study was to explore these possibilities through the development of an O-LCA methodology that considers HEI characteristics.

The methodology presented based on an EMAS EMS considers suggested definitions and procedures for addressing key O-LCA characteristics. However, the EMAS could not provide all quality data needed to carry out our pilot O-LCA of UPV EPSA EUs. Structural modifications are needed to identify information on certain relevant activities of the EPSA (e.g., environmental data related to supplies).

The authors believe that the EMS is capable of managing the information needed but that new procedures are required to obtain such information. Furthermore, the compromising of personnel beyond EMS operators and third parties would be involved.

\subsection{CONCLUSIONS AND FURTHER RESEARCH}

In this study, the suitability of O-LCA for HEIs employing EMSs has been assessed. A methodological proposal that highlights links between the analysis and an organization's EMS is presented.

The structure of EUs defined under the EMAS proved to form a clear and useful reporting organization unit. Advice on the integration of O-LCAs of different EUs was solicited to avoid double counting mistakes. However, O-LCA development for an EU appears to be a good approach to the O-LCA of HEIs as a whole with identified barriers noted. Moreover, once the first O-LCA for the EPSA is conducted, conditions and weaknesses involved in scaling the assessment to all 211 EUs of UPV should come to light and an O-LCA of UPV as a whole might become easier to conduct as a sum of O-LCAs of EU results with special attention to the prevention of double counting mistakes. The proposed procedure should be valid for all HEIs divided into EUs with similar characteristics. Further research should be carried out in this direction.

The number of equivalent students has been recommended as a reporting flow and an upgraded prioritization procedure has been developed. The procedure considers both the quantitative relevance of EAs and EU control over related activities or processes. The methodology aims to highlight those subjects of study to be assessed in detail.

The option to freely choose consolidation methods creates enough flexibility to define a reporting organization, and this in turn allows for synergies between $\mathrm{O}$ LCA and a reliable EMS when implemented. When the reporting organization is clearly defined, risks of double counting or EA omission are low, as system 
boundaries and limits are defined in accordance with EU structures that compose HEIs. The O-LCA approach is thus applicable to HEIs, and the EMS serves as a strong tool for defining the goals and scopes LCIs.

However, using an EMS verified under the EMAS does not ensure the availability of data required, e.g., office supply data for some EPSA flows, and thus does not ensure successful LCIA development. The LCIA has only been assessed in part with little interest to consequences of a lack of access to quality data.

The inclusion of quantitative information on EMS flows is not a lost cause. Nevertheless, significant resources - both human and economic - are needed to centralize detailed information on these flows. This barrier reveals a management weak point that must be considered (particularly for the pilot organization, the EPSA): the accounting system must be updated to be able to provide more accurate and detailed information on procurements and if possible in material units $(\mathrm{kg}, \mathrm{kW}$, etc.) rather than monetary units, which add uncertainty. Another weak point pertains to the flexibility of the organizational chart used, as some activities and processes can change in terms of control approaches, e.g., processes developed through an outsourcing contract could be transferred to an internal area (e.g., cleaning services could become part of the infrastructural affairs subdirection). In this case, clearly reporting such changes in the next iteration of the O-LCA should be sufficient for a correct interpretation of results.

Overall, both tools, the EMAS and O-LCA, are based on the same principles: performance, transparency and credibility. Although running an EMS verified according to the EMAS does not ensure the successful performance of an O-LCA, it can provide an HEI with a solid framework for easily addressing required changes as long as such a project has the support of the responsible HEI.

\subsection{REFERENCES}

Braunschweig A. (2014) GHG-balances and LCA: Applying the concept of scopes in organisational LCAs. E2 Management Consulting. Retrieved on July $1^{\text {st }} 2016$ from http://www.e2mc.com/

Clift R., Wright L. (2000) Relationships between environmental impacts and added value along the supply chain. Technological Forecasting and Social Change, 65(3), 281-295. http://doi.org/ 10.1016/S0040$\underline{1625(99) 00055-4}$

Cortese, A. D. (2003) The critical role of higher education in creating a sustainable future. Planning for higher education. Retrieved on June $1^{\text {st }} 2016$ from http://www.aashe.org/documents/resources/pdf/Cortese_PHE.pdf

Curran, M.A. (Ed.) (2017) Goal and Scope Definition in Life Cycle Assessment. Springer. http://doi.org/10.1007/978-94-024-0855-3 
Disterheft, A., da Silva Caeiro, S.S.F., Ramos, M.R. and de Miranda Azeiteiro, U.M. (2012) 'Environmental management systems (EMS) implementation processes and practices in European higher education institutions - top-down versus participatory approaches', Journal of Cleaner Production, 31, 80-90. http://doi.org/ 10.1016/j.jclepro.2012.02.034

Draucker, L. (2013). GHG Protocol: moving Corporate Accounting Beyond GHGs. Abstract Book: SETAC North American 34th Annual Meeting, Nashville, USA.

European Commission (2009) No, R.;1221/2009 of the European Parliament and of the Council of 25 November 2009 on the Voluntary Participation by Organisations in a Community Eco-management and Audit Scheme (EMAS), Repealing Regulation (EC) No 761/2001 and Commission Decisions 2001/681/EC and 2006/193 Retrieved on December $16^{\text {th }} 2012$ from

http://eur-lex.europa.eu/ LexUriServ/LexUriServ.do?uri=OJ:L:2009:342:0001:01:EN:HTML

European Commission (2016a) European Commission Environment. EcoManagement and Audit Scheme. Retrieved on June $1^{\text {st }} 2016$ from http://ec.europa.eu/environment/emas/

Finkbeiner, M., Wiedemann, M., \& Saur, K. (1998) A comprehensive approach towards product and organisation related environmental management tools. The International Journal of Life Cycle Assessment, 3(3), 169-178. http://doi.org/10.1007/BF02978825

Fleischer, G., Gerner, K., Kunst, H., Lichtenvort, K., Rebitzer, G., (2001) A semiquantitative method for the impact assessment of emissions within a simplified life cycle assessment. The International Journal of Life Cycle Assessment, 6(3), 149-156. http://doi.org/10.1007/BF02978733

Global Reporting Initiative (2005) GRI Boundary Protocol. Global Reporting Initiative. Retrieved on March $1^{\text {st }} 2016$ from https://www.globalreporting.org/resourcelibrary/GRI-BoundaryProtocol.pdf

Hauschild, M.Z., and Huijbregts, M.A. (2015) Introducing Life Cycle Impact Assessment. Chapter 1. Springer Science+Business Media Dordrecht 2015 M.Z. Hauschild, M.A.J. Huijbregts (eds.), Life Cycle Impact Assessment, LCA Compendium - The Complete World of Life Cycle Assessment http://doi.org/10.1007/978-94-017-9744-3 1 
Hellweg S., Milà i Canals L. (2014) Emerging approaches, challenges and opportunities in life cycle assessment. Science, 344(6188), 1109-1113. http://doi.org/10.1126/science.1248361

Hochschorner, E., and Finnveden, G. (2003) Evaluation of two simplified life cycle assessment methods. The International Journal of Life Cycle Assessment, 8(3), 119-128. http://doi.org/10.1007/BF02978456

Huang Y.A., Lenzen M., Weber C.L., Murray J., Matthews H.S. (2009) The role of input-output analysis for the screening of corporate carbon footprints. Economic Systems Research, 21(3), 217-242. http://doi.org/10.1080/09535310903541348

International Organization for Standardization (2004) Environmental management systems -Requirements with guidance for use ISO 14001: 2004. Geneva, Switzerland: International Organization for Standardization.

International Organization for Standardization (2006a) Environmental management - life cycle assessment - principles and framework. ISO 14040:2006.

International Organization for Standardization (2006b) Environmental management - life cycle assessment - requirements and guidelines. ISO 14044:2006(E).

International Organization for Standardization (2014a) ISO/TS 14072: Environmental management - Life cycle assessment — Requirements and guidelines for Organizational Life Cycle Assessment. Geneva, Switzerland: International Organization for Standardization.

Jolliet, O., Frischknecht, R., Bare, J., Boulay, A. M., Bulle, C., Fantke, P., Weisbrod, A. (2014) Global guidance on environmental life cycle impact assessment indicators: Findings of the scoping phase. The International Journal of Life Cycle Assessment, 19(4), 962-967. http://doi.org/1007/s11367-014-0703

Lave, L.B., Cobas-Flores, E., Hendrickson, C.T., McMichael, F.C. (1995) Using input-output analysis to estimate economy-wide discharges. Environmental Science and Technology, 29(9) 420-426 http://doi.org/ $\underline{10.1021 / \mathrm{es} 00009 \mathrm{a} 003}$ 
Lo-Iacono-Ferreira, V.G. Torregrosa-López, J.I Lora-García, J., Bastante-Ceca, M.J. \& Capuz-Rizo, S. F. (2011b) Study of the inclusion of life cycle assessment impact categories in ecological footprint calculation. XV International Congress of Project Engineering. Huesca. AEIPRO ISBN: 978-84-615-4543-8

http://www.aeipro.com/aplic/tree congresos/detalle remository aeipro. php?file $=3329$

Lo-Iacono-Ferreira, V.G., Capuz-Rizo, S.F., Torregrosa-López, J.I. (2016a) Ecological Footprint Assessment of Higher Education applying Life Cycle Assessment framework. Case study: Universitat Politència de València. XX International Congress on Project Management and Engineering. Cartagena. 1423-1432. ISBN: 978-84-617-4180-9 http://www.aeipro.com/aplic/tree congresos/detalle remository aeipro. php?file $=4636$

Lo-Iacono-Ferreira, V.G., Torregrosa-López, J.I., Capuz-Rizo, S.F., (2016b) Applicability of global reporting initiative to assess the environmental performance of higher education institutions. XX International Congress on Project Management and Engineering. Cartagena. 1433-1444. ISBN: 978-84-617-4180-9

http://www.aeipro.com/aplic/tree congresos/detalle remository aeipro. php?file $=4637$

Lo-Iacono-Ferreira, V.G., Torregrosa-López, J.I., \& Capuz-Rizo, S.F. (2016c) Use of Life Cycle Assessment methodology in the analysis of Ecological Footprint Assessment results to evaluate the environmental performance of universities. Journal of Cleaner Production, 133, 43-53. http://doi.org/10.1016/j.jclepro.2016.05.046

Lozano García, F.J., Kevany, K. and Huisingh, D. (2006) Sustainability in higher education: what is happening?, Journal of Cleaner Production, 14(9), 757-760. http://dx.doi.org/10.1016/j.jclepro.2005.12.006

Lozano, R. (2011) The state of sustainability reporting in universities, International Journal of Sustainability in Higher Education, 12(1), 6778. http://doi.org/10.1108/14676371111098311

Manzardo, A., Loss, A., Mazzi, A., Scipioni, A. (2016) Organizational Life-Cycle Assessment (OLCA): Methodological Issues and Case Studies in the Beverage-Packaging Sector. Environmental Footprints of Packaging. Springer. http://doi.org/10.1007/978-981-287-913-4 
Martínez-Blanco, J., Inaba, A., and Finkbeiner, M. (2015b) Halfway point in the flagship project LCA of organizations by UNEP/SETAC Life Cycle Initiative. The International Journal of Life Cycle Assessment, Japan 11(2), 97-103. April 2015.

Martínez-Blanco, J., Inaba, A., Quiros, A., Valdivia, S., Milà-i-Canals, L., and Finkbeiner, M. (2015a) Organizational LCA: the new member of the LCA family - introducing the UNEP/SETAC Life Cycle Initiative guidance document. The International Journal of Life Cycle Assessment, 10-12. http://doi.org/10.1007/s11367-015-0912-9

Martínez-Blanco, J., Inaba, A., and Finkbeiner, M. (2015c) Scoping organizational LCA - challenges and solutions. The International Journal of Life Cycle Assessment 20(6), 829-841. http://doi.org/10.1007/s11367-015-0883-x

Pelletier N., Allacker K., Pant R., Manfredi S. (2013) The European Commission Organisation Environmental Footprint method: comparison with other methods, and rationales for key requirements. The International Journal of Life Cycle Assessment, 19(2), 387-404. http://doi:10.1007/s11367013-0609-x

Resta, B., Gaiardelli, P., Pinto, R., \& Dotti, S. (2016) Enhancing environmental management in the textile sector: An Organisational-Life Cycle Assessment approach. Journal of Cleaner Production, 135, 620-632 http://doi.org/10.1016/j.jclepro.2016.06.135

Taylor A.P., Postlethwaite D. (1996) Overall Business Impact Assessment (OBIA). In Proceedings of the 4th SETAC Case Study Symposium, Brussels, Belgium. Brussels: SETAC. 181-187

Tlapa, D. A., Limón, J., \& Báez, Y. A. (2009) Quality and Environmental Management in Higher Education Institutes by Integrating ISO 9001 and ISO 14001. Formación Universitaria, 2(2), 35-46. http://doi.org/ $\underline{10.4067 / \mathrm{S} 0718-50062009000200006}$

Torregrosa-López, J. I., Lo Iacono-Ferreira, V. G., Barranco-Martí, C., \& BellverNavarro, C. G. (2016) The strengths of EMAS as an environmental management system for European university campuses. International Journal of Environment and Sustainable Development, 15(1), 89-106. http://dx.doi.org/10.1504/IJESD.2016.073339 
United Nations Environment Programme (2015) Guidance on Organizational Life Cycle Assessment. Life-Cycle Initiative, United Nations Environment Program and Society for Environmental Toxicology and Chemistry, Paris, France. Retrieved on June $1^{\text {st }} 2016$ from: http://www.lifecycleinitiative.org/wp- content/uploads/2015/04/olca 24.4.15-web.pdf

Vivancos Bono, J.L. (2005) Propuesta Metodológica para la Simplificación del ACV en su Aplicación a los Componentes Plásticos del Automóvil en el Marco del Ecodiseño. Ed. Universidad Politécnica de Valencia.

Watkins, P., and Glover, A. (2016) Future Generations: Developing Education for Sustainability and Global Citizenship for University Education Students. Teaching Education for Sustainable Development at University Level. Leal Filho, W., Pace, L. (ed) Springer International Publishing. Cham. 6781. http://doi.org/10.1007/978-3-319-32928-4 5

World Resources Institute and World Business Council for Sustainable Development (2011) Corporate Value Chain (Scope 3) Accounting and Reporting Standard - Supplement to the GHG Protocol Corporate Accounting and Reporting Standard. Retrieved on June $1^{\text {st }} 2016$ from http://www.ghgprotocol.org/files/ghgp/public/Corporate-Value-ChainAccounting-Reporing-Standard 041613.pdf 



\subsection{ANNEX 6.A COMPARISON BETWEEN ISO 14072:2014 AND EMAS REQUIREMENTS}

In this Annex, Table 6-7 is presented with a comparison of the most significant requirements of ISO 14072:2014 and EMAS. The table is organized under ISO structure represented in the first left columns.

It has to be notice that EMAS requirements laid down, but are not limited to, ISO 14001:2004. Every organization with an EMAS verification complies with the requirements of ISO 14001:2004 and must address a number of additional issues. Details can be found in Annex 1 of EMAS regulation 1221/2009 (European Commission 2009). As both tools, O-LCA and EMAS have a direct or indirect linkage with ISO 14000 family standard, it is foreseeable that they have certain elements in common.

A color code is used to identify different type of information regarding EMAS column. Regarding ISO 14072:2014 column, all highlights are literally extracted from the requirements or the official guide.

- White background, normal: text literally extracted from requirements and valid both for ISO 14001:2004 and EMAS.

- White background, bold: text literally extracted from requirements only applicable for EMAS.

- Grey background, bold: not explicitly defined concept but implicit in EMAS operation.

- Grey background, normal: not explicitly defined concept. It might be partially implicit in EMAS operations. If so, it is described. 


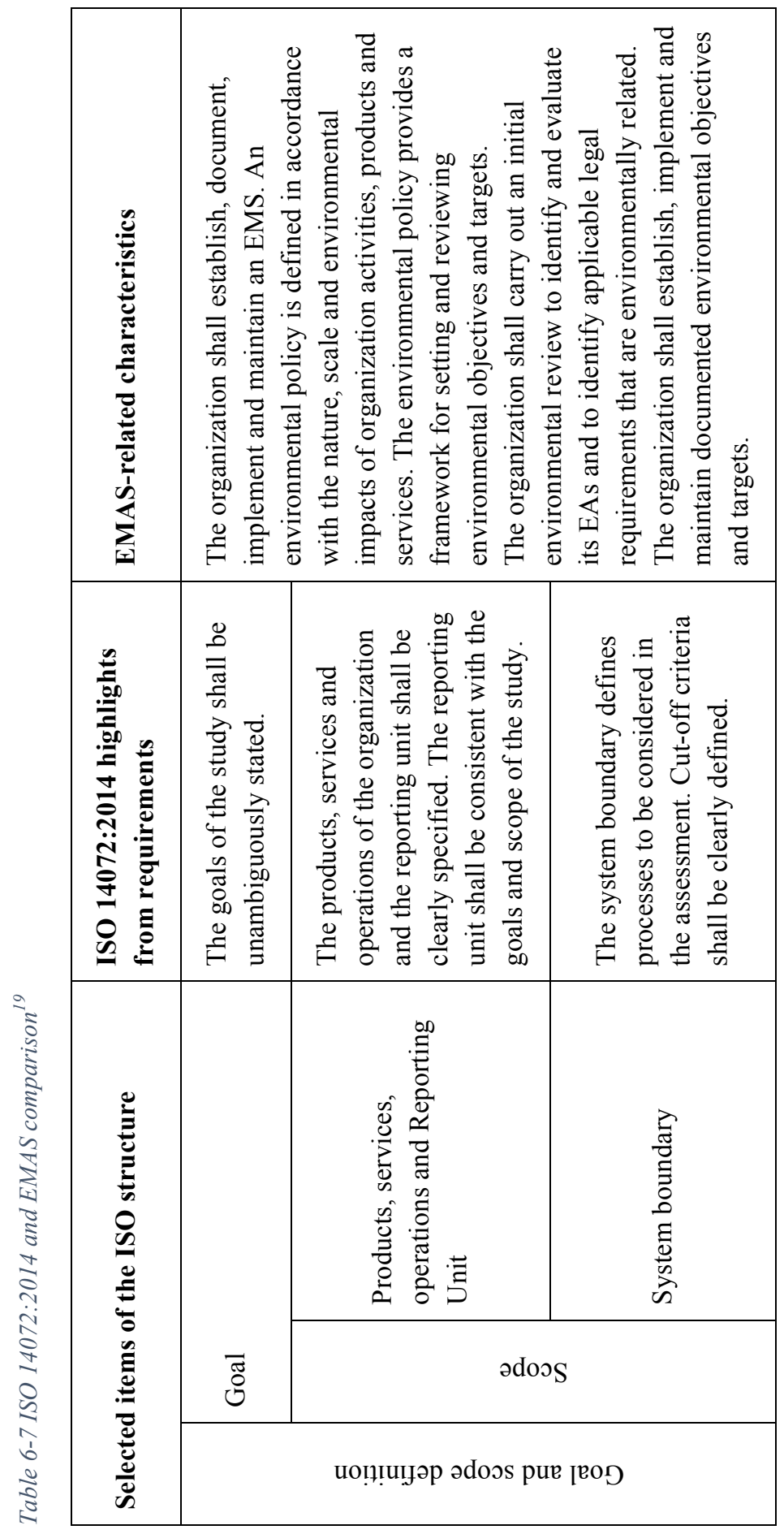

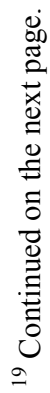




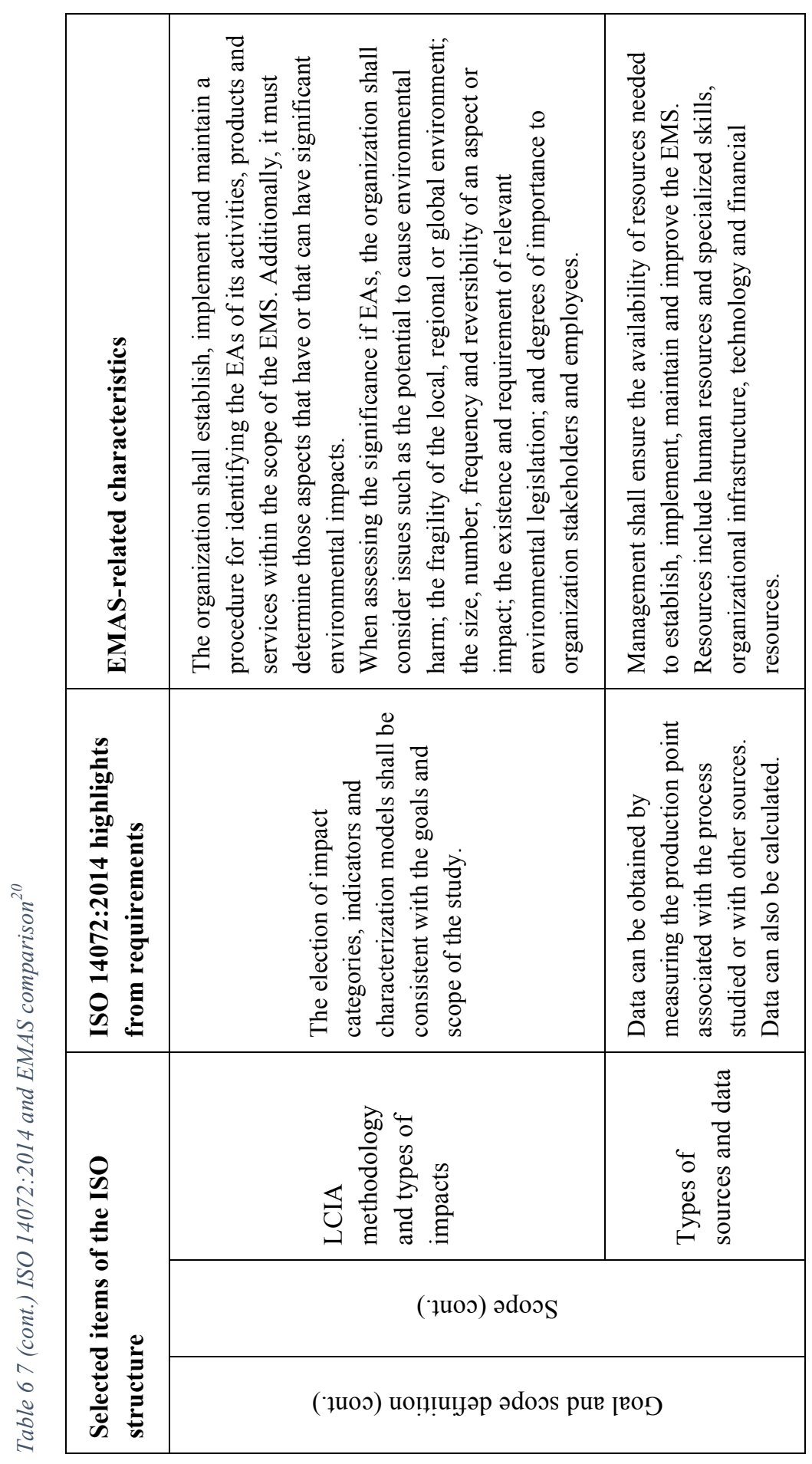

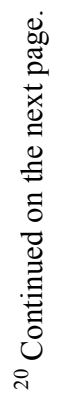




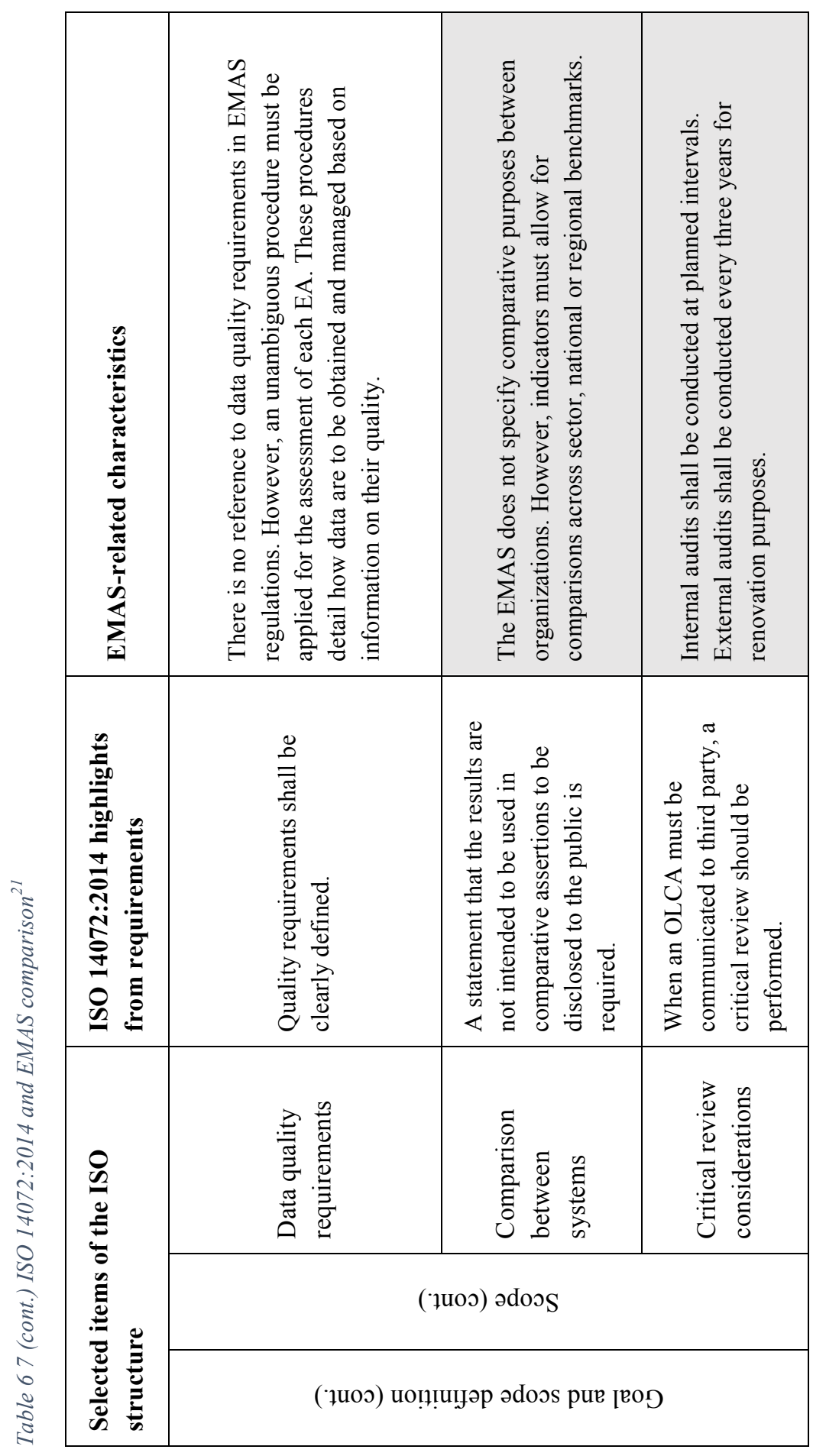

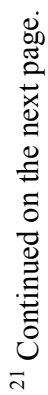



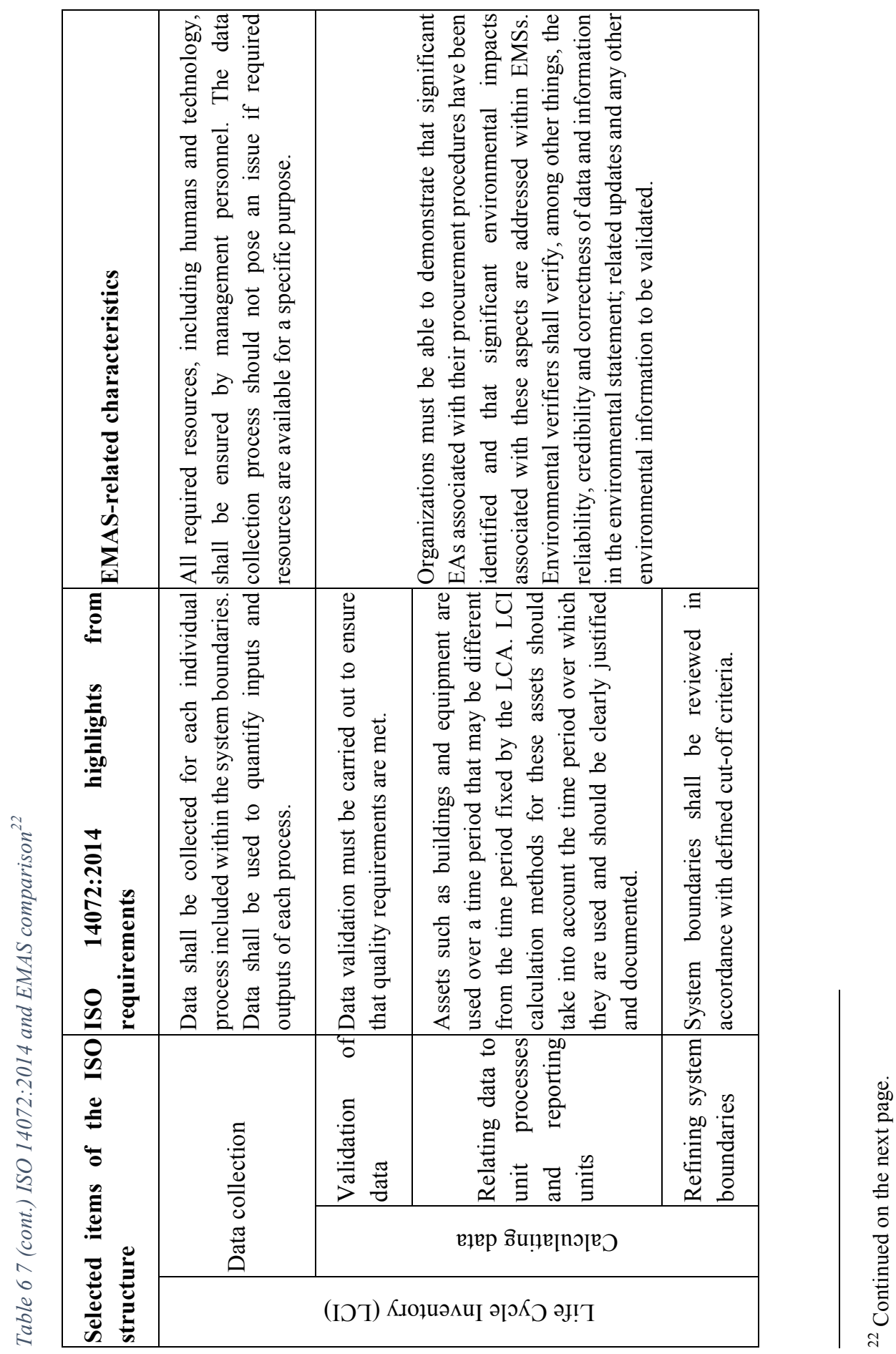

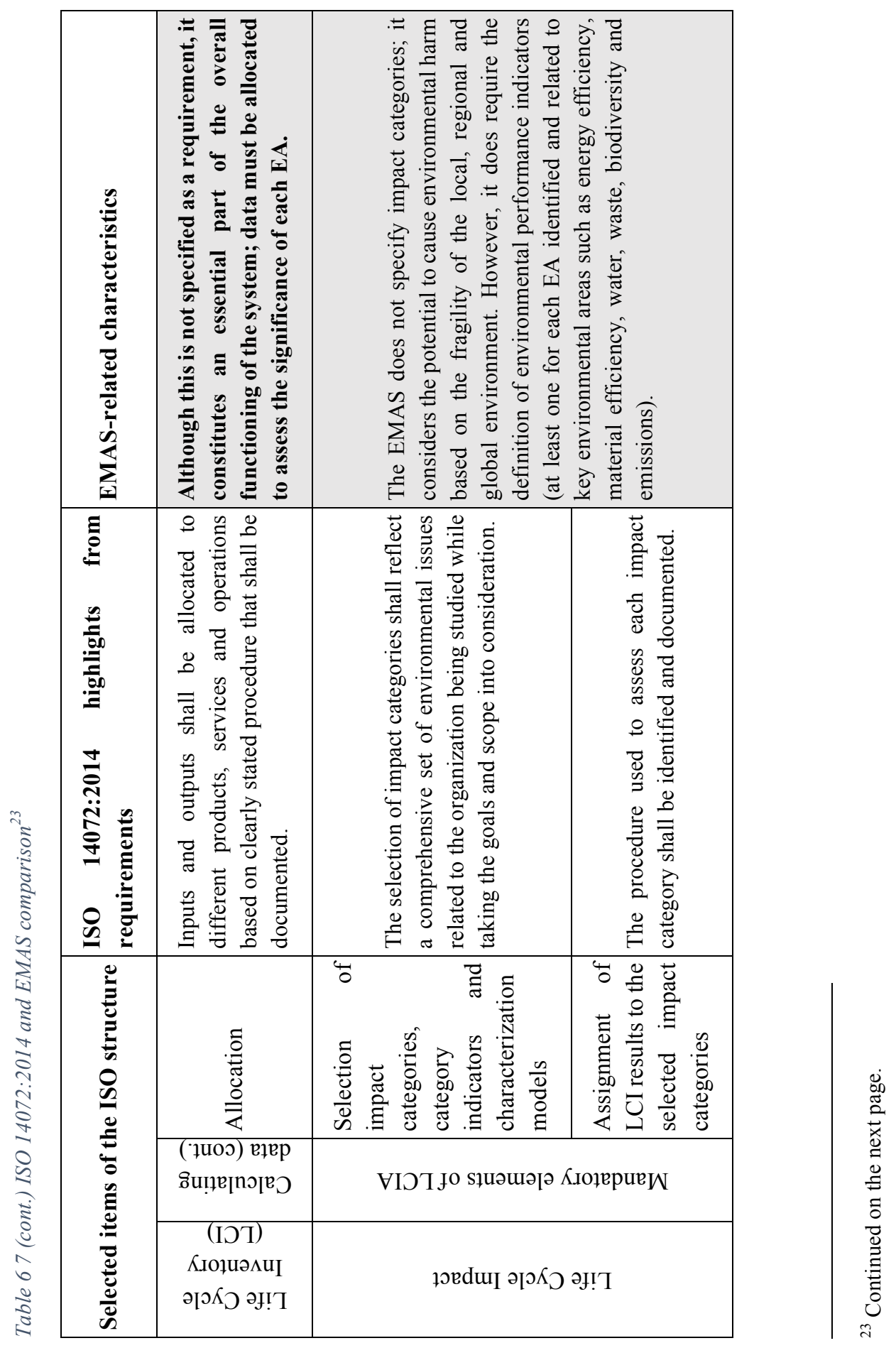

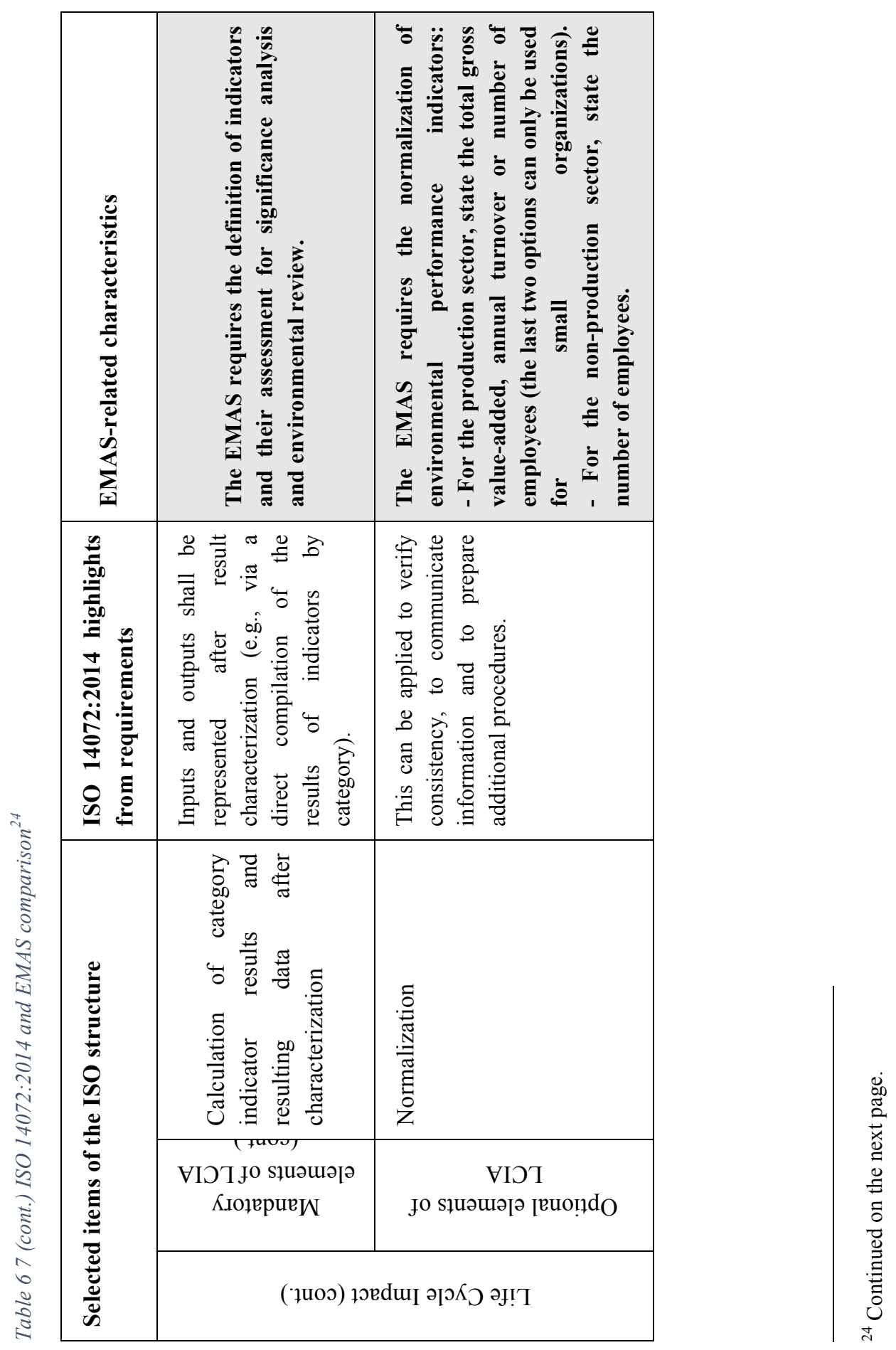


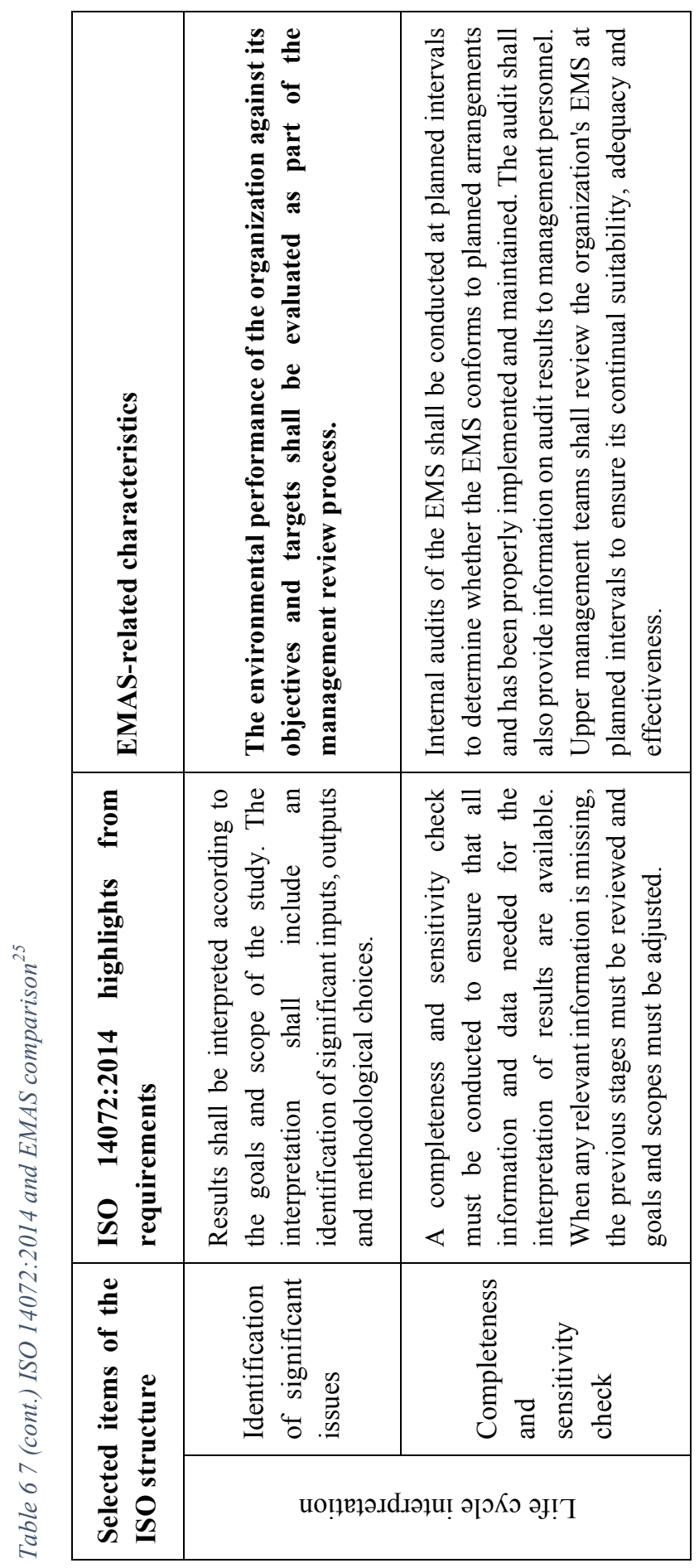

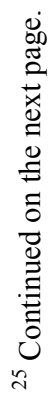




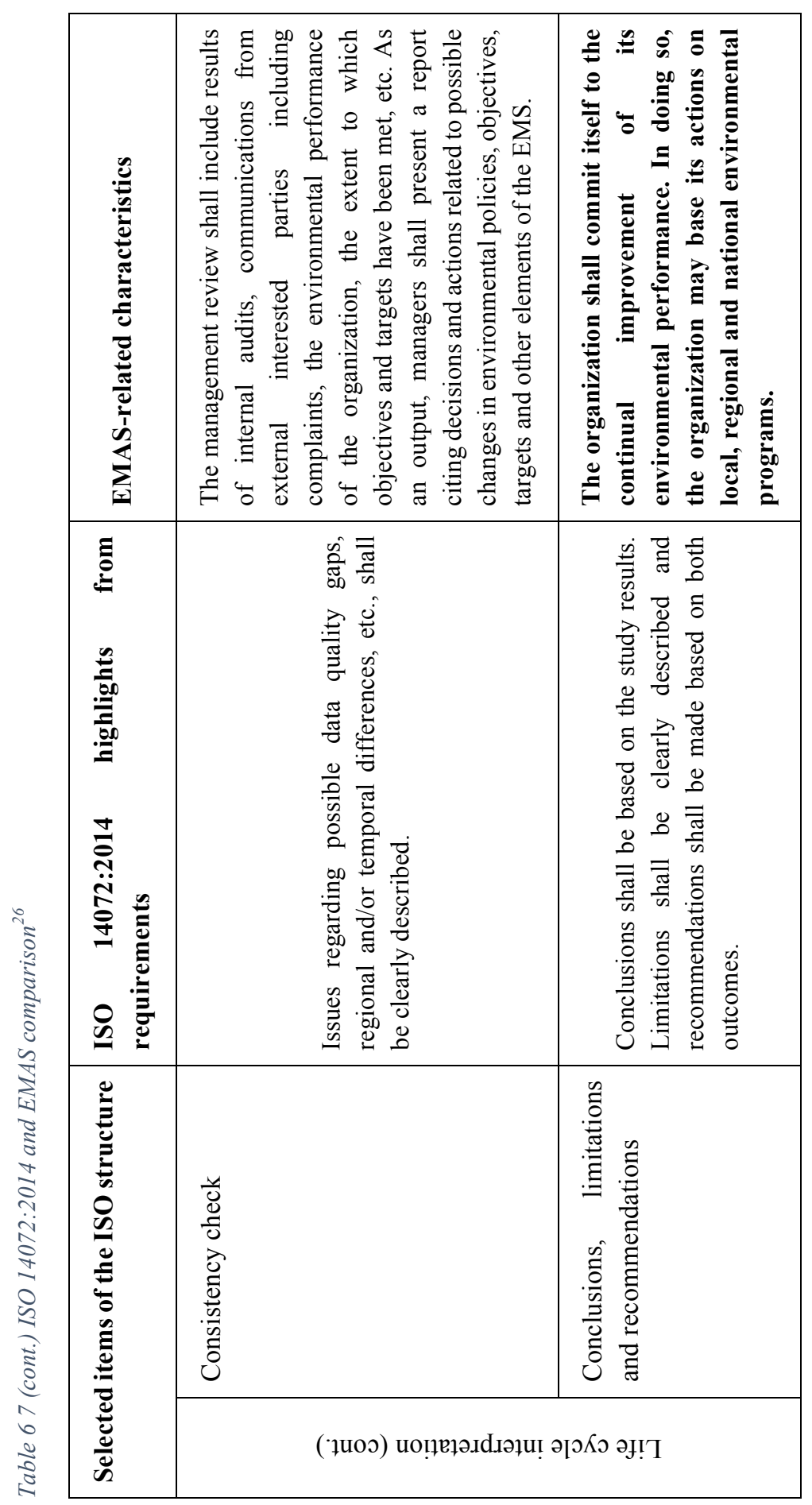

0
0
0
0
0
0
0
0
0
$\Xi$
0
0
0
0
.$\Xi$
.0
0
0
0 


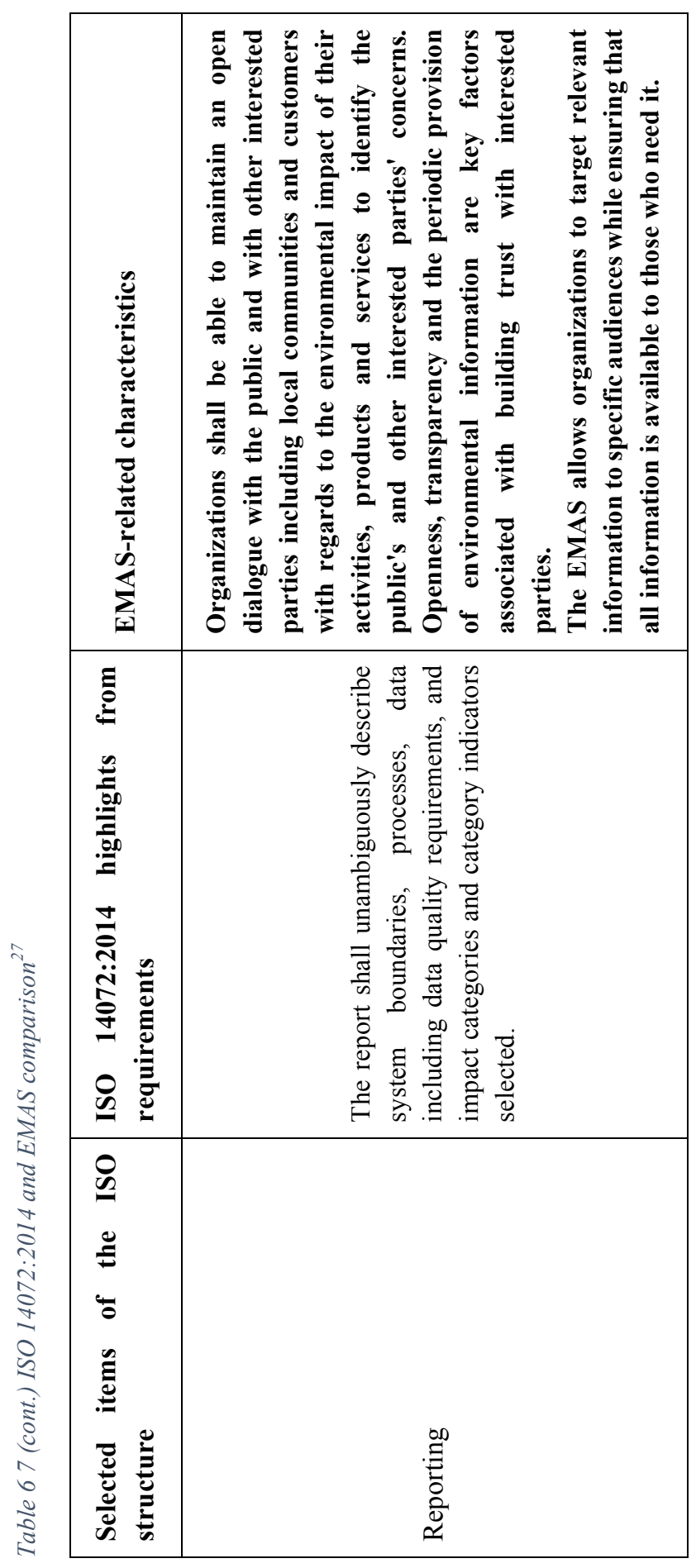

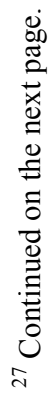




\subsection{ANNEX 6.B EPSA AND UPV DETAILS FOR 2015}

Organization: Universitat Politècnica de València.

CIF: Q4618002B

NACE: 85.42 (tertiary education)

Total staff members: 7,887

Total students: 38,486

Total building surface: $694,169 \mathrm{~m}^{2}$

Total landscaped area: $128,517 \mathrm{~m}^{2}$

Number of environmental units: 211 (see Table 6-8 for more details).

Environmental Unit assessed: Escuela Politécnica Superior de Alcoy (EPSA)

Address: Plaza Ferrándiz y Carbonell 1. (03801 Alcoy) Spain

Staff members: 300

Students: 2,494

Building surface: $28,717 \mathrm{~m}^{2}$

Landscaped area: $1,270 \mathrm{~m}^{2}$

Table 6-8 Environmental units of UPV

\begin{tabular}{ll} 
Type & Units \\
\hline Faculties & 14 \\
Departments & 44 \\
Research institutes & 35 \\
Services & 91 \\
Third party facilities & 27 \\
Total & $\mathbf{2 1 1}$ \\
\hline
\end{tabular}

Data source: Environmental Management System Report 2015. Internal use only. Available under requirement. Code: UPV.MA-INF.RSGA.2015-UPV-01 

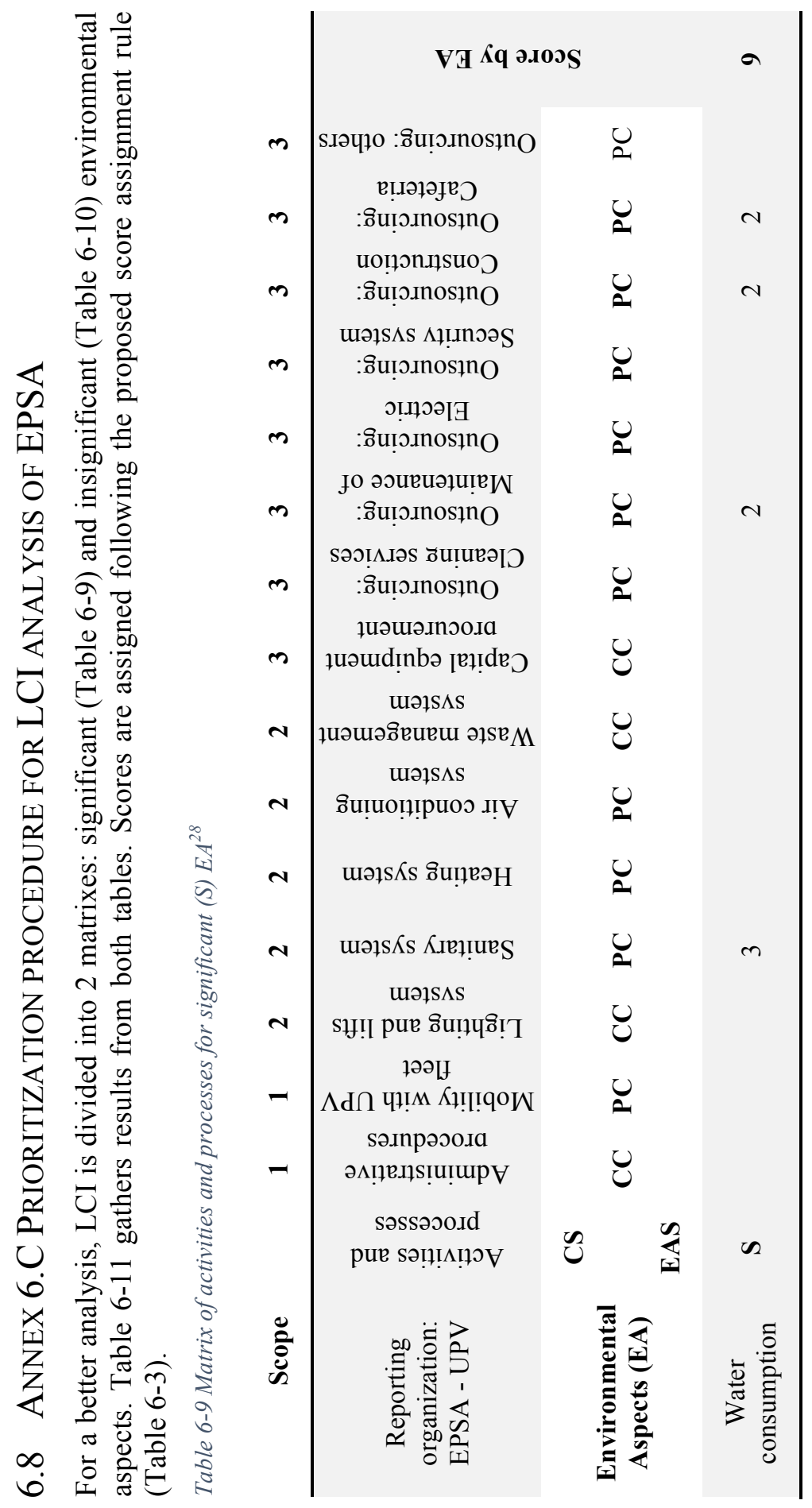

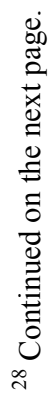




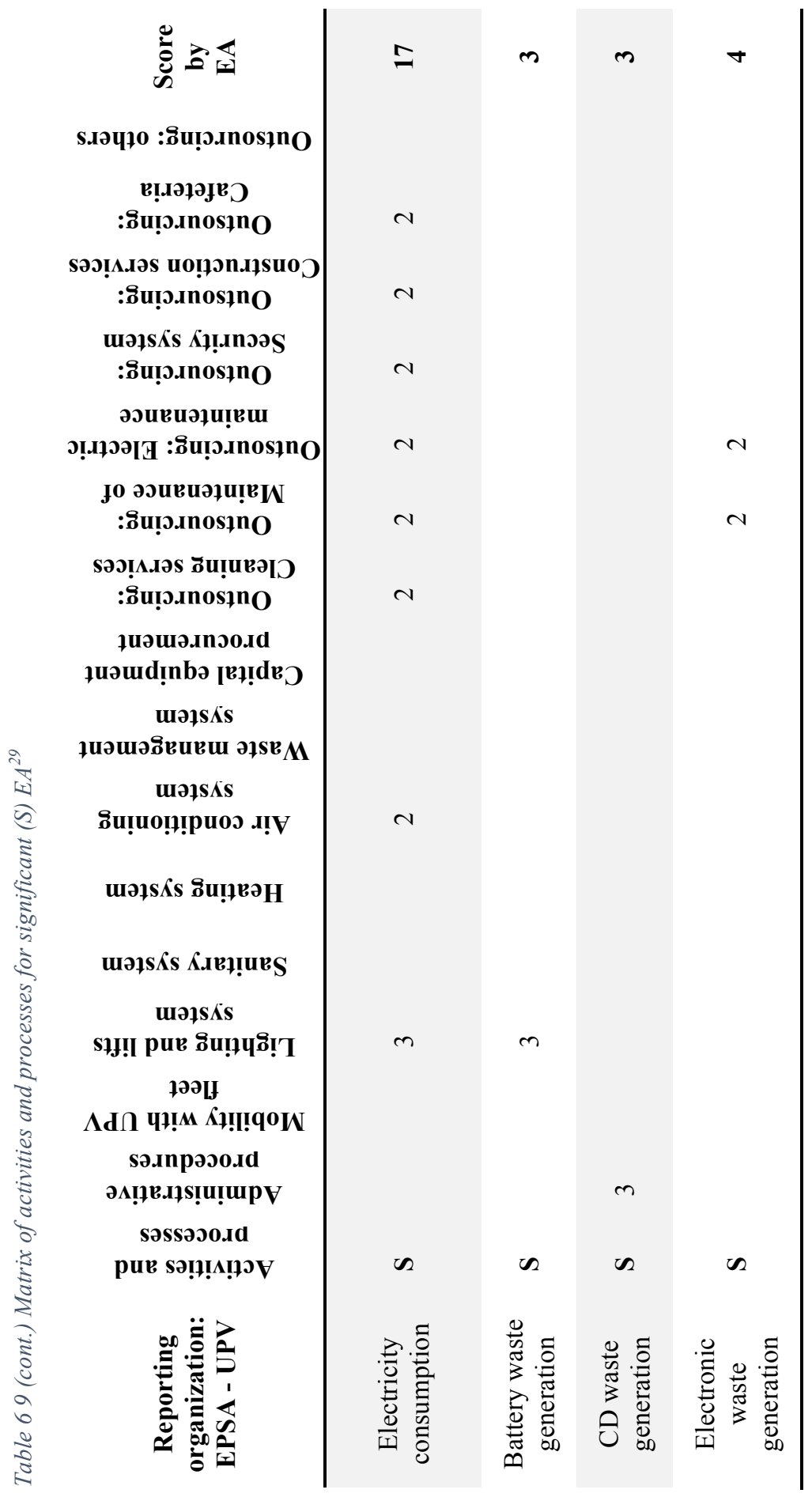




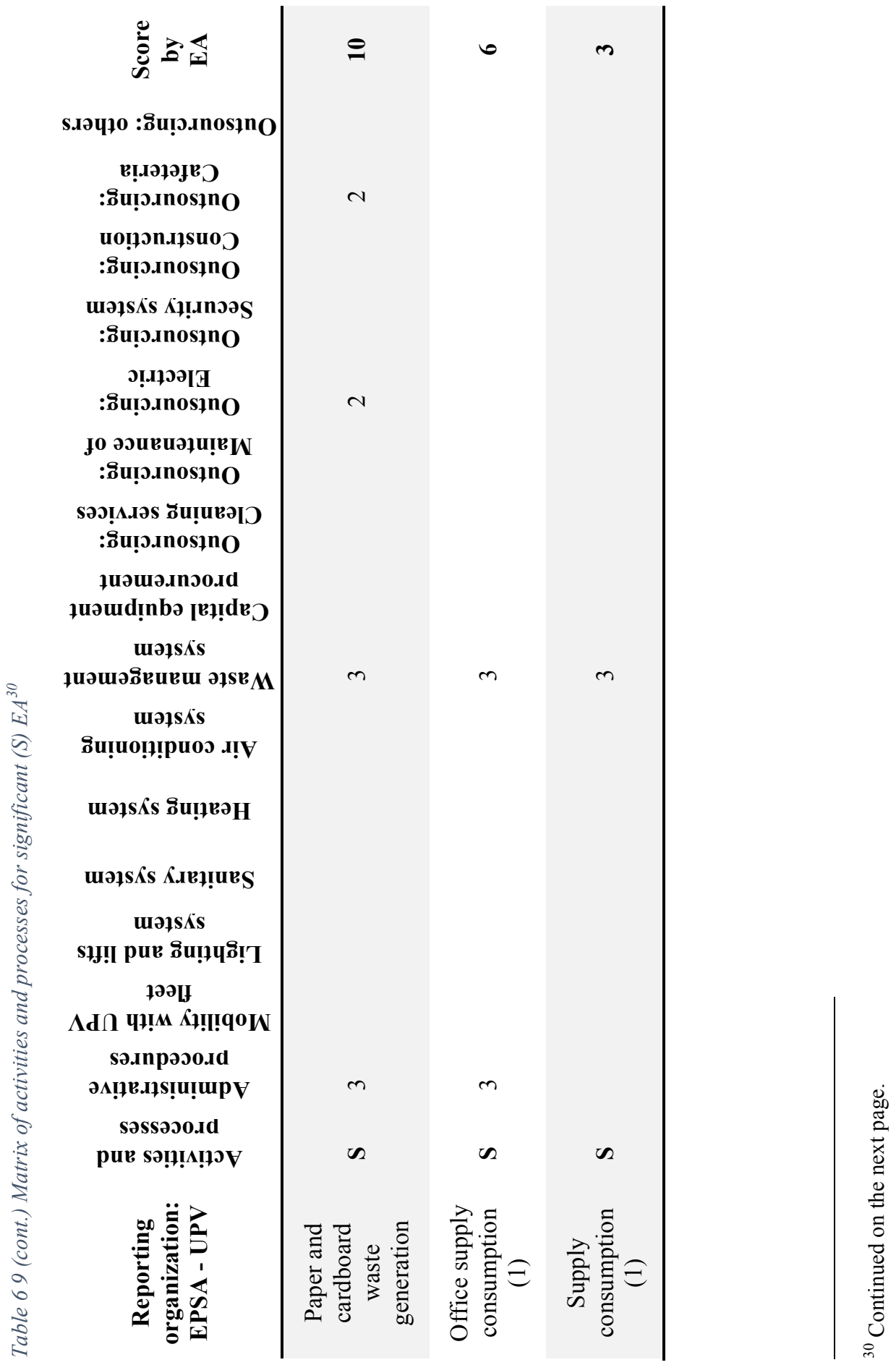




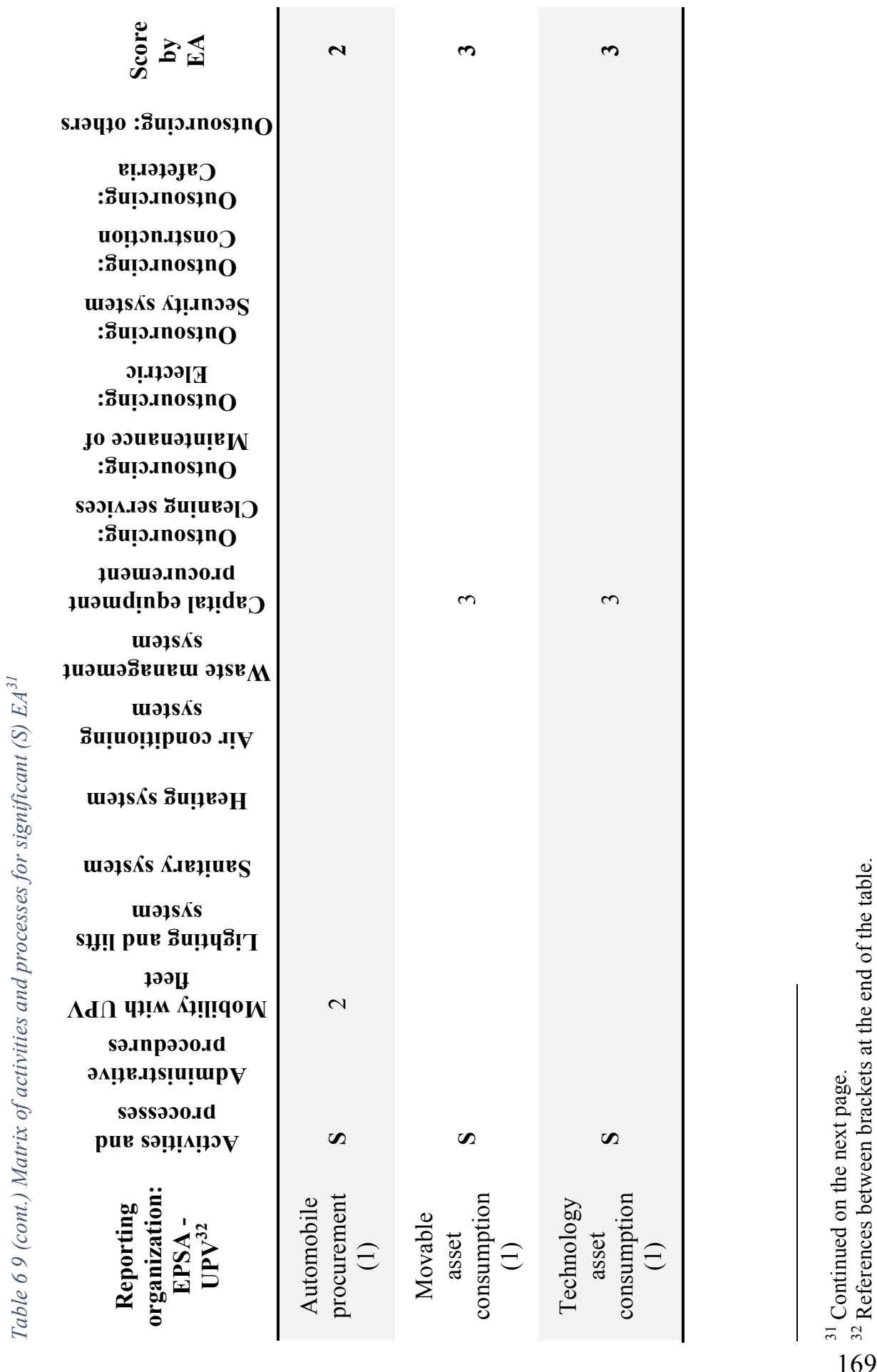




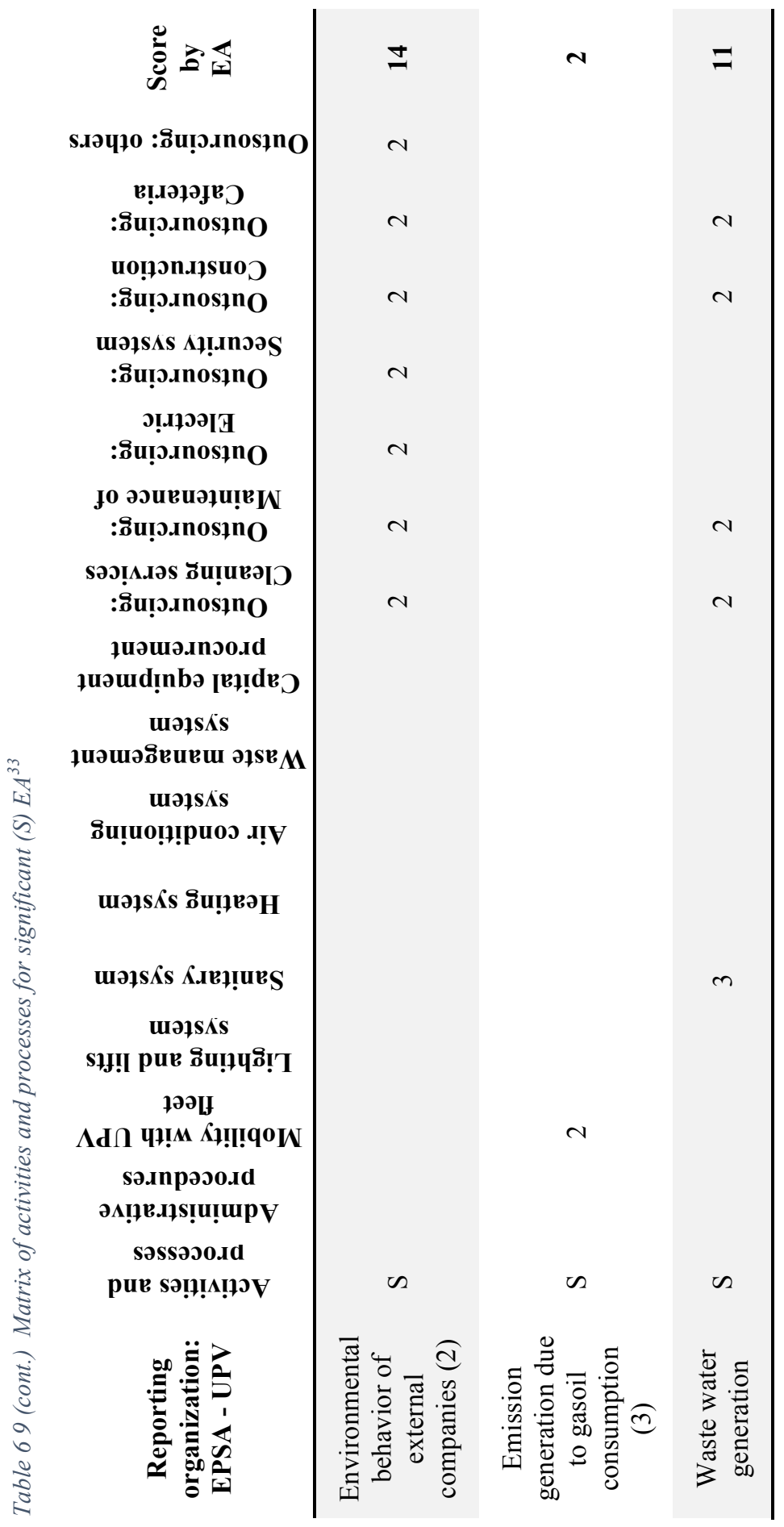

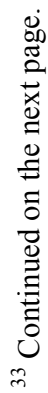




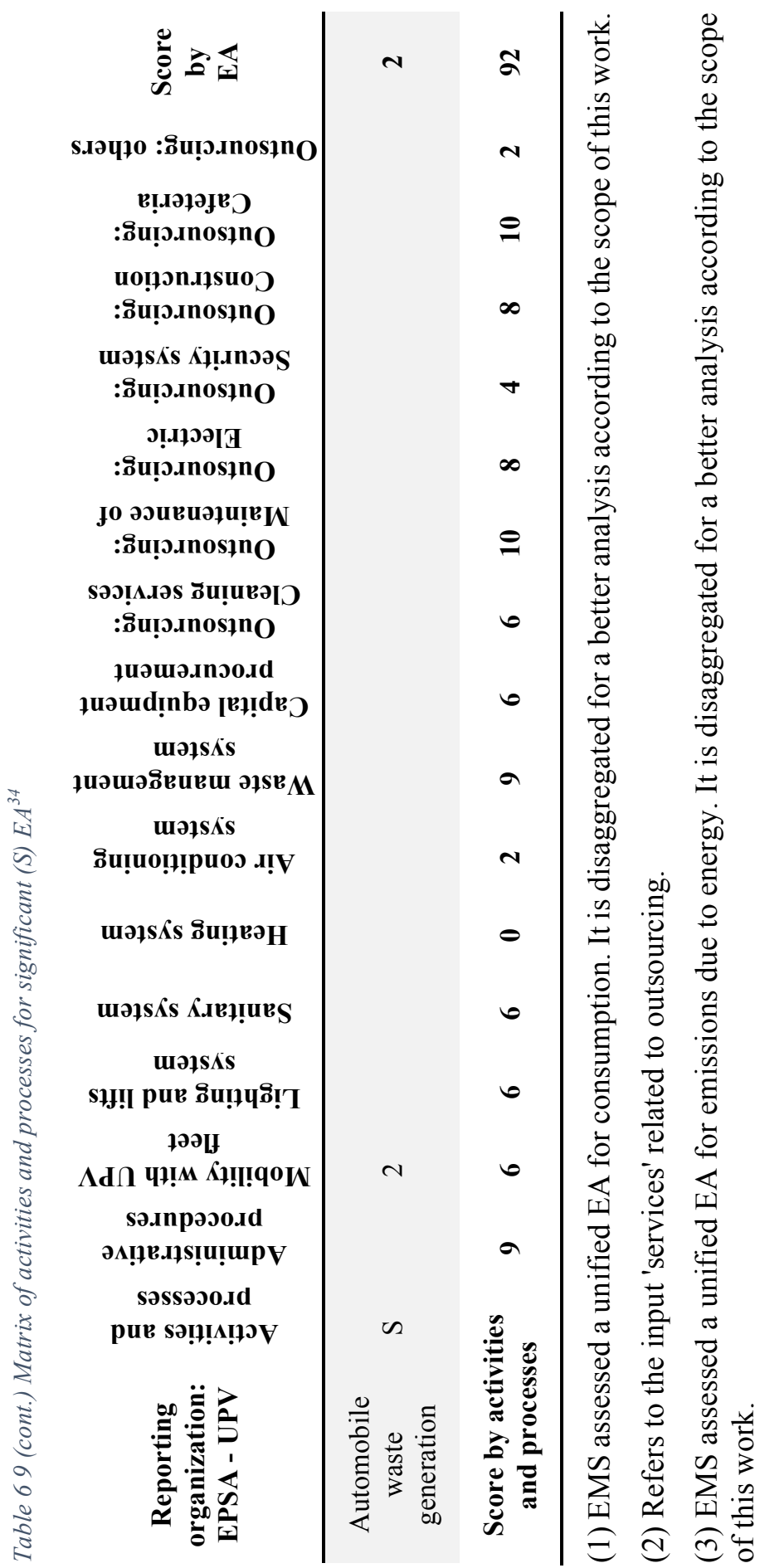




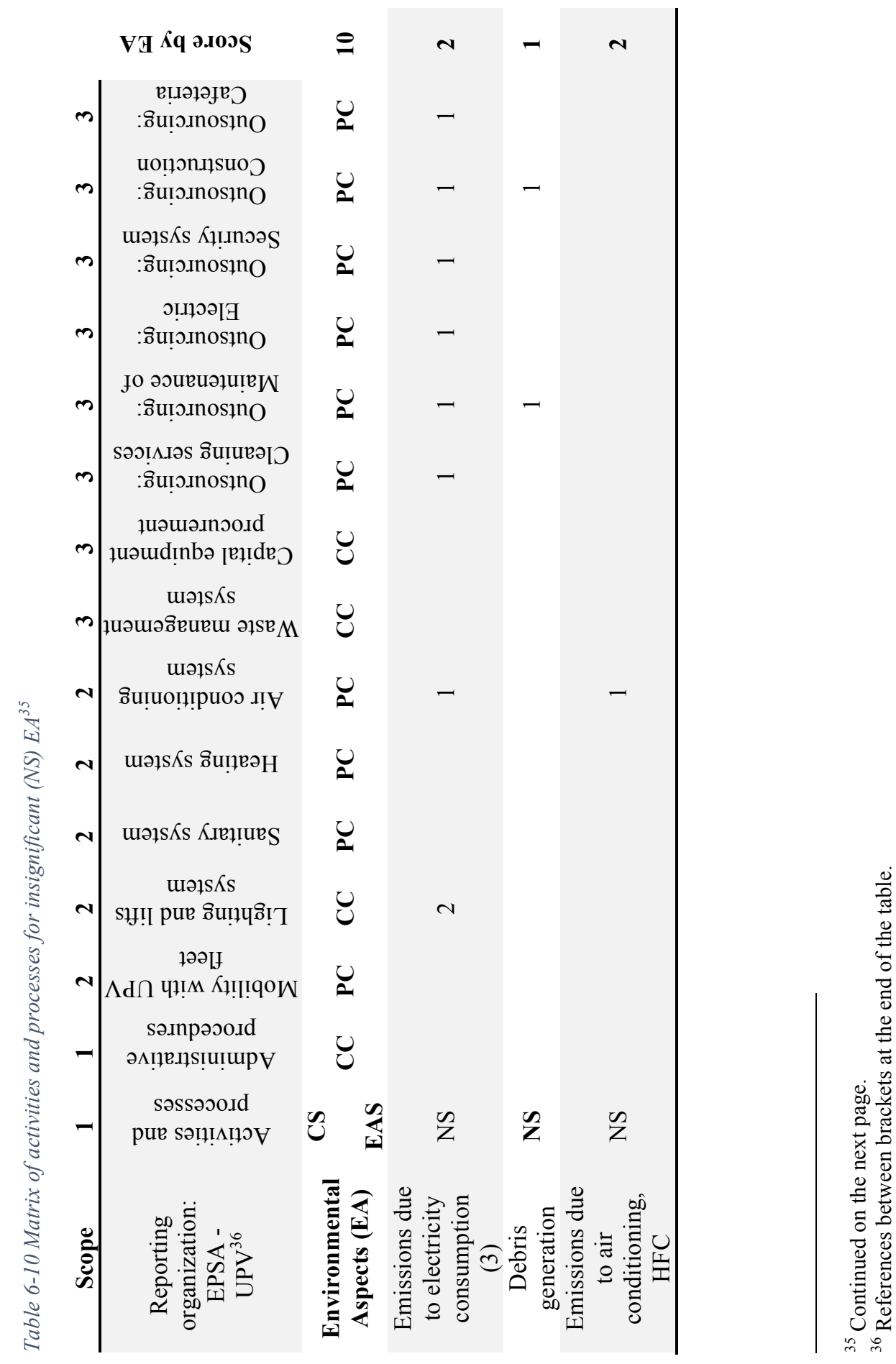




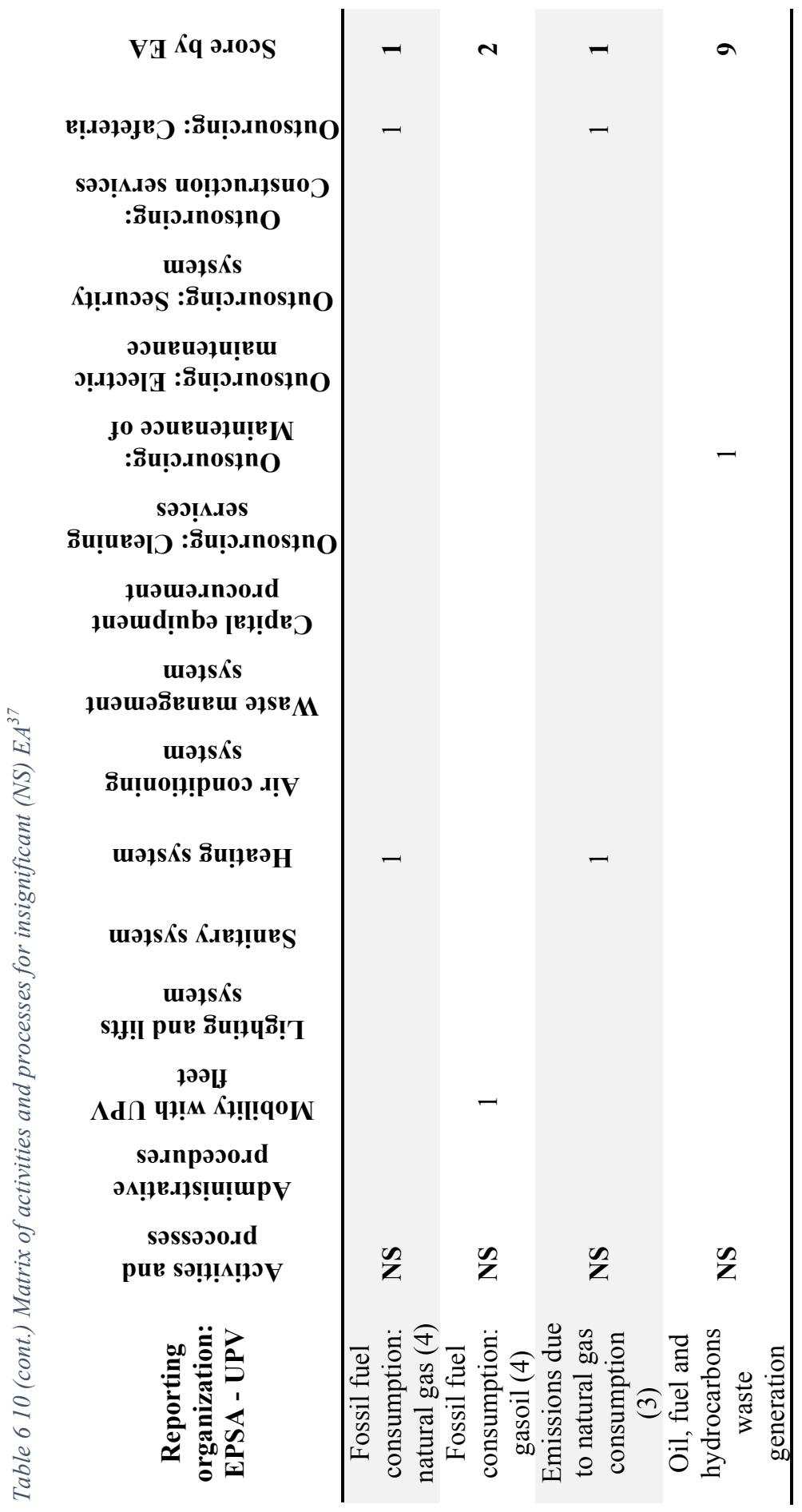




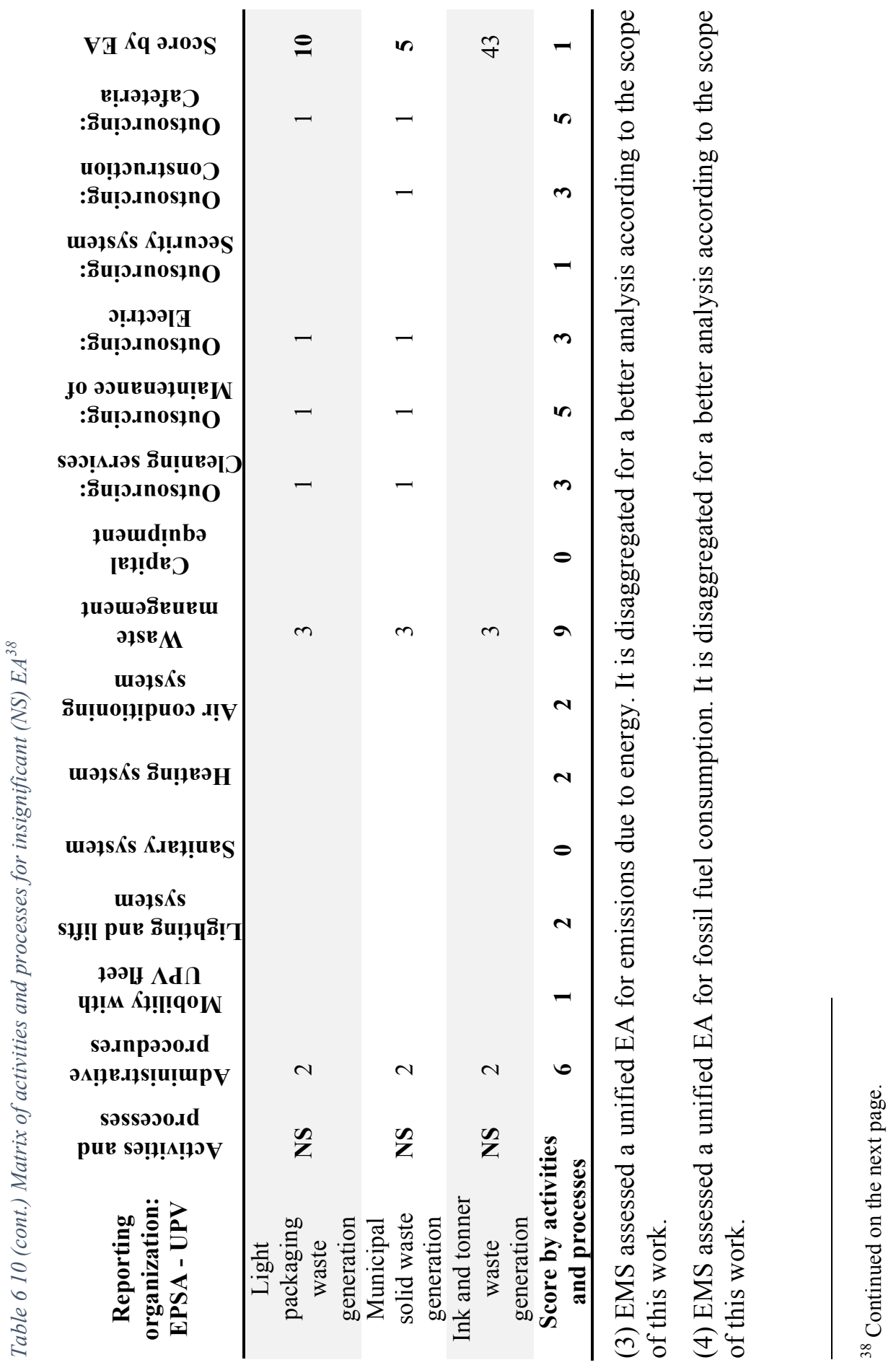




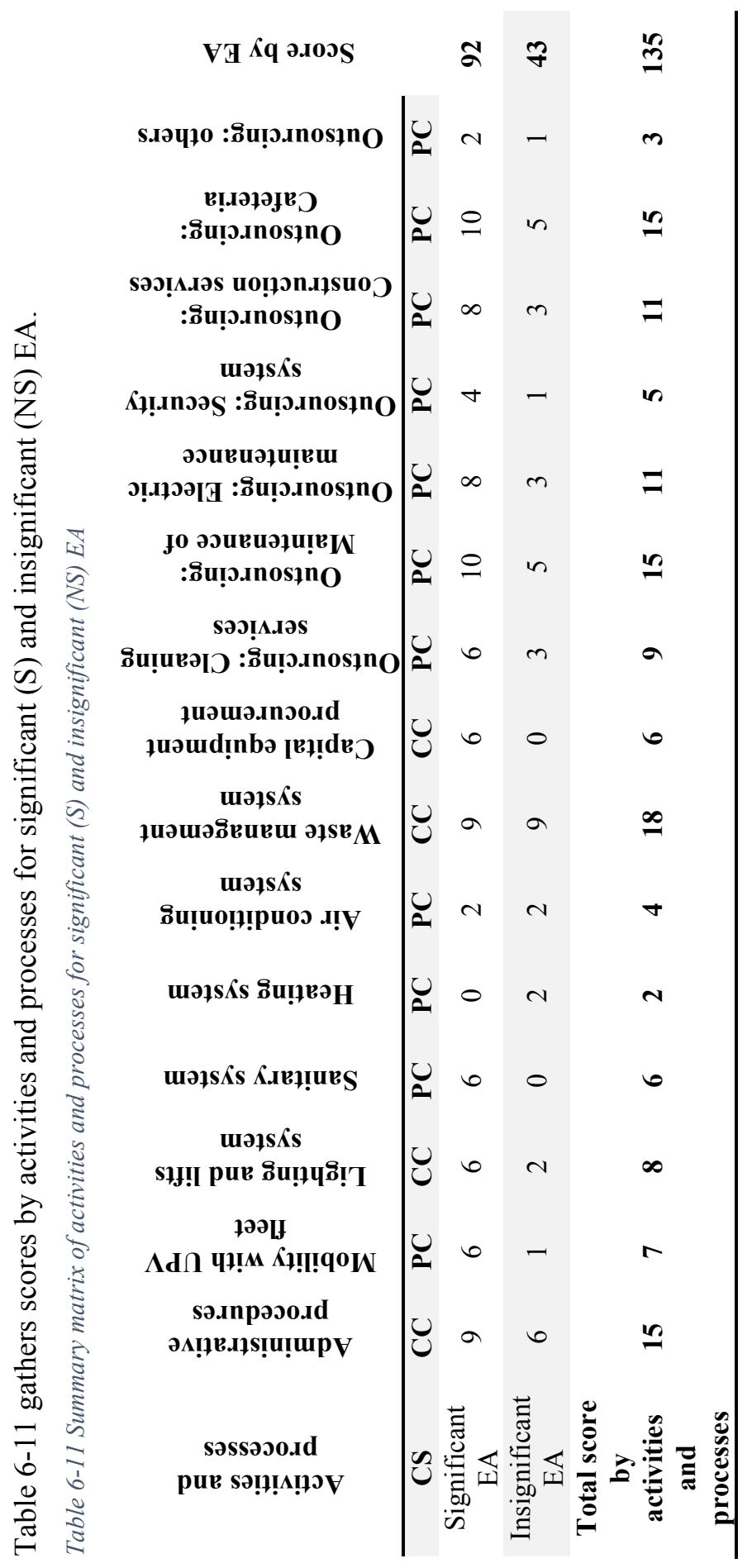





\section{THE ACCOUNTING SYSTEM AS COMPLEMENTARY DATA SOURCE FOR ORGANIZATIONAL LIFE CYCLE ASSESSMENT OF HIGHER EDUCATION INSTITUTIONS}

Lo-Iacono-Ferreira, V. G., Torregrosa-López, J. I., \& Capuz-Rizo, S. F. (2017). The accounting system as complementary data source for Organizational Life Cycle Assessment of Higher Education Institutions. $21^{\text {st }}$ International Congress on Project Management and Engineering. Cadiz. $12^{\text {th }}$ $-14^{\text {th }}$ July 2017. (In press)

Notice that this paper has been edited to match the style chosen for this document. Figures and tables have also been edited (only format). Abbreviations have also been homogenized. A complete abbreviation code is provided in page 23.

\section{ABSTRACT}

Having an environmental management system (EMS) certified in ISO 14001 or verified in EMAS in a Higher Education Institution does not ensure the availability of the data needed to carry an Organizational Life Cycle Assessment (O-LCA) according to ISO 14072. The integration of the accounting system as an information source might provide the necessary missing data.

This research studies the use of the information available in the accounting system as a complementary source of information to assess O-LCA of EPSA, an environmental unit of Universitat Politècnica de Valencia (UPV).

The accounting system manage valuable information that can cover some of the information gaps that UPV EMS has. Nevertheless, structural changes are needed in order to be able to carry an O-LCA based on the data offered by EMS and the current accounting system.

The strength and weaknesses of using the current accounting system as a complementary source to cover the lack of quality data of UPV EMS are highlighted. Measures are proposed with the aim of improving the register and management of environmental data.

\subsection{INTRODUCTION}

The commitment of HEI with the environment by managing and assessing their environmental performance has increased the number of institutions with EMS with different scopes (Lozano et al. 2015, Hancock and Nuttman 2014, 
Proposal of a set of Key Performance Indicators for the environmental assessment of Higher Education Institution

Gustavo De Lima et al. 2016). The implementation and maintenance of an EMS has proven to be a useful tool to manage the EA of a HEI (TorregrosaLópez et al. 2016).

In particular, EMS certified in ISO or verified in EMAS provide a structure to assess the impact of a wide range of activities and processes that constitute significant EA of the institution. These assessments can be made either through the evaluation of environmental indicators as an EF or achieving holistic environmental assessments as an O-LCA (Lo-Iacono-Ferreira et al., 2016a, 2017).

The O-LCA is a life cycle approach for addressing the environmental footprint of organizations (United Nations Environment Programme, 2015). O-LCA is defined by ISO (2014a) as a "compilation and evaluation of the inputs, outputs and potential environmental impacts of the activities associated with the organization as a whole". Therefore, all the activities, processes, inputs and outputs need to be identified and characterized. O-LCA is based on the fourphase methodology stated by ISO 14040 and 14044 (International Organization for Standardization 2006a, 2006b) where the definition of the goal and scope are required along with an inventory analysis, the impact assessment and the interpretation of results. One of the challenges of performing an O-LCA is being able to collect all the quality data required to guarantee the representativeness of the assessment without involving excessive costs for data collection (Martinez-Blanco et al. 2015c).

The activities and processes that constitute an EA interact with the environment through its input and output flows. The evaluability of these EA depends on the availability of quality data regarding these inputs and outputs. Unfortunately, a certified or verified EMS does not ensure the availability of quality data to assess all the inputs and outputs. Previous studies have pointed out data availability and data quality as weaknesses of HEI's EMS (LoIacono-Ferreira et al. 2016c, 2017).

EPSA, one of the EU of UPV, has been chosen as pilot for several environmental assessments where these weaknesses have been highlighted (Lo-Iacono-Ferreira et al., 2011b, 2016a, 2016c, 2017). For example, the EMS of EPSA establishes a protocol for green procurement but does not register the purchases of material and equipment and their characteristics. Therefore, the information to properly assess the environmental performance is not accurate or enough detailed.

The lack of quality data has conditioned results that could only be obtained partially. Consequently, data flows are considered key aspects to fully understand how environmental information is managed and outline solutions for the short term. For that matter, the accounting system is proposed as an 
alternative data source to provide environmental information of those inputs under financial control.

In this paper, an analysis of EPSA accounting registers of 2015 has been made in order to explore the possibility of assessing LCIA for past periods with no additional structures. The following characteristics have been explored:

- Suitability of the categories defined in the system: budget categories.

- LCI coverage.

- Quality of data.

Besides the detailed analysis of the accounting system of EPSA, a proposal to classify and manage the accounting registers with environmental purposes. Furthermore, the available data with acceptable quality is gathered and presented irrespective of its source (accounting system or EMS).

\subsubsection{CASE STUDY DESCRIPTION}

EPSA is one of the 211 EU defined in UPV's EMS. The EPSA consist of 3 buildings located in the city of Alcoy. In 2015, EPSA hosted 2,494 students and was managed by 300 staff members between professors and administrative and service personnel.

EPSA has different degrees of control over its inputs and outputs. Table 7-1 gather all the inputs and outputs related to EA identified in previous studies (Lo-Iacono-Ferreira et al., 2016c, 2017) and the description of its control degree. Partial degree of operational control indicates that although the operational control is not fully in charge of EPSA, the EU has enough control to significantly influence the operations related to this input or output.

In 2015, the accounting system of EPSA managed over 180 different suppliers with more than 1400 registers (products purchases, service contract, taxes and other operations). All inputs under financial control of EPSA are also under operational control. 
Proposal of a set of Key Performance Indicators for the environmental assessment of Higher Education Institution

Table 7-1. EPSA Input / Output control description

\begin{tabular}{lll}
\hline \multicolumn{1}{c}{ Input / Output } & $\begin{array}{c}\text { Financial } \\
\text { control }\end{array}$ & $\begin{array}{c}\text { Operational } \\
\text { control }\end{array}$ \\
\hline Electricity & No & Yes \\
\hline Water & No & Yes \\
\hline Gasoil & No & Yes \\
\hline Natural gas & No & Yes \\
\hline Office supplies & Yes & Yes \\
\hline Supplies & Yes & Yes \\
\hline Automobiles & Yes & Yes \\
\hline Technology assets & Yes & Yes \\
\hline Movable assets & Yes & Yes \\
\hline Services & Yes & Yes \\
\hline SO, NOx, CO, HFC, $\mathrm{CO}_{2}$ emissions & No & Partially yes \\
\hline Debris & No & Partially yes \\
\hline Electric waste & No & Partially yes \\
\hline Oil, fuel and hydrocarbon waste & No & Partially yes \\
\hline Paper and cardboard waste & No & Partially yes \\
\hline Light packaging waste & No & Partially yes \\
\hline Ink and toner waste & No & Partially yes \\
\hline Municipal solid waste & No & No \\
\hline CD waste & No & Partially yes \\
\hline Waste water & No & Partially yes \\
\hline
\end{tabular}

\subsection{METHOD: ACCOUNTING SYSTEM AND BUDGET ANALYSIS}

Figure 7-1 shows the weight of each budget category. Items with less than $1 \%$ budget are grouped in a general category named others. This category includes mail and messaging costs, scholarships (including social security payments), purchases of equipment for information processes, fuel, studies and technical work outsourcing, software purchases, other miscellaneous expenses, acquisition of technical facilities, acquisition of equipment and tools, acquisition of other tangible assets, laboratory equipment supplies, vehicles insurance, acquisition of intangible assets, local tributes, expenses of locomotion and other transport services.

The budget category with more representation is the one that gathers miscellaneous outsourcing with more than a $37 \%$ of the overall weight. In this category are clustered all those services outsourced without a specific budget; social network and communication management are part of this category. The relevance of the environmental impact of this $37 \%$ of the budget is difficult to assess as no detail information is included in the concerning invoices. These 
services may require high environmental impact equipment and travelling impossible to evaluate without full collaboration of the service provider.

The second budget category with more than 28 points of difference is 'advertising and propaganda expenses' with over $9 \%$. This portion includes the design and display of online banners, outdoor advertisement and broadcasting. As in the previous category, its environmental impact assessment requires close involvement of providers.

'Protocol and representation' and 'supplies of other products' are the following categories represented by a weight of $8.1 \%$ and $5.7 \%$, respectively. Other products refer to all the products that are not office or laboratory supplies represented by specific categories. This category includes from keys to light bulbs passing through nails, ropes or gloves. Most of these supplies are purchased at hardware or variety stores where their invoices or receipts either have internal code descriptions or no description at all. However, the environmental impact of some of these supplies might be relevant due to its composition and or provenance. An approach could be possible with direct information from the people that generates the purchase orders or the orders themselves. Anyhow, a system or protocol needs to be built in advance to ensure the accurate register of data. It should also be considered that most of the providers are third parties and not manufacturers, so the assessment process, an LCIA for example, will require extra resources in order to obtain all the information needed for the assessment.

Protocol and representation partition is, mainly, restaurants and transport services although there can be some institutional gifts purchases. Even though the accounting regulation forces to attach a short letter with the purpose and the attendee names, this information is not computerized. In addition, recipes and invoices not always describe the dishes but a general reference to the menu or diners. Having accurate data to assess the impact of each event might be complicated.

With an impact between $5 \%$ and $1 \%$ of the budget of EPSA there are thirteen categories that can be classified in three sub-categories: assets procurement, travelling expenses and other services. Assets procurement includes office supplies and computer equipment not inventoried, teaching and research equipment, newspapers, magazines, etc. Travel expenses includes extraordinary student trips as the ones made for a conference, a visit to a company, contests and congresses charged to EPSA accounts. Telephone costs, leases, maintenance of certain goods (as the owned vehicle) and copying expenses might be included in the service sub-category. 


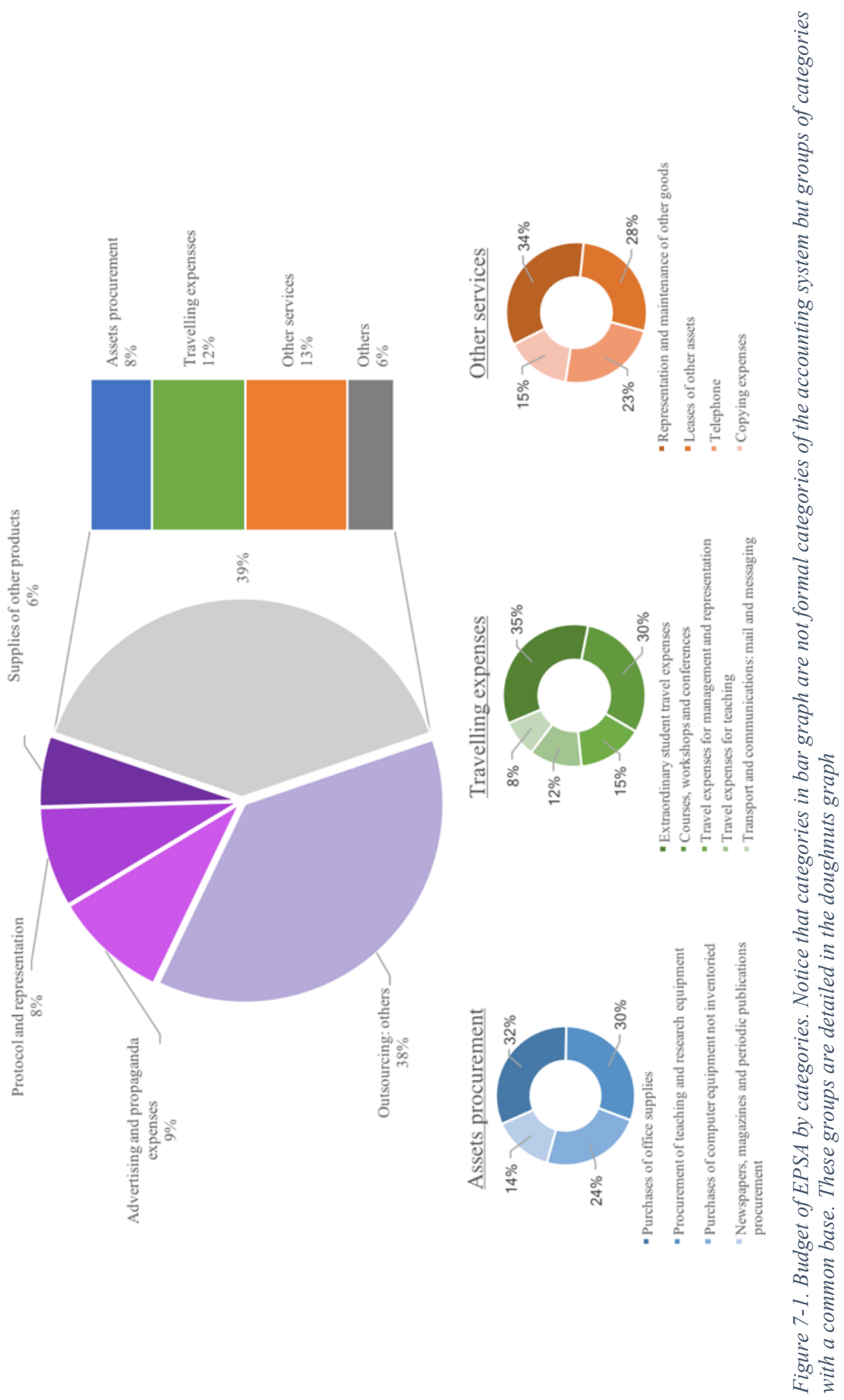


The processing of the cash flows associated with these categories does not require, in the current system, a quality description that may allow a detailed assessment of their environmental impacts. An additional 'other' category gathers the seventeen categories below the $1 \%$ of representation in budget.

The categories that compose the budget have been defined according to the needs of the accounting management only. As a result, these budget categories can feed more than one activity and process of the EU and those activities and processes can require inputs from more than one budget category.

\subsubsection{REGISTERS CLASSIFICATION PROPOSAL}

For a better analysis over the environmental performance of the EU a classification of the register in the accounting system, despite their budget classification, is proposed. Each register is classified in restaurant, catering and food supplies, lease, extraordinary auxiliary staff recruitment, extraordinary staff and student travelling, materials and equipment, services and others for those registers that cannot be placed in one of the previous categories. Figure 7-2 represents the monetary contribution (excluding VAT) of each category for EPSA in 2015. VAT has been excluded in order to simplify the analysis and to set the basis for a future correlation of results for comparing purposes. It is belief that useful correlations can be made in future assessments considering GDP variations; excluding VAT fees, that can also vary in time due to economic policies, the uncertainty of any operation is reduced.

The first category 'restaurant, catering and food supplies' gathers work meals, protocol lunches and dinners, coffee breaks services hire for special events and additional supplies like coffee capsules or others purchases for the daily use at the office. Lease category includes all the registers linked to the leasing of complementary facilities. Extraordinary auxiliary staff recruitment category responds to the recruitment of students through UPV founding 'Servipoli'. This is an organization with the purpose of complementing the training of students through work experience inside and outside UPV strengthening their employability. Students are employed for short periods to cover the needs of UPV services or special events like conferences. Extraordinary staff and student travelling category covers all the expenses of extraordinary trips like meetings in other campuses, field trips, etc. paid by EPSA. Materials and equipment category gathers all the purchases including office supplies, lab supplies, tools, computers and other equipment. Services represents all services hires by the EU from external printing services and advertising to laundry services and mail costs. 


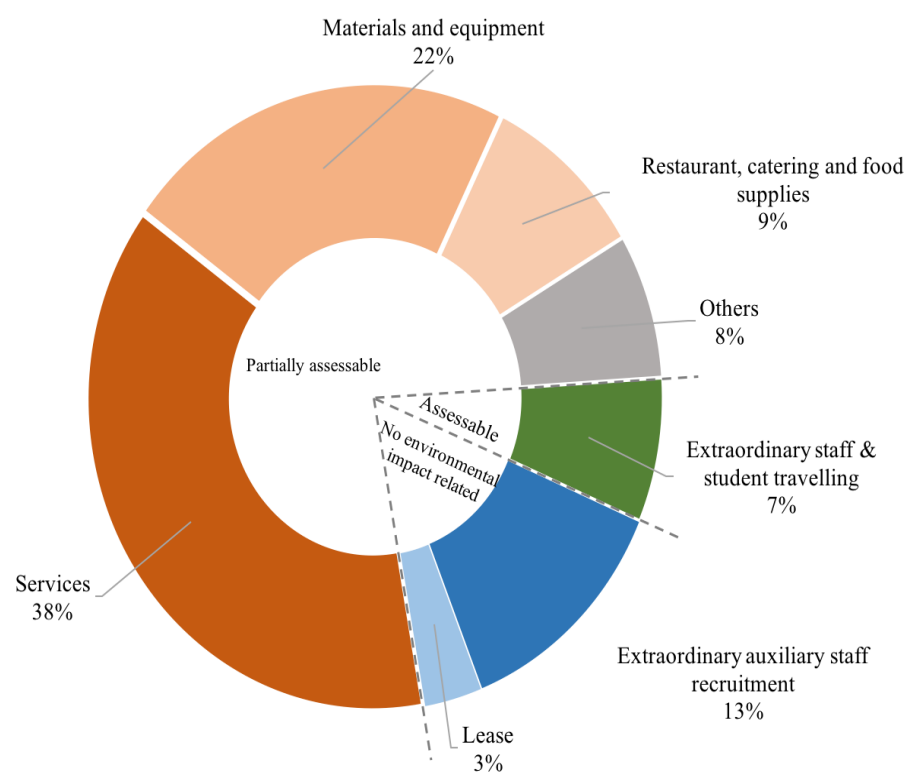

Figure 7-2. Monetary distribution of EPSA inputs for 2015 by category.

The $50 \%$ of expenditures are covered by services, materials and equipment. Both categories might have a relevant environmental impact due to its nature. However, the information available in the current system for the year of analysis is not detailed enough to allow an environmental impact assessment. Regarding services, invoices usually contains general information. It is believed that a good approach can be made for further studies if service providers already have or are willing to conduct an environmental assessment of their performance and share their results.

Materials and equipment environmental impact category might also be approached at least in a fraction. For a better analysis of this category, an additional sub-classification is proposed where purchases are distinguished between inventory equipment, non-inventory equipment, consumables and others (Figure 7-3). Also, the consumable category is deeply analyzed to highlight a specific type of register: fuel purchases for the vehicle owned by the EU. This sub-category has a special meaning because (a) it has a significant environmental impact regarding its GHG emissions in the use phase as shown in previous studies (Lo-Iacono-Ferreira et al., 2016a) and (b) it is fully assessable only by the information contained in the receipts. Although there are 4 of the 25 purchases that do not attach the corresponding receipt, knowing the date of purchase, the amount paid and the type of fuel the volume (in liters) it is easy to draw conclusions using the history average 
price of fuel published by the Spanish Ministry of Industry, Energy and Tourism (2015).

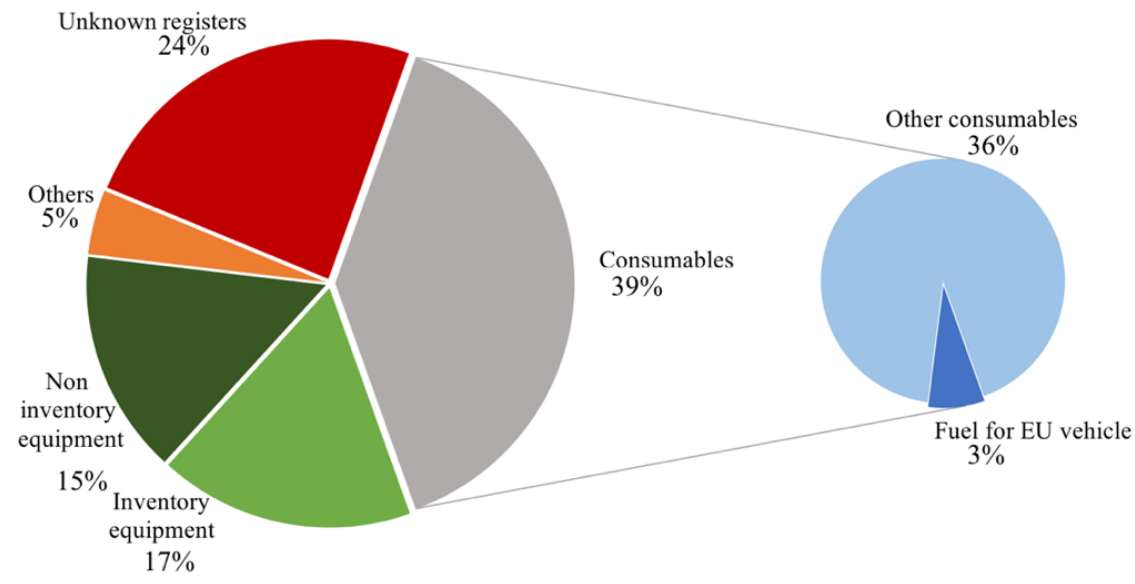

Figure 7-3. Analysis of registers of the material category for EPSA 2015.

There are 100 registers of non-inventory equipment which include different types of products from desktop calculators to small tools. Some of these products have a life of less than a month while others might be in use for several years. The equipment that is registered in the inventory contains computers, lab equipment and other types of complex equipment with unknown composition or manufacturer information. 'Other consumables' include office supplies, maintenance supplies and all type of consumables most of them registered with a generic identification. It is extremely difficult to make assumptions over the composition or manufacturing process of inputs without full collaboration of staff that request the materials, suppliers and manufacturers.

For example, there are more than 20 different registers of adhesives and glues generally described and a similar amount of wires where the type and length is not always registered. Some registers do have detailed information; this is the case of writing material. There are more than 420 pens, pencils and markers that do have the detail of brand, color and model; in this case, it would be possible -with additional resources and the collaboration of the manufacturers or solid research- to approach their environmental impact. Something similar happens with the batteries that are more than 80 . Without a first full assessment, it is extremely difficult to have a realistic approach of the environmental impact of these materials and, therefore, to apply any 
Proposal of a set of Key Performance Indicators for the environmental assessment of Higher Education Institution

additional cut-off criteria. Same happens with the more than 250 services that would need an evaluation of the suppliers or, at least, a more detailed description.

In the overall analysis of these sub-classification, an unknown category has to be included as there are registers with incomprehensible description based on an internal supplier's code or abbreviations not possible to be classified without the collaboration of the supplier or whom made the request; not always identified in the invoice or receipt and not identified in the system.

The next most relevant category in the monetary distribution of EPSA inputs for 2015 (Figure 7-2), extraordinary auxiliary staff recruitment, does not have a direct environmental impact associated as it is a temporary growth of employee workforce. The indirect impact that this increment of human resources implies is reflected in other categories by an increment of services, materials consumption, food supplies, etc. Something similar can be considered for the lease category by increasing services, equipment, materials, etc.

Restaurant, catering and food supplies represents $9 \%$ of the inputs while the category assigned to extraordinary travelling of staff and students is $7 \%$. Both categories might have a significant environmental impact. Nevertheless, the category of restaurant, catering and food supplies is mainly a third-party contribution category. These impacts are difficult to assess; the full collaboration of the suppliers is needed as already discussed. In addition, $42 \%$ of the more than 200 registers related to this category have generic information, i.e. menu for 3 , where no details of food and drinks are provided. In some cases, even the number of diners are not clearly defined. The other $58 \%$ have more specific information (i.e., coffee, small bottle of water, beer) but still not enough details to carry out a proper assessment.

On the contrary, extraordinary staff and students travelling concept have a stricter regulation requiring more specific information. The type of transport and the distance traveled are essential requirements for processing any economic compensation for extraordinary trips made both by staff and students. Figure 7-4 shows that the most common transport mode was by personally-owned car with almost $20,000 \mathrm{~km}$ traveled in 2015 . The bus was the mode used for field trips for groups of students regardless the distance. Train and plane were used by staff for meetings and conferences outside UPV where distances were over $200 \mathrm{~km}$; the meetings that took place in one of the other campuses of UPV (Valencia or Gandía) or inside Valencia Region commonly request one person only that takes, for convenience, his own vehicle. Distance for these last trips were between 15 and $300 \mathrm{~km}$ while train was used for distances between 200 and $1000 \mathrm{~km}$. 


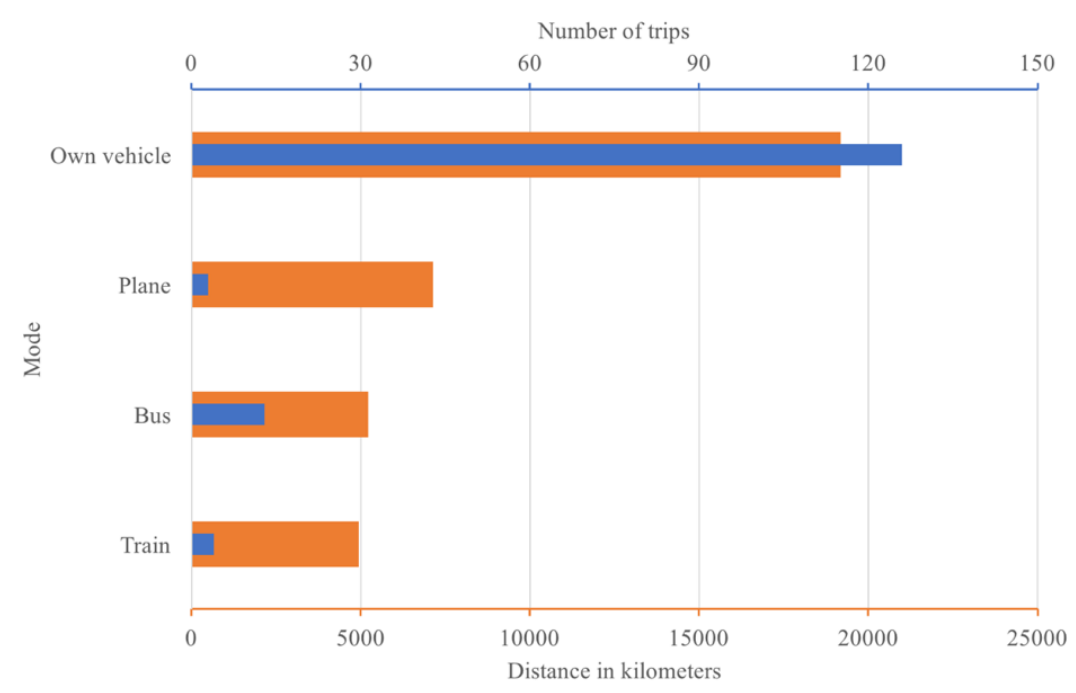

Figure 7-4. Analysis of extraordinary travelling of staff and students of EPSA for 2015.

The category that gathers all the registers that cannot be assigned to any of the previous is a not less significant $8 \%$. This category is composed by taxes, fees and other registers with not enough specifications. The environmental impact of it is uncertain.

\subsection{Results: EPSA AVAILABLE ENVIRONMENTAL QUALITY DATA}

Regarding electricity, water and natural gas consumptions of EPSA (including air conditioning and heating system requirements), it is important to notice that these inputs are not under financial control of the EU. These services are paid from the general budget managed by the rector's office. The analysis of the accounting system of EPSA has no coverage over these inputs and, therefore, no financial control over the environmental aspects related to them. However, there is a direct operational control that allows actions to optimize the use of these supplies. Furthermore, the consumption data related to these inputs is managed by the EMS; as EPSA is a EU of the HEI, the information is allocated allowing its individual assessment.

According to the prioritized list of activities and processes for EPSA that considers the controlling state and the significance of the aspects involved (Lo-Iacono-Ferreira et al., 2017), the electricity consumption is a relevant input. Please notice that all the electricity consumption requirements are gathered in this activity/process item. Something similar happens with the water consumption that is represented by the sanitary system item in the EA 
Proposal of a set of Key Performance Indicators for the environmental assessment of Higher Education Institution

list. Heating system, however, is the less relevant item of all the activities and processes described. Depending on the value assigned to the cut-off criteria, the consumption of gas could be left out of the analysis. For the cut-off proposed by Lo-Iacono-Ferreira et al., (2017), a 5\%, the gas consumption that is fully represented by the heating system would be left out of the assessment.

In any case, electricity, water and natural gas consumption are inputs easy to assess as specific data in consumption units $\left(\mathrm{kWh}, \mathrm{m}^{3}\right.$, etc.) can be obtained from the invoices if there is access to these documents. However, UPV EMS currently includes these data in the annual public report, making it easier to take into any assessment.

Regarding outputs, the EO monitors waste generation and emissions as a regular activity of the EMS. There are defined protocols to assess each flow either by direct measurement or by estimation. These protocols are validated by the EMAS verification procedure and available to every member of the community.

As a summary, Table 7-2 shows all available input and output data for EPSA for 2015 where AS source stands for accounting system. Notice that, in 2015, EPSA had 2494 students and 300 staff members (personnel). The table also includes information regarding the type of procedure:

- Direct, when the data is obtained directly from the source

- Estimated, when an estimation procedure in needed to obtain the date. Estimation procedures, when required, are defined in the corresponding protocol as part of the EMS, therefore, are also validated.

The flows with available data covers partially the activities and processes identified. For example, the data of the inputs and outputs of lighting and lifting system, sanitary system, heating system and air conditioning system is registered in the current system. The other activities or processes have part of the information. However, the assessment of those activities or processes that do have available data of their flows is not possible without an allocation procedure of its flows. For example, although the consumption of electricity of EPSA is known, there are no electrical instruments that allows a proper allocation of the individual consumption of each process that requires electricity. For more details about the identification of flows by activities and processes, please see (Annex 6 B, Lo-Iacono-Ferreira et al., 2017).

In a midterm, with some resources, additional features can be included in the accounting system in order to sub serve the incorporation of more and better data with environmental assessment purposes. For example, a register of the purchase orders with details of the items would allow a cross check with invoices that might help identifying the elements. The identification of the 
person who sets the order might also be useful to assist in some stage. Something similar can be applied with services hired. This could convert the $22 \%$ of material and equipment and the $38 \%$ of services category in the monetary distribution (Figure 7-2) in assessable.

Table 7-2 EPSA available inputs and outputs data for 2015.

\begin{tabular}{|c|c|c|c|c|}
\hline $\begin{array}{l}\text { Flows (Inputs / } \\
\text { Outputs) }\end{array}$ & $\begin{array}{l}\text { Value for } \\
2015\end{array}$ & Units & Source & $\begin{array}{l}\text { Type of } \\
\text { procedure }\end{array}$ \\
\hline Fuel for EPSA vehicle & 1149.25 & 1 & AS & Direct \\
\hline $\begin{array}{l}\text { Distance traveled by } \\
\text { staff and students using } \\
\text { their own car }\end{array}$ & 19173.8 & $\mathrm{~km}$ & AS & Direct \\
\hline $\begin{array}{l}\text { Distance traveled by } \\
\text { staff and students by } \\
\text { train }\end{array}$ & 4954 & $\mathrm{~km}$ & AS & Direct \\
\hline $\begin{array}{l}\text { Distance traveled by } \\
\text { staff and students by } \\
\text { plane }\end{array}$ & 7144 & $\mathrm{~km}$ & AS & Direct \\
\hline Electricity consumption & 1368.87 & $\mathrm{~km}$ & EMS & Direct \\
\hline $\begin{array}{l}\text { Natural gas } \\
\text { consumption }\end{array}$ & 1341001 & $\mathrm{kWh}$ & EMS & Direct \\
\hline Water consumption & 6661 & $\mathrm{~m}^{3}$ & EMS & Direct \\
\hline $\begin{array}{l}\text { Paper and paperboard } \\
\text { waste generation }\end{array}$ & 29040 & $\mathrm{~kg}$ & EMS & Estimated \\
\hline $\begin{array}{l}\text { Light packaging waste } \\
\text { generation }\end{array}$ & 25840 & $\mathrm{~kg}$ & EMS & Estimated \\
\hline Glass waste generation & 2562.02 & $\mathrm{~kg}$ & EMS & Estimated \\
\hline $\begin{array}{l}\text { Municipal solid waste } \\
\text { generation }\end{array}$ & 81504.33 & $\mathrm{~kg}$ & EMS & Estimated \\
\hline $\begin{array}{l}\text { Batteries waste } \\
\text { generation }\end{array}$ & 87 & $\mathrm{~kg}$ & EMS & Direct \\
\hline RAEEs & 1520 & $\mathrm{~kg}$ & EMS & Direct \\
\hline Land use & 28717 & $\mathrm{~m}^{2}$ & EMS & Direct \\
\hline HFC direct emissions & 0 & t CO2e/personnel & EMS & Estimated \\
\hline SO2 direct emissions & 0.0004 & $\mathrm{t} /$ personnel & EMS & Direct \\
\hline $\mathrm{CO}$ direct emissions & 0.0001 & $\mathrm{t} /$ personnel & EMS & Direct \\
\hline NOx & 0.0002 & $\mathrm{t} /$ personnel & EMS & Direct \\
\hline GHG direct emissions & 0.92 & t CO2e/personnel & EMS & Estimated \\
\hline
\end{tabular}

Moreover, with more details about the number of diners and the collaboration of the establishments, some estimations can be made over the category related to food services. As most of the off-campus restauration events take place in a limited number of establishments, it is feasible to make an approach of the impact for the most frequent places previous commitment of the responsible of the establishment and with active support from the HEI. The relation can also serve as tool to improve the performance of the local establishments and 
Proposal of a set of Key Performance Indicators for the environmental assessment of Higher Education Institution

the city by supporting and encouraging stakeholders to implement actions to minimize the impact of their activity (i.e. Green Seal Standard for Food Service GS-46).

\subsection{Discussion AND CONCLUSIONS: STRUCTURE, COVERAGE AND QUALITY}

In the light of the results obtained for the analysis of the budget structure and the registers of the accounting system, only two categories or sub-categories can be assessed with the current information in the system: extraordinary travelling of staff and students that represents a 7\% of the monetary distribution of inputs, and the purchase of fuel for the vehicle owned by the EU that represents a $0.6 \%$. However, this $7.6 \%$ rises up to an $8.4 \%$ when only the value of the registers that have an environmental impact associated $(84 \%$ of the total monetary value of inputs) are considered.

In conclusion, although the budget categories are not completely appropriate for an environmental analysis, a classification has been proposed to address the analysis of the inputs with financial control from EPSA. This proposal classifies inputs in:

- services,

- extraordinary travelling of staff and students,

- restaurant, catering and food supplies,

- lease,

- extraordinary auxiliary staff recruitment,

- materials and equipment that are sub classified in inventory equipment, non-inventory equipment, consumables (separating fuel from other consumables) and

- others

The quality of data is not appropriate and makes impossible an assessment except for the two subcategories described: fuel for the vehicle owned by the EU and extraordinary travelling of staff and students; just $8.4 \%$ of all inputs that directly affect the environmental performance of the institution. The lack of information and the diversity of products and services exclude the possibility to develop a proper assessment. Although some tools like LCA commonly applied monetary cut-off criteria, there is no straight relationship between the monetary value of a product or service and its environmental impact so the uncertainty of the analysis will be unknown. Not knowing the environmental impact of a whole category makes it difficult to assign a relevance value to one of its fractions.

Overall, the accounting system manage valuable information that can cover some of the information gaps that UPV EMS has. Nevertheless, structural 
changes are needed in order to be able to carry an O-LCA based on the data offered by EMS and the current accounting system.

\subsection{REFERENCES}

Gustavo De Lima, R., Lins, H.N., Pfitscher, E.D., Garcia, J., Suni, A., Salgueirinho Osório De Andrade Guerra, J.B., \& Caroline Renata Delle, F. (2016) A sustainability evaluation framework for Science and Technology Institutes: An international comparative analysis. Journal of Cleaner Production, 125, 145-158. http://doi.org/10.1016/j.jclepro.2016.03.028

Hancock, L., \& Nuttman, S. (2014) Engaging higher education institutions in the challenge of sustainability: Sustainable transport as a catalyst for action. Journal of Cleaner Production, 62, 62-71. http://doi.org/10.1016/j.jclepro.2013.07.062

International Organization for Standardization (2006a) Environmental management - life cycle assessment - principles and framework. ISO 14040:2006.

International Organization for Standardization (2006b) Environmental management - life cycle assessment - requirements and guidelines. ISO 14044:2006(E).

International Organization for Standardization (2014a) ISO/TS 14072: Environmental management — Life cycle assessment Requirements and guidelines for Organizational Life Cycle Assessment. Geneva, Switzerland: International Organization for Standardization.

Lo-Iacono-Ferreira, V.G. Torregrosa-López, J.I Lora-García, J., BastanteCeca, M.J. \& Capuz-Rizo, S. F. (2011b) Study of the inclusion of life cycle assessment impact categories in ecological footprint calculation. XV International Congress of Project Engineering. Huesca. AEIPRO ISBN: 978-84-615-4543-8 http://www.aeipro.com/aplic/tree congresos/detalle remository aei pro.php?file $=3329$

Lo-Iacono-Ferreira, V.G., Capuz-Rizo, S.F., Torregrosa-López, J.I. (2016a) Ecological Footprint Assessment of Higher Education applying Life Cycle Assessment framework. Case study: Universitat Politència de València. XX International Congress on Project Management and Engineering. Cartagena. 1423-1432. ISBN: 978-84-617-4180-9 http://www.aeipro.com/aplic/tree congresos/detalle remository aei pro.php? file $=4636$ 
Proposal of a set of Key Performance Indicators for the environmental assessment of Higher Education Institution

Lo-Iacono-Ferreira, V.G., Torregrosa-López, J.I., \& Capuz-Rizo, S.F. (2016c) Use of Life Cycle Assessment methodology in the analysis of Ecological Footprint Assessment results to evaluate the environmental performance of universities. Journal of Cleaner Production, 133, 43-53. http://doi.org/10.1016/j.jclepro.2016.05.046

Lo-Iacono-Ferreira, V.G., Torreogrsa-López, J.I., Capuz-Rizo, S.F. (2017) Organizational Life Cycle Assessment: suitability for Higher Education Institutions with Environmental Management System. International Journal of Life Cycle Assessment (In press).

Lozano, R., Ceulemans, K., Alonso-Almeida, M., Huisingh, D., Lozano, F. J., Waas, T., Lambrechts, W., Lukman, R., Hugé, J. (2015) A review of commitment and implementation of sustainable development in higher education: results from a worldwide survey. Journal of Cleaner Production, 108, 1-18. http://doi.org/10.1016/j.jclepro.2014.09.048

Martínez-Blanco, J., Inaba, A., and Finkbeiner, M. (2015c) Scoping organizational LCA - challenges and solutions. The International Journal of Life Cycle Assessment 20(6), 829-841. http://doi.org/10.1007/s11367-015-0883-x

Ministerio de Agricultura, Alimentación y Medio Ambiente (2015) Ministerio de Agricultura, Alimentación y Medio Ambiente. Cambio Climático. Retrieved on May $3^{\text {rd }} 2015$ from http://www.magrama.gob.es/es/cambio-climatico/temas/mitigacionpoliticas-y-medidas/Registro-Huella-Carbono.aspx

Torregrosa-López, J. I., Lo Iacono-Ferreira, V. G., Barranco-Martí, C., \& Bellver-Navarro, C. G. (2016) The strengths of EMAS as an environmental management system for European university campuses. International Journal of Environment and Sustainable Development, 15(1), 89-106. http://dx.doi.org/10.1504/IJESD.2016.073339

United Nations Environment Programme (2015) Guidance on Organizational Life Cycle Assessment. Life-Cycle Initiative, United Nations Environment Program and Society for Environmental Toxicology and Chemistry, Paris, France. Retrieved on June $1^{\text {st }} 2016$ from: http://www.lifecycleinitiative.org/wp- content/uploads/2015/04/olca 24.4.15-web.pdf 


\section{APPLICABILITY OF GLOBAL REPORTING INITIATIVE TO ASSESS THE ENVIRONMENTAL PERFORMANCE OF HIGHER EDUCATION INSTITUTIONS.}

Lo-Iacono-Ferreira, V.G., Torregrosa-López, J.I., Capuz-Rizo, S.F., (2016) Applicability of global reporting initiative to assess the environmental performance of higher education institutions. XX International Congress on Project Management and Engineering. Cartagena. 1433-1444. ISBN: 978-84$617-4180-9$

http://www.aeipro.com/aplic/tree congresos/detalle remository aeipro.php? $\underline{\text { file }=4637}$

Notice that this paper has been edited to match the style chosen for this document. Figures and tables have also been edited (only format). Abbreviations have also been homogenized. A complete abbreviation code is provided in page 23.

\section{ABSTRACT}

The Global Reporting Initiative (GRI) is a methodology developed to help organizations reporting on their environmental, social and economic performance. In this study, the viability of applying GRI methodology to assess the environmental performance of Higher Education Institutions (HEI) is analyzed and discussed. GRI Guidelines to assess environmental aspect as materials, energy, water, biodiversity, emissions, effluents and waste, products and services, compliance, transport, environmental assessment of suppliers, environmental grievance mechanisms and overall environmental issues. Each environmental aspect guideline is deeply studied. As a result, a proposal of a HEI environmental GRI is presented. A guideline to report environmental performance with fully application to higher education based on GRI.

\subsection{INTRODUCTION}

The Sustainability Reporting Guidelines (SRG) is a guide developed by Global Reporting Initiative (GRI), an international independent organization. GRI pursue an independent and objective sustainability reporting with a common language to communicate economic, social and environmental impacts of organizations. One of the main advantages of reporting in accordance to GRI is giving stakeholders working across organizations confidence that reporting impacts can compare one into another's. 
Hespenheide (2015), chair of the Global Sustainability Standards Board (GSSB) presents reporting with GRI as "[...] a vehicle to try to highlight does issues organizations need to take into account in order to be fully accountable to their full range of stakeholders". GRI strive to reconcile the guidelines with other widely-recognized frameworks as UN principles, ISO standards, CDP (Carbon Disclosure Project), etc. giving organizations worldwide an extra incentive to apply this guideline.

Although SRG are developed to be universally applicable to all types of organizations, previous studies (Lozano, 2011) have shown that complex organizations as HEI have serious difficulties to assess and report sustainability including their environmental behavior. HEI are lighthouses for society and have a key role in implementing sustainable and environmentally responsible practices (Alonso-Almeida, et al., 2015). Different alternatives to report environmental or sustainability performance are available and have been explored; Campus Sustainability Assessment Framework (CFAS) (Cole, 2003), Graphical Assessment of Sustainability in Universities (GASU) (Lozano, 2006a), the Ecological Footprint (Lo Iacono-Ferreira et al., 2011a) and Sustainability Tracking, Assessment and Rating System (STARS) (Urbanski \& Filho, 2014) are some examples.

UPV is a HEI with a clear interest to constantly improve its environmental management and to set an example of good practice (Torregrosa-López et al., 2016). It has an EMS verified in EMAS since 2010. EMS managers in association of some researching groups are constantly searching for opportunities to improve the system.

The main objective of this research is studying the applicability of GRI environmental indicators at HEI with a consistent EMS. UPV is used as case study to assess the ability of a verified EMS to apply GRI.

\subsection{Methodology}

To study the applicability of GRI environmental indicators, the following steps were taken:

- Step 1. Select the most suitable GRI guide for HEI

- Step 2. Extract those indicators related to the environmental aspect

- Step 3. Case Study UPV. Analyze indicators environmentally related

- For step 1, the three latest GRI guides were analyzed. The reasons and general characteristics of the chosen guide are provided in section 4.1.

All indicators defined in the GRI guide chosen were studied to conduct step 2. Those indicators that affects, either directly or indirectly to an environmental assessment using GRI were extracted. A classification and definition of these indicators is shown in section 8.2.2. 
In order to assess the applicability of indicators to HEI using UPV as case study (step 3), a decision scheme (Figure 8-1) was applied. Analysis and results are gathered in section 0 .

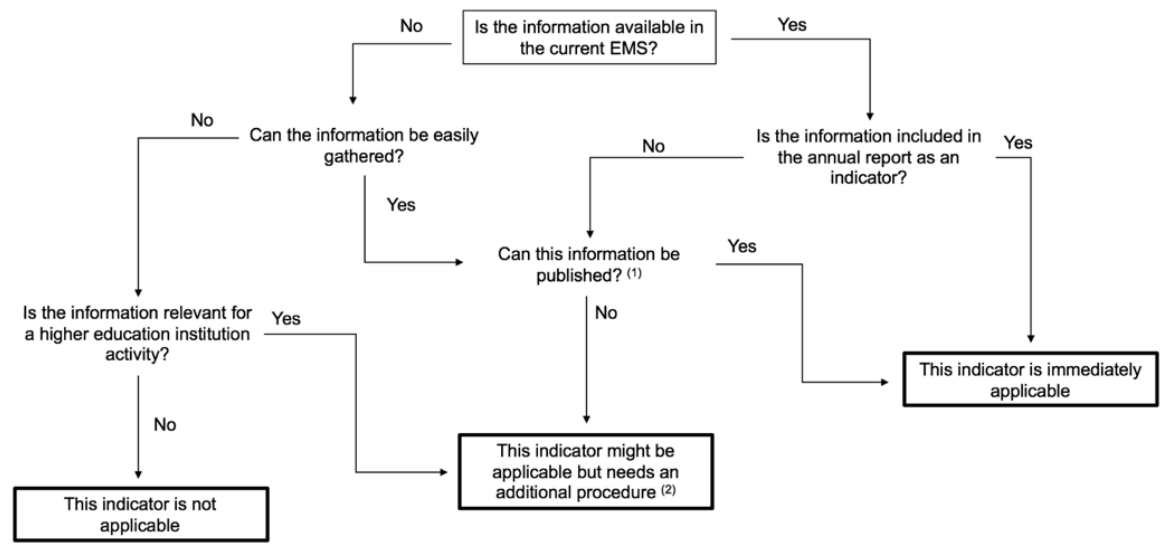

Figure 8-1 Decision scheme

(1) Some information can be considered sensitive and might not be published without a special permission of the head of the institution.

(2) Asking for special permissions, treating data, etc. Actions that are not immediate and require time and resources. Results and discussion

Results and its discussion is presented following methodology steps.

\subsubsection{SteP 1. Select The MOST SuItable GRI GUIDE FOR UNIVERSITIES}

The latest version of GRI is G4 (Global Reporting Initiative, 2013a). Some sectors disclosure guidelines are available for this latest version (G4): airport operators, food processing, construction and real estate, media, electric utilities, mining and metals, event organizers, NGO, financial services and oil and gas. Previous version, G3 (Global Reporting Initiative, 2006) and G3.1 (Global Reporting Initiative, 2011), had also pilot versions (on request) for automotive, logistics and transportation, public agency, telecommunications and apparel and footwear sectors. These supplements by sectors were not developed following current GRI's process. Although GRI only accepts reports based on G4 version, pilot versions based on G3 were also considered.

The guide selected to assess the applicability of GRI to the university was G4 attending to the following reasons:

- It is the latest version. Only reports based on G4 are accepted by GRI since January 1st, 2016. 
- It environmental aspect has more indicators than the previous version; 21 instead of 20.

- General standard disclosures are defined in more detail than previous versions.

G4 Implementation Manual is intuitive and easy-to-use.

G4 is structured in two documents: (a) the Reporting Principles and Standard Disclosures (Global Reporting Initiative, 2013a) and (b) the Implementation Manual (Global Reporting Initiative, 2013b).

\subsubsection{STEP 2. EXTRACT THOSE INDICATORS RELATED TO THE ENVIRONMENTAL ASPECT}

G4 organize indicators according to the following categories in order to assess sustainability: economic, environmental and social. Social category adds subcategories as labor practice and decent work, human rights, society and product responsibility. The guide has also a general standard disclosure, general aspects with indicators that helps establishing the framework of the report. General standard disclosure aspects are defined by 58 indicators organized under the following titles: strategy and analysis, organizational profile, identified material aspects and boundaries, stakeholder engagement, report profile, governance and ethics and integrity. Principles for defining report contest and quality must be previously defined. These principles are deeply described in sections 8.2.1 and 8.2.2 of the Implementation Manual and later applied by indicators in the General Standard Disclosures Overview.

This work focus on the environmental category. However, there are some general indicators that influence over the definition of all other indicators as those that establish material aspects and boundaries.

With the purpose of establishing the framework for the analysis of environmental indicators, the ones that identified material aspects and boundaries are firstly considered and shown in Table 8-1. Each indicator has an ID associated that it is also shown in the table.

As the main objective of GRI is to be fully accountable for to the stakeholders of the organizations, indicators related to Stakeholder Engagement also need to be considered despite if the goal of this work is focus only on environmental aspects. Stakeholder Engagement indicators are listed in Table 8-2. 


\begin{tabular}{|c|c|}
\hline & \\
\hline $4-17$ & $\begin{array}{l}\text { List all entities included in the organization's consolidated financial } \\
\text { statements or equivalent document. Report whether any entity } \\
\text { included in the organization's consolidated financial statements or } \\
\text { equivalent documents is not covered by the report. }\end{array}$ \\
\hline G4 - & $\begin{array}{l}\text { Explain the process for defining the report content and the Aspect } \\
\text { Boundaries. Explain how the organization has the Reporting } \\
\text { Principles for Defining Report Content. }\end{array}$ \\
\hline $4-$ & $\begin{array}{l}\text { ist all material Aspects identified in the process for defining report } \\
\text { ontent. }\end{array}$ \\
\hline $4-$ & $\begin{array}{l}\text { For each material Aspect, report the Aspect Boundary within the } \\
\text { organization. }\end{array}$ \\
\hline $4-$ & $\begin{array}{l}\text { For each material Aspect, report the Aspect Boundary outside the } \\
\text { organization. }\end{array}$ \\
\hline $4-$ & $\begin{array}{l}\text { Report the effect of any restatements of information provided in } \\
\text { previous reports, and the reasons for such restatements. }\end{array}$ \\
\hline $4-2$ & $\begin{array}{l}\text { Report significant changes from previous reporting periods in the } \\
\text { Scope and Aspect Boundaries. }\end{array}$ \\
\hline
\end{tabular}

Table 8-2 Stakeholder Engagement indicators

ID

\section{Indicator}

$\begin{array}{ll}\text { G4 - 24 } & \begin{array}{l}\text { Provide a list of stakeholder groups engaged by the organization. } \\ \text { G4 - 25 }\end{array} \\ \text { G4-26 } & \begin{array}{l}\text { Report the basis for identification and selection of stakeholders with } \\ \text { whom to engage. }\end{array} \\ \begin{array}{l}\text { Report the organization's approach to stakeholder engagement, } \\ \text { including frequency of engagement by type and by stakeholder group, } \\ \text { and an indication of whether any of the engagement was undertaken } \\ \text { specifically as part of the report preparation process. }\end{array} \\ \text { G4-27 } \begin{array}{l}\text { Report key topics and concerns that have been raised through } \\ \text { stakeholder engagement, and how the organization has responded to } \\ \text { those key topics and concerns, including through its reporting. Report } \\ \text { the stakeholder groups that raised each of the key topics and concerns. }\end{array}\end{array}$

GRI also define 5 basic indicators to establish the Report Profile. These indicators are grouped in Table 8-3. 
Proposal of a set of Key Performance Indicators for the environmental assessment of Higher Education Institution

Table 8-3 Report Profile indicators

\begin{tabular}{ll} 
ID & \multicolumn{1}{c}{ Indicator } \\
\hline G4 - 28 & $\begin{array}{l}\text { Reporting period (such as fiscal or calendar year) for information } \\
\text { provided. } \\
\text { Date of most recent previous report (if any). }\end{array}$ \\
$\mathrm{G} 4-30$ & $\begin{array}{l}\text { Reporting cycle (such as annual, biennial). } \\
\mathrm{G} 4-31\end{array}$ \\
$\mathrm{G} 4-32$ & $\begin{array}{l}\text { Provide the contact point for questions regarding the report or its } \\
\text { contents. }\end{array}$ \\
& $\begin{array}{l}\text { Report the 'in accordance' option the organization has chosen. Report } \\
\text { GRI Context Index for the chosen option. Report the reference to the } \\
\text { (recommended). }\end{array}$ \\
\hline
\end{tabular}

The environmental category has no subcategories and defines the 12 aspects and 34 indicators as shown in Table 8-4.

Table 8-4 Environmental aspects and indicators ${ }^{39}$

\begin{tabular}{|c|c|c|}
\hline Aspects & ID & Indicators \\
\hline \multirow[t]{2}{*}{ Materials } & G4 - EN 1 & Materials used by weight or volume \\
\hline & G4 - EN 2 & $\begin{array}{l}\text { Percentage of materials used that are recycled input } \\
\text { materials }\end{array}$ \\
\hline \multirow{5}{*}{ Energy } & G4 - EN 3 & Energy consumption within the organization \\
\hline & $\mathrm{G} 4-\mathrm{EN} 4$ & Energy consumption outside the organization \\
\hline & G4 - EN 5 & Energy intensity \\
\hline & G4 - EN 6 & Reduction of energy consumption \\
\hline & G4 - EN 7 & $\begin{array}{l}\text { Reductions in energy requirements of products and } \\
\text { services }\end{array}$ \\
\hline \multirow[t]{3}{*}{ Water } & $\mathrm{G} 4-\mathrm{EN} 8$ & Total water withdrawal by source \\
\hline & G4 - EN 9 & $\begin{array}{l}\text { Water sources significantly affected by withdrawal } \\
\text { of water }\end{array}$ \\
\hline & G4 - EN 10 & $\begin{array}{l}\text { Percentage and total volume of water recycled and } \\
\text { reused }\end{array}$ \\
\hline
\end{tabular}

${ }^{39}$ Continued on the next page. 
Table 84 (cont.) Environmental aspects and indicators ${ }^{40}$

\begin{tabular}{|c|c|c|}
\hline Aspects & ID & Indicators \\
\hline \multirow[t]{4}{*}{ Biodiversity } & G4 - EN 11 & $\begin{array}{l}\text { Operational sites owned, leased, managed in, or } \\
\text { adjacent to, protected areas and areas of high } \\
\text { biodiversity value outside protected areas }\end{array}$ \\
\hline & G4 - EN 12 & $\begin{array}{l}\text { Description of significant impacts of activities, } \\
\text { products, and services on biodiversity in protected } \\
\text { areas and areas of high biodiversity value outside } \\
\text { protected areas }\end{array}$ \\
\hline & G4 - EN 13 & Habitats protected or restored \\
\hline & G4 - EN 14 & $\begin{array}{l}\text { Total number of IUCN Red List species and } \\
\text { national conservation list species with habitats in } \\
\text { areas affected by operations, by level of extinction } \\
\text { risk }\end{array}$ \\
\hline \multirow[t]{7}{*}{ Emissions } & G4 - EN 15 & Direct greenhouse gas (GHG) emissions (Scope 1) \\
\hline & G4 - EN 16 & $\begin{array}{l}\text { Energy indirect greenhouse gas (GHG) emissions } \\
\text { (Scope 2) }\end{array}$ \\
\hline & G4 - EN 17 & $\begin{array}{l}\text { Other indirect greenhouse gas (GHG) emissions } \\
\text { (Scope 3) }\end{array}$ \\
\hline & $\mathrm{G} 4-\mathrm{EN} 18$ & Greenhouse gas (GHG) emissions intensity \\
\hline & G4 - EN 19 & Reduction of greenhouse gas (GHG) emissions \\
\hline & G4 - EN 20 & Emissions of ozone-depleting substances (ODS) \\
\hline & G4 - EN 21 & $\mathrm{NO}_{\mathrm{X}}, \mathrm{SO}_{\mathrm{X}}$, and other significant air emissions \\
\hline \multirow[t]{2}{*}{$\begin{array}{l}\text { Product and } \\
\text { Services }\end{array}$} & G4 - EN 27 & $\begin{array}{l}\text { Extent of impact mitigation of environmental } \\
\text { impacts of products and services }\end{array}$ \\
\hline & G4 - EN 28 & $\begin{array}{l}\text { Percentage of products sold and their packaging } \\
\text { materials that are reclaimed by category }\end{array}$ \\
\hline Compliance & G4 - EN 29 & $\begin{array}{l}\text { Monetary value of significant fines and total } \\
\text { number of non-monetary sanctions for non- } \\
\text { compliance with environmental laws and } \\
\text { regulations }\end{array}$ \\
\hline Transport & G4 - EN 30 & $\begin{array}{l}\text { Significant environmental impacts of transporting } \\
\text { products and other goods and materials for the } \\
\text { organization's operations, and transporting } \\
\text { members of the workforce }\end{array}$ \\
\hline
\end{tabular}

${ }^{40}$ Continued on the next page. 
Proposal of a set of Key Performance Indicators for the environmental assessment of Higher Education Institution

Table 84 (cont.) Environmental aspects and indicators ${ }^{41}$

\begin{tabular}{|c|c|c|}
\hline Aspects & ID & Indicators \\
\hline \multirow{5}{*}{$\begin{array}{l}\text { Effluents and } \\
\text { Waste }\end{array}$} & G4 - EN 22 & Total water discharge by quality and destination \\
\hline & G4 - EN 23 & $\begin{array}{l}\text { Total weight of waste by type and disposal } \\
\text { method }\end{array}$ \\
\hline & G4 - EN 24 & Total number and volume of significant spill \\
\hline & G4 - EN 25 & $\begin{array}{l}\text { Weight of transported, imported, exported, or } \\
\text { treated waste deemed hazardous under the terms } \\
\text { of the Basel Convention Annex I, II, III, and VIII, } \\
\text { and percentage of transported waste shipped } \\
\text { internationally }\end{array}$ \\
\hline & G4 - EN 26 & $\begin{array}{l}\text { Identity, size, protected status, and biodiversity } \\
\text { value of water bodies and related habitats } \\
\text { significantly affected by the organization's } \\
\text { discharges of water and runoff }\end{array}$ \\
\hline Overall & G4 - EN 31 & $\begin{array}{l}\text { Total environmental protection expenditures and } \\
\text { investments by type }\end{array}$ \\
\hline \multirow{2}{*}{$\begin{array}{l}\text { Supplier } \\
\text { Environmental } \\
\text { Assessment }\end{array}$} & G4 - EN 32 & $\begin{array}{l}\text { Percentage of new suppliers that were screened } \\
\text { using environmental criteria }\end{array}$ \\
\hline & G4 - EN 33 & $\begin{array}{l}\text { Significant actual and potential negative } \\
\text { environmental impacts in the supply chain and } \\
\text { actions taken }\end{array}$ \\
\hline $\begin{array}{l}\text { Environmental } \\
\text { Grievance } \\
\text { Mechanisms }\end{array}$ & G4 - EN 34 & $\begin{array}{l}\text { Number of grievances about environmental } \\
\text { impacts filed, addressed, and resolved through } \\
\text { formal grievance mechanisms }\end{array}$ \\
\hline
\end{tabular}

\subsubsection{STEP 3. CASE STUDY. ANALYZE INDICATORS ENVIRONMENTALLY RELATED}

Applying a case study requires not only the analysis of those indicators environmentally related but the general indicators that gives framework to the assessment as described in section 8.2.2 An EMS verified in EMAS requires certain structural committees and personnel dedicated to its maintenance and continuous improvement. Stakeholders information, environmental policy development and environmental audits engage people across all the institution including higher managers as the rector and offices related with infrastructure and resource management. UPV has an environmental office that takes care of EMS. EMS supporting staff and members of the environmental committee should be able to define indicators listed in section 8.2.2 as:

- Identified material aspects and boundaries indicators,

\footnotetext{
${ }^{41}$ Continued on the next page.
} 
- Stakeholder engagement indicators,

- Report profile indicators.

The results of the applicability test of environmental indicators to UPV according to the decision scheme (Figure 8-1) is shown in Table 8-5. An analysis of each aspect is detailed below.

Table 8-5 Environmental indicators applicability assessment ${ }^{42}$

\begin{tabular}{|c|c|c|}
\hline ID & Indicator & Applicability \\
\hline G4 - EN 1 & Materials used by weight or volume & $\begin{array}{l}\text { Needs additional } \\
\text { procedure }\end{array}$ \\
\hline $\mathrm{G} 4-\mathrm{EN} 2$ & $\begin{array}{l}\text { Percentage of materials used that are } \\
\text { recycled input materials }\end{array}$ & $\begin{array}{l}\text { Needs additional } \\
\text { procedure }\end{array}$ \\
\hline G4 - EN 3 & Energy consumption within the organization & Applicable \\
\hline $\mathrm{G} 4-\mathrm{EN} 4$ & $\begin{array}{l}\text { Energy consumption outside the } \\
\text { organization }\end{array}$ & $\begin{array}{l}\text { Needs additional } \\
\text { procedure }\end{array}$ \\
\hline G4 - EN 5 & Energy intensity & Applicable \\
\hline G4 - EN 6 & Reduction of energy consumption & Applicable \\
\hline G4 - EN 7 & $\begin{array}{l}\text { Reductions in energy requirements of } \\
\text { products and services }\end{array}$ & Not applicable \\
\hline G4 - EN 8 & Total water withdrawal by source & Ap \\
\hline G4 - EN 9 & $\begin{array}{l}\text { Water sources significantly affected by } \\
\text { withdrawal of water }\end{array}$ & App \\
\hline G4 - EN 10 & $\begin{array}{l}\text { Percentage and total volume of water } \\
\text { recycled and reused }\end{array}$ & $\begin{array}{l}\text { Needs additional } \\
\text { procedure }\end{array}$ \\
\hline G4 - EN 11 & $\begin{array}{l}\text { Operational sites owned, leased, managed } \\
\text { in, or adjacent to, protected areas and areas } \\
\text { of high biodiversity value outside protected } \\
\text { areas }\end{array}$ & Applicable \\
\hline $\mathrm{G} 4-\mathrm{EN} 12$ & $\begin{array}{l}\text { Description of significant impacts of } \\
\text { activities, products, and services on } \\
\text { biodiversity in protected areas and areas of } \\
\text { high biodiversity value outside protected } \\
\text { areas }\end{array}$ & ble \\
\hline G4 - EN 13 & Habitats protected or restored & Applicable \\
\hline G4 - EN 14 & $\begin{array}{l}\text { Total number of IUCN Red List species and } \\
\text { national conservation list species with } \\
\text { habitats in areas affected by operations, by } \\
\text { level of extinction risk }\end{array}$ & $\begin{array}{l}\text { Needs additional } \\
\text { procedure }\end{array}$ \\
\hline
\end{tabular}

Table 85 (cont.) Environmental indicators applicability assessment ${ }^{43}$

${ }^{42}$ Continued on the next page.

${ }^{43}$ Continued on the next page. 
Proposal of a set of Key Performance Indicators for the environmental assessment of Higher Education Institution

\begin{tabular}{|c|c|c|}
\hline ID & Indicator & Applicability \\
\hline G4 - EN 15 & $\begin{array}{l}\text { Direct greenhouse gas (GHG) emissions } \\
\text { (Scope 1) }\end{array}$ & Applicable \\
\hline G4 - EN 16 & $\begin{array}{l}\text { Energy indirect greenhouse gas (GHG) } \\
\text { emissions (Scope 2) }\end{array}$ & Applicable \\
\hline G4 - EN 17 & $\begin{array}{l}\text { Other indirect greenhouse gas (GHG) } \\
\text { emissions (Scope 3) }\end{array}$ & $\begin{array}{l}\text { Needs additional } \\
\text { procedure }\end{array}$ \\
\hline G4 - EN 18 & Greenhouse gas (GHG) emissions intensity & Applicable \\
\hline G4 - EN 22 & $\begin{array}{l}\text { Total water discharge by quality and } \\
\text { destination }\end{array}$ & Applicable \\
\hline G4 - EN 23 & $\begin{array}{l}\text { Total weight of waste by type and disposal } \\
\text { method }\end{array}$ & Applicable \\
\hline G4 - EN 24 & Total number and volume of significant spill & Applicable \\
\hline G4 - EN 25 & $\begin{array}{l}\text { Weight of transported, imported, exported, or } \\
\text { treated waste deemed hazardous under the } \\
\text { terms of the Basel Convention Annex I, II, III, } \\
\text { and VIII, and percentage of transported waste } \\
\text { shipped internationally }\end{array}$ & Applicable \\
\hline G4 - EN 26 & $\begin{array}{l}\text { Identity, size, protected status, and } \\
\text { biodiversity value of water bodies and related } \\
\text { habitats significantly affected by the } \\
\text { organization's discharges of water and runoff }\end{array}$ & $\begin{array}{l}\text { Needs additional } \\
\text { procedure }\end{array}$ \\
\hline G4 - EN 27 & $\begin{array}{l}\text { Extent of impact mitigation of environmental } \\
\text { impacts of products and services }\end{array}$ & Not applicable \\
\hline G4 - EN 28 & $\begin{array}{l}\text { Percentage of products sold and their } \\
\text { packaging materials that are reclaimed by } \\
\text { category }\end{array}$ & Not applicable \\
\hline G4 - EN 29 & $\begin{array}{l}\text { Monetary value of significant fines and total } \\
\text { number of non-monetary sanctions for non- } \\
\text { compliance with environmental laws and } \\
\text { regulations }\end{array}$ & Applicable \\
\hline G4 - EN 30 & $\begin{array}{l}\text { Significant environmental impacts of } \\
\text { transporting products and other goods and } \\
\text { materials for the organization's operations, } \\
\text { and transporting members of the workforce }\end{array}$ & Applicable \\
\hline G4 - EN 31 & $\begin{array}{l}\text { Total environmental protection expenditures } \\
\text { and investments by type }\end{array}$ & Applicable \\
\hline
\end{tabular}


Table 85 (cont.) Environmental indicators applicability assessment ${ }^{44}$

\begin{tabular}{|l|l|l|}
\hline ID & Indicator & Applicability \\
\hline G4-EN 32 & $\begin{array}{l}\text { Percentage of new suppliers that were } \\
\text { screened using environmental criteria }\end{array}$ & Applicable \\
\hline G4-EN 33 & $\begin{array}{l}\text { Significant actual and potential negative } \\
\text { environmental impacts in the supply chain } \\
\text { and actions taken }\end{array}$ & $\begin{array}{l}\text { Needs additional } \\
\text { procedure }\end{array}$ \\
\hline G4-EN 34 & $\begin{array}{l}\text { Number of grievances about environmental } \\
\text { impacts filed, addressed, and resolved } \\
\text { through formal grievance mechanisms }\end{array}$ & Applicable \\
\hline
\end{tabular}

The material aspect gathered two indicators, G4 - EN 1 and G4 - EN 2. Although it is clear that main product / service of HEI is to educate students and generate graduates and postgraduates the debate of allocation for materials has not been conclusively define yet (Lo Iacono-Ferreira et al., 2016c). However, as the entire organization is the scope of the report, these indicators should be easy to evaluate with the centralized purchasing system. Currently in UPV, purchases depend on departments and the system it is not centralized. This issue has already been detected by the environmental office and actions are being taken to centralize purchasing information.

Energy consumption and all its branches are included in the monitoring system of UPV EMS. However, as the EMS is restricted to the organization, upstream and downstream energy consumptions (energy computation outside the organization indicator, G4 - EN 4) is not part of the current system. Additional procedures need to be applied in order to be able to estimate or count this indicator. The indicator of energy requirements of products and services is not applicable as the considering product / service are human beings. A philosophical debate can be open about the transversal competences included in academic programs that will affect to graduate's future jobs taking the most energy efficient choices. It does not seem to be the goal of the indicator but it could be considered for a sector version for HEI.

All water related indicators (G4 - EN 8 to G4 - EN 10) are applicable despite the volume of water recycled and reused that need to be measured or estimated. A similar result is obtained for biodiversity indicators (G4-11 to G4 - 14); except from the number of species in danger with habitats in areas affected, all indicators are currently part of EMS. UPV has traditional orchards as part of its main campus in Valencia and a flora micro-reserve as part of the campus of Gandía. Although not environmentally risk activities are

\footnotetext{
${ }^{44}$ Continued on the next page.
} 
develops in those lands, there is no accounting and monitoring of resident species besides the botanic guide of the Campus.

GHG of scope 1 and 2 and other significant air emissions are annually assessed by EMS supplying information for indicators G4 - EN 15, G\$ - EN 16 and G4-EN 18 to 21 . However, the environmental office has not enough information to assess scope 3 needing additional procedures if this indicator G4 - EN 17 wants to be included.

UPV environmental annual report published the balance of all wastes generated by type including paper and paperboard, light packaging, ink and tonner, debris, glass, batteries, vegetable wastes and dangerous waste. It also includes an estimation of municipal solid waste. Both teaching and researching laboratories, as well as maintenance facilities, register any significant spill. Indicators under Effluents and waste aspect (G4 - EN 22 to 26) are already part of EMS.

Products and services indicators (G4 - ES 27 and G4 - EN 28) are not applicable as HEI does not produces conventional products. Moreover, EMS periodically monitor environmental laws and regulations applicable to the institution. G4 - EN 29 can be easily reported.

With regard to transport, UPV developed a mobility plan based on a mobility study entrusted to a third-party specialist. Mobility is a big challenge for HEI and significant improvements can be accomplished in this area. G4 - EN 30 is already part of UPV EMS. Likewise, a general incident reporting system allows the environmental office to evaluate grievances periodically. This information can build indicator G4 - EN34.

General expenditures and environmental investments (G4 - EN 31) can be reported directly form chancellor office. However, some investments may be unnoticed as departments managed certain budget items independently. Same reason why indicators gathered under supplier aspect (G4 - EB 32 and 33) need additional procedure to be assessed.

To sum up, Figure 8-2 shows statistics over results where the $70 \%$ of indicators can be considered as immediately applicable. Although there is a $21 \%$ that need additional procedures, they can be part of the system in a medium term.

A $9 \%$ of the indicators are considered not applicable. Note that not applicable indicators must be included in the index reported as G4 -23 . The reason for omission has to be provided. It is recommended to include the information related to the indicator omitted in the external assurance to be verified. 


\section{- Applicable " Needs additional procedure " Not applicable}

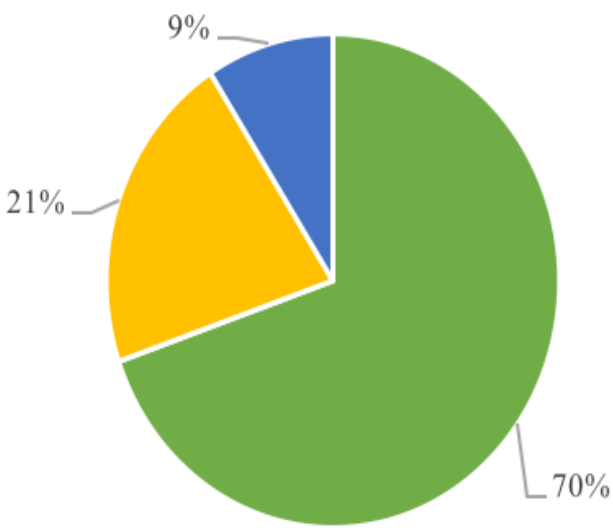

Figure 8-2 Results

\subsection{CONCLUSIONS}

The report of the environmental behavior of an organization like a HEI requires the engagement of influential people to ensure the initiative. G4 GRI provides a robust guideline to deliver information about the environmental behavior of an organization as part of its sustainability report.

Overall, 23 of the 34 environmental indicators defined by GRI can be directly applicable or are already included in UPV EMS. Only 3 indicators, a 9\%, are not applicable and can be justified following the guide. 7 indicators might be added in a medium-term enriching EMS. G4 guideline can be part of the annual environmental report preparation. Moreover, G4 complete sustainability report can add transparency to a public institution as UPV.

Although a material flow analysis is required, aspects are defined by the guide. This is an advantage over other tools that leaves the development of the inventory of aspects to who applies it. i.e. Ecological Footprint. Despite there is no official sector or pilot versions dedicated to HEI, there are some characteristics that might be useful to define officially as if including transversal competences in environmental management reduces the environmental impact of graduates downstream. 


\subsection{REFERENCES}

Alonso-Almeida, M.D.M., Marimon, F., Casani, F., \& Rodriguez-Pomeda, J. (2015) Diffusion of sustainability reporting in universities: current situation and future perspectives. Journal of Cleaner Production, 106, 144-154. http://doi.org/10.1016/j.jclepro.2014.02.008

Cole, L., (2003) Assessing Sustainability on Canadian University Campuses: Development of a Campus Sustainability Assessment Framework. Royal Roads University. Victoria, BC.

Global Reporting Initiative. (2006) RG Sustainability Reporting Guidelines, G3. Global Reporting Initiative. Retrieved on March $1^{\text {st }} 2016$ from https://www.globalreporting.org/resourcelibrary/G3-GuidelinesIncl-Technical-Protocol.pdf

Global Reporting Initiative. (2011) RG Sustainability Reporting Guidelines, G3.1 Global Reporting Initiative. Retrieved on March $1^{\text {st }} 2016$ from https://www.globalreporting.org/resourcelibrary/G3.1-GuidelinesIncl-Technical-Protocol.pdf

Global Reporting Initiative (2013a) G4 Sustainability Reporting Guidelines. Global Reporting Initiative. Retrieved on March $1^{\text {st }} 2016$ from https://www.globalreporting.org/resourcelibrary/G4-Package.zip

Global Reporting Initiative (2013b) G4 Implementation Manual. Global Reporting Initiative. Retrieved on March $1^{\text {st }} 2016$ from https://www.globalreporting.org/resourcelibrary/GRIG4-Part2Implementation-Manual.pdf

Hespenheide, E. (2015, November 27th). The future of reporting. [Video file]. Video published in https://youtu.be/rIS03rn13 I

Lo Iacono Ferreira, V.G., Torregrosa-López, J.I., López Pérez, F., PachecoBlanco, B., Viñoles-Cebolla, R. (2011a) Comparative Analysis of the methodology of calculation of EF in different areas. XV International Congress on Project Management. Huesca. AEIPRO ISBN: 978-84615-4543-8

http:/www.aeipro.com/aplic/tree congresos/detalle remository aei pro.php?file $=3331$

Lo-Iacono-Ferreira, V.G., Torregrosa-López, J.I., \& Capuz-Rizo, S.F. (2016c) Use of Life Cycle Assessment methodology in the analysis of Ecological Footprint Assessment results to evaluate the environmental performance of universities. Journal of Cleaner Production, 133, 43-53. http://doi.org/10.1016/j.jclepro.2016.05.046 
Lozano, R. (2006a) A tool for a graphical assessment of sustainability in universities (GASU). Journal of Cleaner Production, 14, 9-11. http://dx.doi.org/10.1016/j.jclepro.2005.11.041

Lozano, R. (2011) The state of sustainability reporting in universities, International Journal of Sustainability in Higher Education, 12(1), 67-78. http://doi.org/10.1108/14676371111098311

Torregrosa-López, J.I., Lo Iacono-Ferreira, V.G., Barranco-Martí, C., \& Bellver-Navarro, C.G. (2016) The strengths of EMAS as an environmental management system for European university campuses. International Journal of Environment and Sustainable Development, 15(1), 89-106. http://dx.doi.org/10.1504/IJESD.2016.073339

Urbanski, M. \& Filho, W. (2014) Measuring sustainability at universities by means of the Sustainability Tracking, Assessment and Rating System (STARS): early findings from STARS data. Journal of Environment, Development and Sustainability, 17, 209-220. http://doi.org/ 10.1007/s10668-014-9564-3 



\section{KEY PERFORMANCE INDICATORS TO ASSESS ENVIRONMENTAL PERFORMANCE OF HIGHER EDUCATION INSTITUTIONS. CASE STUDY OF UNIVERSITAT POLITĖCNICA DE VALÈNCIA.}

Lo-Iacono-Ferreira, Vanesa G., Capuz-Rizo, Salvador F.; Torregrosa-López, J.I. (n/n) Key Performance Indicators to optimize the environmental performance of Higher Education Institutions with EMS. Case study of Universitat Politècnica de València. (Under review)

Notice that this paper has been edited to match the style chosen for this document. Figures and tables have also been edited (only format). Abbreviations have also been homogenized. A complete abbreviation code is provided in page 23.

\section{ABSTRACT}

The environmental performance has been gaining importance in the organization's decision-making boards. As is the case with all organizations, Higher Education Institutions with environmental awareness require tools to help the development of policies and programs toward a better performance.

Key Performance Indicators are usually part of economic and financial decision-making boards. The definition of a set of Key Performance Indicators regarding the relevant environmental aspects of an institution seems to be a step toward the integration of environmental issues in the overall management.

In this paper, a methodological proposal to define environmental Key Performance Indicators for Higher Education Institutions with a robust Environmental Management System (ISO certified or EMAS verified) is proposed, together with a validation system based on Meta-performance evaluation indicators. The proposal is based on the significant environmental aspects along with the degree of operational control that the organization has over them. Additionally, a list of over 140 environmental indicators described and classified are offered as inspiration.

An environmental unit, EPSA, of Universitat Politècnica de València, EMAS verified, is used as a pilot case study. As a result, seven Key Performance Indicators are defined, although only three could be fully assessed. Energy consumption, waste management treatment and greenhouse gases emissions are the key elements of these indicators. 
Proposal of a set of Key Performance Indicators for the environmental assessment of Higher Education Institution

Institutions with robust Environmental Management Systems have significant advantages on the identification of the relevant environmental aspects and the definition of the goals that set the start point to define Key Performance Indicators. However, these systems do not ensure the availability of data or the quality desired. In the case study, additional resources are required in order to obtain results for the Key Performance Indicators that assess its significant environmental aspects. The effort would benefit both the Environmental Management System and the decision-making board.

\section{Acknowledgements}

Authors would like to thank Universitat Politècnica de València and specially the environmental office for their support during this research.

\subsection{INTRODUCTION}

Many organizations seek ways to understand, communicate and improve their environmental performance. This can be achieved by effectively managing those elements of their activities, products and services that can significantly impact the environment (International Organization for Standardization, 2013b) HEIs are not an exception. The number of HEIs which are aware of their environmental impact has increased in the last decades. As in any enterprise, an EMS can be launched at a HEI. There are several examples with different degrees of involvement and commitment, e.g. Gustavo De Lima et al., (2016), Hancock and Nuttman, (2014) and Lozano et al. (2014). The communication and reporting of performances and strategies related either to the environment or to the whole sustainability package have also emerged, the communication does not necessarily mean that the organization is doing its best (Beloff et al., 2004).

Although activities, products and services are not as easy to identify as in industrial or services companies, they are part of the daily operation of a HEI. Qualified students, expert teachers and successful researchers can be seen as HEIs products along with patents and startups generated as a result of their activities. HEIs frequently provide services to companies and governments on those issues where they have expertise. All these actions are articulated through a large number of management, research, teaching and development activities. Assessing the environmental performance of these activities is the key for having a HEI as environmentally responsible as possible toward its sustainable development (Disterheft et al., 2012).

Traditional environmental assessments of HEIs encompass three activities (teaching, researching and technology transfer services) probably because their individual impacts are difficult to allocate. The simplest systems are limited to treat the information available, without major efforts to expand this information. The results can be useful, in some way, to assess the evolution 
of those aspects studied. HEIs with resources and a certain environmental degree have a dedicated office with an EMS (certified or verified) to manage and assess environmental issues related to their activity. Cons of these systems are widely known; e.g. lack of detailed information, replicate issues, etc. in essence, lack of standardization (Mazzi et al., 2012; Torregrosa-López et al. 2016).

For a successful management (including the definition of environmental policies), managers need information about the performance and tendencies of the organization (Azma, 2010; Bauler, 2012). There are many ways to get information. Their efficiency depends on the type of organization and the use of the information. Aggregate indicators, for example, compile data on a single index. The aggregation of data on a single index might increases the risk of losing relevant information (Alam et al., 2016). Ecological Footprint can be an example of a single index where the result is skewed by the criteria followed through the assessment among other considerations (Lambrechts and Van Liedekerke, 2014; Lo-Iacono-Ferreira et al., 2016a). Other techniques are available to aggregate information. Multi-criteria analysis has proven to be useful in aggregation, although evaluators need to make some choices adding uncertainty to the assessment. Initiatives that combine tools were developed trying to solve some of the problems that traditional EMS has. For example, the combination of different management tasks as life cycle assessment (LCA), multi-criteria analysis and performance indicators trying to solve the lack of detailed information (Hermann et al., 2007). Nevertheless, having accurate environmental information shouldn't be a problem if there is a well-developed EMS.

Performance Indicators (PIs) are goal-related indicators that include the reference point needed for their evaluation (Barnetson and Cutright, 2000). They indicate if targets will be met and shed light over the requirement of additional measures. According to ISO 14031 (International Organization for Standardization, 2013b) environmental PIs provide data and information about the organization's environmental performance. These indicators can be classified in two types: (a) operational performance indicators, which provide environmental performance information on the operation of the production or service processes developed by the organization, and (b) managerial performance indicators which provide information efforts that influence positively the environmental performance of the organization (Perotto et al., 2008).

Performance indicators must have certain characteristics and properties to be considered in order to ensure usability, comparability and consistency (Bonaccosi et al., 2007; Bauler, 2012; International Organization for Standardization, 2013b): 
Proposal of a set of Key Performance Indicators for the environmental assessment of Higher Education Institution

- Intelligible: Meaning and theoretical terms should be clear and welldefined.

- Useful: Procedures must be exhaustively defined in order to ensure comparability even if it is an indicator for internal use only. Indicators must be easy to measure and easy to apply.

- Standardized: A standardization or functional unit is required to give meaning to the indicator. EMAS (European Commission, 2009), for example, proposes the ratio input / output; an easy to use standardization for traditional companies with clear outputs. HEIs required additional considerations regarding outputs or results given their nature as described above.

- Sensitive: The sensitivity to stresses on the system must be perceptible and the response to stress, predictable.

- Coherent: All PIs must be coherent with the environmental policy of the organization.

- Representative: The environmental performance of the organization must be represented by the set of indicators defined.

KPIs are indexes used to evaluate the crucial factors related to a defined goal (e.g. zero waste management system). The success of the organization in achieving this goal depends on these factors. Identifying the crucial factors and follow them up is a way to know how the organization is developing (Kerzner, 2011; Zaman, 2014).

When KPIs are defined, additionally to the properties and characteristics mentioned for PIs, the SMART criteria must be followed ensuring Specific, Measurable, Achievable, Relevant and Timely indicators (Doran, 1981). The set of key indicators should provide coverage of the system having a known response to natural disturbances and changes over time.

If these indicators are also environmental indicators, resulting environmental KPIs, its integration in the EMS would provide relevant information about how the organization is managing those crucial factors linked to the environmental performance. As environmental indicators, it is advisable that they fit in the DPSIR framework (Drive forces, Pressure, State, Impact, Response) used by organizations as the European Environmental Agency in its reporting activities (Smeets and Weterings, 1999). DPSIR scheme is shown in Figure 9-1 where the interactions between each type of indicator can be seen.

- Drive forces indicators represents human influence and natural conditions that drives changes on the environment (population growth).

- Pressures indicators show the stress that human activities and natural conditions place on the environment (e.g. $\mathrm{CO}_{2}$ emissions). 
- State indicators represent the condition of the environment (e.g. Concentration of $\mathrm{CO}_{2}$ ).

- Impacts indicators show the effects of environmental changes, either biological, economic or social (e.g. percentage of population exposed to noise).

- Responses indicators account the actions or responses of society to the environmental situation (e.g. environmental expenditures).

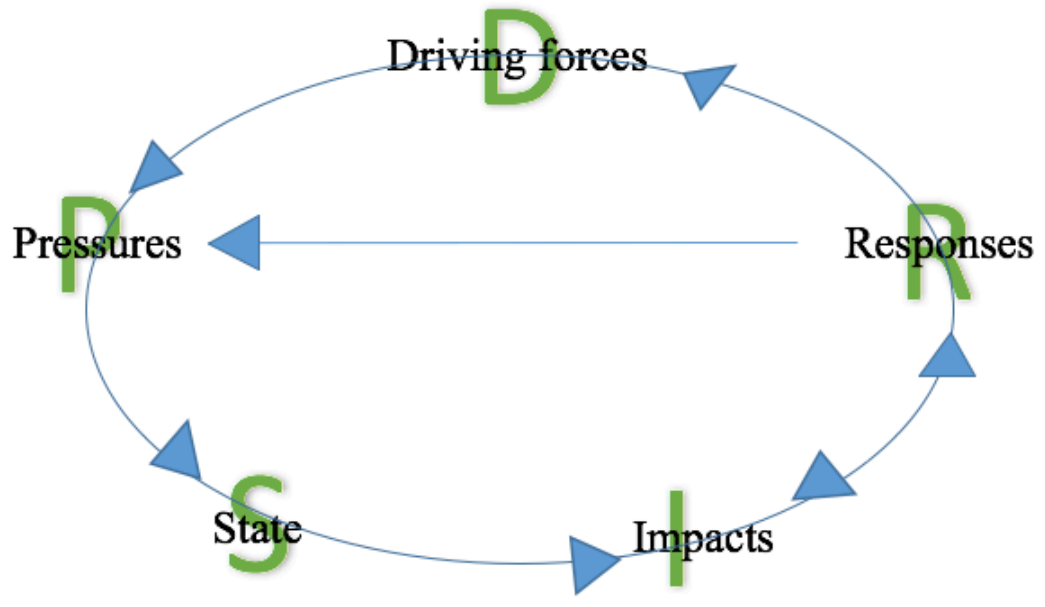

Figure 9-1 DPSIR framework

In addition to the DPSIR framework, the European Environmental Agency (2014) classifies environmental indicators by ABCDE typology where:

- Type A are descriptive indicators;

- Type B gather those indicators that answers the question 'Does it matter?', better known as PIs;

- Type $\mathrm{C}$ are efficiency indicators;

- Type D are policy effectiveness indicators and,

- Type E are total welfare indicators, normally presented by overall measures like the Index of Sustainable and Economic Welfare.

It has to be noticed that any Type A indicator can be easily converted into Type B by referring them to a target or a reference condition. PIs are relevant when an institution is accountable for changes in environmental pressures or states.

A set of KPIs may be a promising decision-making tool if they represent the main characteristics of the system. Other tools or supplementary information might be needed to address additional goals (Hermann et al., 2007; Organization for Economic Cooperation and Development, 2008). 
Proposal of a set of Key Performance Indicators for the environmental assessment of Higher Education Institution

Additionally, to their usefulness for managers, communicating the appropriate indicators can also benefit the overall status of the HEI (Lukman et al., 2010).

In this paper, a methodological procedure for defining environmental KPIs for HEIs is proposed. UPV has been chosen as a case study due to its EMS verified in EMAS that has proven to be a valuable source of environmental information regarding HEIs behavior (Lo-Iacono-Ferreira et al., 2016c). This work also summarizes the analysis made to define KPIs for one of the UPV EUs following the proposed methodology. An environmental unit is a delimitated area with well-defined functions. UPV EMS divided the HEI in EUs for a better tracking and management serving as a pilot for this study. The EU chosen is EPSA. The system boundary of this EU is defined further in this paper.

\subsubsection{LITERATURE REVIEW OVER ENVIRONMENTAL INDICATORS RELEVANT TO HEIS}

There are several tools based on indicators to assess urban sustainability of cities where the environmental performance is included. Campuses have strong similarities to small cities or towns which is the reason why these indicators deserve consideration (Alonso-Almeida et al., 2015; Wright and Wilton, 2012). Braulio-Gonzalo et al. (2015) carried a depth analysis of these tools including LEED ND, BREEAM Communities, CASBEE UD, ECOCITY, Le Modele INDI-RU 2005, The BRIDGE project, KITCSAP among others.

García-Sánchez et al. (2015) explored the Environmental Performance Indicators (EPIs) for countries in the process of a composite index proposal based on Driving Force-Pressure-State-Exposure-Effect-Action (DPSEEA) methodology. A robust and complete method focused on the reduction of the environmental impact on human health. LCA and multi-criteria analysis are combined with EPIs in COMPLIMENT, a tool designed to assess environmental impact of businesses (Hermann et al., 2007). During the process, an exhaustive and interesting description of EPIs is made highlighting its strengths and weaknesses as assessment instruments. Later, Hourneaux Jr et al. (2014) studied the real usefulness of EPIs for businesses. Both studies provide knowledge that can be brought to HEIs with some considerations already studied by Walton and Galea (2006).

The literature on environmental indicators is usually broad and diverse e.g. Moldan et al., (2012) compared a wide number of indicators environmentally related while Singh et al. (2012) overviewed all sustainability assessment methodologies including several environmental composite indexes as the ecological footprint. Furthermore, several handbooks and databases about EPIs definition can be found, e.g. EEA's Indicator Management System 
(European Environmental Agency, 2016), the Yale Center of Environmental Law \& Policy Practical Guide (Hsu et al., 2013), United Nations Statistics Division (2016), Environmental Indicators by Wild et al. (2015) or the Organization for Economic Cooperation and Development (OECD) handbooks (Organization for Economic Cooperation and Development, 2008, $2014,2015)$ that goes beyond generic EIs and focus on key environmental indicators (performance and non-performance indicators).

KPIs are commonly applied with economic or financial purposes (e.g. Azma (2010), Serdar (2010)). Regarding standards, in ISO 14031 a procedure can be found for environmental performance assessment through KPIs (International Organization for Standardization, 2013b; Campos et al., 2015). Although HEIs have substantial differences with regular corporations (in size, aim, management structure, etc.), the procedure and outcomes also deserved consideration. Dočekalová and Kocmanová (2016) identified KPIs related to the environment along with societal and economic indicators for sustainability measurement of corporations by analyzing different sustainability reporting and managing tools also included in Braulio-Gonzalo et al. (2015) analysis.

Fernández et al. (2011) applied Bayesian networks to define the relevance of the indicators that better describe the academic performance of a HEI. Barnetson and Cutright (2000) analyzes funding related PIs applied in HEIs, including a rigorous review of voluminous related literature, to develop a typology of assumptions commonly embedded in these types of indicators contesting its objectivity.

The use of environmental indicators in HEIs is extended although they are not defined and/or managed as key indicators. Olszak (2012) studies the sustainability assessment of campuses where environmental indicators are included as part of the sustainability concept. Waheed et al. (2011) developed a sustainability indicators-based tool for HEIs using DPSEEA framework where the environment is well represented.

Finally, there are two reporting tools that deserve to be highlighted: (a) the GRI, a sustainability reporting guidance for any type of organization (Global Reporting Initiative, 2013a; Lo-Iacono-Ferreira et al., 2016b) and (b) the Sustainability Tracking, Assessment \& Rating System TM STARS (The Association for the Advancement of Sustainability in Higher Education, 2016); a self-reporting framework for HEIs to measure their sustainability performance. Both tools include environmental performance indicators as part of their reporting process. The main difference between them is the complexity of the indicator; while GRI offers simple indicators, the Association for the Advancement of Sustainability in Higher Education (AASHE) suggests composite indicators that require significant time and resources to be measured. 
9.1.2 METHODS

To address the aim of this study, which is to develop a methodology to define environmental KPIs for HEIs with a robust EMS, a detailed review of literature has been made. The characteristics of EMS along with the particularities of HEIs have been deeply considered. Over 300 environmental indicators have been analyzed. A description and classification of the environmental indicators applicable to HEIs is presented in Annex 9 A. This information is used as a complementary support for the methodological proposal. The knowledge acquired from the implementation and management of EMS at UPV has served as guidance.

As a result, in section 9.2, a methodological proposal to define environmental KPIs for HEIs with robust EMS is presented. Section 9.3 presents the results of applying this methodology to one of the EU of UPV, EPSA, as a pilot. Conclusions and further studies are summarily defined in section 9.4.

\subsection{METHODOLOGICAL PROPOSAL}

In order to identify those key indicators to optimize the environmental performance of HEIs that have a robust EMS (either verified in EMAS or simply certified in ISO 14001), a procedure of continuous improvement is suggested. The entire procedure proposed is described in Figure 9-2.

Fiksel (2002) states that key indicators should be defined over the needs of the organization on a stable basis. In this sense, the first step requires the definition of the reporting organization and its system boundary. If any significant changes are detected in further iterations of the study, the definition has to be updated.

The second step identifies the environmental aspects (EA) considering both the relevance and the level of control that HEI has over the aspect. As a result, those aspects with a clear relation to the environmental performance of the organization will be highlighted.

The definition of goals based on these results is the third stage. Scheme shows a link to a highly-recommended procedure, the consulting of stakeholders. The relevance of this protocol is discussed further in this paper.

Goals will serve as a framework for the forth step: the definition of KPIs. The definition of environmental KPIs shall be based on the list of environmental aspects and the specific goals previously described.

Once KPIs are defined, managers can integrate the set of environmental KPIs in the management system together with the other KPIs. The definition of targets, a policy development, the implementation of an action plan and the 
analysis of the degree of compliance are foreseen and are not within the scope of this study.

A report is expected to improve the synergies between the top-management of the HEI and the EMS. The time period of each KPI and, therefore, its next evaluation is strongly related to the targets and action plans defined. However, as KPIs are pretended to be also fully integrated in the EMS, an annual assessment as part of the annual review of the EMS is suggested. The continuous improvement cycle will start with the update of the register of environmental aspects.

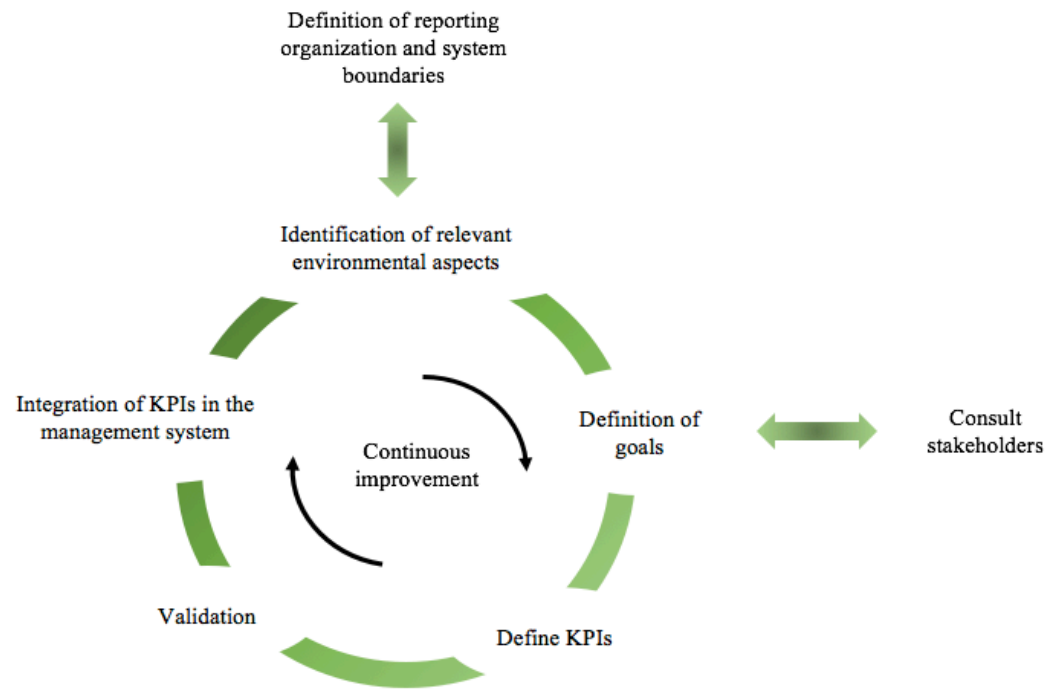

Figure 9-2 Methodological procedure proposal for the definitions of environmental KPIs for HEIs with EMS.

The identification of relevant aspects, the determination of goals and the definition of KPIs are described further in this section. The definition of KPIs includes the definition of a reporting organization and a validation procedure. The analysis of the EIs gathered in the literature review along with its classification is also included as a tool for the KPIs definition step.

The synergies between the methodological proposal and the characteristics of EMS verified in EMAS or certified in ISO are highlighted when applicable.

\subsubsection{DEFINITION OF THE REPORTING ORGANIZATION}

The methodology requires the definition of the reporting organization to describe the organization whose environmental performance want to be optimized. ISO 14072:2014 (International Standard Organization, 2014a) offers a guide to unambiguously state the organization to be studied, the 
reporting organization, its scope and system boundary. The definition of the reporting organization has to be completed with the specification of the activities and processes that take place within the scope of the reporting organization. Following ISO 14072 standard ensure a life cycle point of view to this procedure that enriches the environmental management and builds bridges between well-recognized tools as LCA. The general goal of the study is already pre-defined - the optimization of the environmental performance of the organization - as it is the motivation of this methodological proposal.

The definition of system boundaries shall be based on Braunschweig (2014) proposal as an extension of the GHG Protocol Corporate Standard (World Resources Institute and World Business Council for Sustainable Development, 2011):

- Scope 1 for direct emissions, resources use and waste generation,

- Scope 2 for indirect emissions, resources use and waste generations associated exclusively with infrastructure usage,

- Scope 3 for all other indirect emissions, wastes and resources used

Complex organizations as HEIs might be difficult to assess as a whole, moreover when human and economic resources are limited. For these cases, the environmental unit (EU) is suggested as a reporting organization. The EU is a physically defined area with operational control of, at least, one operation (process or activity). Although it is not a standardized concept, it has been validated during the EMAS verification of the EMS of UPV in 2009.

Any HEI can be divided in independent EUs with the proper definition. However, special care has to be taken to avoid double assignment of operations and impacts. The environmental reviews, mandatory for EMAS, requires a deep description of the organization itself to identify environmental impacts and legal requirements that makes the definition of EU a simple step.

As a result of this first step, assessors should document the definition of the reporting organization including:

- Description of the HEI (size, infrastructure, number of students and employees, etc.),

- System boundary definition,

- Description of HEI's operations: activities and processes that takes place within the scope defined.

The definition of the reporting organization shall be reviewed and rectified if any significant changes take place within the system boundary defined. 


\subsubsection{IDENTIFICATION OF RELEVANT ENVIRONMENTAL ASPECTS}

The second step is to identify and prioritize the EA of the reporting organization. This step is easy to address in HEIs with EMS verified in EMAS, or certified in ISO 14001, as the identification of the EA is a requirement during its implementation process. Additionally, the regular environmental review required by EMAS to identify and assess any new EA, ensures that the list of EA is always up to date.

In previous studies, a prioritization procedure to assign resources and efforts for the collection of EA data has been developed (Lo-Iacono-Ferreira et al., 2017). The procedure considers the significance of each EA (Environmental Aspect State -EAS) and the level of operational control that the reporting organization has over the aspect, the Control State (CS). The scheme of the procedure is shown in Figure 9-3.

Results of each EA are obtained by adding the scores of all activities and processes identified with each EA. As a result, a list of scored EA is obtained. The EA with a higher score deserves more resources (human and economic) to address a more accurate assessment of their impact. It should be noted that the prioritization procedure goal is to optimize the use of resources considering, in the first place, those EA the significance and degree of control of which allows more improvements with less resources. This procedure does not pretend to classify the EA by its environmental impact as, at this stage, the environmental impact is not yet assessed.

As is known, EMS certified in ISO or verified in EMAS must define an environmental policy appropriate to the nature, scale and environmental impacts of its activities (International Organization for Standardization, 2004; European Commission, 2006). This environmental policy becomes a framework for the definition of specific goals along with the sorted list of EA developed in the previous step. These goals would serve as seeds in the process of KPIs definition.

This proposal also encourages assessors to consult stakeholders regarding their interest on the environmental performance of the reporting unit. Taking into account the stakeholders' interests significantly improve the chances of addressing successful action plans. Their commitment benefit the outcome of those plans where they are directly involved. Environmental issues usually require the commitment of at least some of the stakeholders, e.g. applying green purchase criteria, managing waste or changing transport mode. However, addressing stakeholders' interests requires certain expertise to avoid obstacles in the decision-making process that can lead to paralysis (White, 2015). 
Proposal of a set of Key Performance Indicators for the environmental assessment of Higher Education Institution

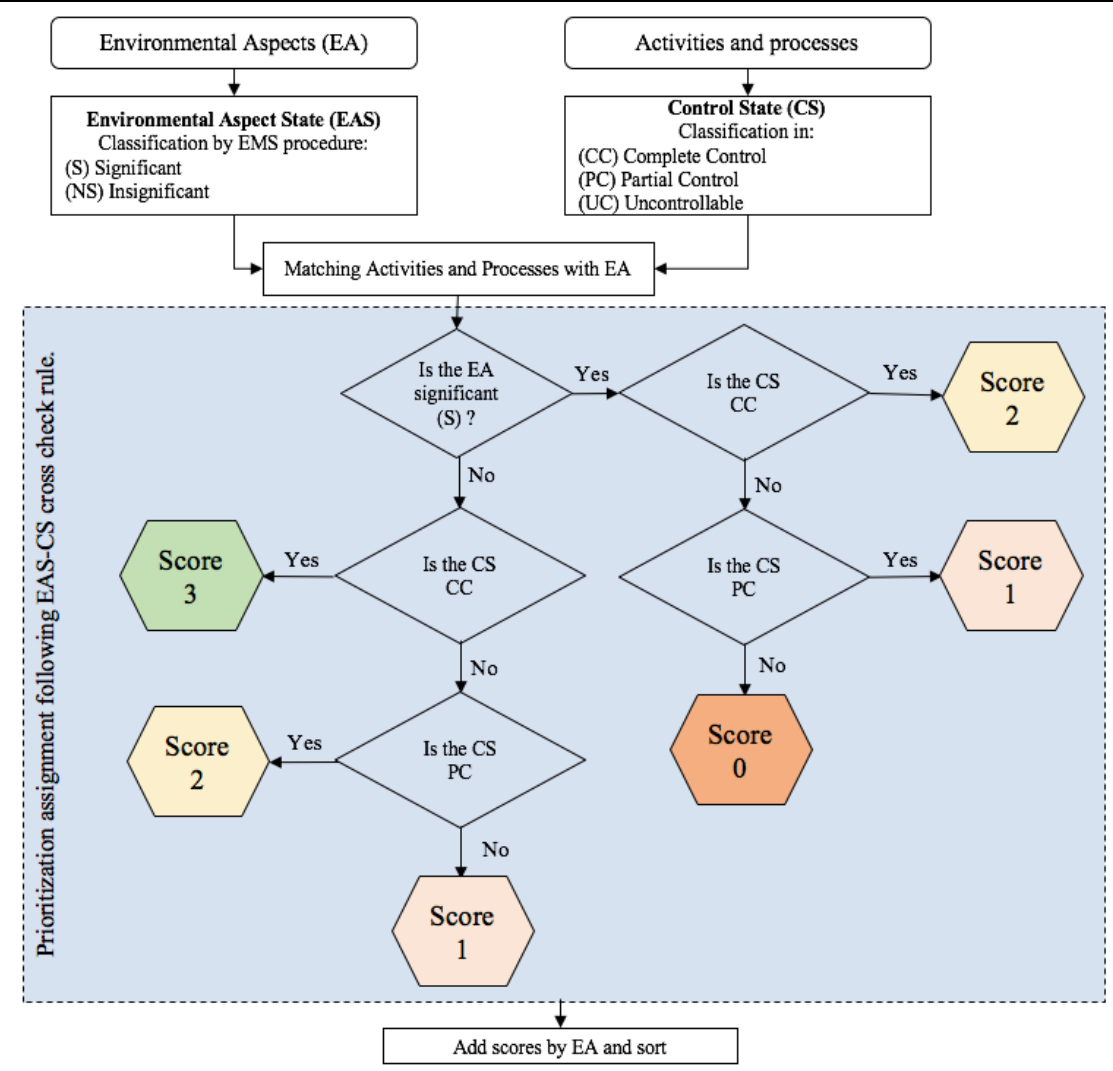

Figure 9-3 Prioritization procedure cross-score EAS-CS. For more details see Lo-IaconoFerreira et al. (2017) Definition of goals

The procedure to identify stakeholders is not within the scope of this research; several methods are available and discussed by recognized authors as Achterkamp \& Vos (2008) and Bryson (2007), among others. Questionnaires, interviews and behavioral analysis might serve as tools to identify stakeholders' interests. HEIs with EMAS can take advantage of their employees' involvement activities to advertise the use of environmental KPIs and benefit from their driving force.

Top managers are natural stakeholders of the organization and their commitment is extremely important as environmental projects need to be developed and the equilibrium of the social and economic dimensions might require their full commitment. When top managers of the reporting organization are chosen by competitive selection, environmental needs of the stakeholders can be easily identified if environmental issues are included in the candidates' programs. 
Goals can also be defined unilaterally by assessors and validated in further iterations analyzing the commitment of the community with the projects developed to address them. The number of goals are directly proportional with the number of KPIs to define, as the aim of KPIs would be to assess the pursue of these environmentally related goals. A conservative number of goals is preferable. Goals can be added on each iteration of the procedure.

\subsubsection{DEFINITION OF KPIS}

The aim of KPIs is to track the performance of the established goals; in this case, environmental goals. They have to be SMART (specific, measurable, achievable, relevant, timely), easy to use, traceable and consistent with the operation of the organization and its policies.

Defining a KPI requires identifying what is going to be measured and how, including the functional or reporting unit to be considered.

When the organization under analysis has an easily defined outcome (product or service), the functional unit is the concept applied (International Organization for Standardization, 2006b). However, for complex organizations as HEIs, the reporting unit can be also useful. The reporting unit is a concept developed for ISO 14072:2014 as a quantified performance expression of the organization to be used as a reference.

Once EA are identified and goals are defined, the definition of environmental KPIs is mainly a matter of straightforward common sense and the assessors' know-how. Notice that the defined KPIs shall be validated in the next step and, as the entire methodological procedure is based on a continuous improvement cycle, the assessors expertise will enrich the review of KPIs in the following iteration.

A list of environmental indicators applicable to HEIs, gathered for the literature review, is shown in Annex A. This list can be used as an inspirational tool to define the most appropriate environmental KPIs considering the EA and the goals previously stated. The list is composed by more than 140 indicators including types A, B, C, D and E and classified under the DPISR framework. Indicators are organized by areas: Air pollution, Biodiversity, Climate change, Energy, Environmental scenarios, Food and beverage, Green economy, Infrastructure, Land use, Materials and resources, Transport, Waste and effluents and Water. A classification of the indicators regarding if they are simple or composite is also included. It has to be considered that additional environmental indicators must be applicable when the organization has specific activities or properties different than the traditional ones, e.g. the management of a forest area for research purposes. 
Proposal of a set of Key Performance Indicators for the environmental assessment of Higher Education Institution

9.2.4 VALIDATION METHOD: META-PERFORMANCE EVALUATION

An adaptation of Ramos and Caeiro (2010) meta-performance evaluation method is suggested as a validation tool. The validation framework has been originally developed for the assessment of sustainable development indicators but it is flexible enough to be adapted to environmental performance indicators for HEIs. The procedure is carried out in two levels:

- Level 1. Performance of KPIs system: planning and methodological approach

- Level 2. Performance of KPIs at the implementation and operation stage

Following Ramos and Caeiro (2010) method, key good practices factors are suggested in the validation framework for each level to be used as a validation tool for the environmental KPIs defined. In addition, each key good practice factor requires at least one meta-performance evaluation indicator. The complete list of meta-performance evaluation indicators related to key good practice factors for both levels are described in Annex 9 B.

The present methodological proposal encourages assessors to rigorously address the validation and strongly advices to consider all the metaperformance evaluation indicators suggested.

Once environmental KPIs are defined and validated, they are ready to be integrated in the overall management system of the reporting organization for which they have been defined. If top-managers were not part of the previous process, a detailed report shall be presented to them in order to provide insight of the KPIs' meaning and utility. However, authors of this proposal strongly encourage the consideration of the stakeholder's interest and their participation, as their commitment might be vital for the success of environmental performance optimization action plans.

The following stages are foreseen as part of regular management operations:

- Targets setting

- Consistency review between indicators and targets

- Policy development

- Definition and implementation of action plans

- Analysis of the degree of compliance of targets

- Reports

Once environmental KPIs are part of the overall management system of the reporting organization, it is expected to consider them in an equal basis with any other KPI already integrated. However, their performance should be reported both to the EMS and to assessors in order to track their SMART characteristics and to close the continuous improvement cycle. 


\subsubsection{CONTINUOUS IMPROVEMENT CYCLE AND REPORTING}

An EMS verified in EMAS already has a continuous improvement procedure as it is required for its verification and its maintenance. The cycle can be easily included in the annual review of the system and verified by the internal audits. ISO certified EMS does not ensure this feature; however, it is compatible with the system if there are enough resources available.

The report of the environmental KPIs defined along with their value is highly recommended. The environmental awareness of the community and the commitment of stakeholders can be significantly improved along with the confidence of the society due to a transparent environmental management.

For those EMS verified in EMAS, KPIs can be easily included as part of the external communications protocol already implemented. As ISO only requires internal communications, an effort has to be made in this direction to improve the benefits of the procedure.

\subsection{Results: Definition of ENVIRONMENTAL KPIS FOR EPSA}

This section presents the results of applying the methodology proposal to define environmental KPIs for a pilot EU of UPV, EPSA.

\subsubsection{DEFINITION OF THE REPORTING ORGANIZATION: EPSA}

UPV is a medium size HEIs located in the south east of Spain and composed by three main campuses in the Valencia region, with almost 70 ha of building surface and 13 ha of landscaped area. In 2015, UPV had more than 38000 students and over 8000 staff members. It is, up to now, the biggest HEI (NACE code: 85.42 ) with an EMS verified in EMAS for the entire university (Code: UPV.MA-INF.RSGA.2015-UPV-01). EMS is managed by the Environmental Office (EO) who takes care of the 211 EU defined.

The decision of applying the methodology to EPSA as a pilot EU of UPV is based on the following:

- Simplicity: HEIs structure is complex and heterogeneous. Contrary to companies that have a pyramidal structure where the executive committee or president coordinate the different areas composed by several departments; each HEI is one-of-a-kind. The EU is a welldefined area easy to identify and assess as already defined in the introduction.

- Accessibility: the authors of this paper have extensive knowledge of the operation of EPSA as well as easy access to data related. 
Proposal of a set of Key Performance Indicators for the environmental assessment of Higher Education Institution

EPSA has 2.9 ha of building surface and 1.2 ha of green areas. In 2015, there were 2500 students in this school and 300 staff members.

As a school, EPSA has control over all of the activities that take place under its structure with different degrees of control (see Lo-Iacono-Ferreira et al. (2017) for more details). The activities and processes that take place in EPSA are listed in Table 9-1 where CC respond to complete operational control, PC to partial control and UC to uncontrolled. Scopes are identified according to the suggested method described in the methodological proposal.

Table 9-1 Activities and processes taking place at EPSA

\begin{tabular}{lll} 
Activities and processes & Level of control & Scope \\
\hline Administrative procedures & CC & 1 \\
Air conditioning system & PC & 2 \\
Capital equipment procurement & CC & 3 \\
Employee and students commuting & UC & 3 \\
Heating system & PC & 2 \\
Lighting and lifts system & CC & 2 \\
Mobility with UPV fleet & PC & 1 \\
Outsourcing: Cafeteria & PC & 3 \\
Outsourcing: Cleaning services & PC & 3 \\
Outsourcing: Construction services & PC & 3 \\
Outsourcing: Electric maintenance & PC & 3 \\
Outsourcing: Maintenance of infrastructure & PC & 3 \\
Outsourcing: others & PC & 3 \\
Outsourcing: Security system & PC & 3 \\
Sanitary system & PC & 2 \\
Waste management system & CC & 2 \\
\hline
\end{tabular}

\subsubsection{IDENTIFICATION OF RELEVANT ENVIRONMENTAL ASPECTS}

The EO carries the identification and significance assessment of EA of the entire EU as part of its EMS routines under EMAS. As a result of the application of the prioritization procedure described in the methodological proposal, the scored list of EA for EPSA is shown in Table 9-2 where (S) stands for significant and NS for insignificant.

It has to be noticed that, although some aspects might be considered insignificant from the EO point of view, their score in the prioritization procedure is high (upper third of the table) deserving consideration as it is an aspect over which EPSA has full operational control and might obtain a relevant improvement. On the contrary, other aspects that might be considered relevant (e.g. mobility of students) have a low score as EO has currently no operation control within the boundaries established (EPSA). 
Table 9-2 EA of EPSA. List in order of priority top-down (most relevant on top).

\begin{tabular}{|c|c|c|}
\hline Environmental aspects & EAS & Score \\
\hline Electricity consumption & $\mathrm{S}$ & 17 \\
\hline Environmental behavior of external companies ${ }^{\text {(a) }}$ & $\mathrm{S}$ & 14 \\
\hline Waste water generation & $\mathrm{S}$ & 11 \\
\hline Paper and cardboard waste generation & $\mathrm{S}$ & 10 \\
\hline Municipal solid waste generation & NS & 10 \\
\hline Emissions due to electricity consumption ${ }^{(b)}$ & NS & 10 \\
\hline Water consumption & $\mathrm{S}$ & 9 \\
\hline Light packaging waste generation & NS & 9 \\
\hline Office supplies consumption ${ }^{(c)}$ & S & 6 \\
\hline Ink and tonner waste generation & NS & 5 \\
\hline Electronic waste generation & S & 4 \\
\hline Batteries waste generation & $\mathrm{S}$ & 3 \\
\hline $\mathrm{CD}$ waste generation & S & 3 \\
\hline Supplies consumption ${ }^{(\mathrm{c})}$ & $\mathrm{S}$ & 3 \\
\hline Movable assets consumption ${ }^{(c)}$ & $\mathrm{S}$ & 3 \\
\hline Technology assets consumption ${ }^{(c)}$ & $\mathrm{S}$ & 3 \\
\hline Automobile procurement ${ }^{(c)}$ & $\mathrm{S}$ & 2 \\
\hline Emission generation due to gasoil consumption ${ }^{(b)}$ & NS & 2 \\
\hline Automobile waste generation & $\mathrm{S}$ & 2 \\
\hline Debris generation & NS & 2 \\
\hline Fossil fuel consumption: natural gas ${ }^{(\mathrm{d})}$ & NS & 2 \\
\hline Emissions due to natural gas consumption ${ }^{(b)}$ & NS & 2 \\
\hline Emissions due to air conditioning, HFC & NS & 1 \\
\hline Oil, fuel and hydrocarbons waste generation & NS & 1 \\
\hline Fossil fuel consumption: gasoil ${ }^{(\mathrm{d})}$ & NS & 1 \\
\hline Noise generation & NS & 0 \\
\hline Mobility of students & NS & 0 \\
\hline
\end{tabular}

Note: (a) It refers to outsourcing. (b) EMS assessed a unified EA for emissions due to energy. It is disaggregated for a better analysis according to the scope of this work. (c) EMS assessed a unified EA for consumption. It is disaggregated for a better analysis according to the scope of this work. (d) EMS assessed a unified EA for fossil fuel consumption. It is disaggregated for a better analysis according to the scope of this work. 


\subsubsection{GOALS DEFINITION}

The motivation of the procedure is the environmental performance optimization of the reporting unit; EPSA. However, in order to be operative in the definition of KPIs, specific goals must be described.

As EMAS requires a public environmental policy for the organizations verified, HEIs as UPV have already done this work. The environmental policy applies to all EU, including the reporting organization studied here. The environmental policy of UPV can be consulted on www.upv.es; main commitments are:

- Identify, evaluate and minimize any environmental impact of its activities.

- Comply with environmental legal requirements and other requirements applicable to UPV.

- Promote adequate environmental learning for all students.

- Help improve the environmental performance of the UPV community inside and out the HEI.

Considering the environmental policy of UPV and the list of EA defined for EPSA, the following specific goals are proposed (Table 9-3):

Table 9-3 Goals proposition for EPSA

\begin{tabular}{ll} 
Macro-level goal & Goal \\
\hline & (G1) Minimize non-renewable energy \\
The conservation of natural & $\begin{array}{l}\text { consumption } \\
\text { (G2) Maximize recycling waste }\end{array}$ \\
& (G3) Minimize waste generation \\
& (G4) Minimize GHG emissions from \\
& scope 1 \\
(G5) Minimize GHG emissions from & scope 2 \\
The fight against climate change & (G6) Minimize GHG emissions from \\
& scope 3 \\
\hline
\end{tabular}

With these goals definition, only one EA is not represented directly: noise generation; one of the last of the list and already classified as insignificant for EPSA.

\subsubsection{KPIS DEFINITION}

In this section, one functional and two reporting units are defined. These units are used in the definition of specific KPIs for EPSA. The definition of KPIs is completed with the proposal of 7 environmental KPIs and a bonus hopefully applicable in further iterations. 


\subsubsection{FUNCTIONAL AND REPORTING UNITS FOR EPSA}

The functional unit of a HEI has already been widely discussed (Lo-IaconoFerreira et al., 2016c) and several options may be considered from which is chosen, for this study, the build-up area (BUA). For those indicators that requires, due to its nature, a reporting unit, the full-time equivalent (FTE) student and the full-time employee are chosen. The description of each unit is presented below.

BUA refers to the physical dimension of the organization and represents a perfect unit of dimension of a traditional HEI (mostly classroom training). According to the international unit system, BUA has been measured in square meters $\left(\mathrm{m}^{2}\right)$ and includes all infrastructures and green areas (classrooms, offices, common facilities, parking areas, gardens, etc.).

The European Commission (2016b) defines FTE student as a student that study full-time. OECD (2016) integrates the course load and the duration of studies in the unit (Equation 9-1). When no information of course load is available, OCDE instructed to consider the simplified definition, 1 FTE equals to a full-time student.

\section{Equation 9-1}

$F T E$ student $=\frac{\text { actual course load }}{\text { normal course load }} \cdot \frac{\text { actual duration of study during reference period }}{\text { normal duration of study during reference period }}$

The number of FTE students is obtained by the relation between enrolled credits in the year of analysis and the average credits of a year of an academic course. At UPV, a full-time student takes 60 ECTS credits a year.

A similar definition can be used for FTE employees if a comparison is needed of the average number of hours worked by an employee to the average number of hours of a full-time worker (Equation 9-2). In Spain, a full-time job has, in average, 40 hours a week.

\section{Equation 9-2}

FTE employee $=\frac{\text { average hours worked }}{\text { average hours of a full-time worker }}$

Notice that both the functional and the reporting unit defined are not restricted to EPSA and can be used in any HEI.

\subsubsection{ENVIRONMENTAL KPIS PROPOSED FOR EPSA}

As a result of the analysis of the specific goals defined for EPSA and considering the description of environmental KPIs suggested in Annex A, the following KPIs are proposed: 
Proposal of a set of Key Performance Indicators for the environmental assessment of Higher Education Institution

ENV KPI 1: Ratio of renewable energy consumption over the total energy consumption

This indicator measures the renewable energy consumption in MWh, both purchased and own generation, over the total energy consumption in MWh. It is a response indicator according to the DPSIR framework and has no units as it is a ratio. It is directly related to goals G1 and G5 as it considers the electric energy consumption purchased and own generated.

It can be easily accessed through direct measurements. Data sources for this indicator may be electric instrumentation and invoices details. The desired value is 1 where all the energy consumed comes from renewable sources.

\section{ENV KPI 2: Ratio of waste recycled over the total waste generated}

This indicator measures the amount of waste recycled over the total waste generated in kilograms. Recycling waste is considered either if it is selfprocessed or sent to a recycling entity. It is a response indicator with no units. It is related with goals $\mathrm{G} 2$ and $\mathrm{G} 3$.

Weights of wastes can be measured either in the institution before being delivered or by the waste manager in which case it requires his collaboration. Although direct measures are preferable, estimation methods can be used for a first approach. As the indicator approaches unity, the percentage of unrecycled waste would be more insignificant. The influence of local laws has to be considered when regulating the waste treatment system and also that not all waste can be recycled.

\section{ENV KPI 3: GHG emissions of Scope 1 * by BUA}

This indicator measures the emissions due to machinery and equipment run by combustion engines, boilers and the use of own fleet (Scope 1). It is a pressure indicator assessed in tons of $\mathrm{CO}_{2} \mathrm{e}$ per $\mathrm{m}^{2}$. It is directly related to goal G4.

The assessment of GHG emissions has to be done based on a standard procedure, e.g., ISO 14064 along with a detailed definition of the scope. It is essential to have a complete inventory of vehicles, combustion engine machinery and boilers owned and installed in the institution along with their technical specifications. Targets can be set annually to help focus efforts in reducing these emissions.

ENV KPI 4: Ratio of sustainable purchases over the total of purchases

This indicator measures the monetary value (U\$S or $€$ ) of materials and services purchases, applying a published or standardized sustainable criteria (e.g. ISO 20400) over the total of purchases made by the HEI. It is a response indicator with no units and directly related to goal G6. 
The sources of information for the assessment of this indicator can be newsletter tenders, applications, invoices, etc. Having a centralized accounting system with an electronic register of purchases is desirable. The final goal would be having a rate of one to ensure all purchases are made under sustainable criteria.

\section{ENV KPI 5: Ratio of sustainable tenders over total tenders}

This indicator measures the number of contracts for tenders made with published or standardized sustainable criteria over the total of tenders of HEIs. It is a response indicator with no units and directly related to goal G6.

The sources of information for the assessment are the newsletter tenders and contracts of the tender. As ENV KPI 4, having a value of one would mean that all tenders follow sustainable criteria, therefore, the environment is carefully considered.

\section{ENV KPI 6: GHG emissions from commuting by FTE student}

This indicator measures GHG emissions from commuting in tons or kilograms of $\mathrm{CO}_{2} \mathrm{e}$ per FTE student. It is a pressure indicator related to goal G6.

It is required to know the characteristics of commuting of students. An easy way to introduce this information to the EMS is thorough regular surveys. This information can help in the development of awareness programs and other actions where the HEI can influence public transport services to benefit students.

\section{ENV KPI 7: GHG emissions from commuting by FTE employee}

The assessment of employees commuting is also relevant for goal G6. It is also a pressure indicator as it measures GHG emissions from commuting in tons or kilograms of $\mathrm{CO}_{2} \mathrm{e}$ but related to employees.

The performance of this indicator is different to the previous as the replacement rate is expected to be significantly lower than for students; students stays at HEIs for short periods of time (4 to 6 years in average). The outcomes of programs developed to make employees aware of the benefits of an environmentally friendly mobility would stay longer in the institution and would also serve as an example for students.

The seven indicators previously described can be measured in a defined time period, normally a year. They are related to, at least one goal, proving to be crucial factors representing a key indicator. They are SMART and their consistence with the EMS is easy to include with small adjustments in a robust EMS as the ones verified in EMAS. Having these indicators as part of EMS ensures that they are measurable. They are also easy to use as functional and 
Proposal of a set of Key Performance Indicators for the environmental assessment of Higher Education Institution

reporting units are part of the current performance analysis of the institution. Ratios are easy to read and sensible to changes of the reporting organization.

Furthermore, considering that EPSA has initiated a process to adapt its EMS to carry out a LCA (i.e. Organizational Life Cycle Assessment (OLCA)) an additional KPI is proposed. ENV KPI 8 might simplify the set of KPIs by replacing ENV KPI 4, ENV KPI 5, ENV KPI 6 and ENV KPI 7.

\section{ENV KPI 8: GHG emissions of Scope 3 * by FTE student}

This indicator measures the emissions due to tenders, purchasing and commuting both for employees and students (Scope 3). It is a pressure indicator assessed in tons or kilograms of $\mathrm{CO}_{2} \mathrm{e}$ per FTE. It is directly related to goal G6.

The assessment of GHG emissions has to be done based on a standard procedure, e.g., ISO 14072:2014 along with a detailed definition of the scope. The difficulty of these indicators lies in gathering all the information required. For that reason, it is proposed as an indicator when a previous life cycle assessment has been carried out and the data network is already stablished. Notice that, if needed for management purposes, ENV KPI indicators from 4 to 7 can be used for a deeper interpretation of the results of this indicator.

\subsubsection{ASSESSMENT OF ENVIRONMENTAL KPIS FOR EPSA}

The results of the assessment of these indicators for EPSA are shown in Table $9-4$.

UPV EMS as it is currently working only allows the assessment of four of the 7 KPIs proposed. Therefore, it has to be highlighted that an EMAS verification, although it is a powerful tool to identify the EA and its crucial factors, does not ensure the assessment of KPIs to manage them.

ENV KPI 1 can be base lines for new targets regarding energy consumption while ENV KPI 3 can be set as a reference for the efficiency of equipment and vehicles owned by UPV that produce $\mathrm{CO}_{2}$. Regarding ENV KPI 2, an additional effort to be able to have a direct measure of municipal solid waste is needed in order to have a more accurate indicator. ENV KPI 5 has the desirable value, however, there is always place for improvement.

Significant changes are required in order to be able to assess ENV KPI 4. Although the EO is working on green procurement guidance as the need is detected, neither the EMS nor the accounting system has a quantitative measure of the green procurement. 
Table 9-4 ENV KPI results for EPSA, 2015

\begin{tabular}{|c|c|c|}
\hline KPI & Result & Observation \\
\hline ENV KPI 1 & 0.37 & $\begin{array}{l}\text { All the energy consumed by EPSA is registered } \\
\text { by the EMS using the corresponding invoices } \\
\text { and related documentation as data source. } \\
\text { Although there might be small renewable } \\
\text { energy generators installed with research } \\
\text { purposes, research activities are not within the } \\
\text { scope of this reporting organization. }\end{array}$ \\
\hline ENV KPI 2 & 0.43 & $\begin{array}{l}\text { It has to be considered that the weight of non- } \\
\text { recycled waste (municipal solid waste) is } \\
\text { estimated by a procedure developed by EMS. }\end{array}$ \\
\hline ENV KPI 3 & $\begin{array}{l}9.66 \mathrm{~kg} \mathrm{CO}_{2} \mathrm{e} \\
\text { per BUA }\end{array}$ & $\begin{array}{l}\text { The assessment of emissions has been made } \\
\text { following the Spanish environmental ministry } \\
\text { procedure. }\end{array}$ \\
\hline ENV KPI 4 & - & $\begin{array}{l}\text { Although there is a good practices guidance for } \\
\text { green procurement available to all members of } \\
\text { UPV, a centralized register of procurement in } \\
\text { the system does not exist at the time of } \\
\text { publishing this article. This indicator could not } \\
\text { be assessed. }\end{array}$ \\
\hline ENV KPI 5 & 1 & $\begin{array}{l}\text { UPV EMS has implemented a procedure to } \\
\text { include sustainability criteria in every tender. } \\
\text { As EPSA is under UPV general regulation, all } \\
\text { EPSA tenders include sustainability criteria. }\end{array}$ \\
\hline ENV KPI 7 & $\begin{array}{l}0.5 \mathrm{t} \mathrm{CO}_{2} \mathrm{e} \text { by } \\
\text { person }\end{array}$ & $\begin{array}{l}\text { These indicators couldn't be assessed as the } \\
\text { information in the current system does not } \\
\text { disaggregate between students and employees. } \\
\text { However, the system did allow a result for the } \\
\text { entire community. }\end{array}$ \\
\hline
\end{tabular}

ENV KPI 6 and ENV KPI 7 could not be evaluated as described because of lack of information or lack of quality of the information available. However, estimations could be made for a different reporting unit: members of the community (person). The result cannot be disaggregated by FTE-student and FTE-employee as quality data is not available. Although it is not the desirable result, it might be useful to (a) justify the need of more resources to address the KPIs as proposed and (b) be a baseline for the immediate actions that topmanagers would like to achieve. Yet, the disaggregation is considered essential as the profiles of students and employees are different, therefore, the targets and action plans must be particularized. 
Proposal of a set of Key Performance Indicators for the environmental assessment of Higher Education Institution

9.3.6 VALIDATION

Following the methodological proposal described in Annex B, the validation of each indicator has been carried out. In this section, a summary of the validation process results is presented.

Regarding the planning and the methodological approach (level 1) metaperformance evaluation indicators, all the proposed indicators have a positive evaluation except for the regular updating and reporting indicator and the reporting and communication to stakeholders. In this regard, although specific actions are planned, they have not yet been executed at the moment of publishing this paper. However, some related environmental information is already part of UPV EMAS annual environmental review, therefore, it is reported and communicated e.g., emission for scope 1.

The results of the level 2 meta-performance evaluation indicators related to quality control cannot be considered fully successful. The ratio of indicators assessed with direct measurement is $3 / 4$. Because the nature of GHG emissions calculation involves certain judgment and estimations, all environmental KPIs related to this output have some degree of uncertainty associated. ENV KPI 3, ENV KPI 6, ENV KPI 7 and ENV KPI 8 have two sources of uncertainty: the input and the conversion factor. ENV KPI 3 presents an uncertainty of $1 \%$. The uncertainty of the other KPIs related to emissions could not be assessed due to a lack of quality data.

The uncertainty of ratios which data sources are measuring instruments is easy to evaluate when technical details are available. Although this information is not available for the year under analysis (2015), the procedure to include it in the system is simple: the EO has to add this information to the registers of emissions for ENV KPI 1 and weight of wastes for ENV KPI 2. This information is expected to be registered for further iterations of the assessment. ENV KPI 4 and ENV KPI 5 are not supposed to have significant uncertainties due to the nature of the indicators.

The conceptual coherence indicator has an optimal value as well as the methodological approach and data calculation indicator, $0 \%$ and $100 \%$ respectively. The same outcome is obtained when considering logistical requirements and information management. EMAS requirements ensure the description and documentation of any procedure developed by the EMS along with the need to communicate results to the community. Finally, a survey applied to decision-makers shows that all the environmental KPIs proposed for EPSA are easy to understand. 


\subsection{CONCLUSIONS}

HEIs have a high flow of people (students) and significant environmental aspects related to their energy consumption and waste generation but also to the scope 3 of the organization; a dimension difficult to assess. Having KPIs as part of the daily management system would make easy to consider all the impacts coming from third parties such as tenders, services and materials purchasing. KPIs can be the operational tool to identify improvement opportunities and tendencies, review system efficiency, help in the identification of strategic opportunities, assess the risk of non-compliance with legal requirements as well as to report and communicate the environmental performance of the organization integrating KPIs in ISO 14031 framework.

However, to apply these types of assessments and policies the support of top managers is needed as resources and structural modifications might be necessary. Other weakness of KPIs is that, as all performance indicators, they can only report on aspects that can be measured. Qualitative information, that may be also relevant for performance assessments, is difficult to express through an indicator. On the contrary, KPIs are $100 \%$ adaptable to the characteristics and needs of the organization, even to particular ones as HEIs.

The proposed procedure for the definition of KPIs as the chosen validation method has proven to be adequate for HEIs with an EMS already implemented. However, an EMS verified in EMAS does not ensure the availability and desirable quality of all the required data. Several advantages have been identified of having an EMS verified in EMAS:

- The institution has already an environmental policy that helps with the definition of goals.

- The system boundaries of the institution are easy to define as the process and activities are clearly identified.

- The environmental aspects and its significance are already identified.

There is a system that collects data related to the environmental aspects of the institution.

Regarding UPV KPIs for EPSA, the following conclusions can be drawn:

- The UPV energy policy of can be updated and specific actions might be needed to address a better rate of renewable energy.

- Although there are estimation procedures for some data such as municipal solid waste generation, allowing the assessment of related indicators, these results need to be carefully interpreted.

- Tenders are handled on a sustainable responsible basis while the evidence of green procurement for products and services is hard to 
Proposal of a set of Key Performance Indicators for the environmental assessment of Higher Education Institution

find. Resources are needed in order to have a centralized system that gathers more accurate information about purchases.

- By assessing GHG emission indicators (Scope 1 by BUA) decision makers have a base line to set targets and policies for the next time period.

- More resources are needed in order to be able to assess the required data for 3 of the 7 KPIs proposed.

Improving the data quality will improve significantly, the accuracy of KPIs which make them more useful and will benefit the decision-making process so as to improve the environmental performance of HEIs.

A set of KPIs may result in a Complex Performance Indicator. Further research can focus on the integration of defined indicators with economic and social KPIs in order to build a Complex Performance Indicator for HEIs.

\subsection{REFERENCES}

Achterkamp, M.C., \& Vos, J.F.J. (2008) Investigating the use of the stakeholder notion in project management literature, a meta-analysis. International Journal of Project Management, 26(7), 749-757. http://doi.org/10.1016/j.ijproman.2007.10.001

Alam, M., Dupras, J., \& Messier, C. (2016) A framework towards a composite indicator for urban ecosystem services. Ecological Indicators, 60, 38-44. http://doi.org/10.1016/j.ecolind.2015.05.035

Alonso-Almeida, M.D.M., Marimon, F., Casani, F., \& Rodriguez-Pomeda, J. (2015) Diffusion of sustainability reporting in universities: current situation and future perspectives. Journal of Cleaner Production, 106, 144-154. http://doi.org/10.1016/j.jclepro.2014.02.008

Azma, F. (2010) Qualitative Indicators for the evaluation of universities performance. Procedia - Social and Behavioral Sciences, 2(2), 54085411. http://doi.org/10.1016/j.sbspro.2010.03.882

Barnetson, B., \& Cutright, M. (2000) Performance indicators as conceptual technologies. Higher Education, 40, 277-292. http://doi.org/10.1023/a:1004066415147

Bauler, T. (2012) An analytical framework to discuss the usability of (environmental) indicators for policy. Ecological Indicators, 17, 3845. http://doi.org/10.1016/j.ecolind.2011.05.013

Beloff, B., Tanzil, D., \& Lines, M. (2004) Sustainable development performance assessment. Environmental Progress, 23(4), 271-276. http://doi.org/10.1002/ep.10045 
Bonaccorsi, A., Daraio, C., Lepori, B., \& Slipersæter, S. (2007) Indicators on individual higher education institutions: addressing data problems and comparability issues. Research Evaluation, 16(2), 66-78. http://doi.org/10.3152/095820207X218141

Braulio-Gonzalo, M., Bovea, M.D., \& Ruá, M.J. (2015) Sustainability on the urban scale: Proposal of a structure of indicators for the Spanish context. Environmental Impact Assessment Review, 53, 16-30. http://doi.org/10.1016/j.eiar.2015.03.002

Braunschweig A. (2014) GHG-balances and LCA: Applying the concept of scopes in organisational LCAs. E2 Management Consulting. Retrieved on July $1^{\text {st }} 2016$ from http://www.e2mc.com/

Bryson, J.M. (2004) What to do when Stakeholders matter. Stakeholder Identification and Analysis Techniques. Journal Public Management review, 6(1), 21-53. http://dx.doi.org/10.1080/14719030410001675722

Campos, L.M.S., de Melo Heinzen, D.A. Verdinelli, M.A., \& Cauchick Miguel, P.A. (2015) Environmental Performance Indicators: A Study on ISO 14001 Certified Companies. Journal of Cleaner Production, 99, 286-296. http://doi.org/10.1016/j.jclepro.2015.03.019

Disterheft, A., da Silva Caeiro, S.S.F., Ramos, M.R. and de Miranda Azeiteiro, U.M. (2012) 'Environmental management systems (EMS) implementation processes and practices in European higher education institutions - top-down versus participatory approaches', Journal of Cleaner Production, 31, 80-90. http://doi.org/ 10.1016/j.jclepro.2012.02.034

Dočekalová, M.P., \& Kocmanová, A. (2016) Composite indicator for measuring corporate sustainability. Ecological Indicators, 61, 612623. http://doi.org/10.1016/j.ecolind.2015.10.012

Doran, G.T. (1981) There's a S.M.A.R.T way to write management's goals and objectives. IIMB Management Review, 70(11) 35-36 Retrieved on June $15^{\text {th }} \quad 2016$ from http://community.mis.temple.edu/mis0855002fall2015/files/2015/10 /S.M.A.R.T-Way-Management-Review.pdf 
Proposal of a set of Key Performance Indicators for the environmental assessment of Higher Education Institution

European Commission (2009) No, R.;1221/2009 of the European Parliament and of the Council of 25 November 2009 on the Voluntary Participation by Organisations in a Community Eco-management and Audit Scheme (EMAS), Repealing Regulation (EC) No 761/2001 and Commission Decisions 2001/681/EC and 2006/193 Retrieved on December $\quad 16^{\text {th }} \quad 2012$ from $\quad$ http://eur-lex.europa.eu/ LexUriServ/LexUriServ.do?uri=OJ:L:2009:342:0001:01:EN:HTML

European Commission (2016b) Eurostat Glossary. Retrieved on July $1^{\text {st }} 2016$ from http://ec.europa.eu/eurostat/statisticsexplained/index.php/Glossary:Full-time equivalent_(FTE)

European Environment Agency (2014) Digest of EEA indicators. Luxembourg. Retrieved on July $1^{\text {st }} 2016$ from http://www.eea.europa.eu/publications/digest-of-eea-indicators2014

Fiksel, J., Spitzely, D., \& Brunetti, T. (2002) Key Performance Indicators (Substudy 5) Retrieved on July $1^{\text {st }} 2016$ from http://www.wbcsdcement.org/pdf/battelle/final report5.pdf

García-Sánchez, I. M., Almeida, T. A. D. N., \& Camara, R. P. D. B. (2015) A proposal for a Composite Index of Environmental Performance (CIEP) for countries. Ecological Indicators, 48, 171-188. http://doi.org/10.1016/j.ecolind.2014.08.004

Global Reporting Initiative (2013a) G4 Sustainability Reporting Guidelines. Global Reporting Initiative. Retrieved on March $1^{\text {st }} 2016$ from https://www.globalreporting.org/resourcelibrary/G4-Package.zip

Gustavo De Lima, R., Lins, H.N., Pfitscher, E.D., Garcia, J., Suni, A., Salgueirinho Osório De Andrade Guerra, J.B., \& Caroline Renata Delle, F. (2016) A sustainability evaluation framework for Science and Technology Institutes: An international comparative analysis. Journal of Cleaner Production, 125, 145-158. http://doi.org/10.1016/j.jclepro.2016.03.028

Hancock, L., \& Nuttman, S. (2014) Engaging higher education institutions in the challenge of sustainability: Sustainable transport as a catalyst for action. Journal of Cleaner Production, 62, 62-71. http://doi.org/10.1016/j.jclepro.2013.07.062

Hermann, B. G., Kroeze, C., \& Jawjit, W. (2007) Assessing environmental performance by combining life cycle assessment, multi-criteria analysis and environmental performance indicators. Journal of Cleaner Production, 15(18), 1787-1796. http://doi.org/10.1016/j.jclepro.2006.04.004 
Hourneaux, F., Hrdlicka, H. A., Gomes, C. M., \& Kruglianskas, I. (2014) The use of environmental performance indicators and size effect: A study of industrial companies. Ecological Indicators, 36, 205-212. http://doi.org/10.1016/j.ecolind.2013.07.009

Hsu, A., Johnson, L., \& Lloyd, A. (2013) Measuring Progress. A Practical Guide from the Developers of the Environmental Performance Index (EPI). New Haven: Yale Center for Environmental Law \& Policy. Retrieved on July $1^{\text {st }} 2016$ from http://epi.yale.edu/content/measuring-progress-practical-guidedevelopers-environmental-performance-index-epi

International Organization for Standardization (2006b) Environmental management - life cycle assessment - requirements and guidelines. ISO 14044:2006(E).

International Organization for Standardization (2013b) Environmental Management - Environmental Performance Evaluation - Guidelines. International Organization for Standardization

International Organization for Standardization (2014a) ISO/TS 14072: Environmental management — Life cycle assessment Requirements and guidelines for Organizational Life Cycle Assessment. Geneva, Switzerland: International Organization for Standardization.

Kerzner, H.R. (2011) Project Management Metrics, KPIs and Dashboards: A guide to Measuring and Monitoring Project Performance. Ed. John Wiley \& Sons, Inc. http://doi.org/10.1002/9781118086254

Lambrechts, W., \& Van Liedekerke, L. (2014) Using ecological footprint analysis in higher education: Campus operations, policy development and educational purposes. Ecological Indicators, 45, 402-406. http://doi.org/10.1016/j.ecolind.2014.04.043

Lo-Iacono-Ferreira, V.G., Capuz-Rizo, S.F., Torregrosa-López, J.I. (2016a) Ecological Footprint Assessment of Higher Education applying Life Cycle Assessment framework. Case study: Universitat Politència de València. XX International Congress on Project Management and Engineering. Cartagena. 1423-1432. ISBN: 978-84-617-4180-9 http://www.aeipro.com/aplic/tree congresos/detalle remository aei pro.php?file $=4636$ 
Proposal of a set of Key Performance Indicators for the environmental assessment of Higher Education Institution

Lo-Iacono-Ferreira, V.G., Torregrosa-López, J.I., Capuz-Rizo, S.F., (2016b) Applicability of global reporting initiative to assess the environmental performance of higher education institutions. XX International Congress on Project Management and Engineering. Cartagena. 14331444. ISBN: 978-84-617-4180-9 http://www.aeipro.com/aplic/tree congresos/detalle remository aei pro.php?file $=4637$

Lo-Iacono-Ferreira, V.G., Torregrosa-López, J.I., \& Capuz-Rizo, S.F. (2016c) Use of Life Cycle Assessment methodology in the analysis of Ecological Footprint Assessment results to evaluate the environmental performance of universities. Journal of Cleaner Production, 133, 43-53. http://doi.org/10.1016/j.jclepro.2016.05.046

Lo-Iacono-Ferreira, V.G., Torreogrsa-López, J.I., Capuz-Rizo, S.F. (2017) Organizational Life Cycle Assessment: suitability for Higher Education Institutions with Environmental Management System. International Journal of Life Cycle Assessment (In press).

Lozano, R., Ceulemans, K., Alonso-Almeida, M., Huisingh, D., Lozano, F. J., Waas, T., Lambrechts, W., Lukman, R., Hugé, J. (2014) A review of commitment and implementation of sustainable development in higher education: results from a worldwide survey. Journal of Cleaner Production, 108, 1-18. http://doi.org/10.1016/j.jclepro.2014.09.048

Lukman, R., Krajnc, D., \& Glavi, P. (2010) University ranking using research, educational and environmental indicators. Journal of Cleaner Production, 18(7), 619-628. http://doi.org/10.1016/j.jclepro.2009.09.015

Mazzi, A., Mason, C., Mason, M., \& Scipioni, A. (2012) Is it possible to compare environmental performance indicators reported by public administrations? Results from an Italian survey. Ecological Indicators, 23 ,

653-659. http://doi.org/10.1016/j.ecolind.2012.05.006

Moldan, B., Sková, S. J., \& Charles, T. s H. (2012) How to understand and measure environmental sustainability: Indicators and targets. Ecological Indicators, $17, \quad 4-13$. http://dx.doi.org/10.1016/j.ecolind.2011.04.033

Olszak, E. (2012) Composite indicators for a sustainable campus - Design rationale and methodology: The case of the Catholic Institute of Lille. Ecological Indicators, 23, 573-577. http://doi.org/10.1016/j.ecolind.2012.05.021 
Organization for Economic Cooperation and Development. (2008) Key environmental indicators. Paris. Retrieved on July $1^{\text {st }} 2016$ from https://www.oecd.org/env/indicators-modellingoutlooks/37551205.pdf

Organization for Economic Cooperation and Development. (2014) Green Growth Indicators 147. http://doi.org/10.1787/9789264202030-en

Organization for Economic Cooperation and Development. (2015) Environment at a Glance 2000: OECD Indicators. OECD Publishing. http://doi.org/10.1787/eag-2013-en

Organization for Economic Cooperation and Development. (2016) Glossary of Statistical Terms. Retrieved on July $1^{\text {st }} 2016$ from http://stats.oecd.org/glossary/detail.asp?ID $=5369$

Perotto, E., Canziani, R., Marchesi, R., \& Butelli, P. (2008) Environmental performance, indicators and measurement uncertainty in EMS context: a case study. Journal of Cleaner Production, 16(4), 517-530. http://doi.org/10.1016/j.jclepro.2007.01.004

Ramos, T. B., \& Caeiro, S. (2010) Meta-performance evaluation of sustainability indicators. Ecological Indicators, 10(2), 157-166. http://doi.org/10.1016/j.ecolind.2009.04.008

Serdar, A. M. (2010) Performance management and key performance indicators for higher education institutions in Serbia. Perspectives of Innovations, Economics and Business, 6(3), 116-119. http://dx.doi.org/10.15208/pieb.2010.95

Singh, R. K., Murty, H. R. R., Gupta, S. K. K., \& Dikshit, A. K. K. (2012) An overview of sustainability assessment methodologies. Ecological Indicators, 15(1), 281-299. http://doi.org/10.1016/j.ecolind.2011.01.007

Smeets, E., \& Weterings, R. (1999) Environmental indicators: Typology and overview. Copenhagen. Retrieved on June $1^{\text {st }} 2012$ from http://www.eea.europa.eu/publications/TEC25

The Association for the Advancement of Sustainability in Higher Education. (2016) stars Technical Manual. Version 2.1. Retrieved on July $1^{\text {st }}$ 2016 from http://www.aashe.org/files/documents/STARS/stars_2.1 technical manual - administrative update one.pdf 
Proposal of a set of Key Performance Indicators for the environmental assessment of Higher Education Institution

Torregrosa-López, J. I., Lo Iacono-Ferreira, V. G., Barranco-Martí, C., \& Bellver-Navarro, C. G. (2016) The strengths of EMAS as an environmental management system for European university campuses. International Journal of Environment and Sustainable Development, $15(1)$

89-106. http://dx.doi.org/10.1504/IJESD.2016.073339

United Nations Statistics Division (2016) Environmental indicators. $\begin{array}{lllll}\text { Retrieved on July } & 1^{\text {st }} & 2016 & \text { from }\end{array}$ http://unstats.un.org/unsd/environment/qindicators.htm

Waheed, B., Khan, F. I., \& Veitch, B. (2011) Developing a quantitative tool for sustainability assessment of HEIs. International Journal of Sustainability in Higher Education, 12(4), 355-368. http://doi.org/10.1108/14676371111168278

Walton, S. V., \& Galea, C. E. (2006) Some considerations for applying business sustainability practices to campus environmental challenges. International Journal of Sustainability in Higher Education, 6(2), 147-160 http://doi.org/http://dx.doi.org/10.1108/1467637051058986

White, J. (2015) How much attention to Stakeholders interests? A practitioner's view of the need to take account of stakeholder interests. Global Policy, 6(4), 501-503. http://doi.org/10.1111/17585899.12254

Wright, T. S. A., \& Wilton, H. (2012) Facilities management directors' conceptualizations of sustainability in higher education. Journal of Cleaner Production, 31, 118-125. http://doi.org/10.1016/j.jclepro.2012.02.030

Zaman, A. U. (2014). Identification of key assessment indicators of the zero waste management systems. Ecological Indicators, 36, 682-693. http://doi.org/10.1016/j.ecolind.2013.09.024 


\subsection{ANNEX 9 A}

The development of this work includes a deep analysis of all the environmental indicators published or included in the main references related. As a result, a recompilation of those environmental indicators applicable to HEIs has been carried out, along with the classification of each indicator by DPSIR framework and ABCDE typology.

Results are presented in this Annex structured in tables by environmental areas. Observations are included when considered appropriate. Further information can be found in the references related. The environmental areas defined are:

- Air pollution (Table 9-5)

- Biodiversity (Table 9-6)

- Climate (Table 9-7)

- Energy (Table 9-8)

- Environmental scenarios (Table 9-9)

- Food and beverage (Table 9-10)

- Green economy (Table 9-11)

- Infrastructure (Table 9-12)

- Land use indicators (Table 9-13)

- Materials and resources (Table 9-14)

- Mobility (Table 9-15)

- Waste and effluents (Table 9-16)

- Water (Table 9-17)

The applicability criteria have been defined considering the activities and processes of a medium size institution with a wide range of studying programs. Indicators regarding specific activities that are not of general development (e.g. management of forest) are not included. In those cases, it is suggested to consult specific literature. 
Proposal of a set of Key Performance Indicators for the environmental assessment of Higher Education Institution

Abbreviations and acronyms in tables

AASHE: Association for the Advancement of Sustainability in Higher Education

C: Composite indicator

$\mathrm{CO} 2 \mathrm{e}$ : carbon dioxide equivalent

EEA: European Environmental Agency

FU: Functional Unit

GHG: Greenhouse gases

GRI: Global Reporting Initiative

ODS: ozone-depleting substances

OP: operations. Refers to AASHE naming for its operational indicators

OECD: Organization for Economic CO-operation and Development

S: Simple indicator

UNSD: United Nations Statistics Division 


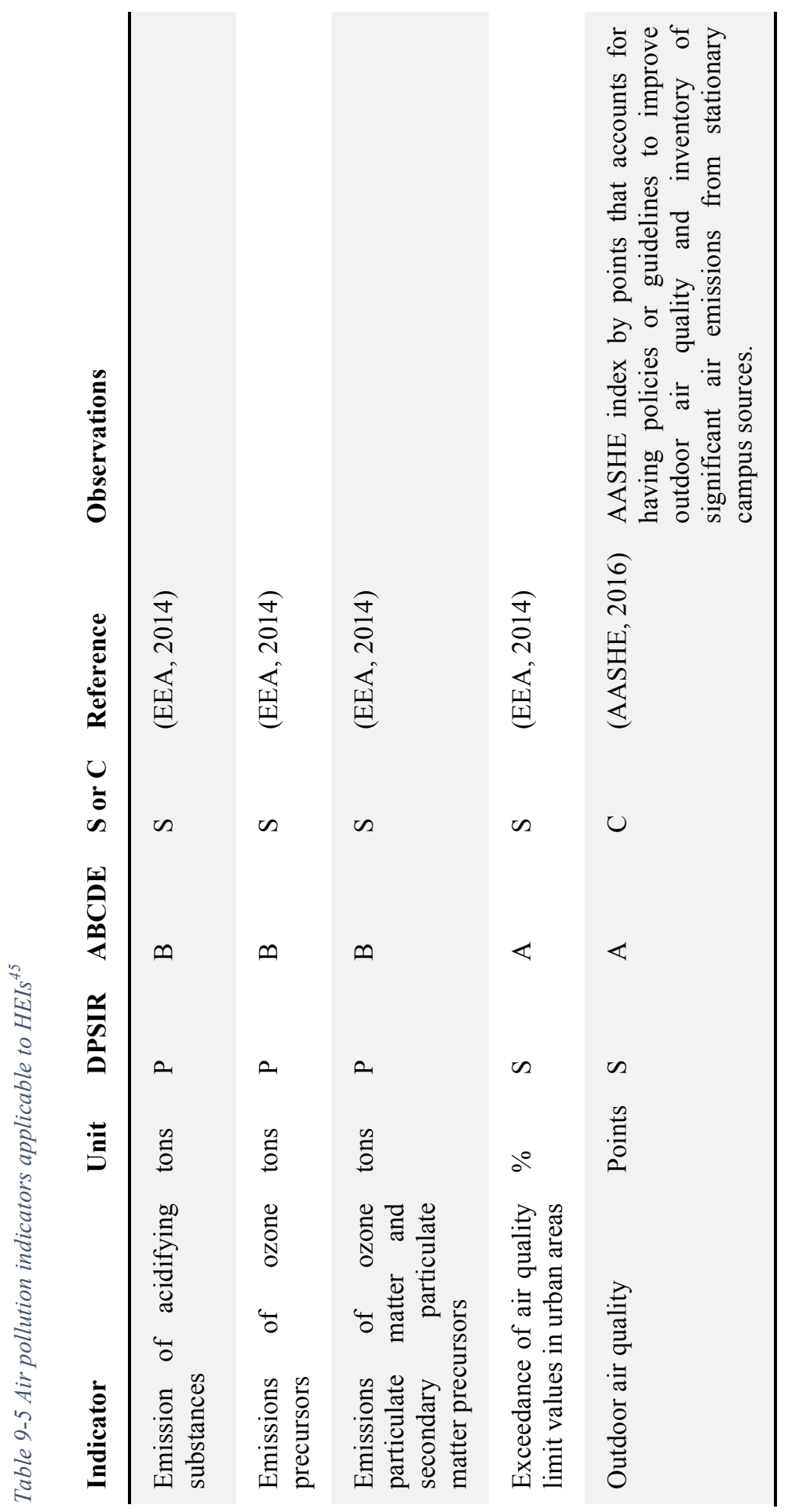

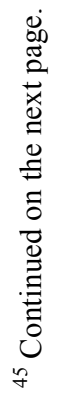




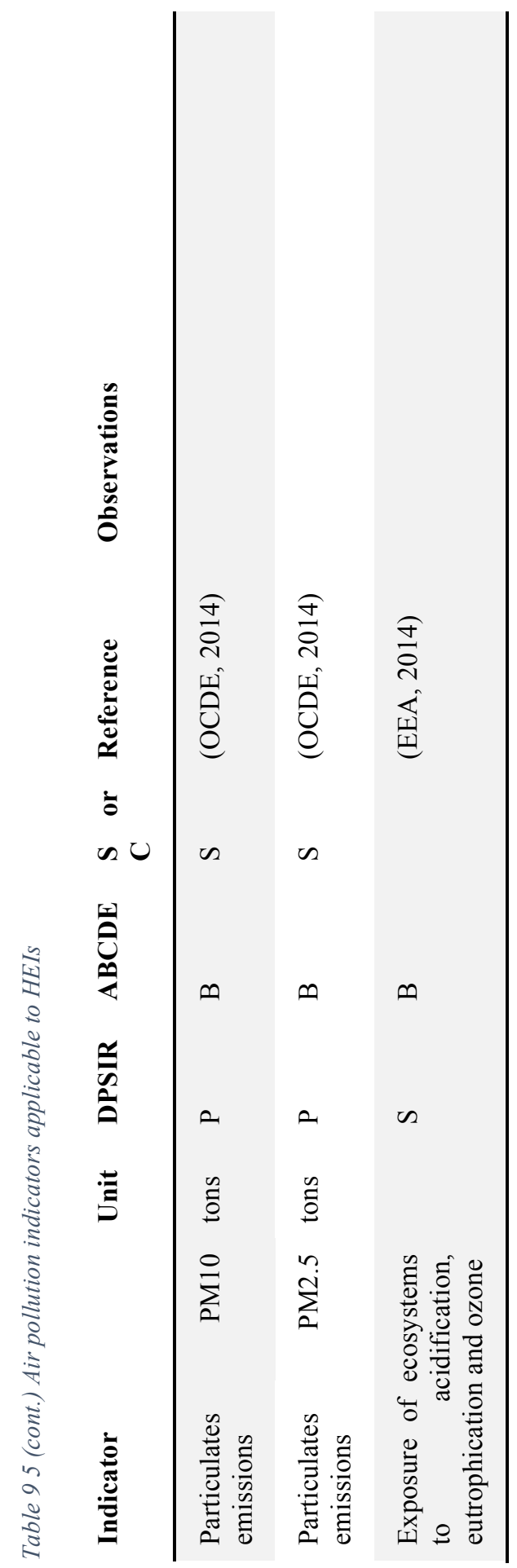




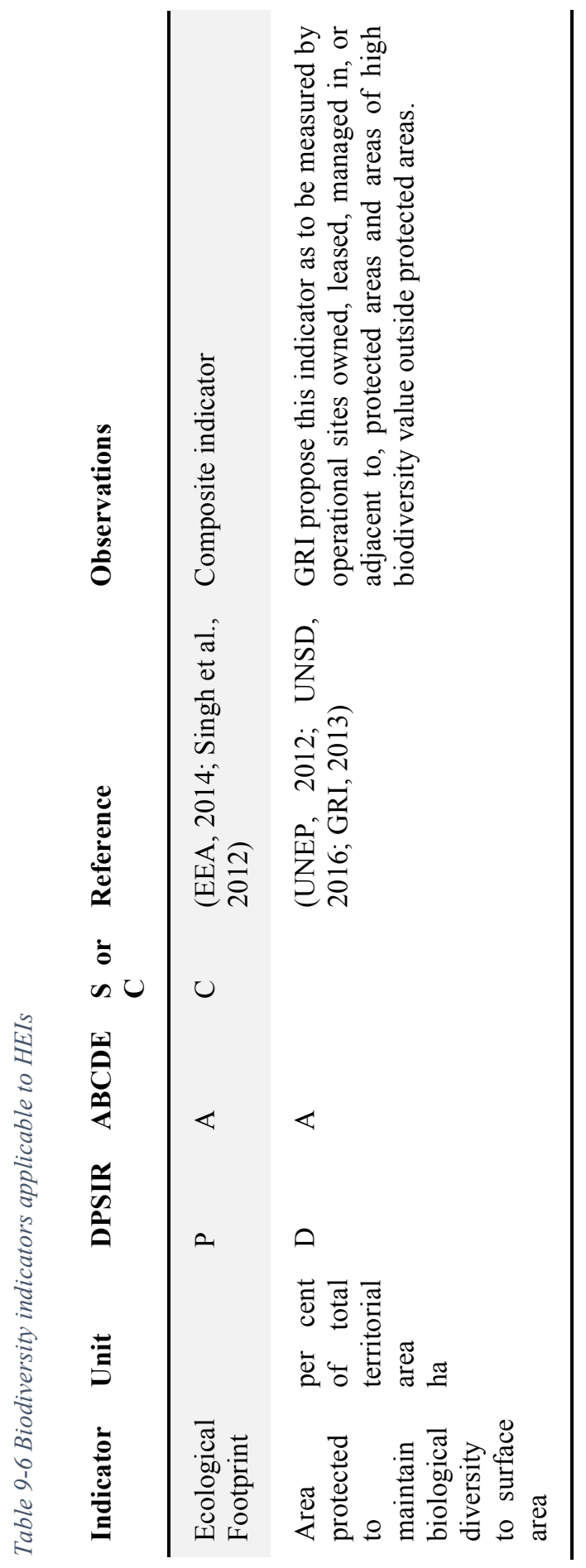




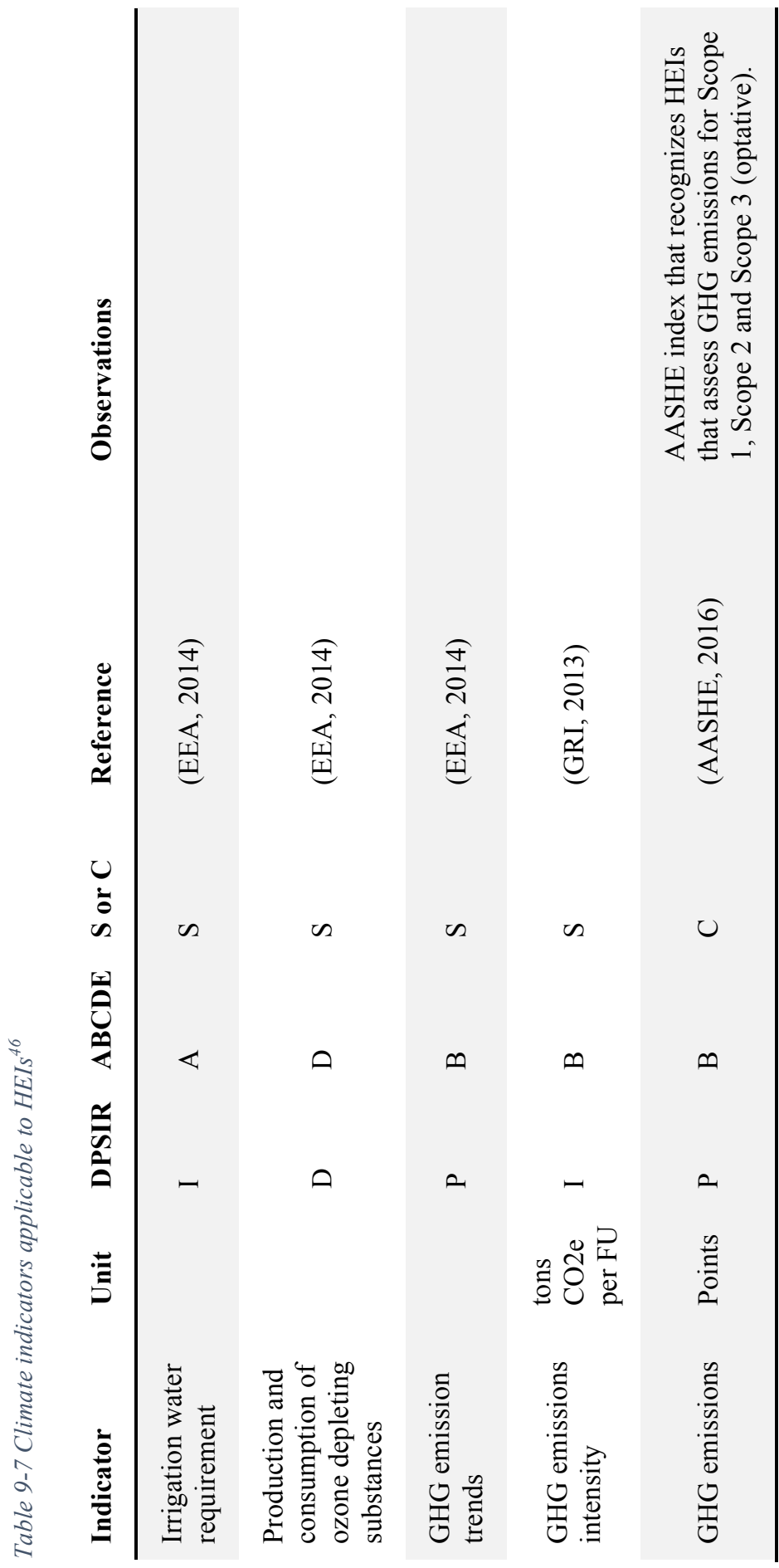

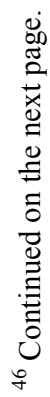




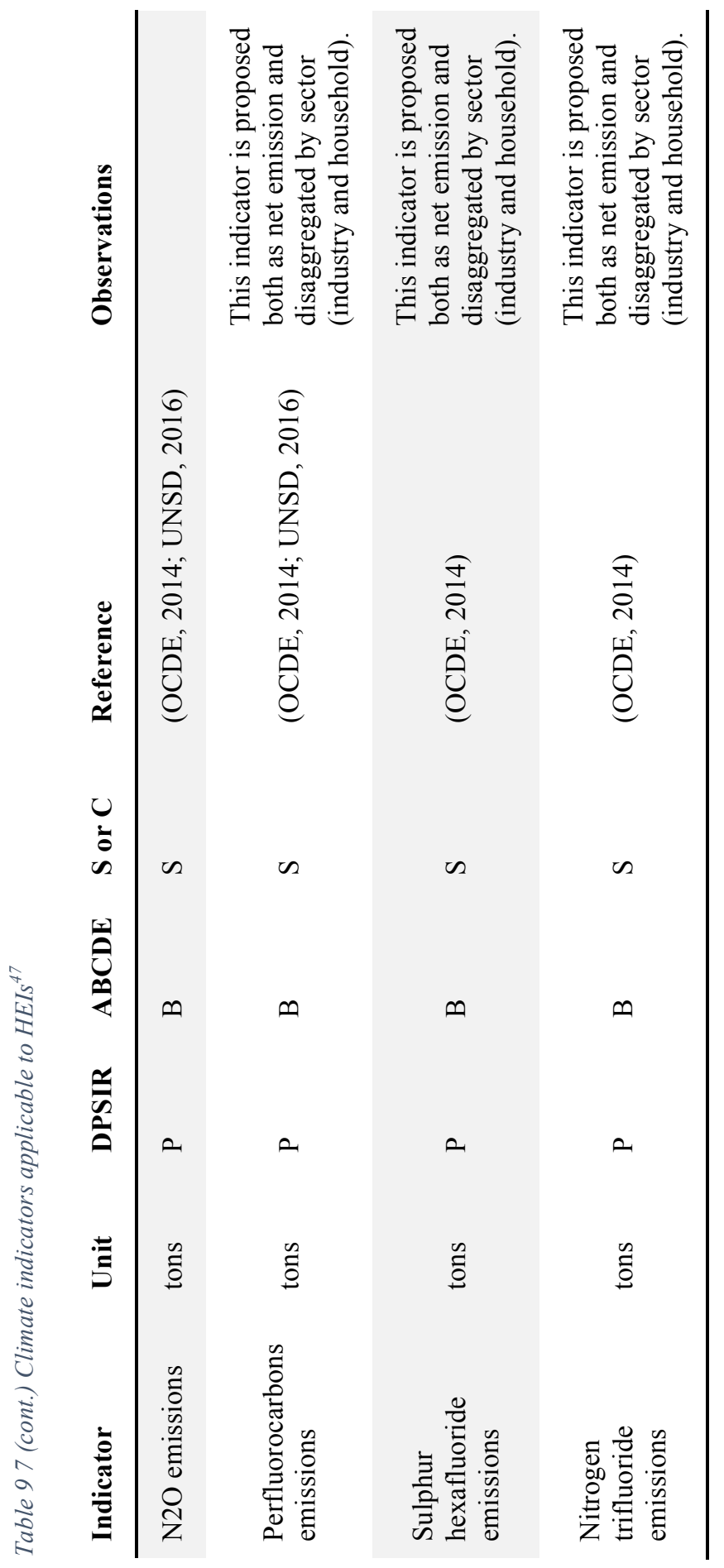

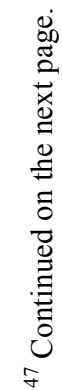




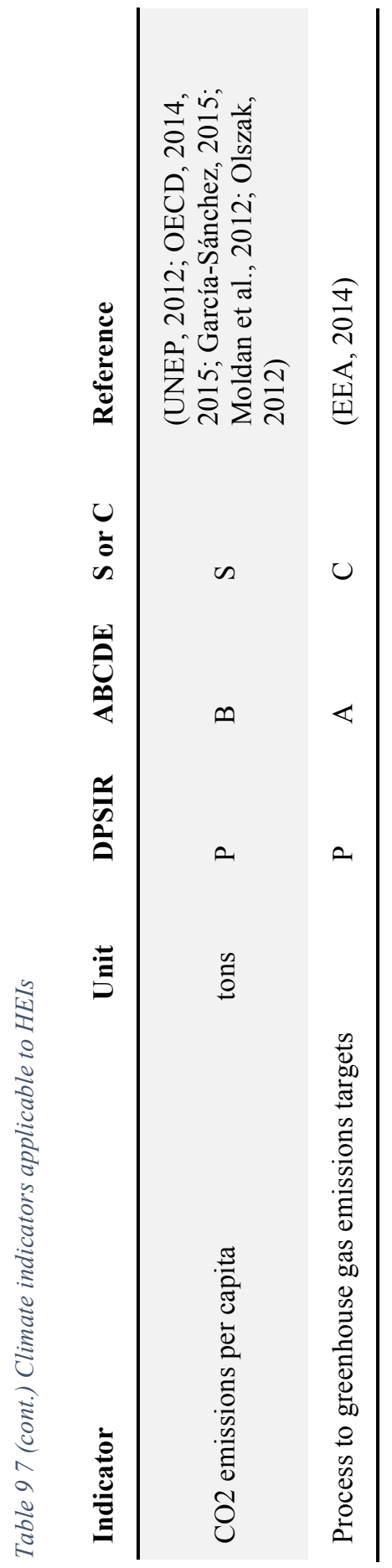



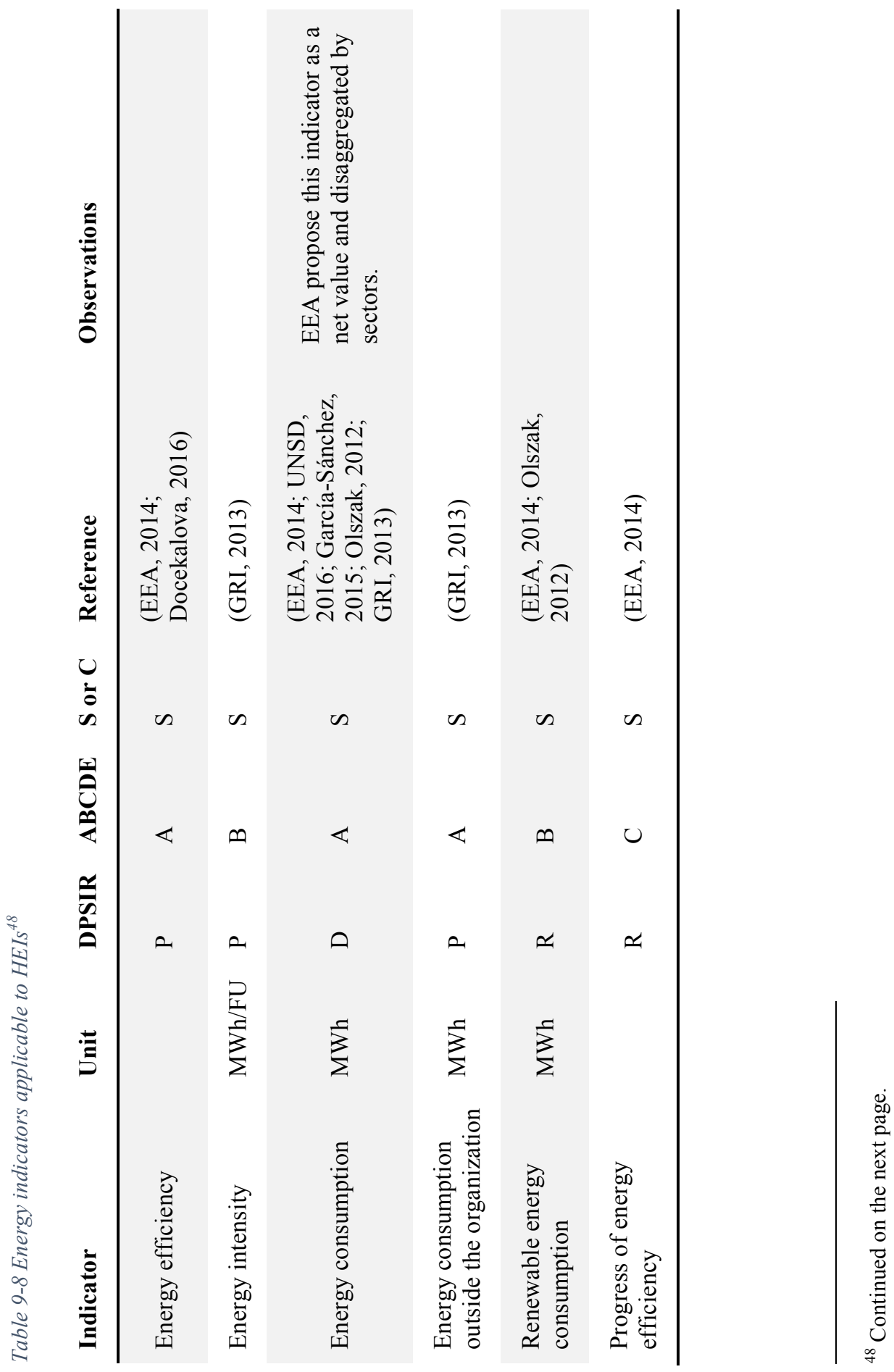


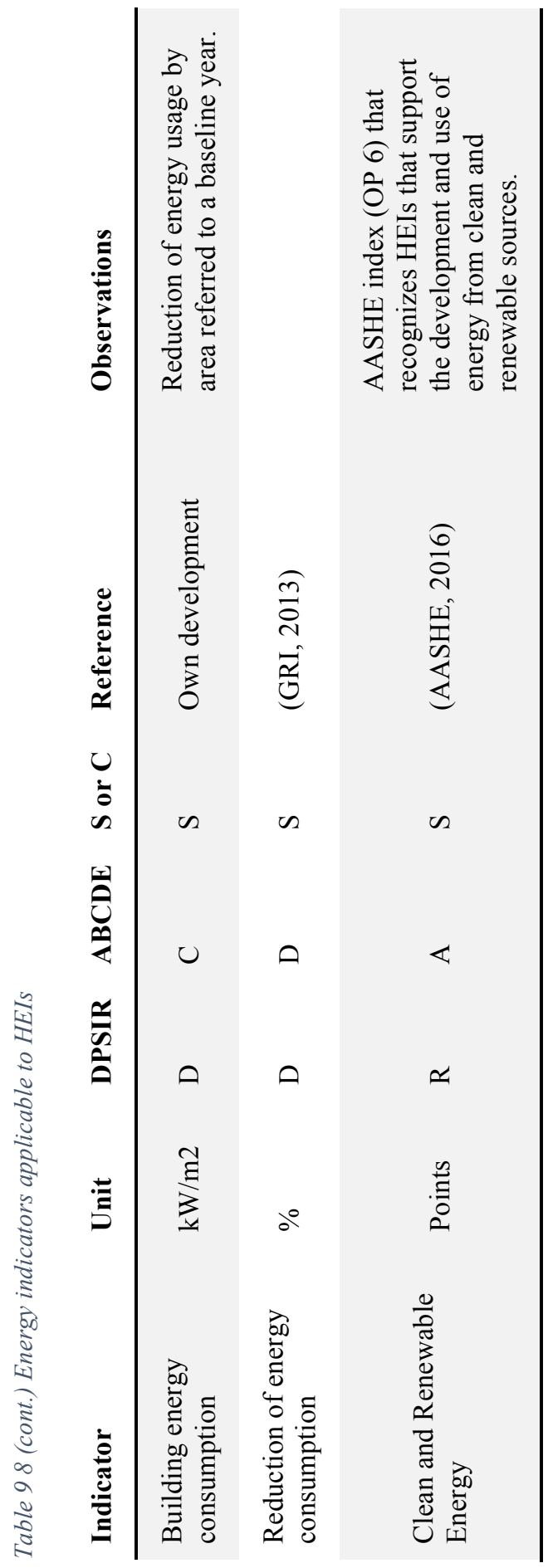




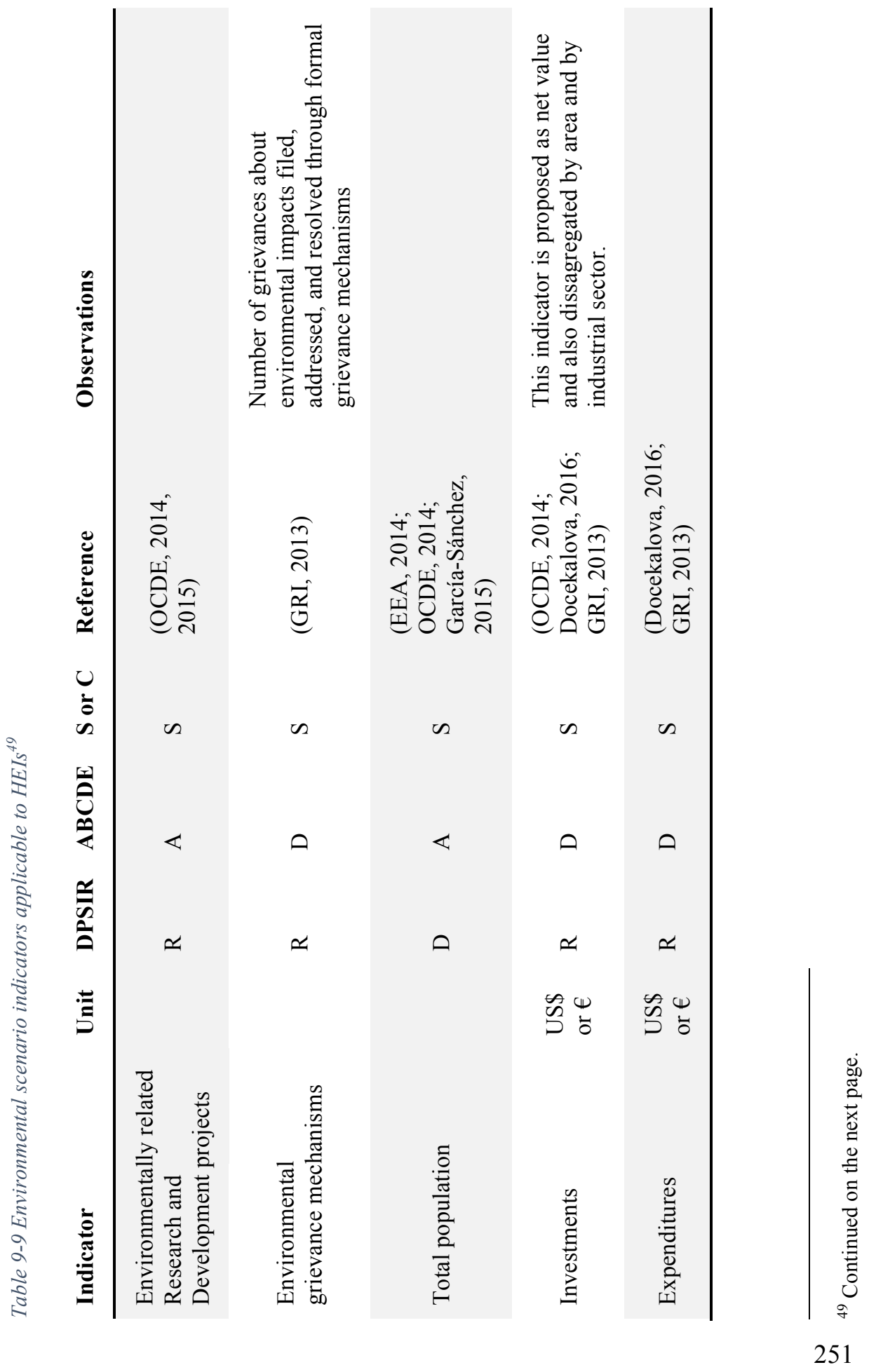




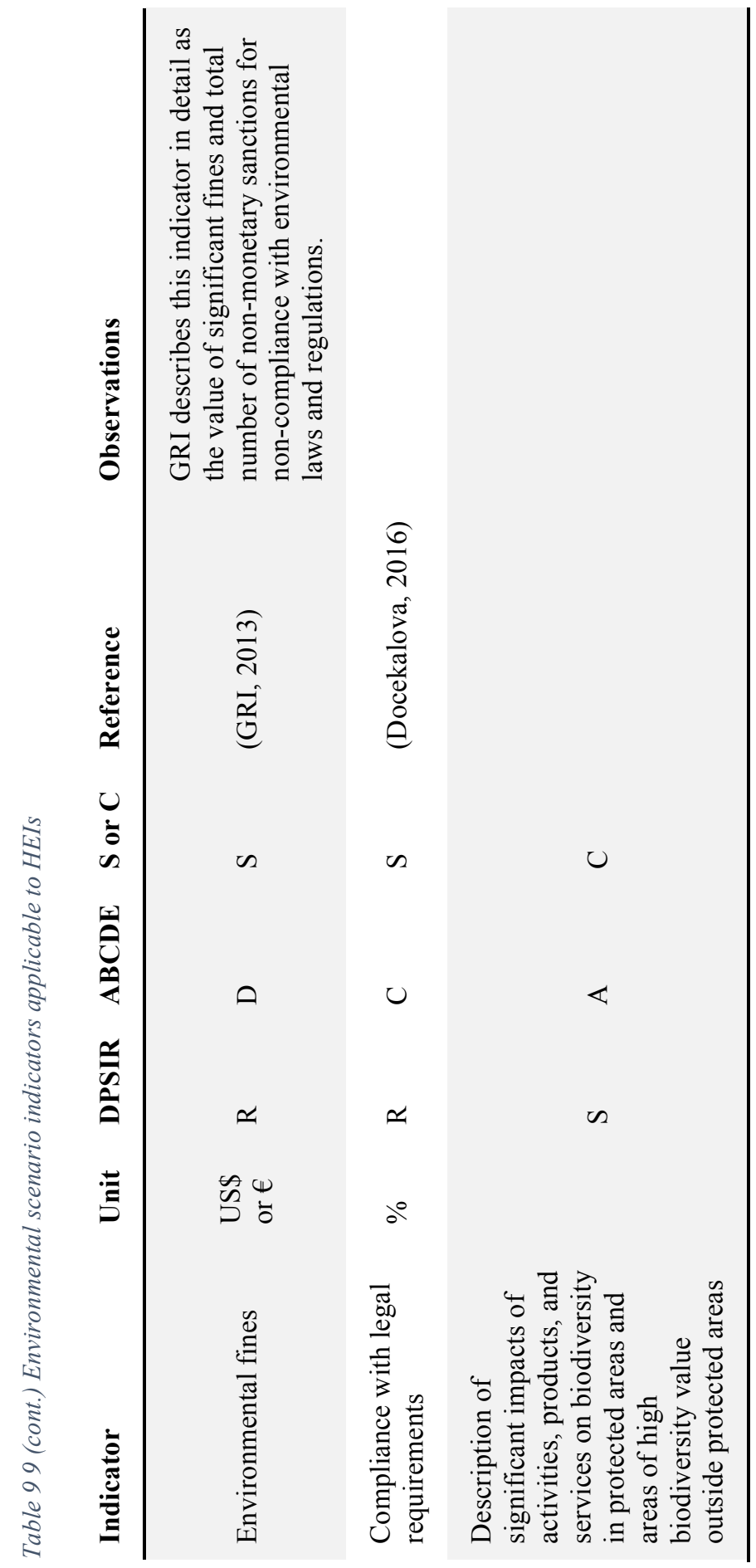




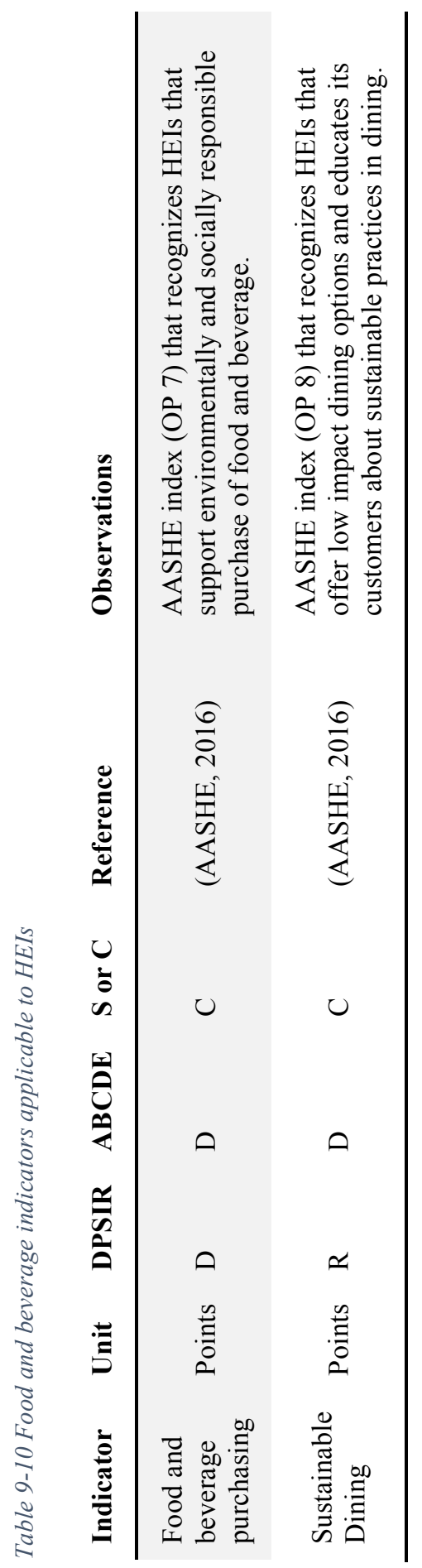




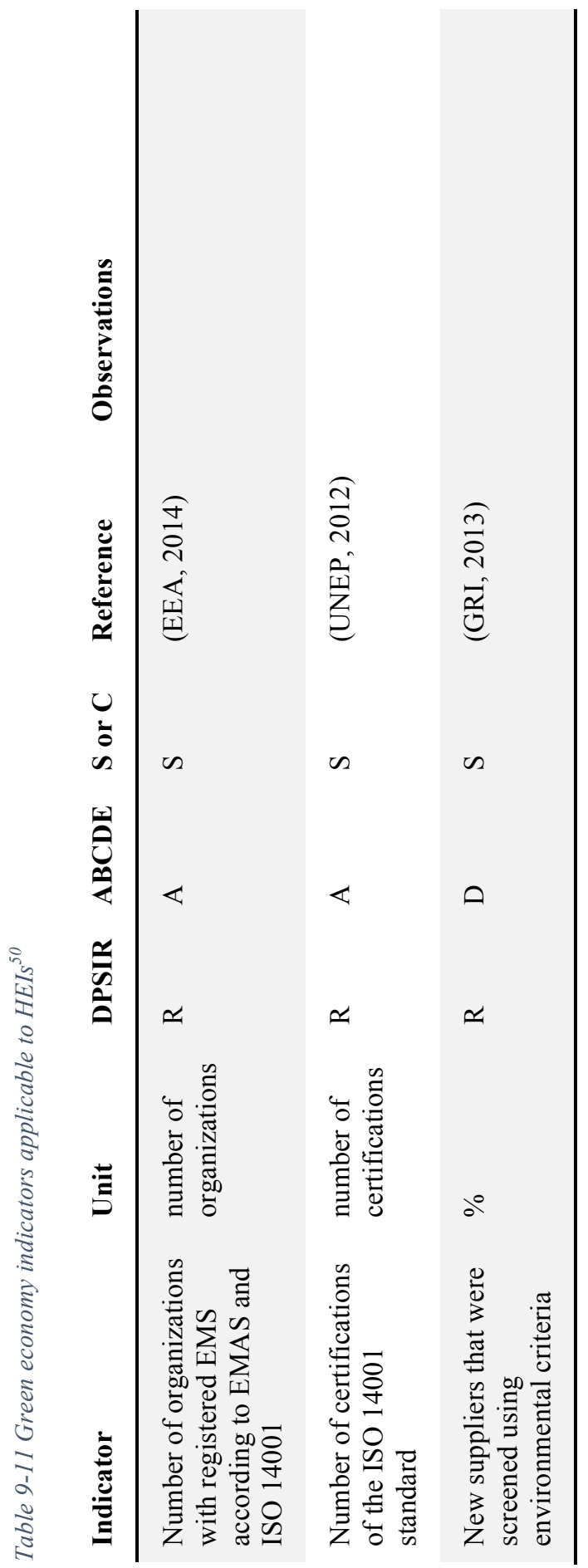

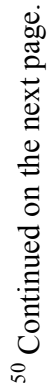




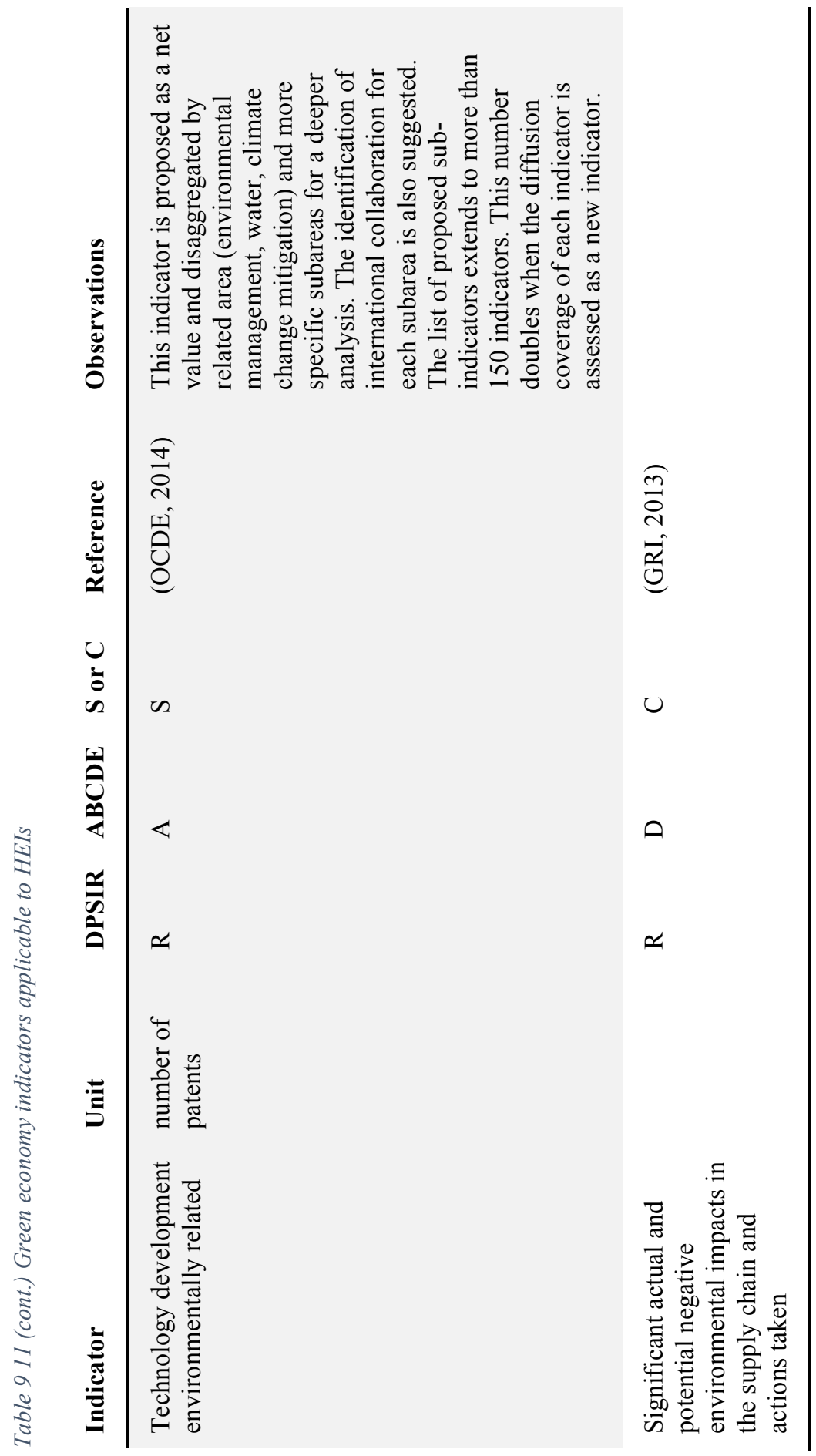




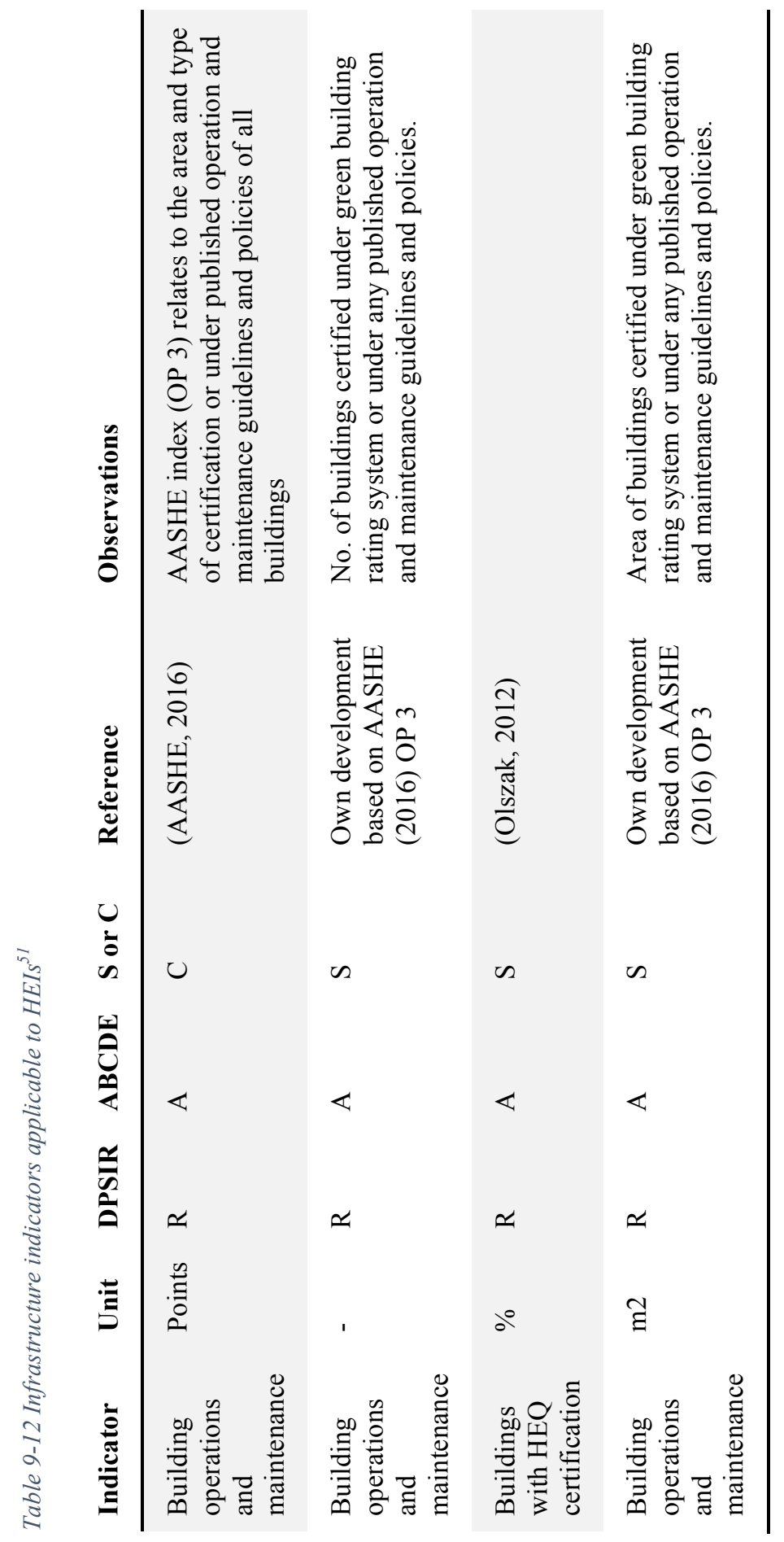

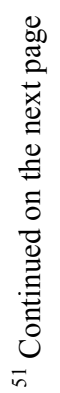




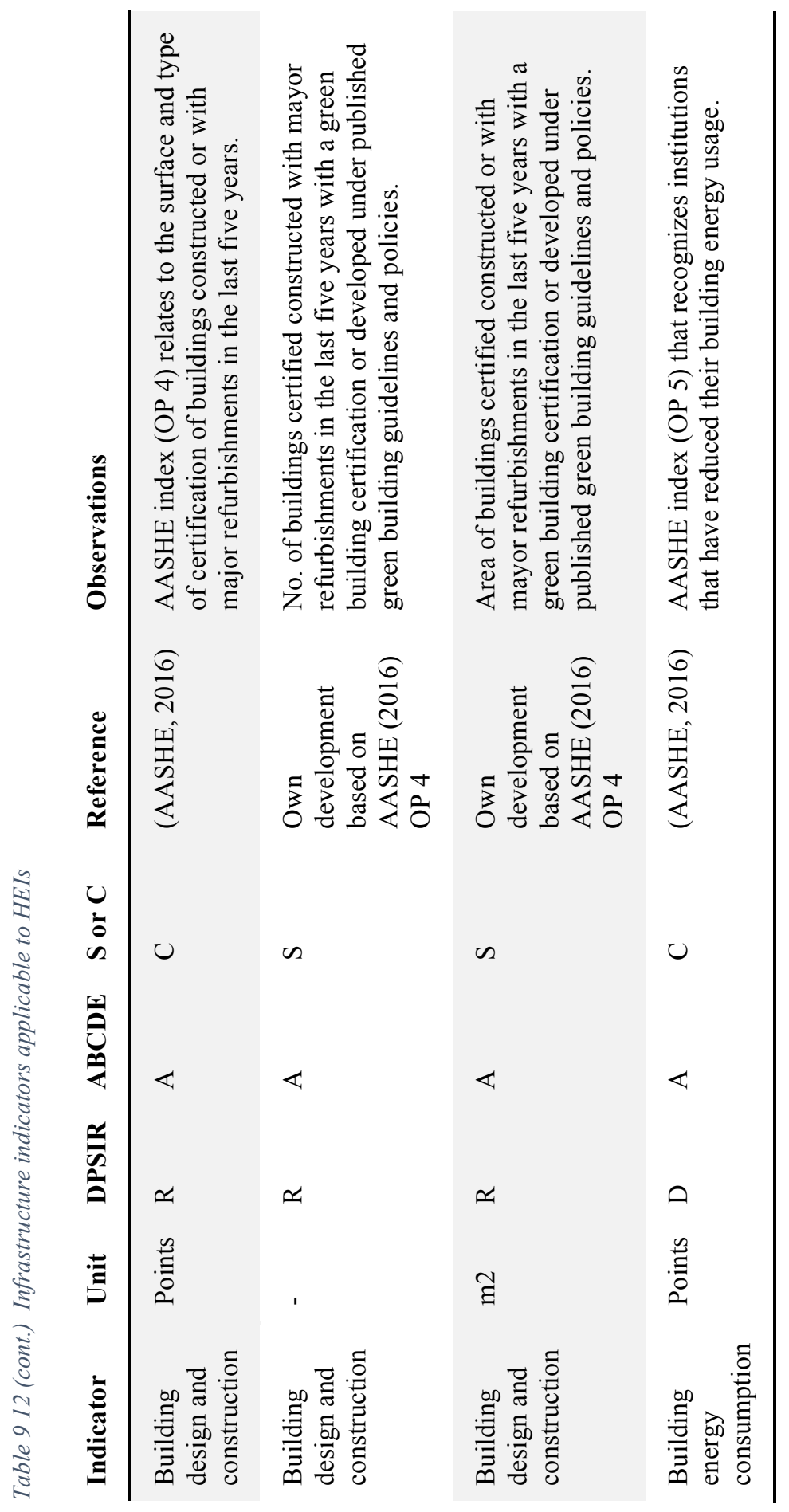




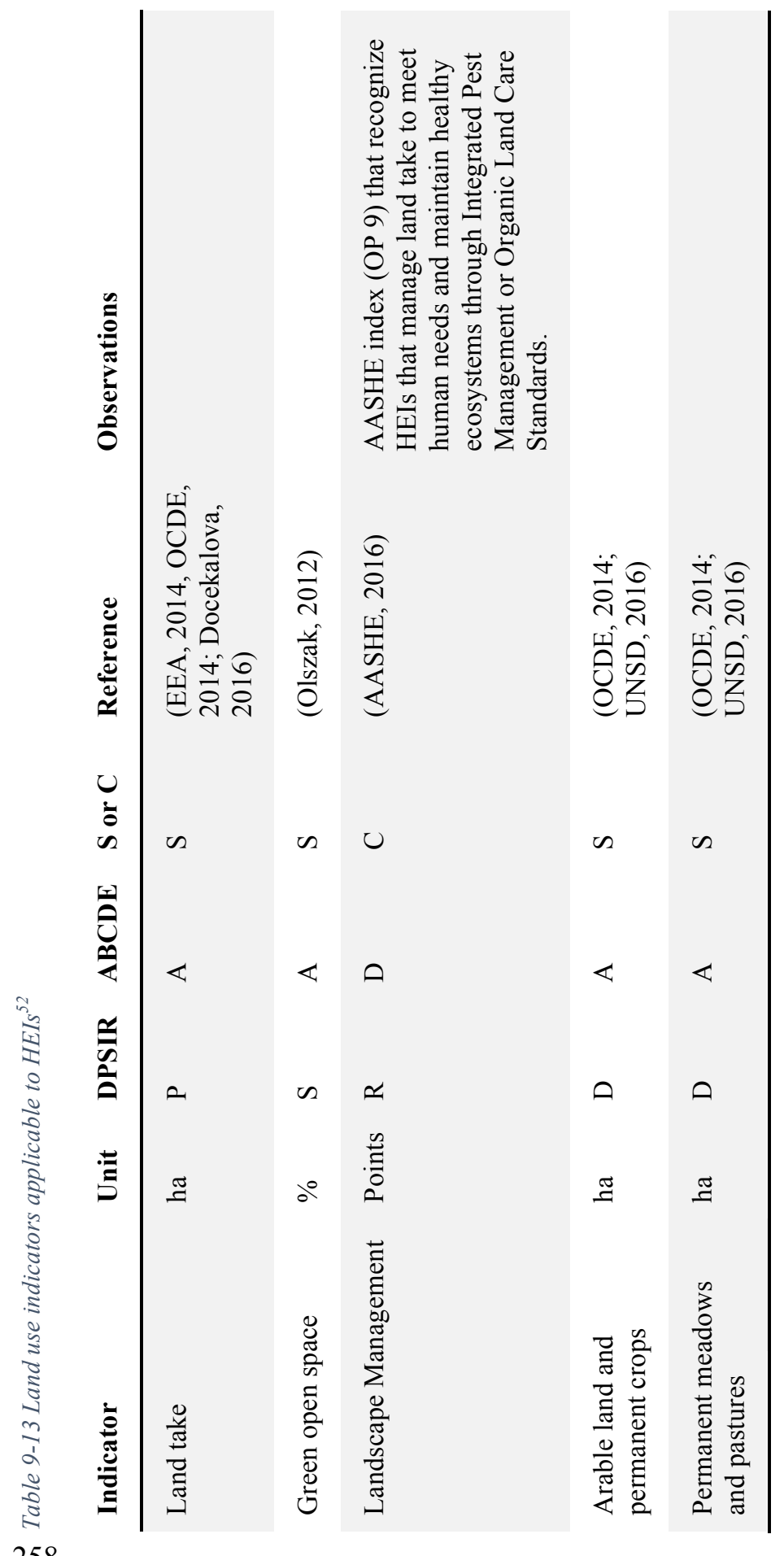

0
0
0
0
0
0
0
0
0
\pm
0
0
0
0
0
0
0
0
0 


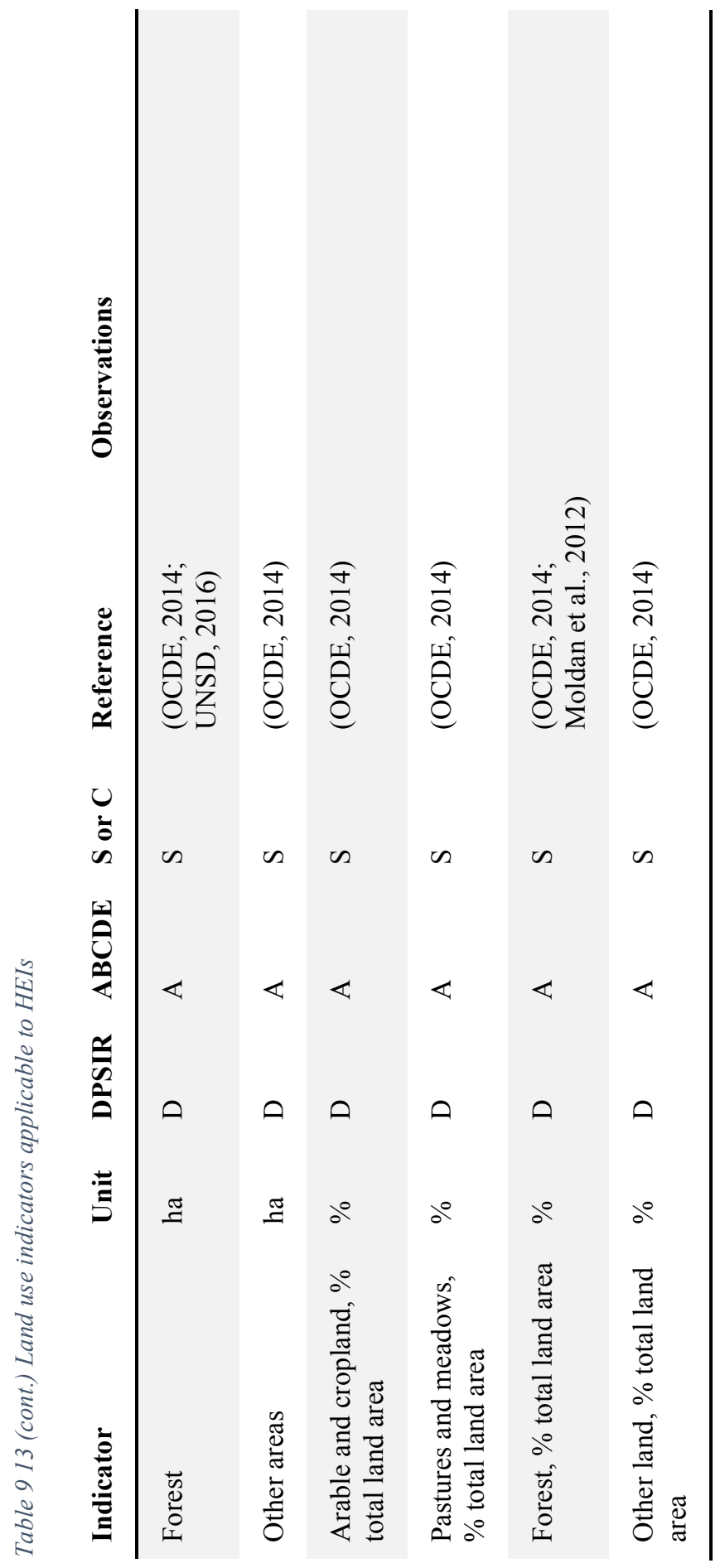




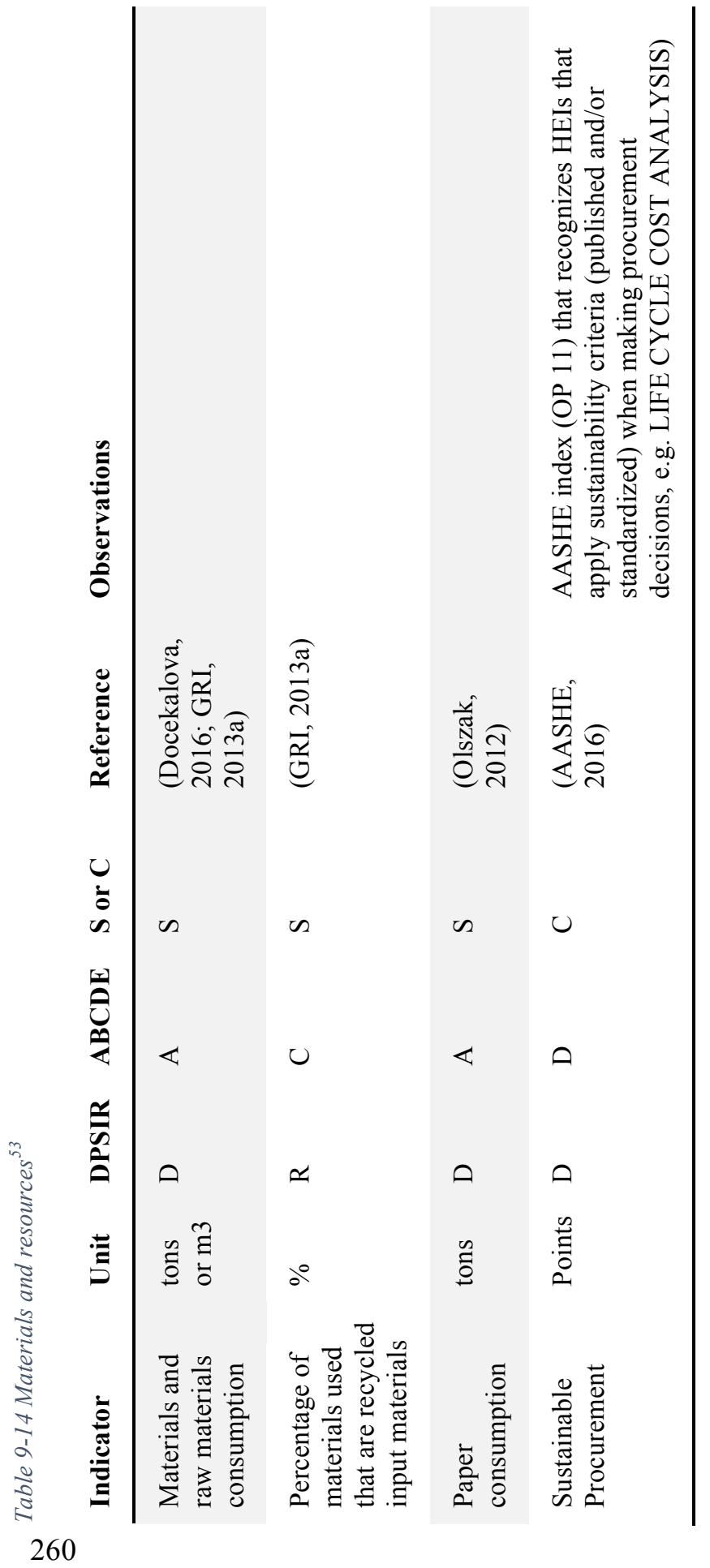

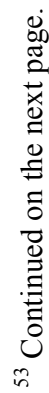




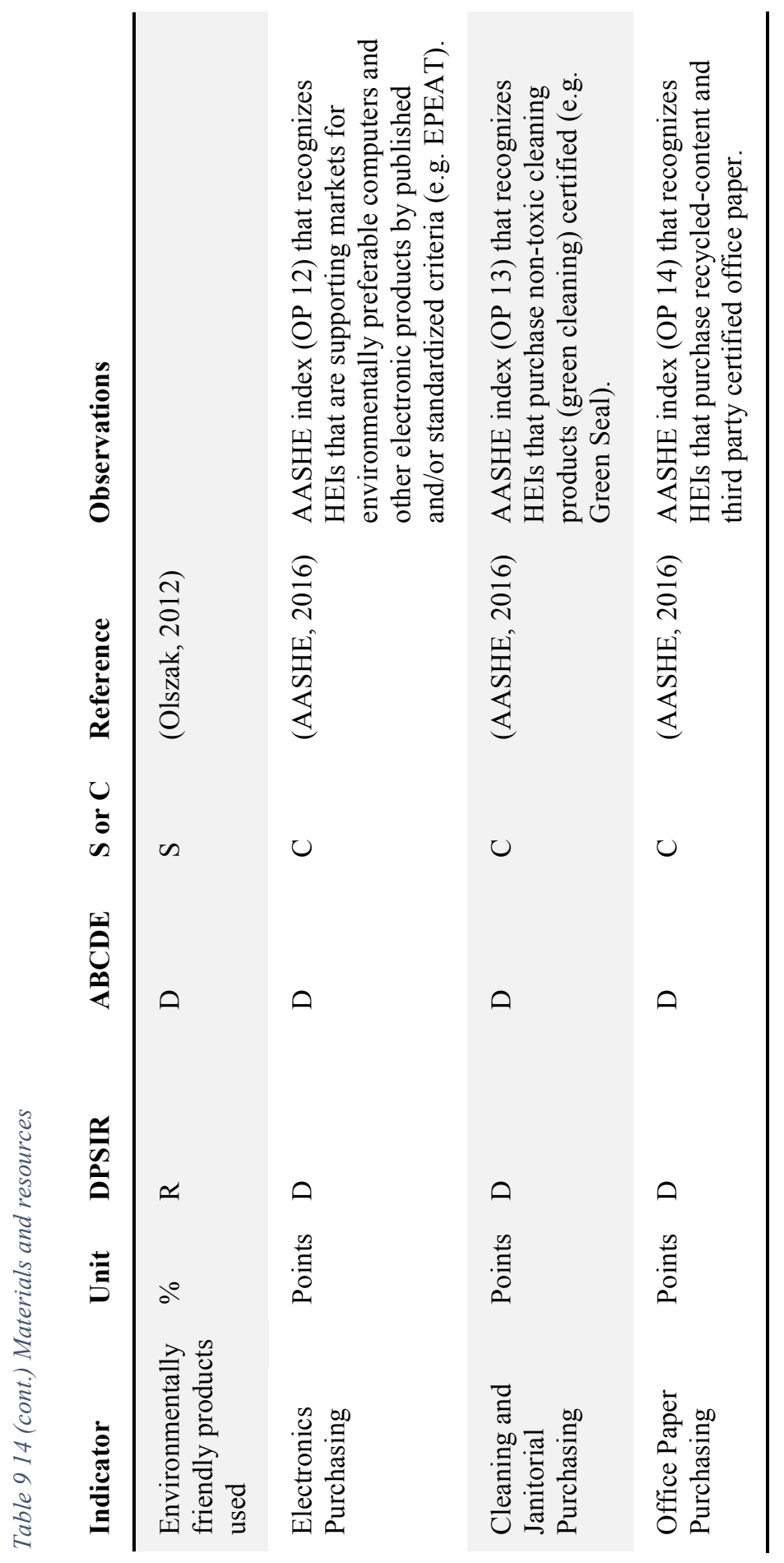




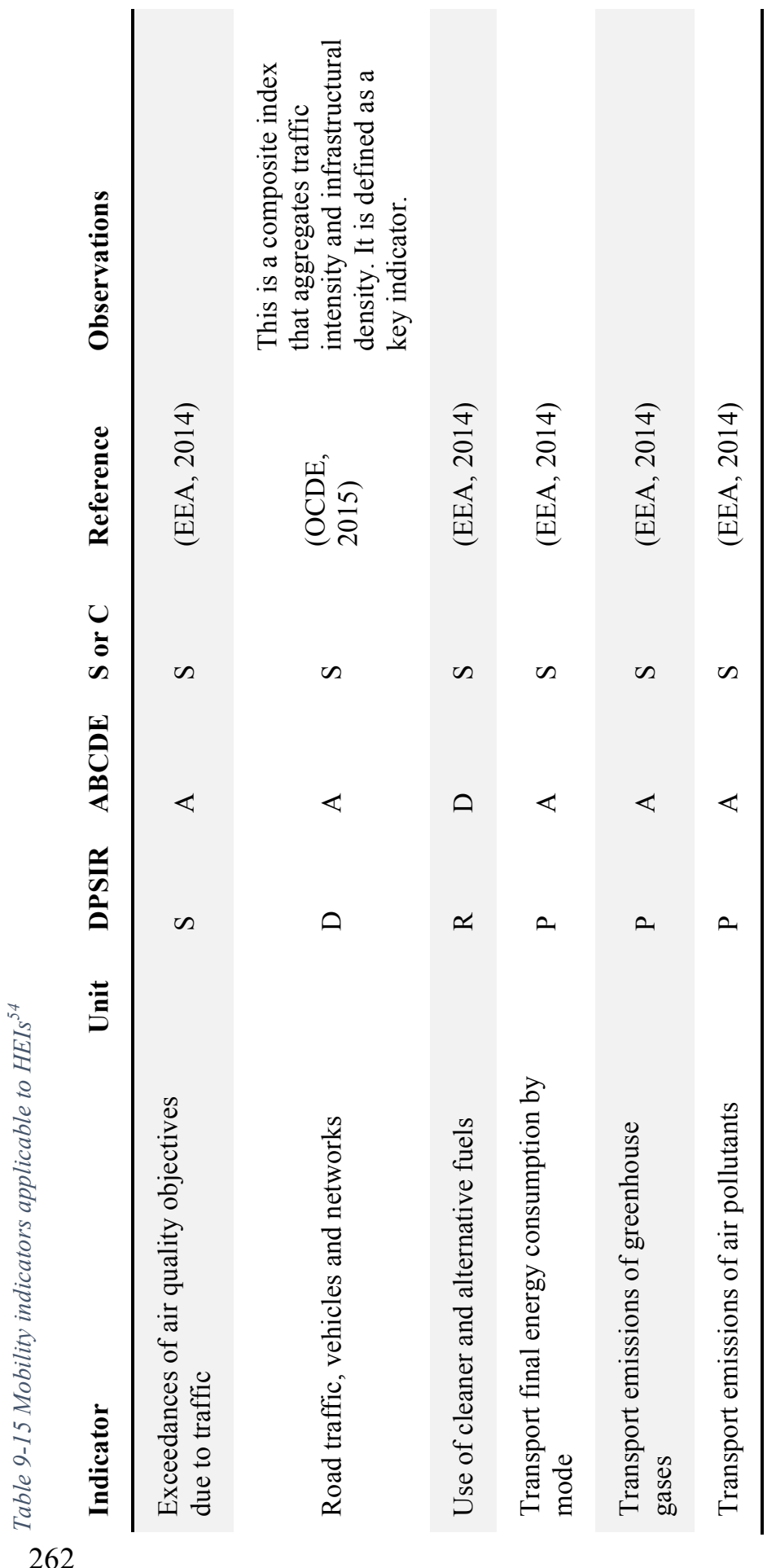

$\dot{0}$
0
0
0
0
0
0
$\Xi$
0
0
0
0
.
0
0
0
0 


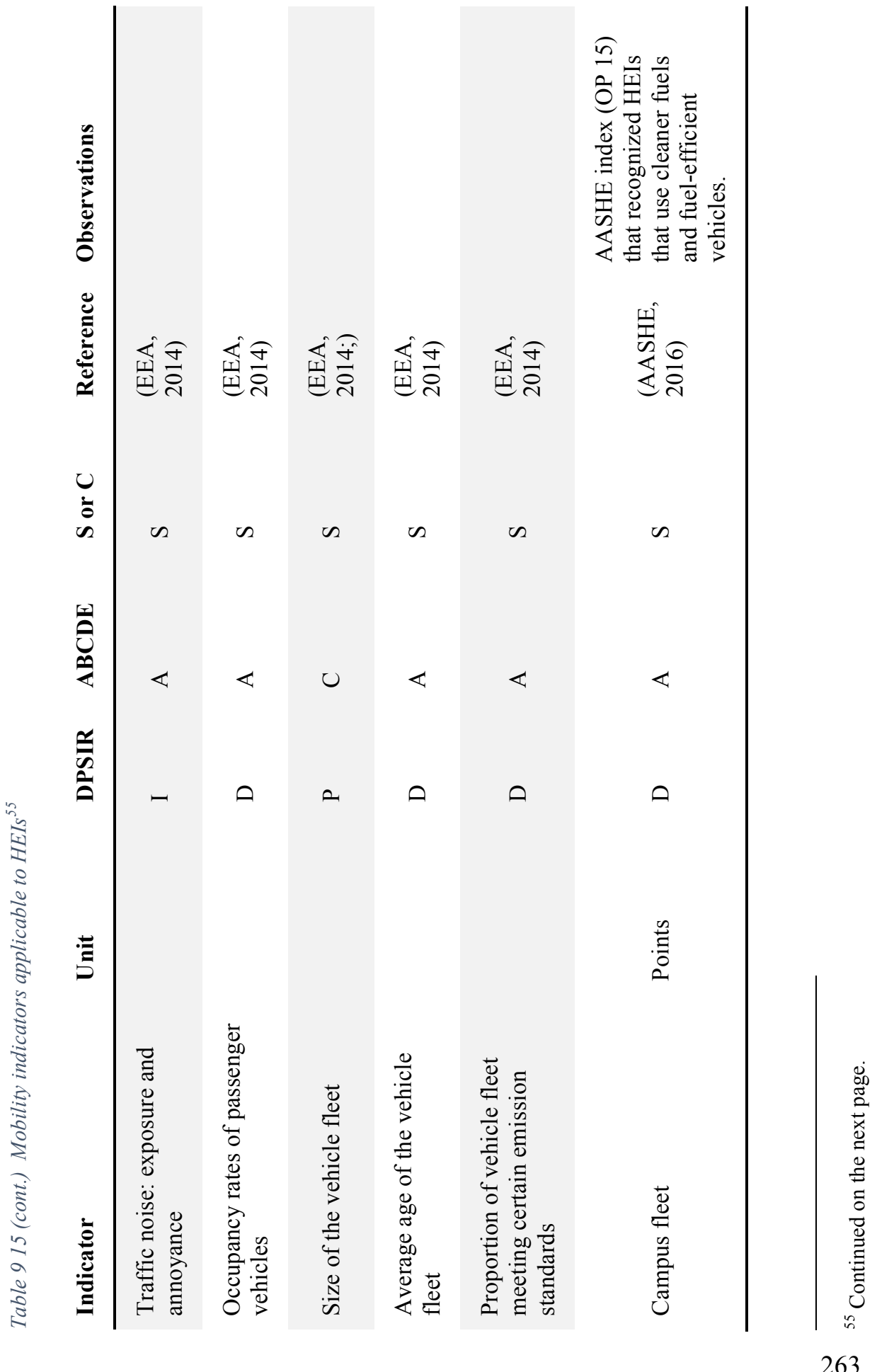




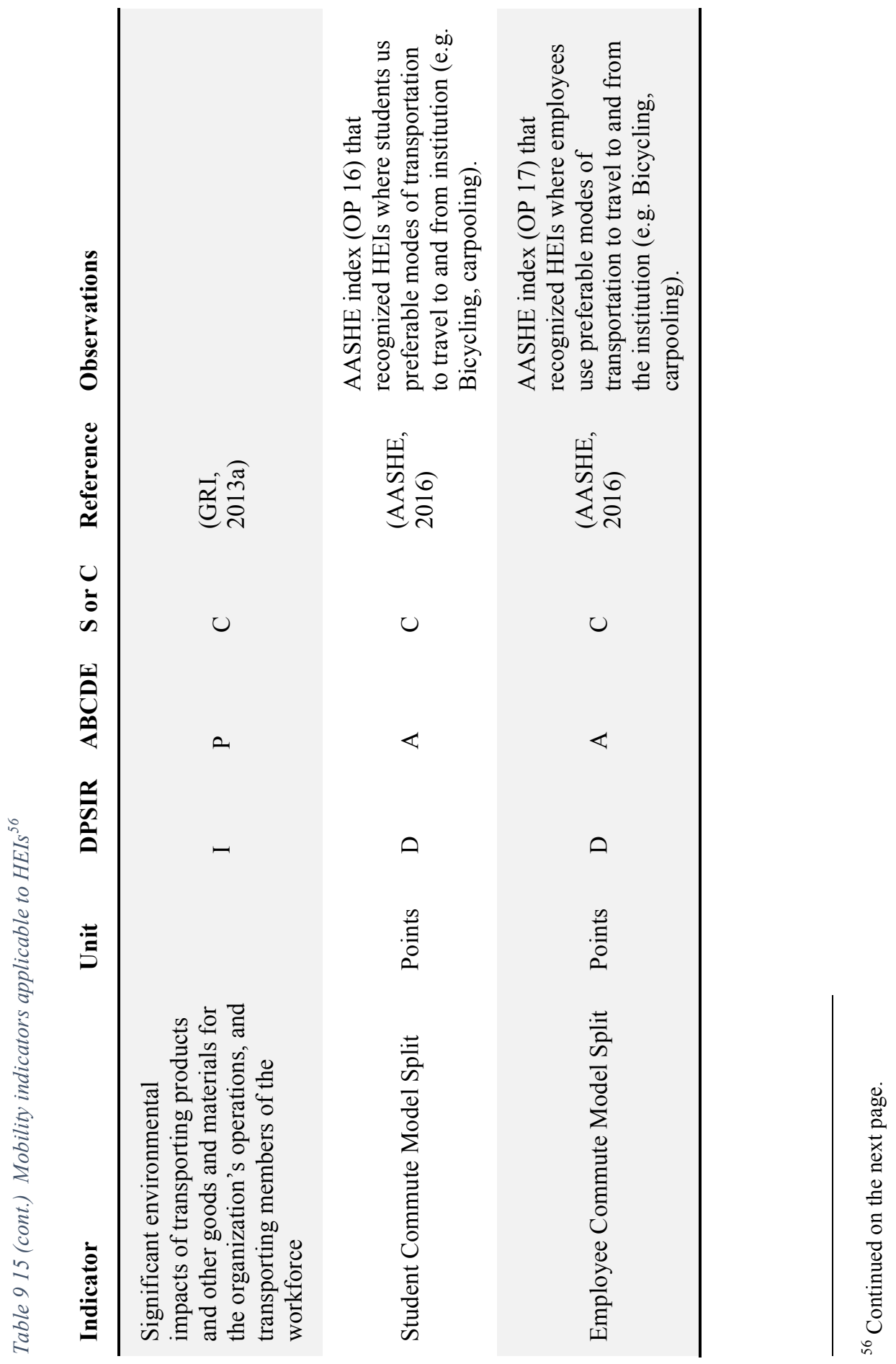




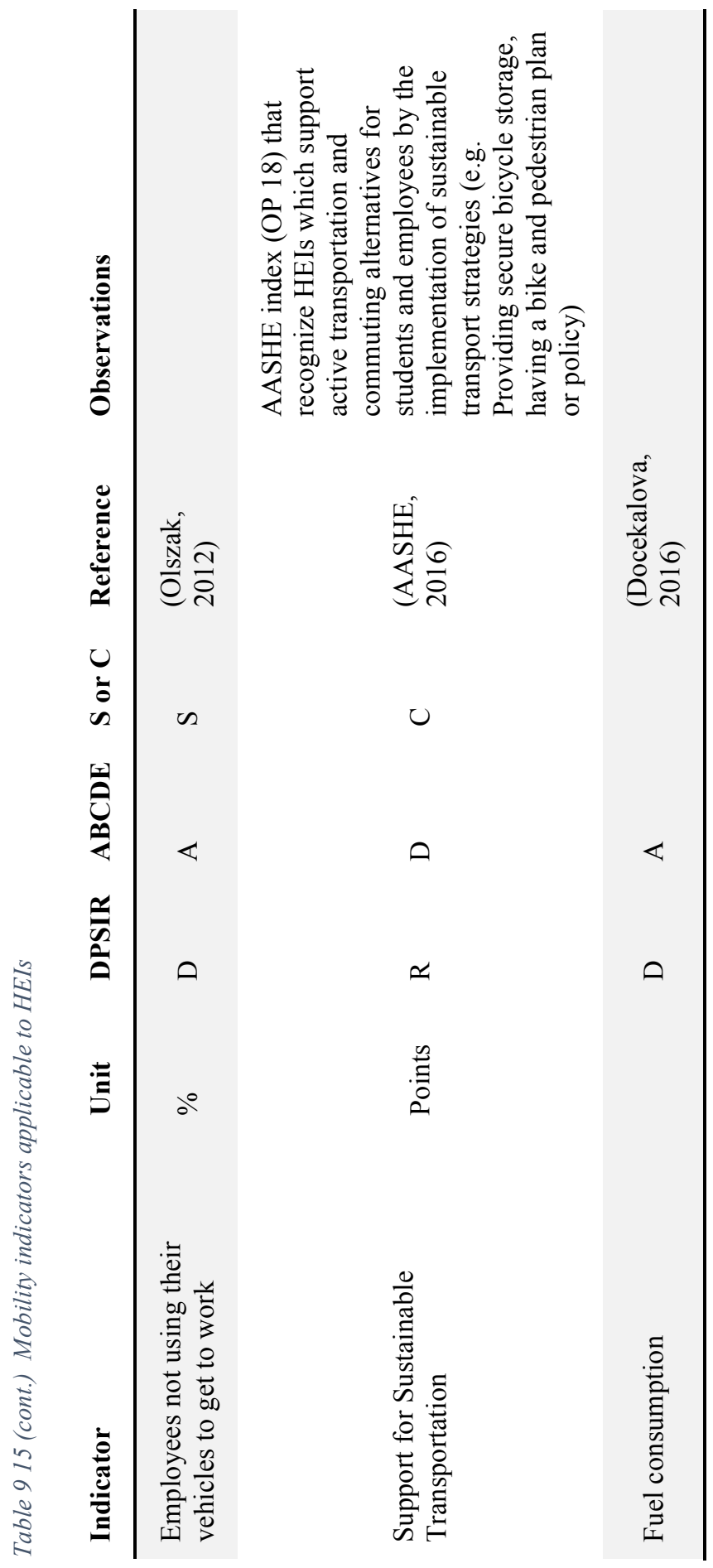




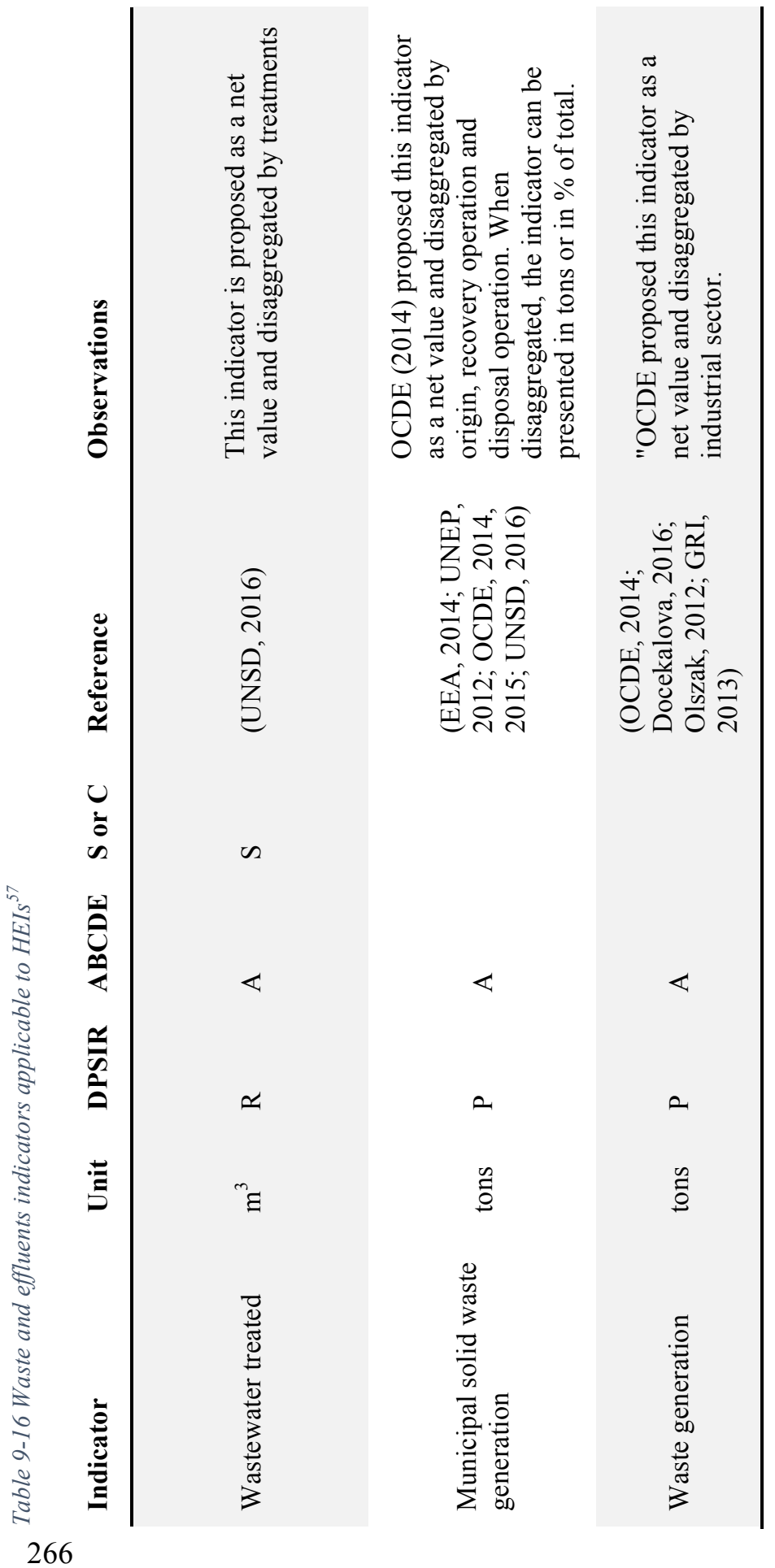

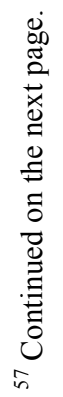




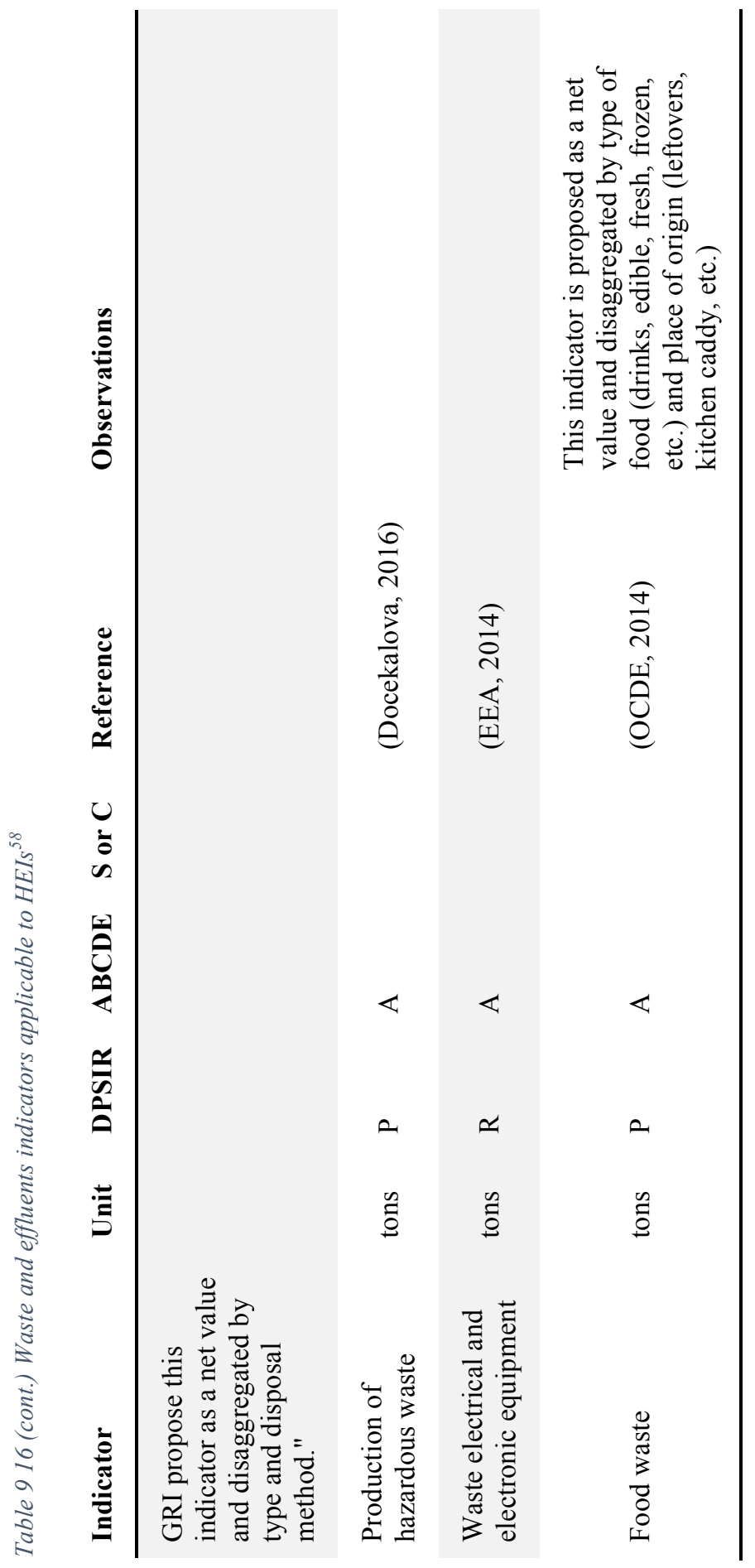

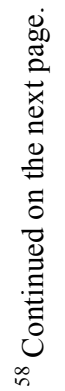




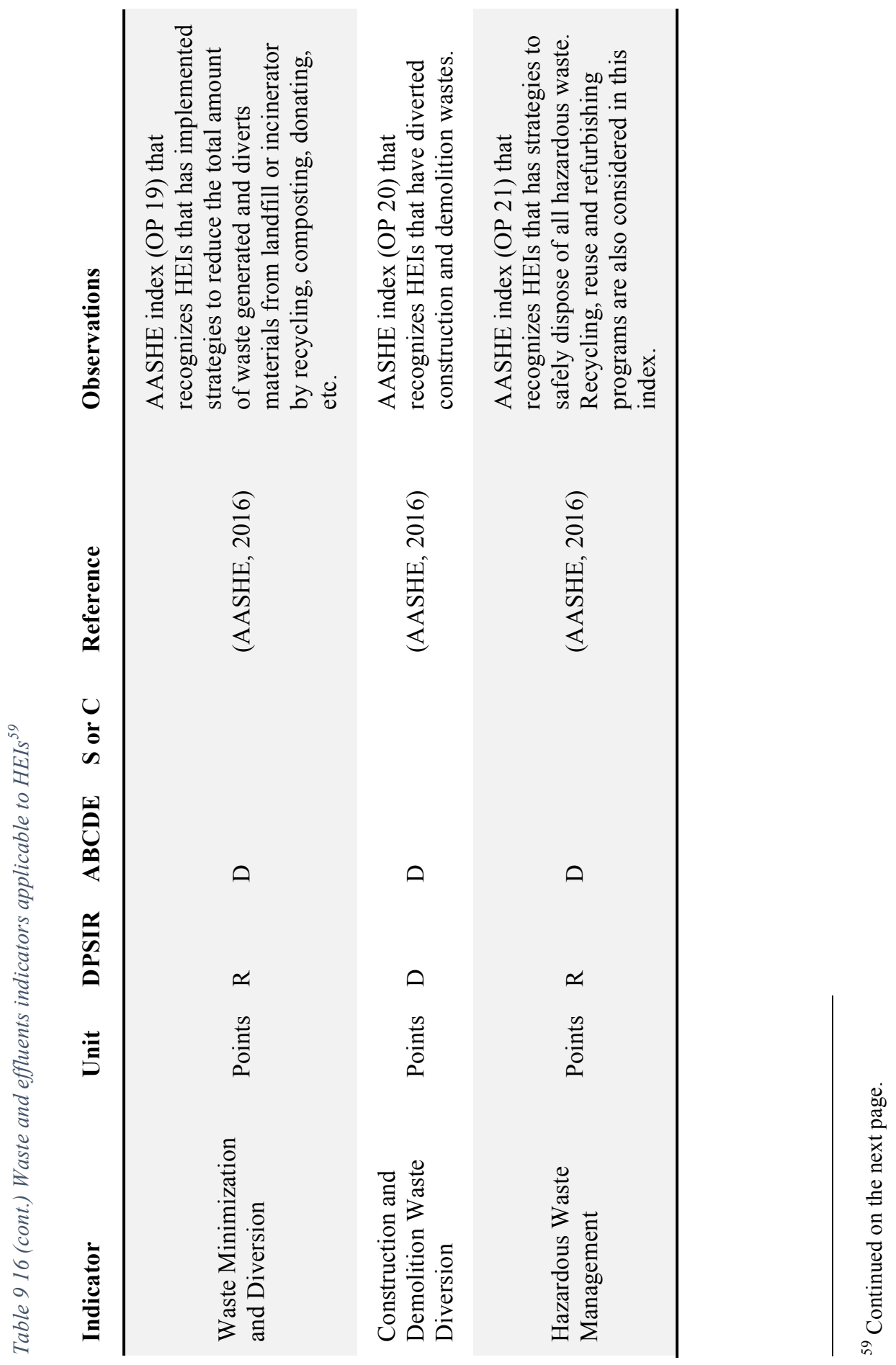




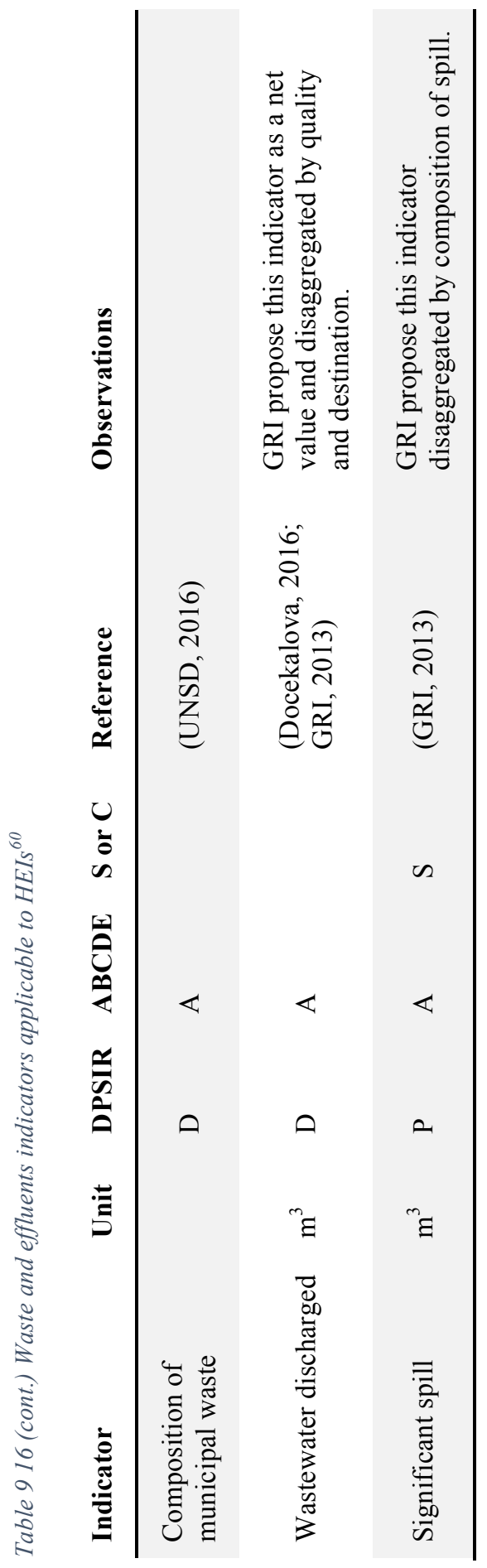

0
0
0
0
0
0
0
0
$\Xi$
0
0
0
0
.
0
0
0
0 


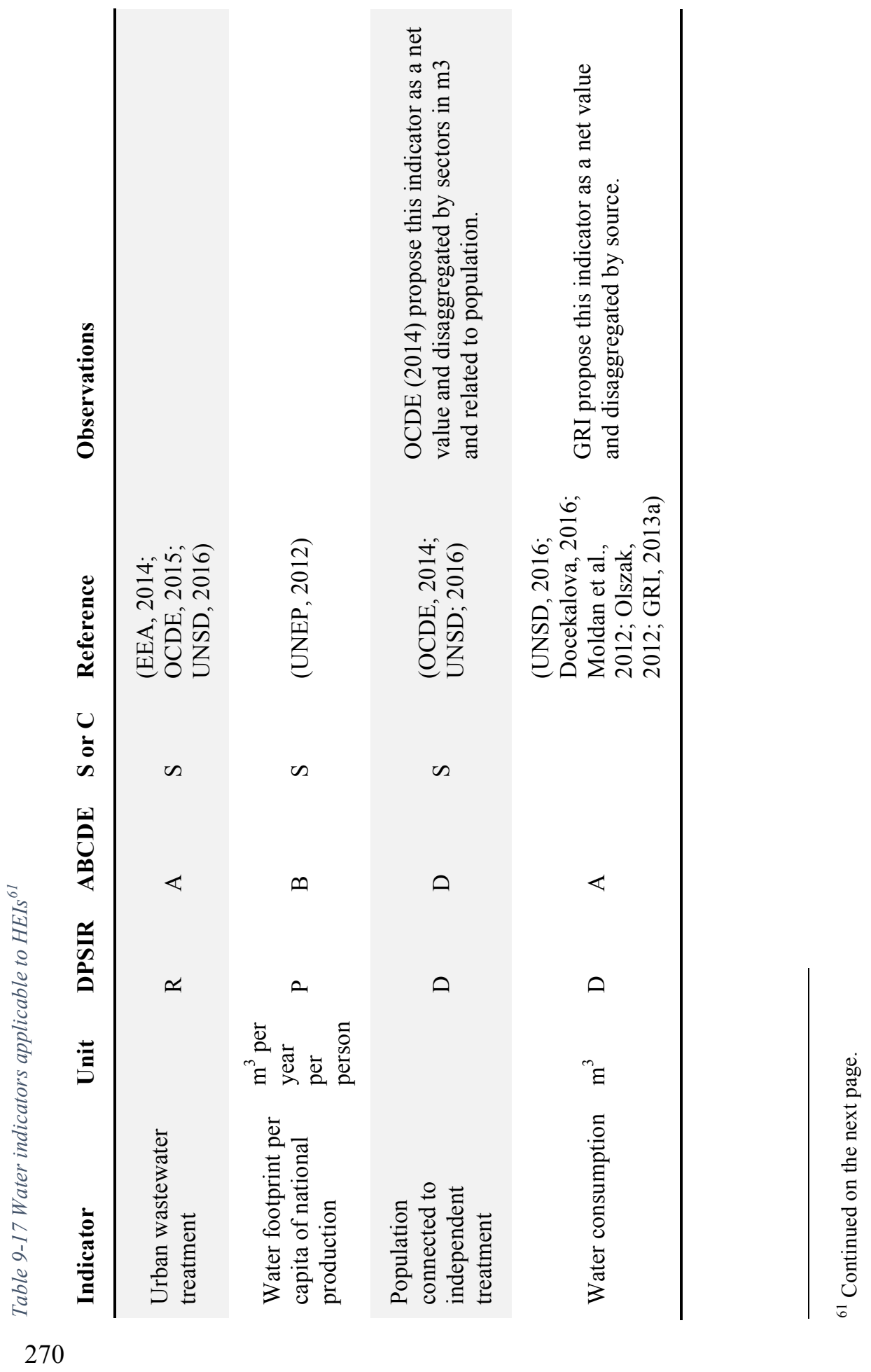



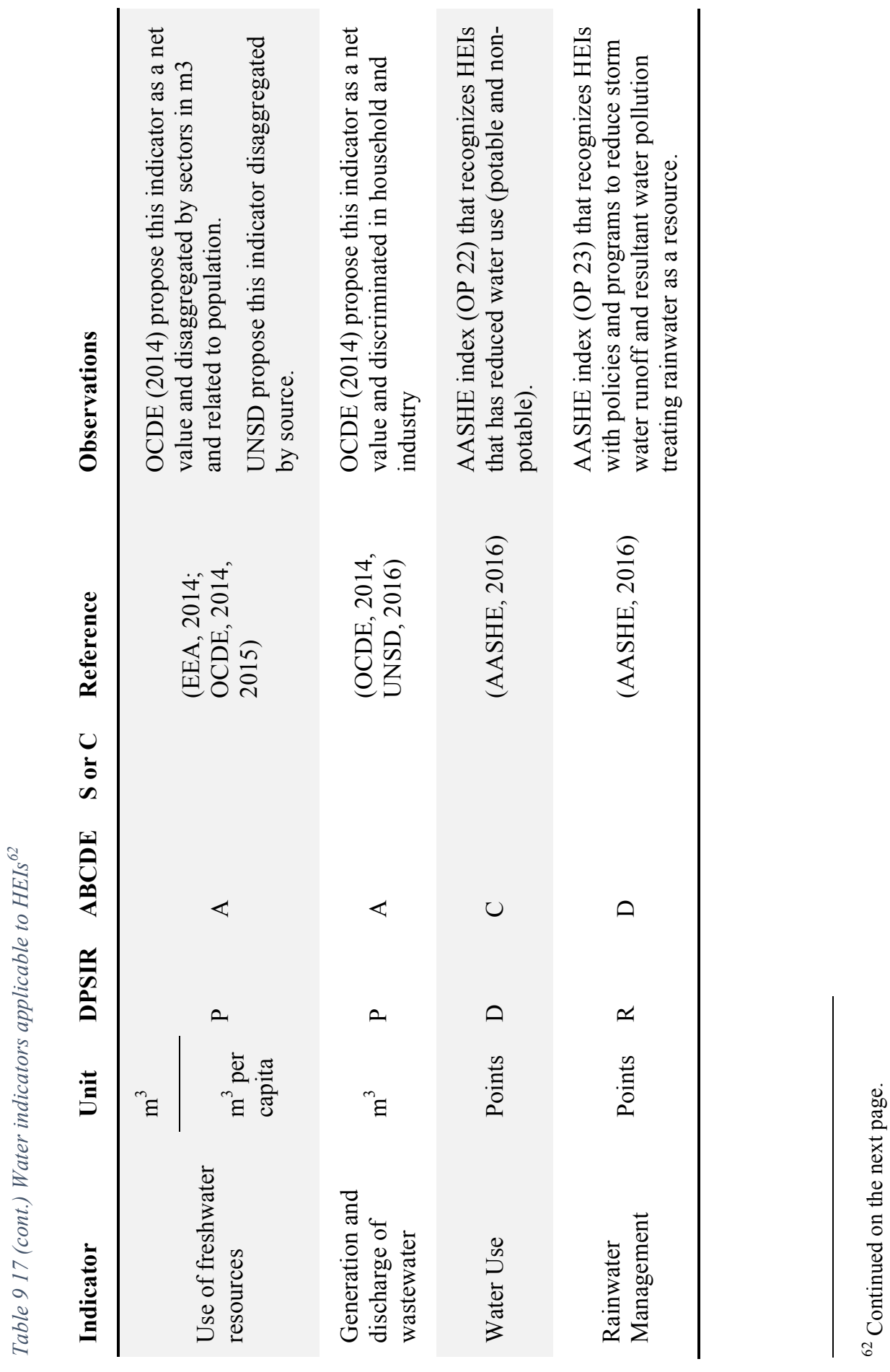


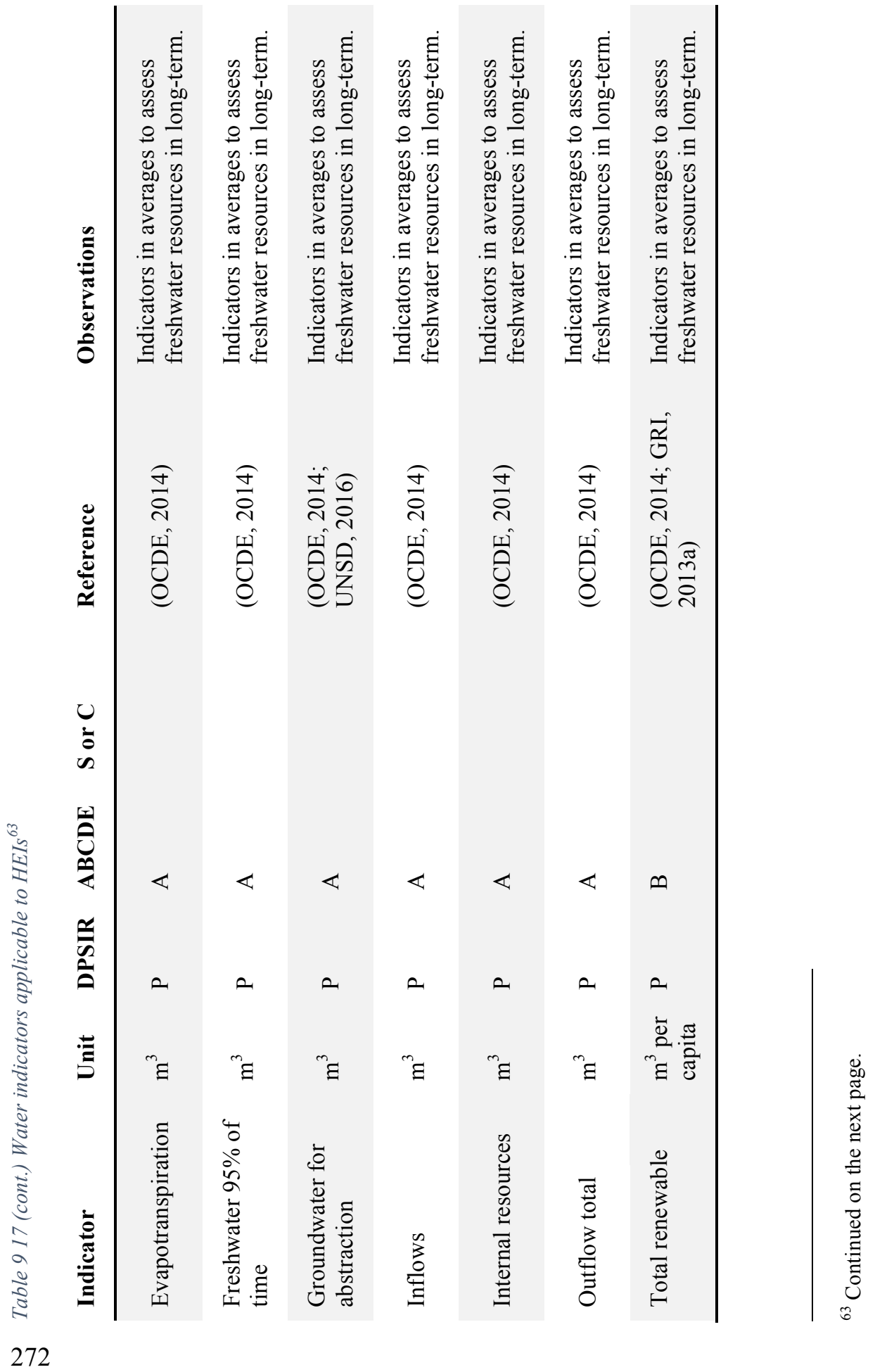




\subsection{ANNEX 9 B. VALIDATION METHOD}

Key good-practice factors and meta-performance evaluation indicators are described, following Ramos and Caeiro (2010) proposal for each level.

Table 9-18 presents the proposal for level 1: Performance of KPIs system: planning and methodological approach. Table 9-19 presents level 2 key goodpractices, performance of KPIs at the implementation and operation stage. Observations are included in both tables for a better interpretation. 


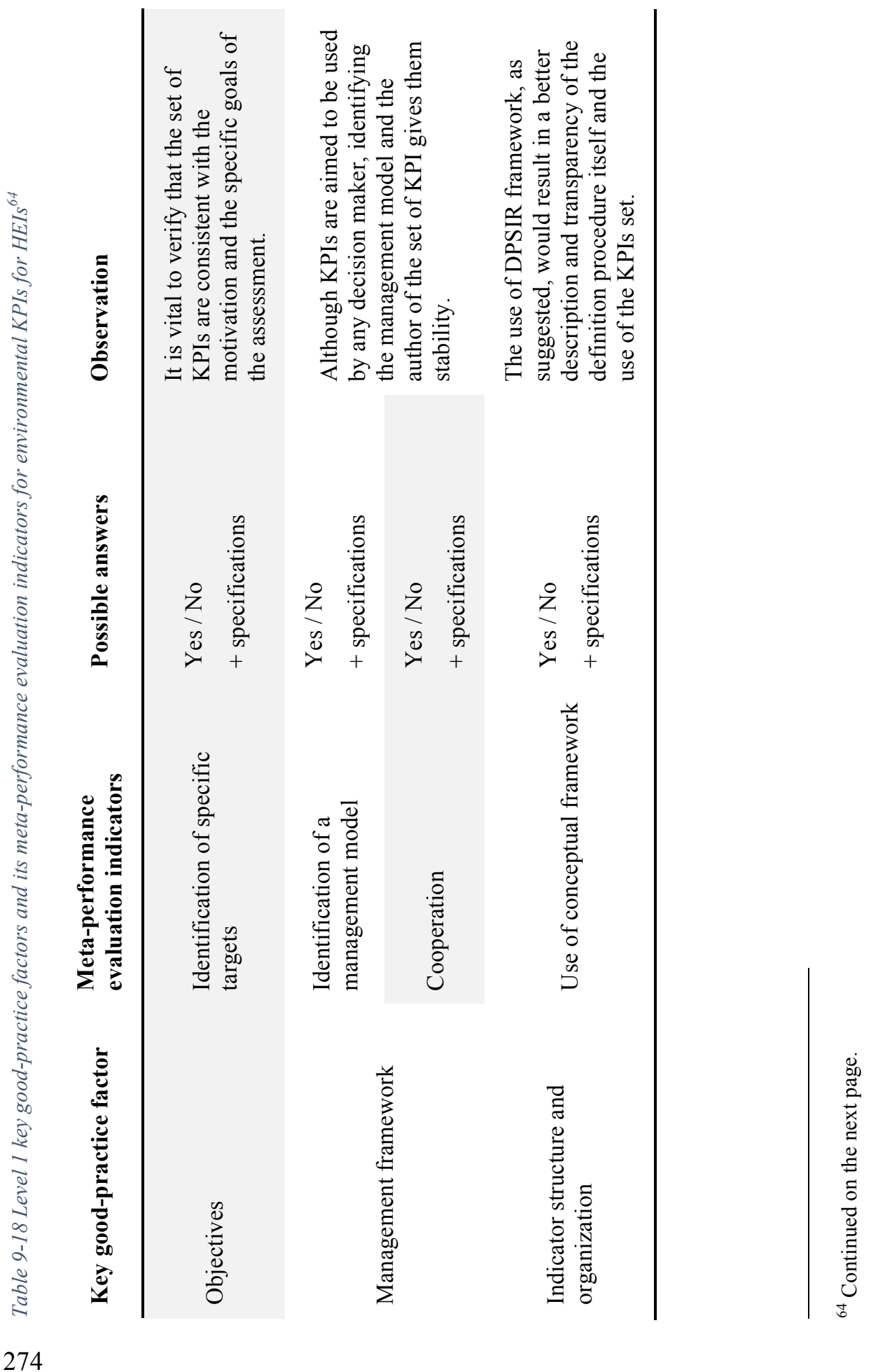




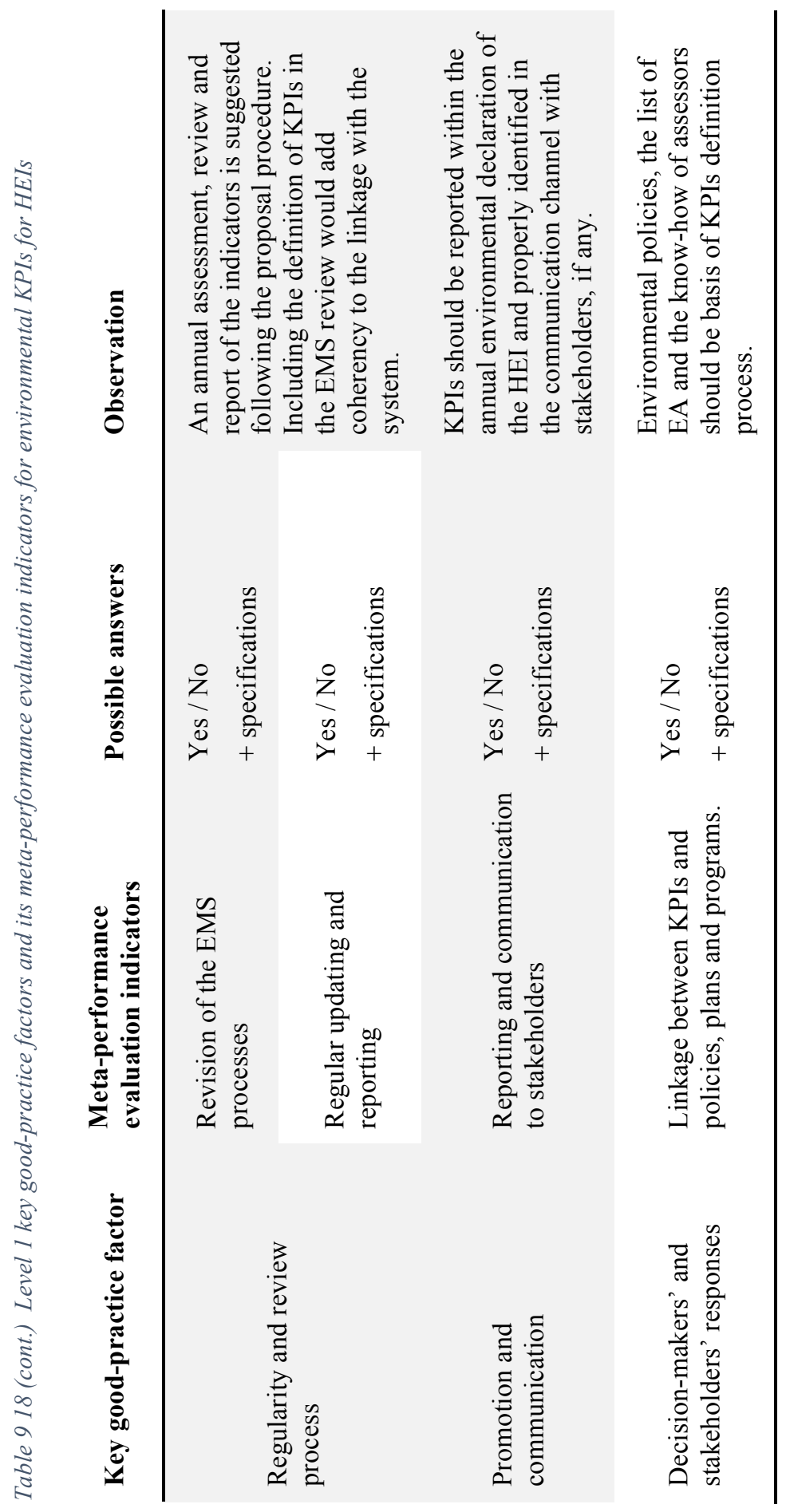




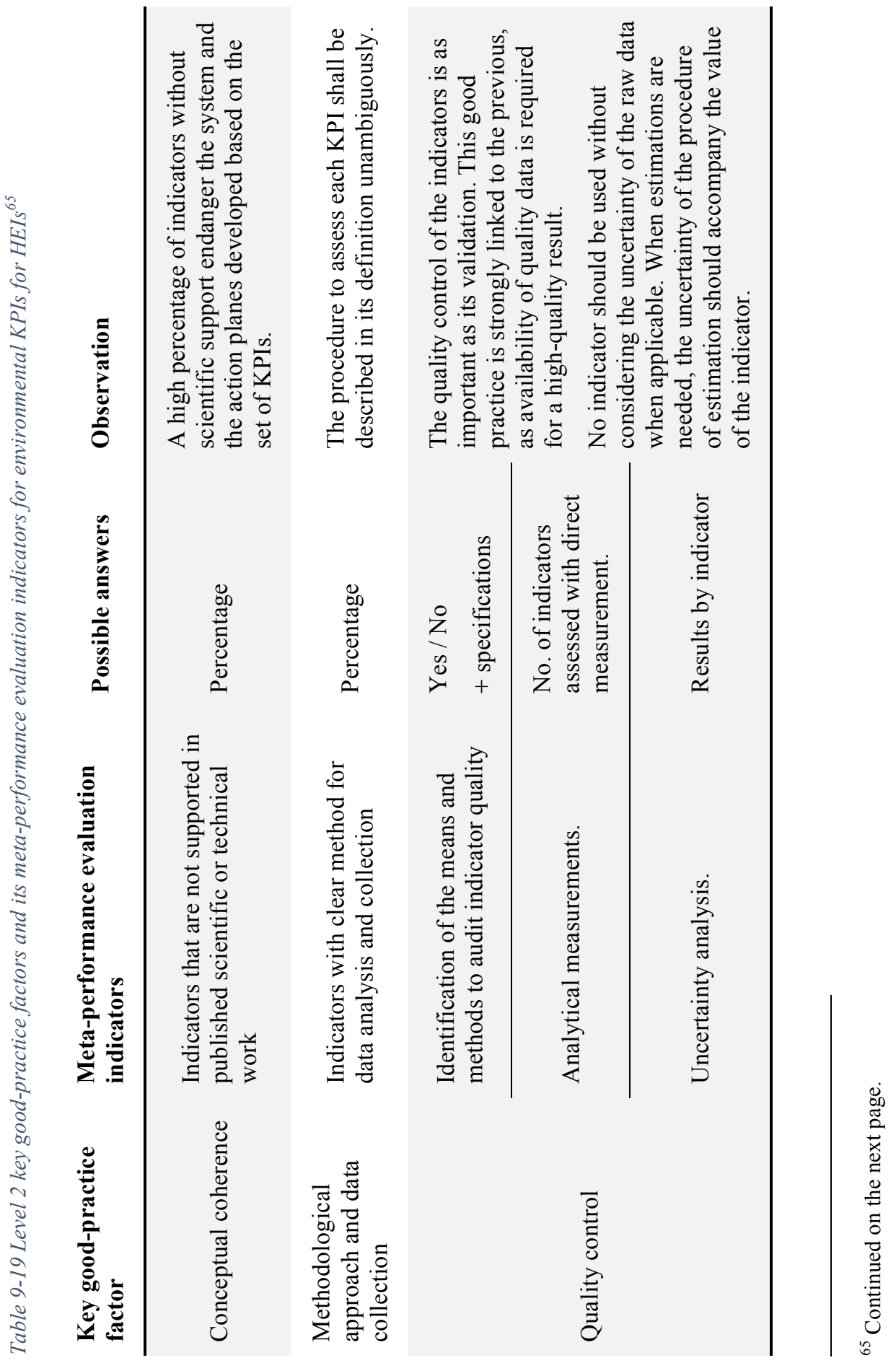




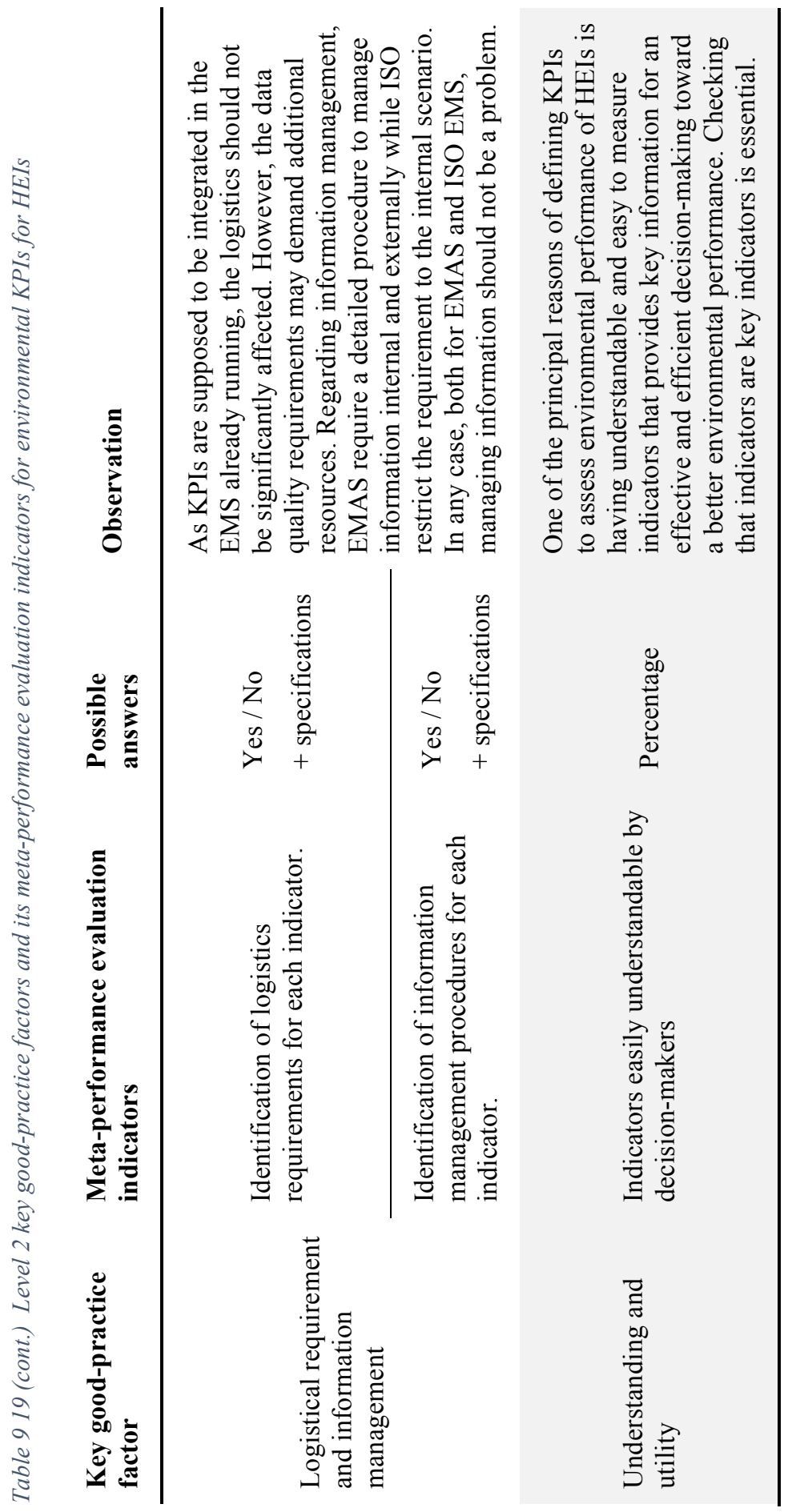





\section{GENERAL DISCUSSION OF RESULTS, CONCLUSIONS AND FURTHER RESEARCH}

Due to the structure of this dissertation, as a compendium of publications, all the previous chapter already have its own discussion of results, conclusions and further research proposals. It is not the aim of this chapter to double analysis but to link the findings of the diverse stages of the research. For a deep insight on particular results, refer to the corresponding chapter or publication.

This chapter presents a general discussion of the results shown in each previous chapter and publication following the guiding thread presented in the introduction. For a better description, the discussion conclusions and further research are divided in two sections: the first one stands for the methodological proposals and approaches over HEIs in general while the second sections discussed the results and presents further research over the case study chosen as common denominator in each phase of this work, EPSA.

\subsection{REGARDING THE STUDY OF ASSESSMENT TOOLS AND METHODOLOGICAL PROPOSALS}

HEIs are complex organizations with several particularities regarding the environmental management; they are not product-based companies with a defined manufacture or service line to assess. Although all HEIs have one common mission, train professionals and educate citizens, they can have other parallel missions that influence, significantly, in their activities and processes (i.e., transferring technology and researching). The list of EA is unique for each HEI as the combination of activities and processes is unlimited. However, there are some core EA that can be considered for almost every HEI; the aspects related to the use of infrastructure. Every HEI that uses and manages infrastructure (e.g. a building) has inputs - like energy and water consumption - and outputs - like waste and waste water - that deserved environmental consideration. The consumption of abiotic and biotic resources and the generation of concerning types of waste (electronics, nuclear, etc.) cannot be generalize as directly depend on the mission of each HEI. For example, HEIs with technological research will have additional EA different to HEIs with research in business, history, etc.

Environmental indicators and reporting tools published has been analyzed. On a first stage, considering the large number of HEIs that publicly show interest in EF, EFA has been deeply studied. Results developed into the proposal of a specific methodology to assess EF in HEIs, due to the lack of a standardized procedure. The methodological proposal presented has been built considering 
Proposal of a set of Key Performance Indicators for the environmental assessment of Higher Education Institution

the life cycle approach trying to have a complete view of the environmental impact of the HEI. Impact categories of LCA have also been studied and considered as tools to assess the environmental performance of this type of organizations.

During the development of this research, a new methodological approach was launched, the O-LCA; a life cycle framework specific for organizations. Both the technical specification document (ISO/TS 14072) developed by ISO and the guidance developed by UNEP has been deeply analyzed considering HEIs structure. This new concept shad light over some of the limitations of LCA already detected by defining the reporting unit concept; an alternative for FU not clear for organizations that does not have a clear product (or service) outcome.

The suitability assessment of O-LCA focus on HEIs with robust EMS, allowed the proposal of a specific methodology for this type of organizations. The methodological proposal includes a prioritization procedure that classifies the EAs regarding the potential impact that action plans over these aspects would have in the environmental performance of the HEI. A cut-off criteria is included in this prioritization procedure. This procedure serves as an optimization tool of resources (human and economic) when assessing the environmental performance of organizations, specially HEIs. The complete procedure can be found in Lo-Iacono-Ferreira et al. (2017).

Assessing a complete O-LCA would give a complete view of the environmental performance of the HEI if impact categories are properly chosen. However, the way in which O-LCA presents results might not be suitable to be integrated in the overall management system of HEIs. It should be recalled that the motivation of this research is having a tool that allows the integration of environmental performance information in the decision-making processes of the HEI. For this purpose, a set of environmental KPI has been suggested.

The results of the study of the different tools (EFA, LCA, STARS, GRI and O-LCA) has provided a solid background to define the basic concepts regarding the definition of environmental KPIs:

- Reporting organization and system boundaries, through the definition of EUs.

- Scopes, following the emerging trend of including materials in the traditional GHG Protocol Corporate Standard scheme.

- Functional and reporting unit attending to the principals of LCA and O-LCA.

Each of these concepts is deeply discussed in chapters 2 to 9 and summarized below. 
The EU is a concept developed by the EMS of UPV and has been verified by EMAS. An EU is a well-defined area, physically localized, unique, with defined activities and processes. This research has tested and proven that EU is not only a useful concept to maintain an EMS but to define the reporting organization and system boundaries in any environmental performance assessment.

The GHG Protocol Corporate Standard scheme by scope has proven to be a useful tool to assess and interpret the results of an environmental assessment. The literature review reveled an emerging trend of extending this scheme beyond emissions including materials as follows:

- Scope 1: direct resource use, emissions and waste.

- Scope 2: indirect emissions and resource associated with infrastructure usage, e.g. power production.

- Scope 3: all other indirect emissions and resource use, e.g. emissions associated with waste and waste water treatment.

The scope definition has been combined with the upstream and downstream model for a better interpretation.

Regarding the FU and the reporting unit, three main units are proposed for a HEI:

- Build-up area (BUA) as functional unit and,

- Full-time equivalent (FTE) student and Full-time equivalent (FTE) employees as reporting units.

On one hand, BUA gives an accurate value to the physical dimensions of the institution. FTE students, on the other hand, represents an equivalent to products or results. Other specific FU had been discussed and can be defined for those EU with particular processes or activities. The following units have been proposed:

- Licenses over results

- Research + Development + innovation incomes

- FTE employees

- FTE person (integrates students and employees)

- Journal Articles Published

- Enrolled credits

Regarding the reporting tools, STARS and GRI gained special attention. STARS, developed specifically for HEI offers a wide catalogue of indicators with a score method; a good tool but a high level of complexity in its evaluation that makes it difficult to include in a daily decision-making process. GRI, however, suggest simpler indicators. For this reason, its applicability to HEIs has been deeply studied. 
Proposal of a set of Key Performance Indicators for the environmental assessment of Higher Education Institution

GRI application reaches all three areas of sustainable development, the scope of each indicator is clearly defined with a classification by area. Environmentally related indicators have been analyze seeking to assess it applicability to HEIs. Other indicators with a general approach have been also considered as useful measurements of the overall activity of an organization. Results shown that $91 \%$ of the environmental indicators proposed by GRI are applicable to HEIs. When the case study is considered, $21 \%$ of those indicators, although they are applicable, required an additional procedure or resources before they can become part of the current EMS.

In addition to the specific concepts described, the study and assessment of these existing methodologies also highlighted the need of a more specific, achievable, timely and relevant methodology to assess the performance of HEIs. Coherency and representativeness has to be inherent to the proposal in order to be useful and intelligible. Overall, to be able to be included in an EMS, a desirable characteristic, there has to be a normalize procedure and measures.

The existing reporting tool, STARS, specific for HEIs stands out of some of these requirements; e.g. most of its environmental indicators are assessed by a score assignation system that integrates several indicators. The measure has big advantages for reporting, however, that integration of different aspects or indicators make them not the best tool for a decision-making process as it would require an additional allocation procedure in order to know how is affecting what.

The solution has been presented as a methodology to define environmental KPIs to assess the significant environmental aspects of HEIs. Significant environmental aspects can be detected using the prioritization procedure developed and presented in chapter 6 .

The methodological proposal for the definition of environmental KPIs for HEIs has been presented (chapter 0 ) including a validation procedure essential to ensure accurate and useful results. The validation procedure is as important as the definition procedure, as will allowed EMS managers to set the level of trust of the KPIs defined. The validation procedure is based on a set of key good-practice factors and meta-performance evaluation indicators in two levels: the performance of KPIs system and its implementation and operational stage. The proposal attaches a list of more than 140 environmental indicators suitable for HEIs classified both within the DPSIR and the ABCDE framework as guidance to support the definition process.

As an advantage, KPIs are usually part of decision-making boards of HEIs regarding economic or social issues. Incorporating a small set of environmental KPIs most likely will not affect the overall management system. Further, the KPIs environmentally related will add valuable 
information to the decision-making processes giving decision-makers an easy-to-use tool to tilt actions toward an optimization of the environmental performance of HEIs.

Summarizing, the interest of HEIs in being able to assess their environmental performance is evidenced by the numerous initiatives taken during last decades. Results of the implementation of EMS, the application of reporting tools and the assessment of different environmental indicators reviewed in this work has shown the structural particularities of HEIs and the need of tailored solutions. The adaptability of EMAS make this standard a good framework for HEIs EMS. However, the commitment and support of high level decisionmakers is needed to make an EMS useful and productive.

Strength and weaknesses has been detected for all tools analyzed. It has been concluded that these characteristics stands not only for the tool itself but for the requirements that the tool makes to the EMS. However, all these tools added value and know-how for the procedure of finding a solution. Furthermore, they provided an approach of the environmental performance of the case study that is discussed in the following section.

As for any organization, having an EMS requires a strong commitment from the management board and resources (economic and human) but also carries significant benefits as a framework to measure, collect and manage relevant information. A set of KPIs can be easily integrated in a robust EMS, as those verified in EMAS. Still, EMAS does not ensure that all data needed would be available or have the desire quality.

The hypothesis has been confirmed; it is possible to define a set of KPIs to assess environmental performance of HEIs. A procedure, including validation, has been developed to guide the definition of HEIs environmentally related KPIs.

\subsection{RESULTS DISCUSSION, CONCLUSIONS FOR THE CASE STUDY, EPSA}

In order to have insights of the versatility, advantages and suitability of the proposed procedure, a case study has been chosen as a pilot and further used as common thread through all the research: one of the EUs of UPV, EPSA. The following statements founded the election:

- UPV counts on a robust EMS verified in EMAS that managed the HEI divided in EU. EPSA is one of them.

- UPV EMS assess and communicates the EA of each EU making available environmental information. The quality of this data has also been a subject of study in this research. 
Proposal of a set of Key Performance Indicators for the environmental assessment of Higher Education Institution

- Thesis supervisors and author have in-depth knowledge of EPSA operations and their performance.

EPSA has been used as a case study in each phase of the research e.g. regarding the proposal of a methodological procedure for EFA considering life cycle approach, Figure 10-1 shows the last and more detailed EPSA EF annual results from 2006 to 2015. Mobility, infrastructure, food and energy consumptions stands as the main significant environmental aspects due to these results. A deep analysis of these results can be found in chapter 5 .

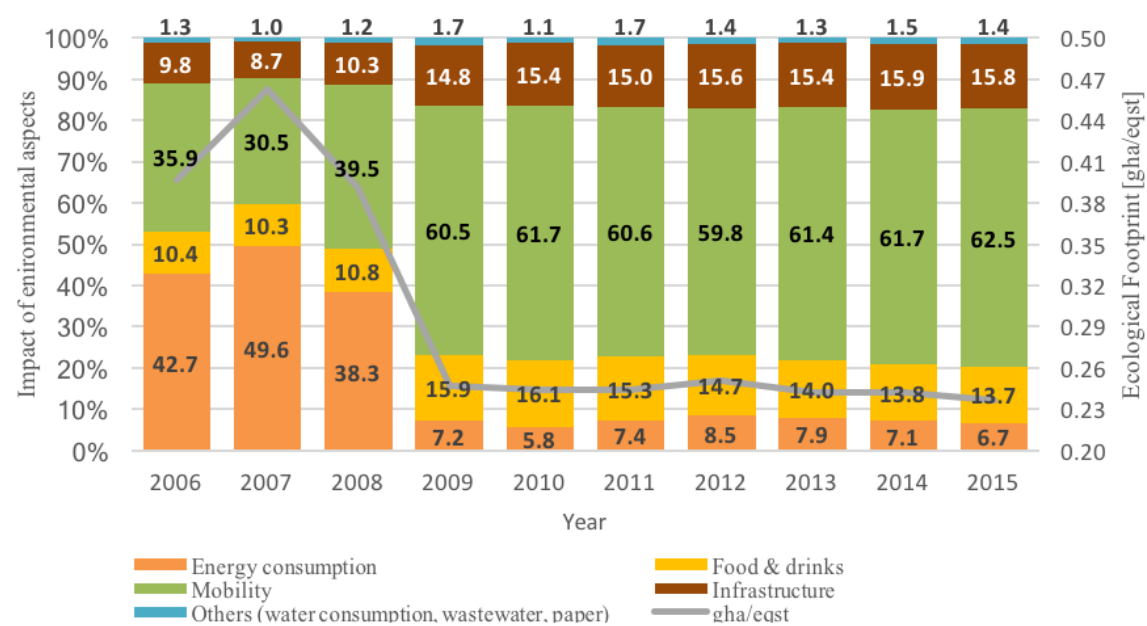

Figure 10-1 Results of UPV's case study: ecological footprint. Figure presented in Lo-IaconoFerreira et al., (2016). See chapter 5 for more details.

EFA results served for understanding the magnitude of the environmental impact of EPSA. It also allowed the identification of significant limitations of EFA as an environmental performance indicator:

- the complexity of the organization that required a deep analysis of its structure and operation to define SB and an adequate FU,

- the availability of quality data,

- the availability of conversion factors with an adequate time and geographic scope and,

- the complexity of applying an allocation procedure when diverse activities and processes developed at the HEI want to be considered separately.

Other main topic of discussion has been the definition of SB. As described in the previous section, the use of EU has become a useful outcome regarding this subject. An extension of the three scopes considered by the GHG Protocol Corporate Standard has been suggested when analyzing the suitability of O- 
LCA for HEIs. Figure 10-2 shows the activities and processes identified for EPSA and classified by scope following this definition.

Results obtained by impact category for the O-LCA approach are shown in Table 10-1 while results for the inventory indicator are shown in Figure 10-1, An additional inventory indicator has also been proposed: waste generation by type where the municipal solid waste is, by difference, the most significant with a representation of $57.99 \%$ followed by paper and light packaging waste. Although the LCIA of the O-LCA could not be fully performed (as shown in Table 10-1) the approach gives a dimension of the impact of EPSA, as the reporting organization chosen.

The suitability assessment of O-LCA has been presented along with a prioritization procedure of EA aiming to optimize the resources available for the assessment itself. Table 10-2 shows the results of the application of this procedure to the EA of EPSA previously detected by it EMS together with the environmental impact categories chosen for the O-LCA study.

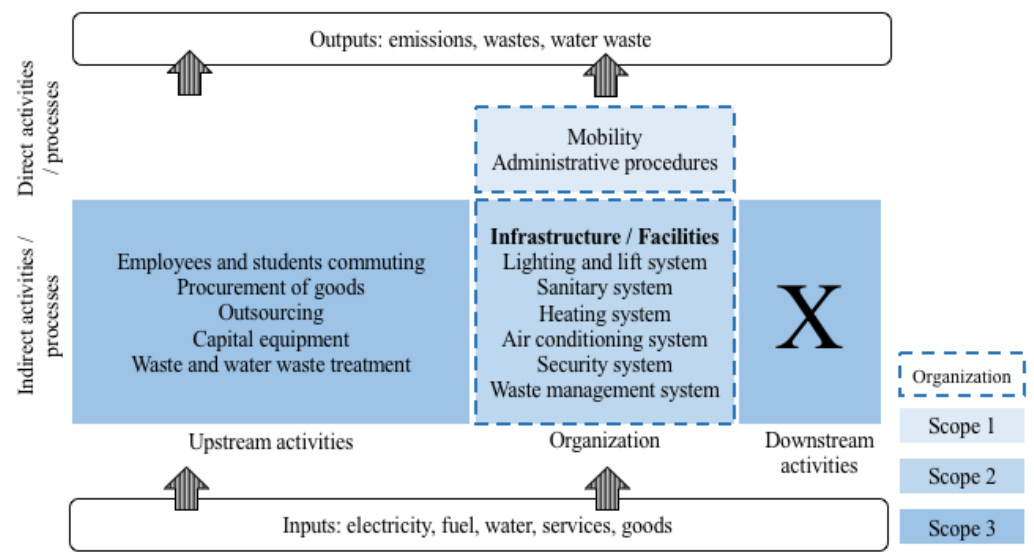

Figure 10-2. Activities and processes of HEIs prepared by the authors on the basis of UNEP (2015) guidance. Published in Lo-Iacono-Ferreira et al., (2017). See chapter 6 for more details.

The methodological proposal to define a set of environmental KPIs for HEIs, as a solution to the lack of a tool with the proper characteristics has been presented together with the results of applying this methodology to the case study. 
Proposal of a set of Key Performance Indicators for the environmental assessment of Higher Education Institution

Table 10-1 Partial LCIA results for EPSA 2015

\begin{tabular}{|c|c|c|c|c|c|}
\hline Impact Categories & value & unit & Scope 1 & Scope 2 & Scope 3 \\
\hline Climate change & 677.90 & $\mathrm{t} \mathrm{CO}_{2} \mathrm{e}$ & - & $\mathbf{\square}$ & $\square$ \\
\hline Land use & 2.87 & ha & 口 & - & - \\
\hline Water footprint & 6661 & $\mathrm{~m}^{3}$ & घ & - & - \\
\hline Abiotic resources use & - & - & - & - & - \\
\hline Acidification & 0.17 & $\mathrm{t} \mathrm{SO}_{2} \mathrm{e}$ & - & - & - \\
\hline
\end{tabular}

- assessed; $\square$ assessed partially; - not assessed;

The KPIs that has been presented for EPSA achieved scope 1, 2 and 3 focusing only in the most relevant EAs; those where a minor action can become a major improvement in the environmental performance. Significance and operational control have been considered simultaneously to point relevant EA.

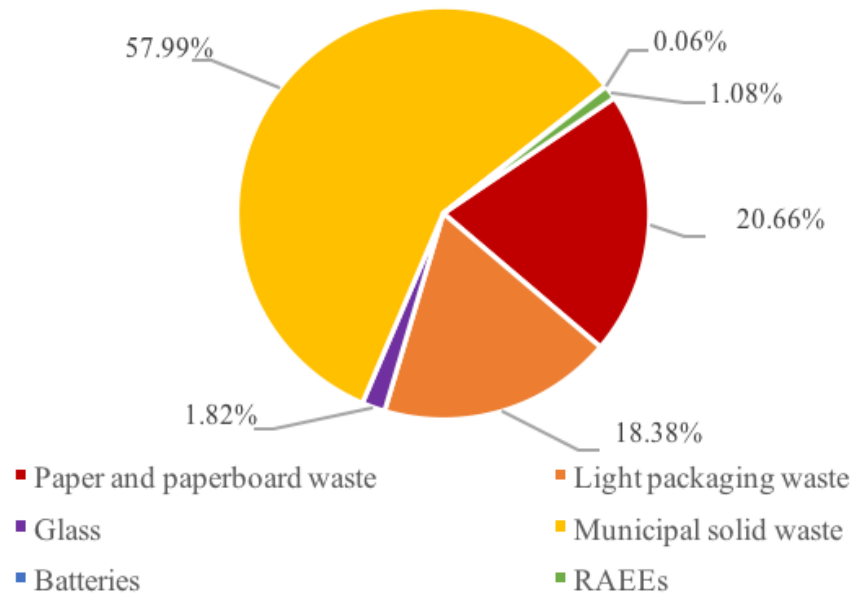

Figure 10-3 Results of the waste generation by type of waste. Inventory indicator for EPSA 2015

Stakeholder's interests and desired about the environmental performance of the institution have been used as pillars for establishing the starting point for the definition of macro-level and specific environmental goals for EPSA. Two macro-level goals have been defined: the conservation of natural resources and the fight against climate change. To achieve these macro-level goals, six specific goals have been identified:

- (G1) Minimize on- renewable energy consumption

- (G2) Minimize recycling waste 
- (G3) Minimize waste generation

- (G4) Minimize GHG emissions from scope 1

- (G5) Minimize GHG emissions from scope 2

- (G6) Minimize GHG emissions from scope 3

Considering the specific goals, SB, scopes, functional unit and reporting units proposed for HEIs discussed in the previous section and following the methodological procedure developed to define and validate environmental KPIs a set of 7 ENV KPIs has been defined. The definition, value and observations are summarized in Table 10-3.

Furthermore, an additional ENV KPI has been defined under the provision that, on a near future, EPSA will achieve an O-LCA. The following would become measurable and easy-to-assess and would simplify the set KPI by replacing indicators from 4 to 7: ENV KPI 8: GHG emissions of Scope 3 * by FTE student

The definition of the set of KPIs responds to those EAs detected as most relevant along with stakeholder's needs. KPIs defined for EPSA focus the attention on the conservation of natural resources and fight against climate change.

The validation procedure has been successful both for level 1 and 2 metaperformance indicators except for the uncertainty that could not be assesses for ENV KPI 6 and 7 due to the lack of information.

\subsection{SUMMARY}

The goal of this thesis, as it is defined in its title is to develop a proposal of a set of KPI to assess and report the environmental performance of HEIs. Section 10.2 summarize the results of applying these indicators to a case study. However, it is important to highlight that the proposal of the set of KPI is the outcome of a deep analysis of the different existing and new tools and a wide discussion of the assessment methodologies associated - developed in chapters 2, 3, 4, 5, 6 and 8 and summarized in 10.1-. It is the know-how gathered in these studies what has allowed the definition of a solid set of environmental indicators, KPIs, for HEIs.

An additional outcome of this research is publishing two articles in high impact factor index journals, a third article in a specialized journal and four communications in international congresses proceedings with peer review. At the time of closing this thesis, two more articles are under revision. 
A new productive research window can be opened if the HEI commit to work with their suppliers for the development of environmental assessments of their products and services with the ultimate goal of the optimization of the use of natural resources. To carry any further research in this direction, the following issues need to be addressed:

- Full collaboration of the service provider defined in the contract.

- Human resources to support service providers if they need it.

This could be a key for strategic environmental plans long-term focus on the upstream stage.

The methodology developed to define the set of KPIs is applicable to any kind of HEIs. It would be interesting to evaluate the applicability in other type of educational institutions. Other organizations might also benefit from this methodology. As already mentioned, medium and big size campuses are often managed as small cities. The applicability of the methodology and different case studies can be new subjects of study; i.e. regions, cities, etc.

The next natural step is researching the interaction of these KPIs environmentally related with social and economic indicators of HEIs. The development of a theoretical model that allowed testing and simulation might be useful to consider certain actions without compromising the institution directly.

Although KPIs are commonly used to assess economic performance, this research has proven their usefulness in assessing environmental performance. The social area should also be explored seeking for a macro set of KPIs to assess sustainable development as a whole. 


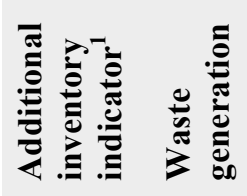

!

Uే

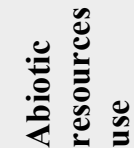

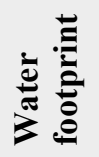

前:

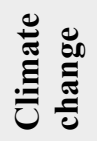

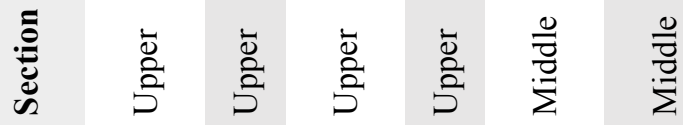

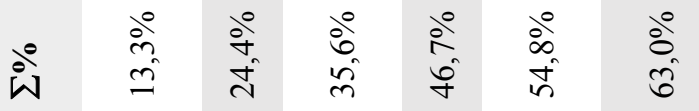

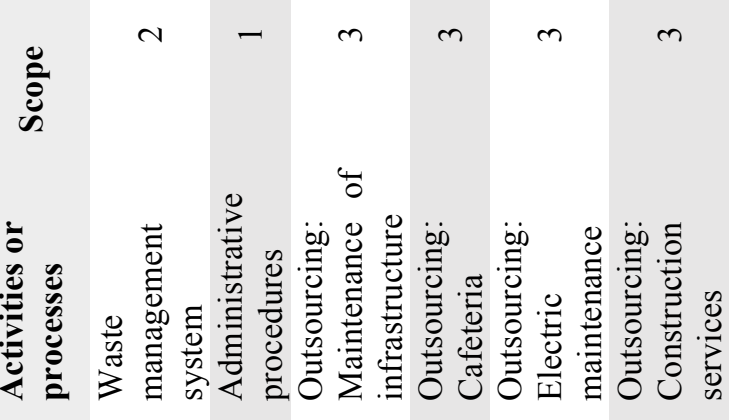

0
0
0
0
0
0
0
0
$\Xi$
0
0
0
0
0
0
0
0
0 


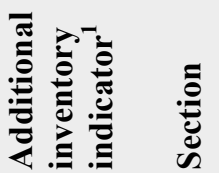

อั

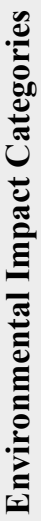

¿ั̊

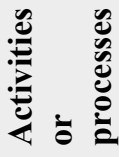

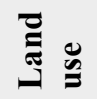

芯 范

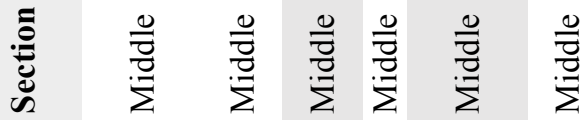

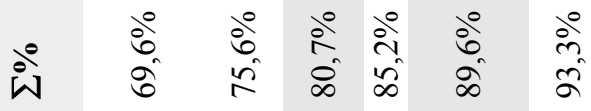

$m n-N m$

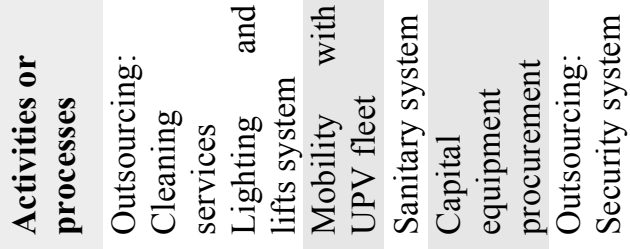




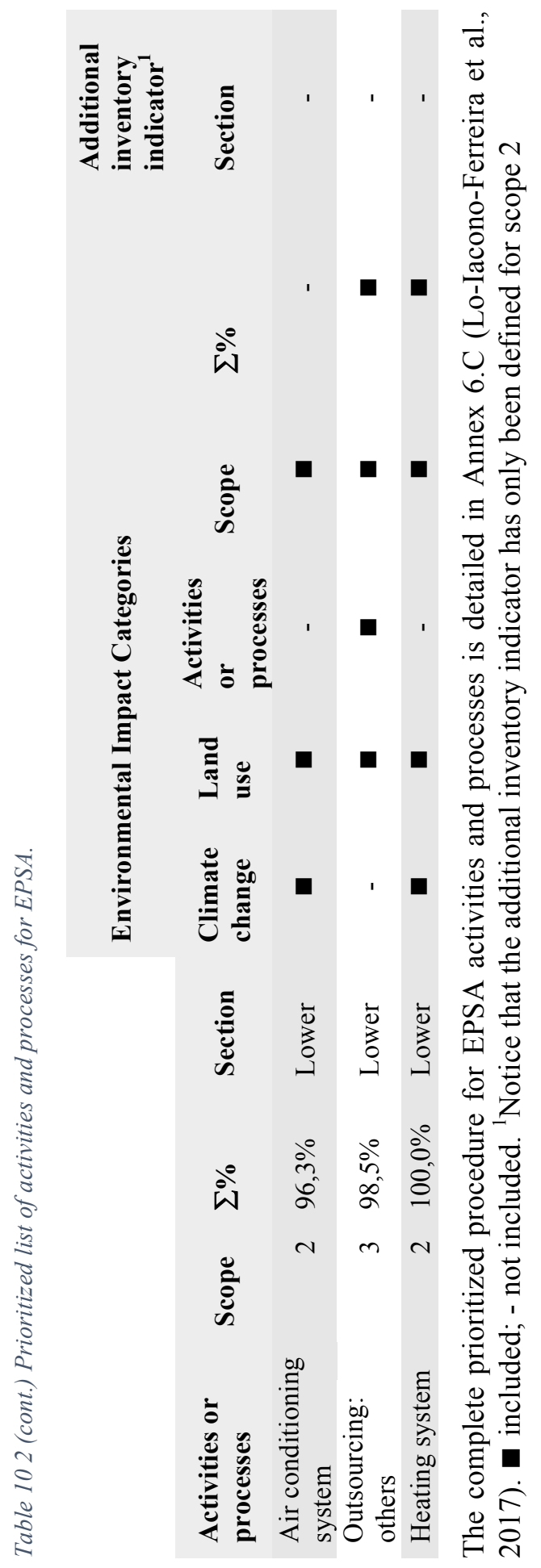



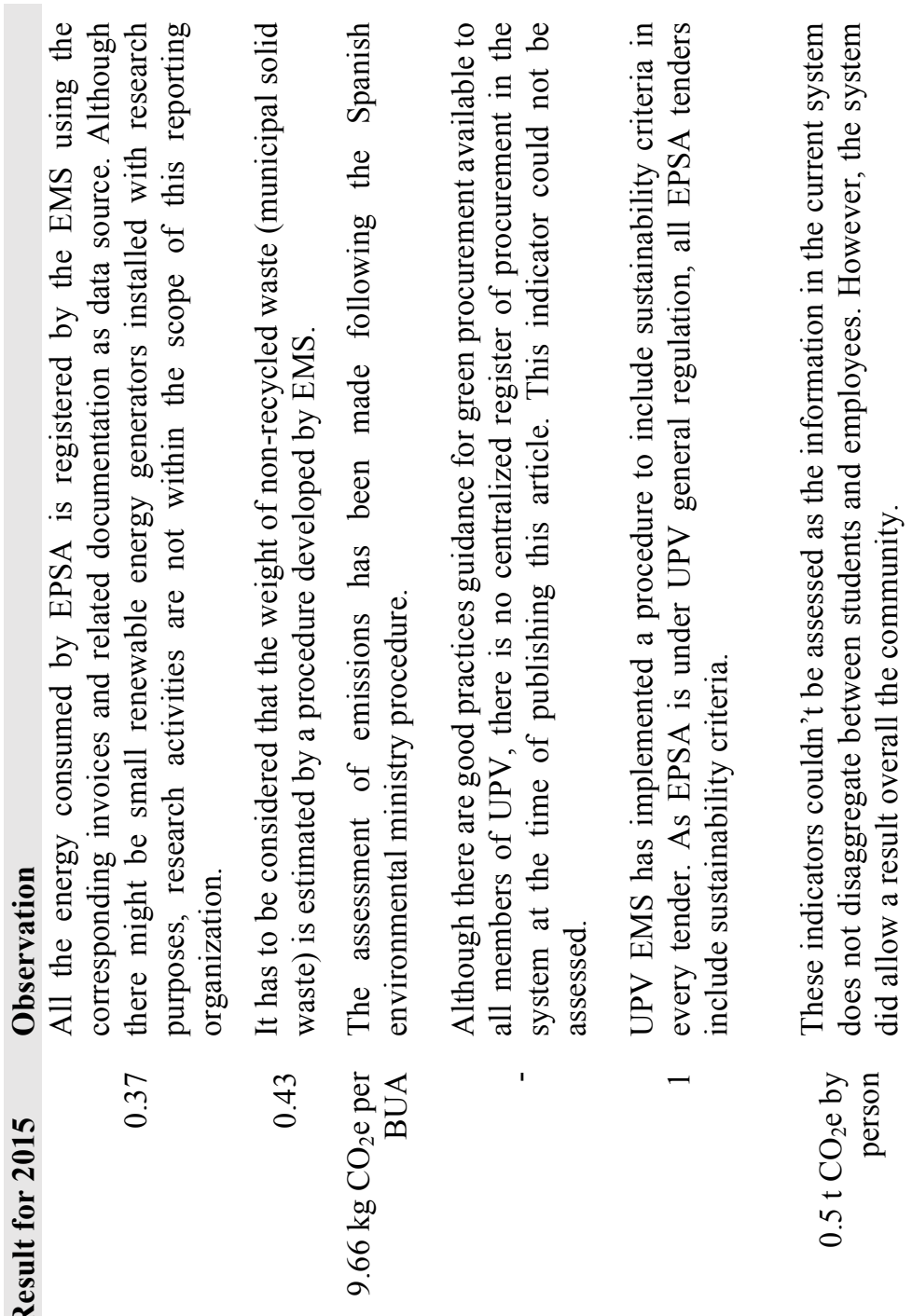

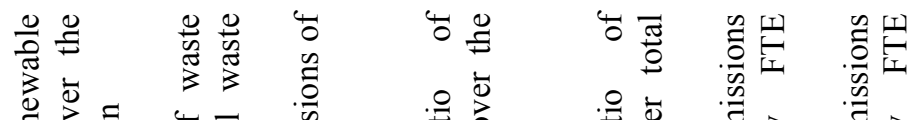

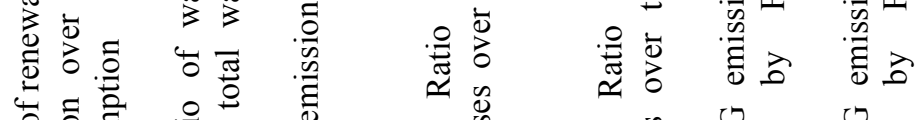

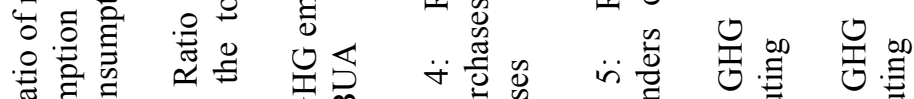

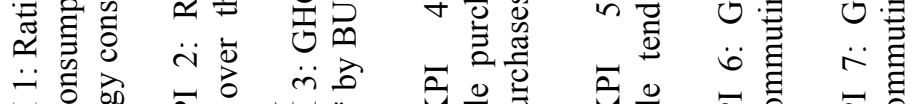

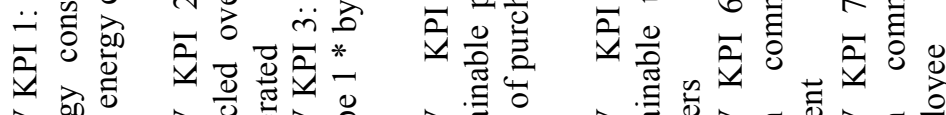

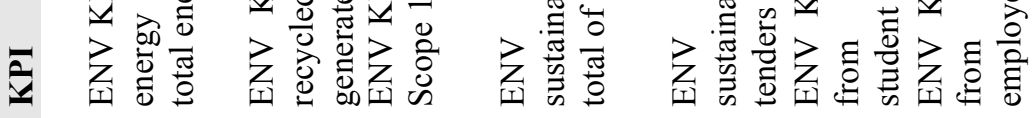


As already discussed in the previous section, the EMS verified in EMAS of UPV could not ensure the availability of quality data. The lack of needed information has been a common denominator during all the stages of this research regarding the case study. In order to cover the deficiencies of data availability detected in the EMS, the accounting system of EPSA has been characterized and study as a complementary source of information. Valuable information has been obtained for significant environmental aspects as extraordinary travelling of students and staff (conferences, meetings, field trips, etc.) and the fuel consumption of the vehicle owned by the EU. This analysis also revealed that other activities or process that might have a significant environmental impact (purchases, protocol events, outsourcing services, etc.) cannot be assessed environmentally with the information given by the accounting system (neither by the information given by the EMS). Although the data required to assess the set of environmental KPIs defined for EPSA is significantly inferior to the requirements of other tools (e.g. O-LCA), structural improvements are still required to address a proper environmental assessment. Main needs are:

- The implementation and management of a centralized accounting system that allows analyzing the environmental characteristics of procurements.

- The improvement of procedures and new resources to be able to perform direct measurements of those environmental aspects that, up to now, are estimated.

- The strengthening of relations between the institution and its suppliers through a mechanism that allows EMS to evaluate accurately is scope 3.

In the light of the results obtained for the different tools and environmental assessments carried during this work, the environmental aspects of EPSA that deserves special attention due to its relevance are the electricity consumption and its emissions, the behavior of external companies and waste generation.

The methodological proposal for the definition of environmental KPIs applied to EPSA proven to be specific, achievable, relevant and timely although some of them required the improvement of the EMS in order to be measurable. Further information is required as well as the full cooperation of suppliers in order to carry a full environmental assessment with life cycle perspective for EPSA. Besides to the EMS and the accounting system additional resources (both economic and human) are required and a careful planning need to be outlined to ensure all the needed data is obtained.

The next step is to solve the lack of information required to fully assess the environmental KPIs defined for EPSA and its validation. 
Proposal of a set of Key Performance Indicators for the environmental assessment of Higher Education Institution

Further researches focus on the case study shall shad light over the procedure and implications of assessing all the EUs that compose the UPV and how to integrate their results in order to have a useful measure of the overall environmental performance of UPV. 


\section{REFERENCES}

Achterkamp, M.C., \& Vos, J.F.J. (2008) Investigating the use of the stakeholder notion in project management literature, a meta-analysis. International Journal of Project Management, 26(7), 749-757. http://doi.org/10.1016/j.ijproman.2007.10.001

Asociación Española de Normalización y Certificación (2006a) UNE-EN ISO 14040. Gestión Ambiental. Análisis del ciclo de vida. Principios y marco de referencia. AENOR. Madrid, España

Asociación Española de Normalización y Certificación (2006b) UNE-EN ISO 14044 Gestión ambiental. Análisis del ciclo de vida. Requisitos y directrices. Madrid, España

Alam, M., Dupras, J., \& Messier, C. (2016) A framework towards a composite indicator for urban ecosystem services. Ecological Indicators, 60, 38-44. http://doi.org/10.1016/j.ecolind.2015.05.035

Alonso-Almeida, M.D.M., Marimon, F., Casani, F., \& Rodriguez-Pomeda, J. (2015) Diffusion of sustainability reporting in universities: current situation and future perspectives. Journal of Cleaner Production, 106, 144-154. http://doi.org/10.1016/j.jclepro.2014.02.008

Alshuwaikhat, H.M., Abubakar, I., (2008) An integrated approach to achieving campus sustainability: assessment of the current campus environmental management practices. Journal of Cleaner Production, 16(16), 1777-1785. http://dx.doi.org/ 10.1016/j.jclepro.2007.12.002

Álvares, N.L., \& Rodriguez, R.L. (2007) Estimación da pegada ecolóxica en dous centros da universidade de santiago de compostela. Posibles implicacións educativas. Ambientalmente sustentable. 99-117.

Arroyo, P. (2009) Ecological footprint of the campus de Vegazana, León university; a calculation approach. Implications for the sustainability of the university community. MAPFRE, 1-20.

Azma, F. (2010) Qualitative Indicators for the evaluation of universities performance. Procedia - Social and Behavioral Sciences, 2(2), 54085411. http://doi.org/10.1016/j.sbspro.2010.03.882

Azqueta, D., \& Delacamara, G. (2006) Ethics, economics and environmental management. Ecological Economics, 56(4), 524-533. http://doi:10.1016/j.ecolecon.2005.03.003 
Proposal of a set of Key Performance Indicators for the environmental assessment of Higher Education Institution

Barnetson, B., \& Cutright, M. (2000) Performance indicators as conceptual technologies. Higher Education, 40, 277-292. http://doi.org/10.1023/a:1004066415147

Barrett, J., Vallack, H., Jones, A., and Haq, G. (2002) A material flow analysis and ecological footprint of York. Stockholm, 129. Retrieved on June $15^{\text {th }} 2013$ from http://seiinternational.org/mediamanager/documents/Publications/Future/Mat erial Flow Analysis york.pdf/npapers2://publication/uuid/9F1C847 A-09B8-47F5-BAF8-892555E87ACE

Bauler, T. (2012) An analytical framework to discuss the usability of (environmental) indicators for policy. Ecological Indicators, 17, 38 45. http://doi.org/10.1016/j.ecolind.2011.05.013

Beloff, B., Tanzil, D., \& Lines, M. (2004) Sustainable development performance assessment. Environmental Progress, 23(4), 271-276. http://doi.org/10.1002/ep.10045Bonaccorsi, A., Daraio, C., Lepori, B., \& Slipersæter, S. (2007) Indicators on individual higher education institutions: addressing data problems and comparability issues. Research Evaluation, 16(2), 66-78. http://doi.org/10.3152/095820207X218141

Braulio-Gonzalo, M., Bovea, M.D., \& Ruá, M.J. (2015) Sustainability on the urban scale: Proposal of a structure of indicators for the Spanish context. Environmental Impact Assessment Review, 53, 16-30. http://doi.org/10.1016/j.eiar.2015.03.002

Braunschweig A. (2014) GHG-balances and LCA: Applying the concept of scopes in organisational LCAs. E2 Management Consulting. Retrieved on July $1^{\text {st }} 2016$ from http://www.e2mc.com/

British Standard Institute (2008) Specifications for the assessment of the life cycle greenhouse gas emissions of goods and services. PAS 2050.

British Standard Institute (2010) PAS 2060. Specification for the demonstration of carbon neutrality.

Brundtland Commission. (1987) Our common future: Report of the World Commission on Environment and Development. UN Documents Gatheringa Body of Global Agreements. A/RES/42/187

Bryson, J.M. (2004) What to do when Stakeholders matter. Stakeholder Identification and Analysis Techniques. Journal Public Management review, 6(1), 21-53. http://dx.doi.org/10.1080/14719030410001675722 
Buonocore, E., Mellino, S., De Angelis, G., Liu, G., \& Ulgiati, S. (2016) Model Life cycle assessment indicators of urban wastewater and sewage sludge treatment. Ecological Indicators. In press. http://doi.org/10.1016/j.ecolind.2016.04.047

Burgess, B., \& Lai, J. (2006) How much land is used by Kwantlen University College? Retrieved on June $15^{\text {th }} 2013$ from http://www.kpu.ca/ shared/assets/KUC Ecological Footprint Rep ort2114.pdf

Burnham, A., Wang, M., Wu, Y. (2006) Development and applications of GREET 2.7-The transportation vehicle-cycle model. Argonne: Argonne National Laboratory (ANL), U.S. Department of Energy. http://doi.org/10.2172/898530

Campos, L.M.S., de Melo Heinzen, D.A. Verdinelli, M.A., \& Cauchick Miguel, P.A. (2015) Environmental Performance Indicators: A Study on ISO 14001 Certified Companies. Journal of Cleaner Production, 99, 286-296. http://doi.org/10.1016/j.jclepro.2015.03.019

Castellani, V., \& Sala, S. (2012) Ecological footprint and life cycle assessment in the sustainability assessment of tourism activities. Ecological Indicators, 16 , 135-147. http://doi.org/10.1016/j.ecolind.2011.08.002

Ceulemans, K., Lozano, R., and Alonso-Almeida, M. (2015) Sustainability Reporting in Higher Education: Interconnecting the Reporting Process and Organizational Change Management for Sustainability. Sustainability, 7, 8881-8903. http://doi.org/10.3390/su7078881

Clarke, A., Kouri, R., (2009) Choosing an appropriate university or college environ- mental management system. Journal of Cleaner Production, 17(11), 971-984. http://dx.doi.org/ 10.1016/j.jclepro.2009.02.019

Clift R., Wright L. (2000) Relationships between environmental impacts and added value along the supply chain. Technological Forecasting and Social Change, 65(3), 281-295. http://doi.org/ 10.1016/S0040$\underline{1625(99) 00055-4}$

Cole, L., (2003) Assessing Sustainability on Canadian University Campuses: Development of a Campus Sustainability Assessment Framework. Royal Roads University. Victoria, BC. 
Proposal of a set of Key Performance Indicators for the environmental assessment of Higher Education Institution

Conway, T. M., Dalton, C., Loo, J., \& Benakoun, L. (2008) Developing ecological footprint scenarios on university campuses: A case study of the University of Toronto at Mississauga. International Journal of Sustainability in Higher Education, 9(1), 4-20. http://doi.org/10.1108/14676370810842157

Cortese, A. D. (2003) The critical role of higher education in creating a sustainable future. Planning for higher education. Retrieved on June $1^{\text {st }} 2016$ from http://www.aashe.org/documents/resources/pdf/Cortese PHE.pdf

Cuchí i Burgos, A., \& López Cabeallero, I. (2005) Informe MIES: Una proximació a l'impacte ambiental de l'Escola d'Artquitectura del Vallès. Universitat Politècnica de Catalunya. ISBN: 84-7653-870-7

Curran, M.A. (Ed.) (2017) Goal and Scope Definition in Life Cycle Assessment. Springer. http://doi.org/10.1007/978-94-024-0855-3

Dawe, G.F.M., Vetter, A., \& Martin, S. (2004) An overview of ecological footprint and other tools and their application to the development of sustainability process: Audit and methodology at Holme Lacy College, UK. International Journal of Sustainability in Higher Education, 5(4), 340-371. http://doi.org/10.1108/14676370410561063

de Miguel, J.J. (2012) Emisiones de CO2 en la EUP. Escuela Politécnica Universitaria de Valladolid. Retrieved on June $15^{\text {th }} 2013$ from http://www.eup.uva.es/emisionesco2/

Defra/DECC (2009) Guidance on how to measure and report your greenhouse gas emissions. Retrieved on January $1^{\text {st }} 2010$ from https://www.gov.uk/government/publications/guidance-on-how-tomeasure-and-report-your-greenhouse-gas-emissions

Defra/DECC (2014) Government conversion factors for company reporting Retrieved June $15^{\text {th }} 2013$ from http://www.ukconversionfactorscarbonsmart.co.uk/

Delakowitz, B. and Hoffmann, A. (2000) The HochschuleZittau/Görlitz: Germany's first registered environmental management (EMAS) at an institution of higher education, International Journal of Sustainability in Higher Education, 1(1), 35-47. http://dx.doi.org/10.1108/1467630010307084

Denman, B. D. (2009) What is a university in the 21st century? Higher Education Management and Policy, 17(2), 9-28. http://doi.org/10.1787/17269822 
Disterheft, A., da Silva Caeiro, S.S.F., Ramos, M.R. and de Miranda Azeiteiro, U.M. (2012) 'Environmental management systems (EMS) implementation processes and practices in European higher education institutions - top-down versus participatory approaches', Journal of Cleaner Production, 31, 80-90. http://doi.org/ 10.1016/j.jclepro.2012.02.034

Departamento de Medio Ambiente, Ordenación del Territorio y Vivienda de la Comunidad foral de Navarra (2001) La Huella ecológica de la comunidad foral de Navarra, aplicaciones técnicas y de comunicación. Navarra.

Dočekalová, M.P., \& Kocmanová, A. (2016) Composite indicator for measuring corporate sustainability. Ecological Indicators, 61, 612623. http://doi.org/10.1016/j.ecolind.2015.10.012

Doménech, J., \& Arenales, M. G. (2008) La Huella Ecológica de las empresas: 4 años de seguimiento en el puerto de Gijón. (U. d. Málaga, Ed.) Observatorio Iberoamericano del Desarrollo Local y la Economía Social.

Doménech Quesada, J. L. (2009) Huella de carbono corporativa: una herramienta de gestión empresarial contra el cambio climático. CONAMA 9.

Doran, G.T. (1981) There's a S.M.A.R.T way to write management's goals and objectives. IIMB Management Review, 70(11) 35-36 Retrieved on June $15^{\text {th }} \quad 2016 \quad$ from http://community.mis.temple.edu/mis0855002fall2015/files/2015/10 /S.M.A.R.T-Way-Management-Review.pdf

Draucker, L. (2013). GHG Protocol: moving Corporate Accounting Beyond GHGs. Abstract Book: SETAC North American 34th Annual Meeting, Nashville, USA.

Escuela Politécnica Universitaria de Valladolid. (2009) Emisiones CO2. Retrieved on June $15^{\text {th }} 2013$ from http://www.eup.uva.es/emisionesco2 
Proposal of a set of Key Performance Indicators for the environmental assessment of Higher Education Institution

European Commission (1993) Council Regulation (EEC) No 1836/93 of 29 June 1993 Allowing Voluntary Participation by Companies in the Industrial Sector in a Community Eco-management and Audit Scheme, Official Journal L. 10/07, 0001-0018 Retrieved on December $\quad 16^{\text {th }} \quad 2012$ from $\quad$ http://eurlex.europa.eu/LexUriServ/LexUriServ.do?uri=OJ:L:2001:114:0001: 0029:EN:PDF

European Commission (2008) Public Procurement for a Better Environment. Communication from the Commission to the European Parliament, The Council, The European Economic and Social Committee and the Committee of the Regions. Retrieved on December $16^{\text {th }} 2012$ from http://eur-lex.europa. eu/LexUriServ/LexUriServ.do?uri=COM:2008:0400:FIN:EN:HTM $\underline{\mathrm{L}}$

European Commission (2009) No, R.;1221/2009 of the European Parliament and of the Council of 25 November 2009 on the Voluntary Participation by Organisations in a Community Eco-management and Audit Scheme (EMAS), Repealing Regulation (EC) No 761/2001 and Commission Decisions 2001/681/EC and 2006/193 Retrieved on December $\quad 16^{\text {th }} \quad 2012$ from http://eur-lex.europa.eu/ LexUriServ/LexUriServ.do?uri=OJ:L:2009:342:0001:01:EN:HTML

European Commission (2011a) Corporate environmental footprint. Retrieved on $\quad$ March $29^{\text {th }} \quad 2011 \quad$ from http://ec.europa.eu/environment/eussd/corporate footprint.htm

European Commission (2011b) Environmental footprint of products. Retrieved on March $29^{\text {th }} \quad 2011$ from http://ec.europa.eu/environment/eussd/product footprint.htm

European Commission (2013) European Commission Organization Environmental Footprint Guide. European Commission - Joint Research Centre - Institute for Environment and Sustainability. Retrieved on June $1^{\text {st }} 2016$ from http://eurlex.europa.eu/JOHtml.do?uri=OJ:L:2013:124:SOM:EN:HTML

European Commission (2016a) European Commission Environment. EcoManagement and Audit Scheme. Retrieved on June $1^{\text {st }} 2016$ from http://ec.europa.eu/environment/emas/

European Commission (2016b) Eurostat Glossary. Retrieved on July $1^{\text {st }} 2016$ from http://ec.europa.eu/eurostat/statisticsexplained/index.php/Glossary:Full-time equivalent (FTE) 
European Environment Agency (2014) Digest of EEA indicators. Luxembourg. Retrieved on July $1^{\text {st }} 2016$ from http://www.eea.europa.eu/publications/digest-of-eea-indicators2014

European Environmental Agency (2016) Indicators. Retrieved on July $1^{\text {st }}$ 2016 from http://www.eea.europa.eu/data-and-maps/indicators/

Ewing B., D. Moore, S. Goldnger, A. Oursler, A. Reed, and M. Wackernagel. (2010) The Ecological Footprint Atlas 2010. Oakland: Global Footprint Network. Retrieved on January $3^{\text {rd }} 2011$ from http://www.footprintnetwork.org/images/uploads/Ecological Footpr int Atlas 2010.pdf

Fernández, A., Morales, M., Rodríguez, C., \& Salmerón, A. (2011) A system for relevance analysis of performance indicators in higher education using Bayesian networks. Knowledge and Information Systems 27(3) 327-344 http://doi.org/10.1007/s10115-010-0297-9

Fiala, N. (2008) Measuring sustainability: Why the ecological footprint is bad economics and bad environmental science. Ecological Economics 67 516-525 http://dx.doi.org/10.1016/j.ecolecon.2008.07.023

Fiksel, J., Spitzely, D., \& Brunetti, T. (2002) Key Performance Indicators (Substudy 5) Retrieved on July $1^{\text {st }} 2016$ from http://www.wbcsdcement.org/pdf/battelle/final_report5.pdf

Finkbeiner, M., Wiedemann, M., \& Saur, K. (1998) A comprehensive approach towards product and organisation related environmental management tools. The International Journal of Life Cycle Assessment, 3(3), 169-178. http://doi.org/10.1007/BF02978825

Finkbeiner, M., Ackermann, R., Bach, V., Berger, M., Brankatschk, G., Chang, Y.-J., Grinberg, M., Lehmann, A., Martínez-Blanco, J., Minkov, N. (2014) Background and Future Prospects in Life Cycle Assessment. In Background and Future Prospects in Life Cycle Assessment, W. Klöpffer, 207. http://doi.org/10.1007/978-94-017$\underline{8697-3}$

Finkbeiner, M. (2009) Carbon footprinting. Opportunities and threats. International Journal of Life Cycle Assessment, (14), 91-94. http://doi.org/ 10.1007/s11367-009-0064-X 
Proposal of a set of Key Performance Indicators for the environmental assessment of Higher Education Institution

Fleischer, G., Gerner, K., Kunst, H., Lichtenvort, K., Rebitzer, G., (2001) A semi-quantitative method for the impact assessment of emissions within a simplified life cycle assessment. The International Journal of Life Cycle Assessment, 6(3), 149-156. http://doi.org/10.1007/BF02978733

Flint, K. (2001) Institutional ecological footprint analysis. A case study of the University of Newcastle, Australia. International Journal of Sustainability in Higher Education, 2(1), 48-62. http://dx.doi.org/10.1108/1467630110380299

Galli, A., Kitzes, J., Niccolucci, V., Wackernagel, M., Wada, Y., \& Marchettini, N. (2012) Assessing the global environmental consequences of economic growth through the ecological footprint: A focus on china and India. Ecological Indicators, 17, 99-107. http://doi.org/10.1016/j.ecolind.2011.04.022

García-Sánchez, I. M., Almeida, T. A. D. N., \& Camara, R. P. D. B. (2015) A proposal for a Composite Index of Environmental Performance (CIEP) for countries. Ecological Indicators, 48, 171-188. http://doi.org/10.1016/j.ecolind.2014.08.004

Giménez, A., Pérez, I., Montesions, P., Vera, V., \& Bordonado, S. (2009) Transporte y sostenibilidad. Pautas de movilidad y alternativas de reducción de la huella ecológica en centros de trabajo. La universidad Miguel Hernández como caso de estudio. Seguridad y Medio Ambiente, 40-51.

Global Footprint Network (2009) Ecological Footprint Standards 2009. Oakland: Global Footprint Network. Retrieved on January $1^{\text {st }} 2010$ from

http://www.footprintnetwork.org/content/images/uploads/Ecological Footprint Standards 2009.pdf

Global Reporting Initiative (2005) GRI Boundary Protocol. Global Reporting Initiative. Retrieved on March $1^{\text {st }} 2016$ from https://www.globalreporting.org/resourcelibrary/GRI-BoundaryProtocol.pdf

Global Reporting Initiative. (2006) RG Sustainability Reporting Guidelines, G3. Global Reporting Initiative. Retrieved on March $1^{\text {st }} 2016$ from https://www.globalreporting.org/resourcelibrary/G3-GuidelinesIncl-Technical-Protocol.pdf 
Global Reporting Initiative. (2011) RG Sustainability Reporting Guidelines, G3.1 Global Reporting Initiative. Retrieved on March $1^{\text {st }} 2016$ from https://www.globalreporting.org/resourcelibrary/G3.1-GuidelinesIncl-Technical-Protocol.pdf

Global Reporting Initiative (2013a) G4 Sustainability Reporting Guidelines. Global Reporting Initiative. Retrieved on March $1^{\text {st }} 2016$ from https://www.globalreporting.org/resourcelibrary/G4-Package.zip

Global Reporting Initiative (2013b) G4 Implementation Manual. Global Reporting Initiative. Retrieved on March $1^{\text {st }} 2016$ from https://www.globalreporting.org/resourcelibrary/GRIG4-Part2Implementation-Manual.pdf

Goedkoop, M., \& Spriensma, R. (2001) The Eco-indicator 99. A damage oriented method for Life Cycle Impact Assessment. Amersfoort: PRé Consultants B.V. Retrieved on June $1^{\text {st }} 2012$ from https://www.presustainability.com/download/EI99 annexe v3.pdf

Gustavo De Lima, R., Lins, H.N., Pfitscher, E.D., Garcia, J., Suni, A., Salgueirinho Osório De Andrade Guerra, J.B., \& Caroline Renata Delle, F. (2016) A sustainability evaluation framework for Science and Technology Institutes: An international comparative analysis. Journal of Cleaner Production, 125, 145-158. http://doi.org/10.1016/j.jclepro.2016.03.028

Hancock, L., \& Nuttman, S. (2014) Engaging higher education institutions in the challenge of sustainability: Sustainable transport as a catalyst for action. Journal of Cleaner Production, 62, 62-71. http://doi.org/10.1016/j.jclepro.2013.07.062

Hauschild, M.Z., and Huijbregts, M.A. (2015) Introducing Life Cycle Impact Assessment. Chapter 1. Springer Science+Business Media Dordrecht 2015 M.Z. Hauschild, M.A.J. Huijbregts (eds.), Life Cycle Impact Assessment, LCA Compendium - The Complete World of Life Cycle Assessment http://doi.org/10.1007/978-94-017-9744-3 1

Hellweg S., Milà i Canals L. (2014) Emerging approaches, challenges and opportunities in life cycle assessment. Science, 344(6188), 11091113. http://doi.org/10.1126/science. 1248361

Hermann, B. G., Kroeze, C., \& Jawjit, W. (2007) Assessing environmental performance by combining life cycle assessment, multi-criteria analysis and environmental performance indicators. Journal of Cleaner Production, 15(18), 1787-1796. http://doi.org/10.1016/j.jclepro.2006.04.004 
Proposal of a set of Key Performance Indicators for the environmental assessment of Higher Education Institution

Hernández Gallego, E., Cano Herrador, C., Correoa Guimaraes, A. (2015) La Huella Ecológica de la Universidad de Valladolid Retrieved on January $1^{\text {st }} 2016$ from http://www.uva.es/export/sites/uva/7.com

Hertwich, E.G. (2005) Life cycle approaches to sustainable consumption: A critical review. Environmental Science \& Technology, 39(13), 46734684. http://doi.org/10.1021/es0497375

Herva, M., Franco, A., Ferreiro, S., Alvarez, A., \& Roca, E. (2008) An approach for the application of the ecological footprint as environmental indicator in the textile sector. Journal of Hazardous Materials, 156(1-3),

478-487. http://doi.org/10.1016/j.jhazmat.2007.12.077

Herva, M., Hernando, M., R., Carrasco, E. F., \& Roca, E. (2010) Development of a methodology to assess the footprint of wastes. Journal of Hazardous Materials, $180(1)$ 264-273. http://doi.org/10.1016/j.jhazmat.2010.04.026

Herva, M., Franco, A., Carrasco, E. F., \& Roca, E. (2011) Review of corporate environmental indicators. Journal of Cleaner Production, 19(15), 1687-1699. http://doi.org/10.1016/j.jclepro.2011.05.019

Hespenheide, E. (2015, November 27th). The future of reporting. [Video file]. Video published in https://youtu.be/rIS03rn13 I

Hochschorner, E., and Finnvenden, G.. (2003) Evaluation of two simplified life cycle assessment methods. The International Journal of Life Cycle Assessment, 8(3), 119-128. http://doi.org/10.1007/BF02978456

Hourneaux, F., Hrdlicka, H. A., Gomes, C. M., \& Kruglianskas, I. (2014) The use of environmental performance indicators and size effect: A study of industrial companies. Ecological Indicators, 36, 205-212. http://doi.org/10.1016/j.ecolind.2013.07.009

Hsu, A., Johnson, L., \& Lloyd, A. (2013) Measuring Progress. A Practical Guide from the Developers of the Environmental Performance Index (EPI). New Haven: Yale Center for Environmental Law \& Policy. Retrieved on July $1^{\text {st }} 2016$ from http://epi.yale.edu/content/measuring-progress-practical-guidedevelopers-environmental-performance-index-epi 
Huang Y.A., Lenzen M., Weber C.L., Murray J., Matthews H.S. (2009) The role of input-output analysis for the screening of corporate carbon footprints. Economic Systems Research, 21(3), 217-242. http://doi.org/10.1080/09535310903541348

Hunter, C., \& Shaw, J. (2005) The ecological footprint as a key indicator of sustainable tourism. Tourism management, 46-57. http://dx.doi.org/10.1016/j.tourman.2005.07.016

International Organization for Standardization (2004) Environmental management systems -Requirements with guidance for use ISO 14001: 2004. Geneva, Switzerland: International Organization for Standardization.

International Organization for Standardization (2006a) Environmental management - life cycle assessment - principles and framework. ISO 14040:2006.

International Organization for Standardization (2006b) Environmental management - life cycle assessment - requirements and guidelines. ISO 14044:2006(E).

International Organization for Standardization (2013a) Greenhouse gases -Carbon footprint of products -- Requirements and guidelines for quantification and communication. ISO 14067:2013

International Organization for Standardization (2013b) Environmental Management - Environmental Performance Evaluation - Guidelines. International Organization for Standardization ISO 14031:2013

International Organization for Standardization (2014a) ISO/TS 14072: Environmental management — Life cycle assessment Requirements and guidelines for Organizational Life Cycle Assessment. Geneva, Switzerland: International Organization for Standardization.

International Organization for Standardization (2014b) ISO 14046: Water footprint - principles, requirements and guidance. Geneva, Switzerland: International Organization for Standardization.

International Organization for Standardization (2015) ISO 14001:2015 Environmental management systems - Requirements with guidance for use.

Janis, J. (2007) Quantifying the ecological footprint of the Ohio State University Ohio State University. Retrieved June $15^{\text {th }} 2013$ from http://hdl.handle.net/1811/28365 
Proposal of a set of Key Performance Indicators for the environmental assessment of Higher Education Institution

Jim, C., \& Chen, W. (2008) Assessing the ecosystem service of air pollutant removal by urban trees in Guangzhou (China). Journal of Environmental Management, $\quad 88, \quad$ 665-676. http://dx.doi.org/10.1016/j.jenvman.2007.03.035

Jolliet, O., Frischknecht, R., Bare, J., Boulay, A. M., Bulle, C., Fantke, P., Weisbrod, A. (2014) Global guidance on environmental life cycle impact assessment indicators: Findings of the scoping phase. The International Journal of Life Cycle Assessment, 19(4), 962-967. http://doi.org/1007/s11367-014-0703

Jones, N., Panoriou, E., Thiveou, K., Roumeliotis, S., Allan, S., Clark, J.R.A. and Evangelinos, K. (2012) Investigating benefits from the implementation of environmental management systems in a Greek university, Clean Technologies and Environmental Policy, 4(4), 669676. http://doi.org/ 10.1007/s10098-011-0431-8

Jorge, J., \& Busquets, P. (2000) La petjada ecologica de l'EUPM. Universitat Politecnica de Catalunya. Retrieved on June $15^{\text {th }} 2013$ from http://www.upc.edu/mediambient

Joseph, G. (2012) Ambiguous but tethered: An accounting basis for sustainability reporting. Critical Perspectives on Accounting, 23(2), 93-106. http://doi.org/10.1016/j.cpa.2011.11.011

Kerzner, H.R. (2011) Project Management Metrics, KPIs and Dashboards: A guide to Measuring and Monitoring Project Performance. Ed. John Wiley \& Sons, Inc. http://doi.org/10.1002/9781118086254

Klassen, R.D., \& McLaughlin, C.P. (1996) The impact of environmental management on firm performance. Management Science, 42(8), 1199-1214. http://doi.org/0.1287/mnsc.42.8.1199

Klein-Banai, C., \& Theis, T.L. (2011) An urban university's ecological footprint and the effect of climate change. Ecological Indicators, 11(3), 857-860. http://doi.org/10.1016/j.ecolind.2010.11.002

Lambrechts, W., \& Van Liedekerke, L. (2014) Using ecological footprint analysis in higher education: Campus operations, policy development and educational purposes. Ecological Indicators, 45, 402-406. http://doi.org/10.1016/j.ecolind.2014.04.043

Lave, L.B., Cobas-Flores, E., Hendrickson, C.T., McMichael, F.C. (1995) Using input-output analysis to estimate economy-wide discharges. Environmental Science and Technology, 29(9) 420-426 http://doi.org/ 10.1021/es00009a003 
Lemos, D., Dias, A., Gararrell, X. \& Arroja, L. (2013) Environmental assessment of an urban water system. Journal of Cleaner Production, 54, 157-165. http://doi.org/10.1016/j.jclepro.2013.04.029

Lenzen, M., Lundie, S., Bransgrove, G., Charet, L., \& Sack, R. (2002) A novel ecological footprint and an example application. ISA Research Paper, 02-02.

Lenzen, M., \& Murray, S. (2001) A modified ecological footprint method and its application to Australia. Ecological Economics, 37, 229-255. http://dx.doi.org/10.1016/S0921-8009(00)00275-5

Lenzen, M., Hansson, C. B., \& Bond, S. (2007) On the bioproductivity and land-disturbance metrics of the Ecological Footprint. Ecological Economics, 61(1), 6-10. Retrieved on January $3^{\text {rd }} 2011$ from http://www.isa.org.usyd.edu.au/publications/documents/ISA\&WWF Bioproductivity\&LandDisturbance.pdf

Letete, T. C., Mungwe, N. W., Guma, M., \& Marquard, A. (2011) Carbon footprint of the University of Cape Town. Journal of Energy in Southern Africa, 22(2), 2-12.

Li, G., Wang, Q., Gu, X., Liu, J., Ding, Y., \& Liang, G. (2008) Application of the componential method for ecological footprint calculation of a Chinese university campus. Ecological Indicators, 8(1), 75-78. http://doi.org/10.1016/j.ecolind.2007.01.007

Life Cycle Initiative (2016) Retrieved on June $22^{\text {nd }} 2016$ from http://www.lifecycleinitiative.org/

Lindeijer, E. (2000) Review of land use impact methodologies. Journal of Cleaner Production, 273-281. http://dx.doi.org/10.1016/S09596526(00)00024-X

Lo Iacono Ferreira, V.G., Torregrosa-López, J.I., López Pérez, F., PachecoBlanco, B., Viñoles-Cebolla, R. (2011a) Comparative Analysis of the methodology of calculation of EF in different areas. XV International Congress on Project Management. Huesca. AEIPRO ISBN: 978-84615-4543-8

http://www.aeipro.com/aplic/tree congresos/detalle remository aei pro.php?file $=3331$ 
Proposal of a set of Key Performance Indicators for the environmental assessment of Higher Education Institution

Lo-Iacono-Ferreira, V.G. Torregrosa-López, J.I Lora-García, J., BastanteCeca, M.J. \& Capuz-Rizo, S. F. (2011b) Study of the inclusion of life cycle assessment impact categories in ecological footprint calculation. XV International Congress of Project Engineering. Huesca. AEIPRO ISBN: 978-84-615-4543-8 http://www.aeipro.com/aplic/tree congresos/detalle remository aei pro.php?file $=3329$

Lo-Iacono-Ferreira, V.G., Capuz-Rizo, S.F., Torregrosa-López, J.I. (2016a) Ecological Footprint Assessment of Higher Education applying Life Cycle Assessment framework. Case study: Universitat Politència de València. XX International Congress on Project Management and Engineering. Cartagena. 1423-1432. ISBN: 978-84-617-4180-9 http://www.aeipro.com/aplic/tree congresos/detalle remository aei pro.php?file $=4636$

Lo-Iacono-Ferreira, V.G., Torregrosa-López, J.I., Capuz-Rizo, S.F., (2016b) Applicability of global reporting initiative to assess the environmental performance of higher education institutions. XX International Congress on Project Management and Engineering. Cartagena. 1433$1444 . \quad$ ISBN: 978-84-617-4180-9 http://www.aeipro.com/aplic/tree congresos/detalle remository aei pro.php?file $=4637$

Lo-Iacono-Ferreira, V.G., Torregrosa-López, J.I., \& Capuz-Rizo, S.F. (2016c) Use of Life Cycle Assessment methodology in the analysis of Ecological Footprint Assessment results to evaluate the environmental performance of universities. Journal of Cleaner Production, 133, 43-53. http://doi.org/10.1016/j.jclepro.2016.05.046

Lo-Iacono-Ferreira, V.G., Torreogrsa-López, J.I., Capuz-Rizo, S.F. (2017) Organizational Life Cycle Assessment: suitability for Higher Education Institutions with Environmental Management System. International Journal of Life Cycle Assessment (In press).

Lozano García, F.J., Kevany, K. and Huisingh, D. (2006) Sustainability in higher education: what is happening?, Journal of Cleaner Production, 14(9), 757-760. http://dx.doi.org/10.1016/j.jclepro.2005.12.006

Lozano, R., Lozano, F. J., Mulder, K., Huisingh, D., \& Waas, T. (2013) Advancing higher education for sustainable development: International insights and critical reflections. Journal of Cleaner Production, 48, 3-9. http://doi.org/10.1016/j.jclepro.2013.03.034

Lozano, R., Ceulemans, K., Alonso-Almeida, M., Huisingh, D., Lozano, F. J., Waas, T., Lambrechts, W., Lukman, R., Hugé, J. (2015) A review of commitment and implementation of sustainable development in 
higher education: results from a worldwide survey. Journal of Cleaner Production, $108, \quad 18$. http://doi.org/10.1016/j.jclepro.2014.09.048

Lozano, R. (2006a) A tool for a graphical assessment of sustainability in universities (GASU). Journal of Cleaner Production, 14, 9-11. http://dx.doi.org/10.1016/j.jclepro.2005.11.041

Lozano, R. (2006b) Incorporation and institutionalization of SD into universities: breaking through barriers to change, Journal of Cleaner Production, 14(9), 787-796. http://doi.org/10.1016/j.jclepro.2005.12.010

Lozano, R. (2010) Diffusion of sustainable development in universities' curricula: an empirical example from Cardiff University, Journal of Cleaner Production, 18(7), 637-644. http://dx.doi.org/10.1016/j.jclepro.2009.07.005

Lozano, R. (2011) The state of sustainability reporting in universities, International Journal of Sustainability in Higher Education, 12(1), 67-78. http://doi.org/10.1108/14676371111098311

Lukman, R., Krajnc, D., \& Glavi, P. (2010) University ranking using research, educational and environmental indicators. Journal of Cleaner Production, 18(7), 619-628. http://doi.org/10.1016/j.jclepro.2009.09.015

Manzardo, A., Loss, A., Mazzi, A., Scipioni, A. (2016) Organizational LifeCycle Assessment (OLCA): Methodological Issues and Case Studies in the Beverage-Packaging Sector. Environmental Footprints of Packaging. Springer. http://doi.org/10.1007/978-981-287-913-4

Marañón, E., Iregui, G., Doménech, J.L., Fernández-Nava, Y. \& González, M. (2008) Propuesta de índices de conversion para la obtención de la huella de los residuos y vertidos. Observatorio Iberoamericano del Desarrollo Local y la Economía Social, 4. ISSN: 1988-2483.

Martínez-Blanco, J., Inaba, A., and Finkbeiner, M. (2015b) Halfway point in the flagship project LCA of organizations by UNEP/SETAC Life Cycle Initiative. The International Journal of Life Cycle Assessment, Japan 11(2), 97-103. April 2015.

Martínez-Blanco, J., Inaba, A., Quiros, A., Valdivia, S., Milà-i-Canals, L., and Finkbeiner, M. (2015a) Organizational LCA: the new member of the LCA family-introducing the UNEP/SETAC Life Cycle Initiative guidance document. The International Journal of Life Cycle Assessment, 10-12. http://doi.org/10.1007/s11367-015-0912-9 
Proposal of a set of Key Performance Indicators for the environmental assessment of Higher Education Institution

Martínez-Blanco, J., Inaba, A., and Finkbeiner, M. (2015c) Scoping organizational LCA-challenges and solutions. The International Journal of Life Cycle Assessment 20(6), 829-841. http://doi.org/10.1007/s11367-015-0883-X

Mazzi, A., Mason, C., Mason, M., \& Scipioni, A. (2012) Is it possible to compare environmental performance indicators reported by public administrations? Results from an Italian survey. Ecological Indicators, 23 ,

653-659. http://doi.org/10.1016/j.ecolind.2012.05.006

Michael, F. L., Noor, Z. Z., \& Figueroa, M. J. (2014) Review of urban sustainability indicators assessment - Case study between Asian countries. Habitat International, 44, 491-500. http://doi.org/10.1016/j.habitatint.2014.09.006

Ministerio de Agricultura, Alimentación y Medio Ambiente (2015) Ministerio de Agricultura, Alimentación y Medio Ambiente. Cambio Climático. Retrieved on May $3^{\text {rd }} 2015$ from http://www.magrama.gob.es/es/cambio-climatico/temas/mitigacionpoliticas-y-medidas/Registro-Huella-Carbono.aspx

Moldan, B., Sková, S. J., \& Charles, T. s H. (2012) How to understand and measure environmental sustainability: Indicators and targets. Ecological Indicators, $17, \quad 4-13$. http://dx.doi.org/10.1016/j.ecolind.2011.04.033

Muñiz, I., \& Galindo, A. (2005) Urban form and the Ecological Footprint of commuting. Case of Barcelona. Ecological Economics, 499-514. http://dx.doi.org/10.1016/j.ecolecon.2004.12.008

Nguyen, H. X., Wang, Y., Morimoto, K., \& Yamamoto, R. (2005, December). Modified Ecological Footprint Evaluation to include Resource Depletion. In 2005 4th International Symposium on Environmentally Conscious Design and Inverse Manufacturing, 785-790. http://doi.org/ 10.1109/ECODIM.2005.1619350

Nunes, L., Catarino, A., Teixeira, M. R., \& Cuesta, E. (2013) Framework for the inter-comparison of ecological footprint of universities. Ecological Indicators, $\quad 32, \quad 276-284$. http://doi.org/10.1016/j.ecolind.2013.04.007

Olalla-Tárraga, M. A. (2003) Indicadores de sostenibilidad y huella ecológica aplicada a la UAM. Retrieved on June $1^{\text {st }} 2012$ from https://www.uam.es/servicios/ecocampus/especifica/descargas/inves tigacion/Resumen PFC Indicadores.pdf 
Olszak, E. (2012) Composite indicators for a sustainable campus - Design rationale and methodology: The case of the Catholic Institute of Lille. Ecological Indicators, 23, 573-577. http://doi.org/10.1016/j.ecolind.2012.05.021

Organization for Economic Cooperation and Development. (2008) Key environmental indicators. Paris. Retrieved on July $1^{\text {st }} 2016$ from https://www.oecd.org/env/indicators-modellingoutlooks/37551205.pdf

Organization for Economic Cooperation and Development. (2014) Green Growth Indicators 147. http://doi.org/10.1787/9789264202030-en

Organization for Economic Cooperation and Development. (2015) Environment at a Glance 2000: OECD Indicators. OECD Publishing. http://doi.org/10.1787/eag-2013-en

Organization for Economic Cooperation and Development. (2016) Glossary of Statistical Terms. Retrieved on July $1^{\text {st }} 2016$ from http://stats.oecd.org/glossary/detail.asp?ID=5369

Patterson, T., Niccolucci, V., \& Marchettini, N. (2008) Adaptive environmental management of tourism in the Province of Siena, Italy using the ecological footprint. Journal of Environmental Management, 86, 407-418. http://dx.doi.org/10.1016/j.jenvman.2006.04.017

Paulson, K. (1997) The transport footprint of Oxford Brookes University. Oxford Brookes University. Technical Report.

Pelletier N., Allacker K., Pant R., Manfredi S. (2013) The European Commission Organisation Environmental Footprint method: comparison with other methods, and rationales for key requirements. The International Journal of Life Cycle Assessment, 19(2), 387-404. http://doi:10.1007/s11367-013-0609-x

Peris-Mora, E. (2002) Environmental responsibility of universities. The environmental management systems, Environmental Management Systems for Sustainable Universities Conference 2002, 339-346.

Perotto, E., Canziani, R., Marchesi, R., \& Butelli, P. (2008) Environmental performance, indicators and measurement uncertainty in EMS context: a case study. Journal of Cleaner Production, 16(4), 517-530. http://doi.org/10.1016/j.jclepro.2007.01.004

Ramos, T. B., \& Caeiro, S. (2010) Meta-performance evaluation of sustainability indicators. Ecological Indicators, 10(2), 157-166. http://doi.org/10.1016/j.ecolind.2009.04.008 
Proposal of a set of Key Performance Indicators for the environmental assessment of Higher Education Institution

Rees, W., \& Wackernagel, M. (1996) Urban ecological footprints: Why cities cannot be sustainable - and why they are a key to sustainability. Environmental Impact Assessment Review, 16(4-6), 223-248. http://dx.doi.org/10.1016/S0195-9255(96)00022-4

Resta, B., Gaiardelli, P., Pinto, R., \& Dotti, S. (2016) Enhancing environmental management in the textile sector: An OrganisationalLife Cycle Assessment approach. Journal of Cleaner Production, 135, 620-632 http://doi.org/10.1016/j.jclepro.2016.06.135

Röling, W., \& van Verseveld, H. (2002) Natural attenuation: What does the subsurface have in store? Biodegradation, 13, 53-64. http://doi.org/10.1023/A:1016310519957

Roorda, N. and Onderwijs, S.D.H. (2001) AISHE Auditing Instrument for Sustainability in Higher Education Retrieved on December $16^{\text {th }} 2012$ from

http://www.eauc.org.uk/audit instrument for sustainability in hig her educ

Roseland, M. (2000) Sustainable community development: Integrating environmental, economic, and social objectives. Progress in Planning, $\quad 54(2), \quad 73-132 . \quad$ http://doi.org/10.1016/S03059006(00)00003-9

Savely, S.M., Carson, A.I. \& Delclos, G.L. (2007) A survey of the implementation status of environmental management systems in US colleges and universities, Journal of Cleaner Production, 15(7), 650659. http://dx.doi.org/10.1016/j.jclepro.2006.01.014

Seiffert, M. E. B., \& Loch, C. (2005) Systemic thinking in environmental management: Support for sustainable development. Journal of Cleaner Production, 13(12), 1197-1202. http://doi.org/10.1016/j.jclepro.2004.07.004

Serdar, A. M. (2010) Performance management and key performance indicators for higher education institutions in Serbia. Perspectives of Innovations, Economics and Business, 6(3), 116-119. http://dx.doi.org/10.15208/pieb.2010.95

Singh, R. K., Murty, H. R. R., Gupta, S. K. K., \& Dikshit, A. K. K. (2012) An overview of sustainability assessment methodologies. Ecological Indicators, 15(1), 281-299. http://doi.org/10.1016/j.ecolind.2011.01.007

Smeets, E., \& Weterings, R. (1999) Environmental indicators: Typology and overview. Copenhagen. Retrieved on June $1^{\text {st }} 2012$ from http://www.eea.europa.eu/publications/TEC25 
Sonnemann, G., Castells, F., Schuhmacher, M., \& Hauschild, M. (2004) Integrated life-cycle and risk assessment for industrial processes. The International Journal of Life Cycle Assessment, 9(3), 206-207. http://doi.org/ 10.1007/BF02994195

Soto, M., \& Pérez, M. (2010) A pegada ecolóxica da Universidade da Coruña Vicerrectoría da Infraesttuturas e Xerstión Ambiental - Universidade da Coruña.

Taylor A.P., Postlethwaite D. (1996) Overall Business Impact Assessment (OBIA). In Proceedings of the 4th SETAC Case Study Symposium, Brussels, Belgium. Brussels: SETAC. 181-187

The Association for the Advancement of Sustainability in Higher Education. (2016) stars Technical Manual. Version 2.1. Retrieved on July $1^{\text {st }}$ 2016

from http://www.aashe.org/files/documents/STARS/stars 2.1 technical manual - administrative update one.pdf

Tlapa, D. A., Limón, J., \& Báez, Y. A. (2009) Quality and Environmental Management in Higher Education Institutes by Integrating ISO 9001 and ISO 14001. Formación Universitaria, 2(2), 35-46. http://doi.org/ 110.4067/S0718-50062009000200006

Torregrosa López, J.I., Lo Iacono Ferreira, V.G., Lledó Lagadera, D., Martí Barranco, C. (2010a) Un indicador ambiental para medir la sostenibilidad en las Universidades, la Huella Ecológica: Caso de estudio de la Universidad Politécnica de Valencia. CONAMA 10. Retrived on June $1^{\text {st }} 2010$ from http://www.conama10.conama.org/web/generico.php?idpaginas $=\& 1$ ang $=$ es\&menu $=90 \&$ referer $=1 \& i d=499 \&$ tipo $=C \& o p=v i e w \&$ from $=v i$ ew personas

Torregrosa López, J., Martí Barranco, C., \& Lo Iacono Ferreira, V. (2010b) La Huella Ecológica y de Carbono como indicador ambiental en las Universidades: estudio del caso en la UPV. Cuaderno de Investigación en la Ingeniería. Investigación en Ingeniería medioambiental, III, 133-136. ISBN 978-84-268-1533-0 
Proposal of a set of Key Performance Indicators for the environmental assessment of Higher Education Institution

Torregrosa López, J., Martí Barranco, C., \& Lo Iacono Ferreira, V. (2011) Ecological Footprint and Carbon Footprint as an environmental indicator for universities. Case of study Polytechnic University of Valencia. GUNI 2010. 5th International Barcelona Conference on Higher Education.

Torregrosa-López, J. I., Lo Iacono-Ferreira, V. G., Barranco-Martí, C., \& Bellver-Navarro, C. G. (2016) The strengths of EMAS as an environmental management system for European university campuses. International Journal of Environment and Sustainable Development, 15(1),

89-106. http://dx.doi.org/10.1504/IJESD.2016.073339

Torres Martínez, A.J., Colomer Ferrandiz, J.V., Gallego Pérez, M.R., Pino Hernandez, E.M.; Ruiz Sánchez, T., Fiore, M.F. (2010) Plan de transporte para la Universidad Politécnica de Valencia. http://hdl.handle.net/10251/7301

Udo de Haes, H. A., Jolliet, O., Finnveden, G., Hauschild, M., Krewitt, W., Müller-Wenk, R. (1999) Best available practice regarding impact categories and category indicators in Life-Cycle Impact Assessment. SETAC-Europe: Second Working Group on LCIA (WIA-2). The International Journal of Life Cycle Assessment, 4, 66-74. http://doi.org/10.1007/BF02979403

United Nations Environment Programme (UNEP) (1992) Rio declaration on environment and development. United Nations Environment Program (UNEP). Retrieved on September $15^{\text {th }} 2015$ from http://www.unep.org/Documents.Multilingual/Default.asp?documen tid $=78 \&$ articleid $=1163$

United Nations Environment Programme (2012) Key environmental indicators. Retrieved on July $1^{\text {st }} 2016$ from http://www.unep.org/yearbook/2012/pdfs/UYB 2012 CH 4.pdf

United Nations Environment Programme (2015) Guidance on Organizational Life Cycle Assessment. Life-Cycle Initiative, United Nations Environment Program and Society for Environmental Toxicology and Chemistry, Paris, France. Retrieved on June $1^{\text {st }} 2016$ from: http://www.lifecycleinitiative.org/wp- content/uploads/2015/04/olca 24.4.15-web.pdf 
United Nations Statistics Division (2016) Environmental indicators. Retrieved on July $1^{\text {st }} \quad 2016$ from http://unstats.un.org/unsd/environment/qindicators.htm

Universitat de Girona (2013) Petjada ecològica de la UdG - càlcul de la petjada ecològica derivada dels consums energètics dels edificis universitaris, 1999 - 2008. Retrieved June $15^{\text {th }} 2013$ from http://www3.udg.edu/ov/recursos/petjada.htm

Universitat Politècnica de València (2015) Plan de movilidad sostenible. Diagnóstico de situación inicial. Unidad de Medio Ambiente. Retrieved on January $2^{\text {nd }} \quad 2015$ from https://www.upv.es/entidades/AMAPUOC/infoweb/ov/info/887195 normalc.html

Urbanski, M. \& Filho, W. (2014) Measuring sustainability at universities by means of the Sustainability Tracking, Assessment and Rating System (STARS): early findings from STARS data. Journal of Environment, Development and Sustainability, 17, 209-220. http://doi.org/ $\underline{10.1007 / \mathrm{s} 10668-014-9564-3}$

Van den Bergh, J.C.J.M. (2010) Externality or sustainability economics? Ecological Economics, 69(11), 2047-2052 http://dx.doi.org/10.1016/j.ecolecon.2010.02.009

Velazquez, L., Munguia, N., Platt, A. and Taddei, J. (2006) Sustainable university: what can be the matter? Journal of Cleaner Production, 14(9), 810-819. http://dx.doi.org/10.1016/j.jclepro.2005.12.008

Venetoulis, J. (2001) Assessing the ecological impact of a University. The ecological footprint for the University of Redlands. International Journal of Sustainability in Higher Education, 180-196. http://doi.org/10.1108/14676370110388381

Vernon, J., Peacock, M., Belin, A., Ganzleben, C. and Candell, M. (2010) Study on the Costs and Benefits of EMAS to Registered Organizations Retrieved on January $1^{\text {st }} 2011$ from http://ec.europa.eu/environment/emas/ pdf/news/costs and benefits of emas.pdf Accessed $16^{\text {th }}$ December 2012

Viebahn, P. (2002) An environmental management model for universities: from environmental guidelines to staff involvement, Journal of Cleaner Production, 10(1), 3-12. http://dx.doi.org/10.1016/S0959$\underline{6526(01) 00017-8}$ 
Proposal of a set of Key Performance Indicators for the environmental assessment of Higher Education Institution

Viñoles-Cebolla, R., Bastante-Ceca, M., Capuz-Rizo, S.F. (2015) An integrated method to calculate an automobile's emissions throughout its life cycle. Energy, 83, 125-136. http://doi.org/10.1016/j.energy.2015.02.006

Vivancos Bono, J.L. (2005) Propuesta Metodológica para la Simplificación del ACV en su Aplicación a los Componentes Plásticos del Automóvil en el Marco del Ecodiseño. Ed. Universidad Politécnica de Valencia.

Wackernagel, M., \& Rees, W. (1996) Our ecological footprint: reducing human impact on the earth. Gabriola Island, Canada: New Society Publishers 0-86571- 312-X.

Wackernagel, M., \& Rees, W. E. (1997) Perceptual and structural barriers to investing in natural capital: Economics from an ecological footprint perspective. Ecological Economics, 20(1), 3-24. http://doi.org/10.1016/S0921-8009(96)00077-8

Waheed, B., Khan, F. I., \& Veitch, B. (2011) Developing a quantitative tool for sustainability assessment of HEIs. International Journal of Sustainability in Higher Education, 12(4), 355-368. http://doi.org/10.1108/14676371111168278

Walton, S. V., \& Galea, C. E. (2006) Some considerations for applying business sustainability practices to campus environmental challenges. International Journal of Sustainability in Higher Education, 6(2), 147-160 http://doi.org/http://dx.doi.org/10.1108/1467637051058986

Watkins, P., and Glover, A. (2016) Future Generations: Developing Education for Sustainability and Global Citizenship for University Education Students. Teaching Education for Sustainable Development at University Level. Leal Filho, W., Pace, L. (ed) Springer International Publishing. Cham. 67-81. http://doi.org/10.1007/978-3-319-32928-4 5

Weideman, B.P., Thrane, M., Christensen, P., Schmidt, J., Løkke, S. (2008) Carbon footprint, a catalyst for LCA. Journal of Industrial Ecology, 12(1), 3-6. http://doi.org/10.1111/j.1530-9290.2008.00005.x

White, J. (2015) How much attention to Stakeholders interests? A practitioner's view of the need to take account of stakeholder interests. Global Policy, 6(4), 501-503. http://doi.org/10.1111/1758$\underline{5899.12254}$

Wiedmann, T., \& Barrett, J. (2010) A review of the ecological footprint indicator-perceptions and methods. Sustainability, 2(6), 1645-1693. http://doi.org/10.3390/su2061645 
Wild, C., Jessen, C., Bednarz, V. N., Rix, L., \& Teichberg, M. (2015) Environmental Indicators. (R. H. Armon \& O. Hänninen, Eds.). Springer. http://doi.org/10.1007/978-94-017-9499-2

Willamette University Sustainability Council. (2008) 2007-2008 sustainability indicators report. Willamette University

Wright, E. P., \& Drossman, H. (2002) The ecological footprint of the Colorado College: An examination of sustainability. Environmental Science, 5(1), 23.

Wright, E., Gill, B., Wallin, P., Hutchison, K., \& Prebble, M. (2009) The ecological footprint of UEA.

Wright, T. S. A., \& Wilton, H. (2012) Facilities management directors' conceptualizations of sustainability in higher education. Journal of Cleaner Production, 31, 118-125. http://doi.org/10.1016/j.jclepro.2012.02.030

World Resources Institute and World Business Council for Sustainable Development (2011) Corporate Value Chain (Scope 3) Accounting and Reporting Standard - Supplement to the GHG Protocol Corporate Accounting and Reporting Standard. Retrieved on June $1^{\text {st }} 2016$ from http://www.ghgprotocol.org/files/ghgp/public/Corporate-ValueChain- Accounting-Reporing-Standard 041613.pdf

World Wild Foundation (2015) Observatorio de la electricidad. Retrieved on June $15^{\text {th }} \quad 2013 \quad$ from http://www.wwf.es/que hacemos/cambio_climatico/nuestras soluci ones/energias renovables/observatorio de la electricidad/

Zaman, A. U. (2014). Identification of key assessment indicators of the zero waste management systems. Ecological Indicators, 36, 682-693. http://doi.org/10.1016/j.ecolind.2013.09.024 



\section{ANNEX 1: COMPARATIVE ANALYSIS OF THE METHODOLOGY OF CALCULATION OF EF IN DIFFERENT AREAS.}

Lo Iacono Ferreira, V.G., Torregrosa-López, J.I., López Pérez, F., PachecoBlanco, B., Viñoles-Cebolla, R. (2011a) Comparative Analysis of the methodology of calculation of EF in different areas. XV International Congress on Project Management. Huesca. AEIPRO ISBN: 978-84-6154543-8

http://www.aeipro.com/aplic/tree congresos/detalle remository aeipro.php? file $=3331$

Notice that this paper has been edited to match the style chosen for this document. Figures and tables have also been edited (only format). Abbreviations have also been homogenized. A complete abbreviation code is provided in page 23.

\section{ABSTRACT}

Ecological Footprint (EF) has been widely used as an environmental indicator in countries and, lesser extent, as a sustainable indicator in cities and corporations (Torregrosa-López et al, 2010b). This is due to the lack of a calculation methodology that allows analysis of EF in systems considered big demanders of ecological productive land and, therefore, highly deficient in EF. For this matter, EF gets a different significance as for what it gets when is applied with a bigger scale, therefor it significance and interpretation must be different (Fiala, 2008).

In this paper, an analysis of difference between goals and the methodology of calculation to applied EF in diverse area, as countries, regions, municipalities, corporations, universities and schools will be presented. Special attention in the difficulties that presents the methodologies will be paid, as in alternatives for them. A comparison between different scopes will be emphasizing, using $\mathrm{EF}$ as an indicator of sustainability in universities.

\subsection{INTRODUCTION AND GOALS}

EF concept was developed by M. Wackernagel and W. Rees (1996) as 'the ecologically productive territory needed to produce the resources used and to assimilate the waste and emissions produced by a population with a specific life mode indefinitely'. From that point on, EF has been applied to diverse scenarios as regions, countries, municipalities, corporations, universities and schools. 
Proposal of a set of Key Performance Indicators for the environmental assessment of Higher Education Institution

Roughly, calculation procedure proposes by Wackernagel \& Rees consists on selecting major categories and individual items. Personal average annual consumption of particular items (i) is calculated from national databases.

Few of them has used strictly Wackernagel \& Rees procedure, most of them has adapted the methodology to their own scenarios depending the interest of results, available information, etc. Trades have to be considered and included as follows (Equation 12-1):

\section{Equation 12-1}

Trade corrected consumption $\left[\frac{\mathrm{kg}}{\mathrm{capita}}\right]=$ production + imports - exports

Annual productivity average (p) and consumption (c) for each item is also needed. An estimation of land area appropriated (aa) per capita is calculated as follows (Equation 12-2):

Equation 12-2

$$
\mathrm{aa}_{\mathrm{i}}\left[\frac{\mathrm{ha}}{\text { capita }}\right]=\frac{\mathrm{c}_{\mathrm{i}}\left[\frac{\mathrm{kg}}{\text { capita }}\right]}{\mathrm{p}_{\mathrm{i}}\left[\frac{\mathrm{kg}}{\mathrm{ha}}\right]}
$$

Finally, EF is calculated by aggregation of aai (Equation 12-3):

Equation 12-3

$$
\mathrm{EF}\left[\frac{\mathrm{ha}}{\text { capita }}\right]=\sum_{\mathrm{i}} \mathrm{aa}_{\mathrm{i}}\left[\frac{\mathrm{ha}}{\text { capita }}\right]
$$

Wackernagel \& Rees define items based on the classification made in official statistics, to simplify data collection. Items selected are:

- Food

- Housing

- Transportation

- Consumer goods

- Services

For each item, for types of area are considered:

- Energy land: area needed to produce necessary energy

- Consumed land: area needed for necessary infrastructure

- Farm land: area needed to produce necessary food

- Forest land: area needed to produce necessary forest products

Several types of lands are taking into account: Energy or $\mathrm{CO}_{2}$ land (land appropriated by fossil energy use), degraded land (built environment), 
reversibly built environment (gardens), cultivated systems (crop land), modified systems (pastures and managed forest), productive natural ecosystems (untouched forest to assimilate $\mathrm{CO}_{2}$ emissions) and nonproductive areas (deserts and icecaps).

As said before, not all EF assessments were made strictly as Wackernagel \& Rees propose. Most of them were made adapting the methodology to the needs of the area/organization analyzed.

Main goal of this paper is to analyze and compare different EF methodologies applied for different areas as countries, municipalities, schools and universities.

\subsection{EF METHODOLOGIES AND ITS APPLICATIONS}

This section collects some of the most significant EF assessment made over different areas or environments.

\subsubsection{COUNTRIES AND CONTINENTS}

Undoubtedly most significant EF assessment applied on countries and continents are those conducted by GFN (Ewing et al, 2010), an organization funded by Mathis Wackernagel. GFN has evaluated EF of 240 countries, territories and regions for annual periods of time starting in 1961. Results are bunch on an Atlas with a detail analysis published every two years.

As expected, methodology applied in EF assessment is a close relative of the original methodology propose by Wackernagel \& Rees although every assessment the methodology is updated. Variations are informed together with analysis and results.

Items considered in $2007 \mathrm{EF}$ assessment (Ewing et al, 2010) considered six land-use types:

- Built-up land

- Forest land

- Cropland

- Grazing land

- Carbon Footprint

- Fishing grounds

EF results are expressed in units of global hectares (gha). The "global" characteristic considered world average bioproductivity to obtain hectares of bioproductivity area needed.

As well as in the original methodology, hectares demanded (D) are calculating by dividing the consumption of an item by the yield (Y) per hectare or waste 
Proposal of a set of Key Performance Indicators for the environmental assessment of Higher Education Institution

emissions by the absorptive capacity per hectare. Math operation can be represented as in Equation 12-4.

Equation 12-4

$$
E F\left[\frac{g h a}{\text { year }}\right]=\sum_{i} \frac{D_{i}\left[\frac{\text { unit }}{\text { year }}\right]}{Y_{i}\left[\frac{\text { unit }}{\text { gha }}\right]}
$$

Yi can be obtained as in Equation 12-5.

Equation 12-5

$$
Y_{i}=\frac{Y_{N}}{Y F \cdot E Q F}
$$

Where YF correspond to yield factor that compare national average yield to world average yield, EQF to equivalence factor that introduce the relative productivity among lands and sea areas and $\mathrm{YN}$ is the national average yield for Di.

Principal source of information for yields is United Nations Food and Agriculture Organization database (FAOSTAT). This database has a strict policy of mutually exclusive yields, if various types of crops are grown in the same area, proportional area is assign to each crop avoiding double counting.

Notice a change in the identification of each parameter, where in the original methodology was "c", as consumption, the actual methodology named "D", as demand. The same way, " $p$ " for productivity is change by "Y" for yield. Change in numerator is based on a modification of the concept, nowadays not only consumption is considered, emissions are considered too. The same way, "yield" includes capacity concept.

\subsubsection{NATIONAL FOOTPRINT ACCOUNTS}

To obtain the most rigorous results as possible, GFN considered four types of Footprints: Footprint for Production (EFP), Footprint for consumption (EFC), Footprint for imported commodities (EFI) and Footprint for exported commodities (EFE). Amount trades of imports and exports (resources and $\mathrm{CO} 2$ emissions) are needed.

EF subscribed to a country is the one known as EFC, to obtain this value Equation 12-6 is applied:

Equation 12-6

$$
E F_{C}=E F_{P}+E F_{I}-E F_{E}
$$

$\mathrm{EF}$ results are compared to biocapacity $(\mathrm{BC})$ in order to establish a debt and credit relation. 
$\mathrm{BC}$ is calculated as shown in Equation 12-7 where A represents the available area for a given land use type.

Equation 12-7

$$
B C=A \cdot Y F \cdot E Q F
$$

Evolution of $\mathrm{EFC}$ and $\mathrm{BC}$ of each country is analyzed taking into account variations on population.

\subsubsection{CitiES AND MUNICIPALITIES}

Many cities and municipalities have evaluated its EF and different methodologies have been applied. As a sample, EF Barcelona analysis is presented.

Main goal of Barcelona EF analysis (Muñiz \& Galindo, 2005) of its commuting evaluate its urban layout and transport.

Different variables have been taken into account; to characterize land use, parameters as accessibility and suburbanization patterns of density population have been considered as well as socio-economic factors. Energy efficiency and local pollution has been included in transport energy consume indicators.

Territorial scope has been defined, Barcelona Metropolitan Region (BMR), and analyze with ring theory. An important aspect has been emphasized, evolution area of BMR on time between 1986 and 1996.

Items or aspects considered for EF calculation are:

- Energy use in traction

- Vehicle manufacturing

- Construction and maintenance of transport infrastructure

- Land occupied by transport infrastructure

Scope has been limited to cars, buses, motorbikes, trains, underground and bicycles, considering walking excluded for non-impact contribution.

Base of calculation has been chosen as residents (i) by municipality. Direct parameters involved in EF evaluation are:

ECz: energy consumption of mode transport $\mathrm{z}$ per kilometer and passenger $[\mathrm{GJ} / \mathrm{km}]$

ELz: ecological land per GJ by mode transport z [ha/GJ]

Dij: network distance between municipalities I and $\mathrm{j}[\mathrm{km}]$

Tripijz: annual trips made by residents from municipality I towards municipality $\mathrm{j}$ by mode transport $\mathrm{z}$. 
Proposal of a set of Key Performance Indicators for the environmental assessment of Higher Education Institution

Lz: land area corresponding to the infrastructure space used by mode transport $\mathrm{z}[\mathrm{ha}]$

Applied formula is represented in Equation 12-8.

Equation 12-8

$$
E F_{i}=\sum_{z}\left[\left[\sum_{j} E C_{z} E L_{z} D_{i j} \operatorname{Trip}_{i j z}\right]+L_{z}\right]
$$

EF results and growth rate are express by metropolitan rings. Complete results can be found in Muñiz \& Galeano article. Barcelona city EF and BMR EF are grouped in Table 12-1.

Table 12-1 EF results for BMR

\begin{tabular}{lllll}
\hline \multirow{2}{*}{ Metropolitan area } & \multicolumn{3}{c}{ Year } & Growth rate \\
\cline { 2 - 4 } & 1986 & 1991 & 1996 & $\begin{array}{l}\text { 1986-1996 } \\
\text { Barcelona city }\end{array}$ \\
\cline { 2 - 4 } BMR & 16,891 ha & 22,742 ha & 25,799 ha & 0.52 \\
\hline
\end{tabular}

Muñiz \& Galeano observed that urban transport is main responsible for environmental impact of Barcelona area. Limitations on methodology applied as technology and level of vehicles occupancy variation in time are remarked in conclusions. Even though, data analyses were made and conclusions about transport impact in Barcelona area were taken.

Other example of EF application in this kind of areas is the case of Navarra (Departamento de Medio Ambiente, Ordenación del Territorio y Vivienda de la Comunidad foral de Navarra, 2001) that starts with EF assessments in 2000. Traditional methodology is applied and local territorial information system used to access needed data. EF indicator is applied regularly to evaluate activities and process taking place in this region.

\subsubsection{ECONOMIC AREAS}

In Mediterranean zone, perhaps one of de most important economic area is tourism. EF has been applied as a key of tourism sustainability (Hunter \& Shaw, 2005).

Modify methodology for tourism sector use parameters as per capita national EF data, flight data and length of stay information to obtain EF estimation. 
Additional information as number of tourist arrived by air and it source, an estimation of EF destination area can be made.

Aspects considered for EF calculation are:

- Round trip flight distance

- Energy use per tourist

- Required forest land

- Air transport EF on forest land

- Air transport EF in world average space

- Host country per capita EF for average length of stay

- Gross per sourest EF

- Deducting home country

Scenarios considered and EF results are presented in Table 12-2.

Table 12-2 Scenarios for EF tourism assessment

\begin{tabular}{|c|c|c|c|c|c|}
\hline \multicolumn{4}{|l|}{ Scenario } & \multirow{2}{*}{$\begin{array}{l}\text { Year } \\
\text { of data }\end{array}$} & \multirow{2}{*}{$\begin{array}{l}\text { EF } \\
\text { [gha/tourist] }\end{array}$} \\
\hline Tourist origin & $\begin{array}{l}\text { Tourist } \\
\text { destination }\end{array}$ & $\begin{array}{l}\text { Night } \\
\text { stay }\end{array}$ & per & & \\
\hline International & New Zealand & & 18 & 1999 & 2.19 \\
\hline UK & New Zealand & & 28 & 1999 & 3.74 \\
\hline Australia & New Zealand & & 12 & 1999 & 0.66 \\
\hline USA Miami & Costa Rica & & 14 & - & 0.09 \\
\hline UK - London & Manaus & & 28 & - & 2.05 \\
\hline
\end{tabular}

Benefits of using EF as sustainable tourism indicator are identified over conclusions of Hunter \& Shaw paper. Most significant appreciations are: it capacity for comparisons between different impact components and it value providing an indication of the overall ecological impact of tourism products on global biological resources.

Other tourism sector studies (Patterson et al., 2008) applied EF as a tool to design strategies to increase or decrease visitation or its associated consumption in the coming years based on observed and desired EF of tourist and residents.

EF application has been applied in textile industry (Herva et al., 2008). Object of study is manufacturing work of cloth. A flow analysis is made and energy, resources and waste categories are considered and traditional EF methodology is applied.

\subsubsection{COMPANIES AND CORPORATIONS}

MC3 methodology (Doménech Quesada, 2009) is design to evaluate corporation and companies EF. The proposal combine books of the 
Proposal of a set of Key Performance Indicators for the environmental assessment of Higher Education Institution

corporation with specific factors to convert economic values of an accounting register in hectares.

An inventory of principal consumption categories of the company has to be made and waste (Marañón et al., 2008) and land use considered. A matrix consumption-surface is constructed in a worksheet as principal tool to evaluate Corporative Ecological Footprint.

This methodology provides a solution to those EF goods that can be evaluated by traditional EF methodology because of it not biotic origin. Examples of these goods are machinery, computers and tools. Energy intensity factor are applied and good depreciation rates considered. Gijon Port Corporation was first case of study where Doménech applied his method (Doménech \& Arenales, 2008).

Aspects considered for these analyses are: electricity, fuels, raw materials, building materials, services, office, land use, agricultural resources and forestall resources. Results are resumed in Table 12-3.

Table 12-3 Gijon Port Corporation Ecological and Carbon Footprint results.

\begin{tabular}{lrrrr}
\hline Year & \multicolumn{1}{c}{$\mathbf{2 0 0 4}$} & \multicolumn{1}{c}{$\mathbf{2 0 0 5}$} & \multicolumn{1}{c}{$\mathbf{2 0 0 6}$} & \multicolumn{1}{c}{$\mathbf{2 0 0 7}$} \\
\hline Carbon Footprint [tCO,/year] & 30,426 & 32,097 & 30,194 & 29,845 \\
Ecological Footprint [ha/year] & 5,298 & 6,693 & 6,182 & 6,167 \\
\hline
\end{tabular}

Main conclusion express by Doménech \& Arenales about this analysis is that EF has demonstrated to be a good corporative sustainable indicator that permits waste controlling and resource controlling.

\subsection{Schools and Universities}

Two relevant cases are analyzed, University of Redlands methodology, pioneer in EF application to Universities and UPV, a special condition university because it magnitude and it EMAS environmental management system.

\subsubsection{Redlands University}

EF has been used as a sustainable indicator for the university; an exhaustive analysis has been performed (Venetoulis, 2001).

The assessment, extract of traditional EF methodology, consists in evaluation three different footprints: hydric footprint, waste footprint and energetic footprint. A comparison between each footprint and available land for each particular action constituted main evaluating method. Results for 1998 are presented in Table 12-4. 


\begin{tabular}{ll}
\hline Hydric Footprint & $116 \mathrm{gha}$ \\
Waste Footprint & $287 \mathrm{gha}$ \\
Energetic Footprint & $1900 \mathrm{gha}$ \\
Ecological Footprint & $2303 \mathrm{gha}$ \\
\hline
\end{tabular}

As conclusion, Venetoulis points that EF analysis help to reveal hidden ecological costs of consumption that cannot be capture by traditional indicators. EF capacity as an awareness tool to achieve sustainability is discussed. Desire of university members to understand environmentally intensive consumption and make changes that reduce it are assigned as clue aspects to make EF indicator for sustainability useful.

\subsubsection{UNIVERSITAT POLITÈCNICA DE VALÈNCIA}

Proposed methodology provides a global EF and three partials EF, one for each campus, has been considered (Torregrosa-López et al., 2011). An inventory with the aspects that constitute the universe has been defined as follows: Electric Energy, Infrastructures, Fuel, Water, Paper, Waste, Food \& Drinks and Mobility.

EF methodology applied can be obtained by adding CF to PF (Equation 129).

\section{Equation 12-9}

$$
E F\left(\frac{h a}{y e a r}\right)=C F\left(\frac{h a}{y e a r}\right)+P F\left(\frac{h a}{y e a r}\right)
$$

Equation 12-10

$$
C F\left(\frac{h a}{\text { year }}\right)=\frac{\sum_{i=1}^{n} \operatorname{aspect}_{i}\left(\frac{\text { unit }}{\text { year }}\right) * \operatorname{CoF}_{i}\left(\frac{\text { ggCO }_{2}}{\text { unit }}\right)}{O A U\left(\frac{k g C O_{2}}{h a}\right)}
$$

Equation 12-11

$$
P F\left(\frac{h a}{\text { year }}\right)=\sum_{i=1}^{n} \frac{\operatorname{aspect}_{i}\left(\frac{\mathrm{kg}}{\text { year }}\right)}{\operatorname{productivity}_{i}\left(\frac{\mathrm{kg}}{\mathrm{ha}}\right)}
$$

Equation 10 and Equation 11 shows how to obtain $\mathrm{CF}$ and PF amounts, where: (i) represent each aspect considered and aspect the amount of it per year; CoFi is the conversion factor for each (i) aspect; OAU represents de Overall Average Uptake of the earth; and productivity is the average productivity of (i) aspect. 
Proposal of a set of Key Performance Indicators for the environmental assessment of Higher Education Institution

EF is calculated for the total student population of the university. For UPV, the parameter that defines student population is the equivalent student (es): an es is a student enrolled in 70 credits per year. Days of classes, holydays and exam has been taken into account. In 2009, the figure of the total student populations using this parameter was 27,865 es.

Years 2006, 2007, 2008 and 2009 have been evaluated. For the first three years, not all information was available because EMS was still being implemented. However, for 2009, environmental audits have provided sufficient quantitative information.

Table 12-5 collects EF real results by aspects. Table 12-6 summarize UPV EF results for each year evaluated.

Table 12-5 EF results by aspects for Universitat Politècnica de València

\begin{tabular}{ll|llll}
\hline \multicolumn{2}{l}{ Units: [ha/year] } & 2006 & 2007 & 2008 & 2009 \\
\hline & Electric energy & $3,965.67$ & $4,191.92$ & $3,492.29$ & $3,134.43$ \\
& Fuel & 590.95 & 768.76 & 583.49 & 182.44 \\
& Water & 25.98 & 22.85 & 28,81 & 58.85 \\
Carbon & Paper & & & 7,67 & 8.23 \\
Footprint & Waste & & & & 6.42 \\
& Mobility & & & & $4,317.77$ \\
& Infrastructure & $12,077.94$ & $12,208.99$ & $12,208.99$ & $12,208.99$ \\
& Food \& Drinks & $1,445.32$ & $1,481.24$ & $1,281.51$ & $1,248.60$ \\
\hline Productive & Waste & & & & $4.10^{-4}$ \\
Footprint & Food \& Drinks & $1,254.49$ & $1,492.69$ & 1291.42 & 1258.25 \\
\hline Ecological Footprint & $\mathbf{1 9 , 5 6 2 . 3 5}$ & $\mathbf{2 0 , 1 6 6 . 4 5}$ & $\mathbf{1 8 , 8 9 4 . 1 9}$ & $\mathbf{2 2 , 4 2 5 . 9 8}$ \\
\hline
\end{tabular}

EMS of the PUV has been one of the more important sources (TorregrosaLópez et al., 2010b) of information as well as the mobility study of PUV carried out by ITRAT in 2009 (Torres Martínez et al., 2010).

Initiatives, activities and actions implemented are reflected in PUV EF, although a deeper analysis to draw better conclusions is required. Authors remark than EF results interpretation is simple and can be used as a tool to direct awareness. 


\begin{tabular}{lllll}
\hline & $\mathbf{2 0 0 6}$ & $\mathbf{2 0 0 7}$ & $\mathbf{2 0 0 8}$ & $\mathbf{2 0 0 9}$ \\
\hline CO $_{2}$ emissions (kg/es.year) & 2859 & 2949 & 2782 & 3344 \\
CF (ha/es.year) & 0.650 & 0.670 & 0.632 & 0.760 \\
PF (ha/es.year) & 0.052 & 0.054 & 0.046 & 0.045 \\
EF (ha/es.year) & 0.702 & 0.724 & 0.678 & 0.805 \\
\hline
\end{tabular}

\subsection{Discussion AND CONCLUSIONS}

This study evidences that standard methodologies for each different area are needed. To fulfil this necessity, the European Commission together with the European Commission's Joint Research Centre and DG environment is developing a technical guide for the calculation of the environmental footprint of companies (European Commission, 2011a) that will be based on different methodologies and guidance widely recognized as, for example, Guidance on how to measure and report your greenhouse gas emissions (Defra/DECC, 2009).

As well, same pool directed by the European Commission is developing a methodology for the calculation of the environmental footprint of products (European Commission, 2011b) using references as PAS 2050 (British Standard Institute, 2008) and GFN (Global Footprint Network, 2009).

A summary of significant characteristics of each methodology is presented in Table 12-7. Influence of aspects in methodology applied is express by '+++++' for biggest grade of influence to '-' for no influence.

Table 12-7 shows energy as the aspect with most influence in EF. Mobility has strong influence in the case of big areas (countries, regions and cities) and Universities and should be always included in the calculation of EF these areas. In case of big areas of study, land use has a special relevance.

Result balance gives a view of EF concept for each area. For big regions as countries or cities, EF result can be rather positive or negative compared to area territory. However, economic areas, companies and universities have always negative results; resources needed have an important weight while area resources are insignificant or inexistent. 
Proposal of a set of Key Performance Indicators for the environmental assessment of Higher Education Institution

Table 12-7 Comparison of EF methodologies

\begin{tabular}{|c|c|c|c|c|c|c|c|c|c|}
\hline \multirow{2}{*}{ 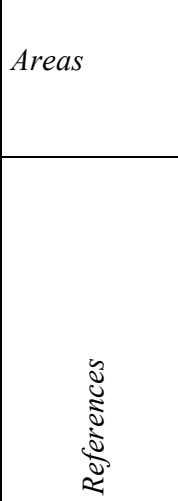 } & \multirow{2}{*}{ 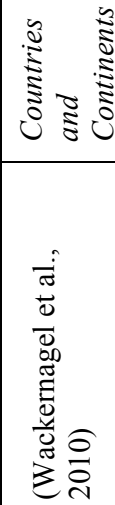 } & \multicolumn{2}{|c|}{$\begin{array}{l}\text { Cities and } \\
\text { municipalities }\end{array}$} & \multicolumn{3}{|c|}{ Economic areas } & \multirow{2}{*}{ 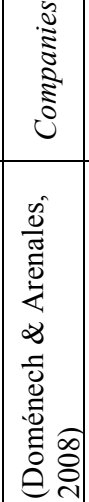 } & \multicolumn{2}{|c|}{$\begin{array}{l}\text { Schools and } \\
\text { Universities }\end{array}$} \\
\hline & & 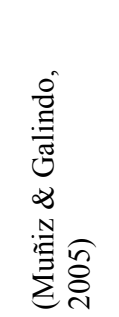 & 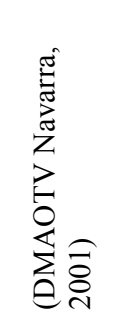 & 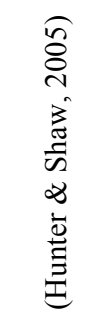 & 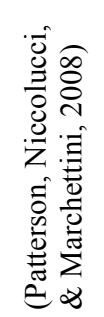 & 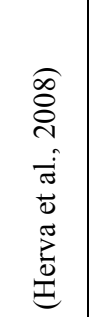 & & 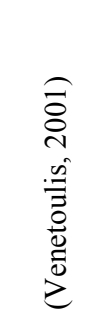 & 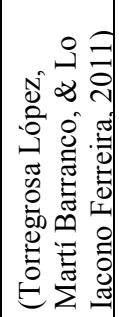 \\
\hline \begin{tabular}{l|l} 
Energy &
\end{tabular} & +++ & \multicolumn{2}{|l|}{+++} & \multicolumn{3}{|l|}{ +++++ } & \begin{tabular}{l|}
+++ \\
++
\end{tabular} & +++++ & +++++ \\
\hline के Land use & ++++ & \multirow{2}{*}{\multicolumn{2}{|c|}{$\begin{array}{ll}++ \\
+++++\end{array}$}} & \multicolumn{3}{|l|}{+} & + & - & + \\
\hline Mobility & + & & & +++++ & & - & + & ++++++ & ++++++ \\
\hline $\begin{array}{l}\text { Infrastru } \\
\text { șture }\end{array}$ & - & \multicolumn{2}{|l|}{+} & \multicolumn{3}{|l|}{ +++ } & + & - & +++ \\
\hline Others & Yes & \multicolumn{2}{|l|}{ Yes } & \multicolumn{3}{|l|}{ Yes } & Yes & Yes & Yes \\
\hline $\begin{array}{l}\text { Calculation } \\
\text { basis }\end{array}$ & $\begin{array}{l}\text { populat } \\
\text { ion per } \\
\text { year }\end{array}$ & $\begin{array}{l}\text { resident } \\
\text { s by } \\
\text { municip } \\
\text { ality per } \\
\text { year }\end{array}$ & $\begin{array}{l}\text { Residen } \\
\mathrm{t} \text { per } \\
\text { year }\end{array}$ & $\begin{array}{l}\text { Tourist } \\
\text { by } \\
\text { origin } \\
\text { per } \\
\text { year }\end{array}$ & $\begin{array}{l}\text { Tourist } \\
\text { per } \\
\text { year } \\
\text { and } \\
\text { residen } \\
\text { t per } \\
\text { vear }\end{array}$ & $\begin{array}{l}\text { Units } \\
\text { prod } \\
\text { uce } \\
\text { per } \\
\text { year }\end{array}$ & year & $\begin{array}{l}\text { Studen } \\
\text { ts and } \\
\text { popula } \\
\text { tion } \\
\text { per } \\
\text { year }\end{array}$ & \begin{tabular}{|l|} 
Equiva \\
lent \\
student \\
s per \\
year
\end{tabular} \\
\hline $\begin{array}{l}\text { Source } \\
\text { information }\end{array}$ & $\begin{array}{l}\text { Nation } \\
\text { al } \\
\text { Statisti } \\
\text { c } \\
\text { Institut } \\
\text { ions } \\
\text { and } \\
\text { United } \\
\text { Nations }\end{array}$ & $\begin{array}{l}\text { Referen } \\
\text { ces }\end{array}$ & $\begin{array}{l}\text { Local } \\
\text { territori } \\
\text { al } \\
\text { informa } \\
\text { tion } \\
\text { system }\end{array}$ & $\begin{array}{l}\text { Nation } \\
\text { al } \\
\text { statistic } \\
\text { Institut } \\
\text { ions }\end{array}$ & $\begin{array}{l}\text { Popula } \\
\text { tion } \\
\text { census }\end{array}$ & Books & & $\begin{array}{l}\text { Fieldw } \\
\text { ork }\end{array}$ & \begin{tabular}{|l|} 
EMAS \\
EMS
\end{tabular} \\
\hline $\begin{array}{l}\text { Results } \\
\text { balance }\end{array}$ & \multicolumn{3}{|c|}{ Can be positive or negative } & \multicolumn{6}{|c|}{ Mostly negative } \\
\hline
\end{tabular}

Input-Output statistic tables are the source of information for country EF calculation. In case of cities, companies and universities this information is not available and it has to be substituted for other kind of sources based on books of the corporations, EMS data or fieldworks.

In case of companies or universities there is not very clear methodology to avoid double counts in the calculation of EF. Scopes of the assessment are not well defined and direct and indirect aspects are many times counted together. 
Results of EF have different interpretations depending of the area of study. For countries and regions, EF focuses on measure the environmental impact of the activities vs biocapacity of the area of study. For cities, companies and universities, EF is focus on the assessment of environmental impact of the consumption of resources and the use of energy because of their character of net consumer of resources and energy of these activities.

In all cases, EF measures the capacity of the environment to provide biotic resources and energy to human activities. Other aspects, as the capacity of the ecosystems to provide other ecological functions, most of the abiotic resources, whereas to measure the loss of quality of the ecosystems and the damage on health of the human activities are not included in EF assessment. This statement should be strongly considered for a good interpretation of EF results.

\section{ACKNOWLEDGMENTS}

The results of this study are a part of the project titled: "Proposal of a Methodology for the assessment of environmental footprint and carbon footprint at the university: a case study of Universitat Politècnica de València", financial supported by the "Program of Support to the Research and Development 2010-2011 (PAID-05-10)." of the Universitat Politècnica de València.

\subsection{REFERENCES}

British Standard Institute (2008) Specifications for the assessment of the life cycle greenhouse gas emissions of goods and services. PAS 2050.

Defra/DECC (2009) Guidance on how to measure and report your greenhouse gas emissions. Retrieved on January $1^{\text {st }} 2010$ from https://www.gov.uk/government/publications/guidance-on-how-tomeasure-and-report-your-greenhouse-gas-emissions

Departamento de Medio Ambiente, Ordenación del Territorio y Vivienda de la Comunidad foral de Navarra (2001) La Huella ecológica de la comunidad foral de Navarra, aplicaciones técnicas y de comunicación. Navarra. 
Proposal of a set of Key Performance Indicators for the environmental assessment of Higher Education Institution

Doménech, J., \& Arenales, M. G. (2008) La Huella Ecológica de las empresas: 4 años de seguimiento en el puerto de Gijón. (U. d. Málaga, Ed.) Observatorio Iberoamericano del Desarrollo Local y la Economía Social.

Doménech Quesada, J. L. (2009) Huella de carbono corporativa: una herramienta de gestión empresarial contra el cambio climático. CONAMA 9.

European Commission (2011a) Corporate environmental footprint. Retrieved on $\quad$ March $29^{\text {th }} \quad 2011$ from http://ec.europa.eu/environment/eussd/corporate footprint.htm

European Commission (2011b) Environmental footprint of products. Retrieved on March 29 $9^{\text {th }} 2011$ from http://ec.europa.eu/environment/eussd/product footprint.htm

Ewing B., D. Moore, S. Goldnger, A. Oursler, A. Reed, and M. Wackernagel. (2010) The Ecological Footprint Atlas 2010. Oakland: Global Footprint Network. Retrieved on January $3^{\text {rd }} 2011$ from http://www.footprintnetwork.org/images/uploads/Ecological Footpr int Atlas 2010.pdf

Fiala, N. (2008) Measuring sustainability: Why the ecological footprint is bad economics and bad environmental science. Ecological Economics 67 516-525 http://dx.doi.org/10.1016/j.ecolecon.2008.07.023

Global Footprint Network (2009) Ecological Footprint Standards 2009. Oakland: Global Footprint Network. Retrieved on January $1^{\text {st }} 2010$ from

http://www.footprintnetwork.org/content/images/uploads/Ecological Footprint Standards 2009.pdf

Herva, M., Franco, A., Ferreiro, S., Alvarez, A., \& Roca, E. (2008) An approach for the application of the ecological footprint as environmental indicator in the textile sector. Journal of Hazardous Materials, 156(1-3), 478-487. http://doi.org/10.1016/j.jhazmat.2007.12.077

Hunter, C., \& Shaw, J. (2005) The ecological footprint as a key indicator of sustainable tourism. Tourism management, 46-57. http://dx.doi.org/10.1016/j.tourman.2005.07.016

Marañón, E., Iregui, G., Doménech, J.L., Fernández-Nava, Y. \& González, M. (2008) Propuesta de índices de conversion para la obtención de la huella de los residuos y vertidos. Observatorio Iberoamericano del Desarrollo Local y la Economía Social, 4. ISSN: 1988-2483. 
Muñiz, I., \& Galindo, A. (2005) Urban form and the Ecological Footprint of commuting. Case of Barcelona. Ecological Economics, 499-514. http://dx.doi.org/10.1016/j.ecolecon.2004.12.008

Patterson, T., Niccolucci, V., \& Marchettini, N. (2008) Adaptive environmental management of tourism in the Province of Siena, Italy using the ecological footprint. Journal of Environmental Management, $\quad 86, \quad 407-418$. http://dx.doi.org/10.1016/j.jenvman.2006.04.017

Torregrosa López, J., Martí Barranco, C., \& Lo Iacono Ferreira, V. (2010b) La Huella Ecológica y de Carbono como indicador ambiental en las Universidades: estudio del caso en la UPV. Cuaderno de Investigación en la Ingeniería. Investigación en Ingeniería medioambiental, III, 133-136. ISBN 978-84-268-1533-0

Torregrosa López, J., Martí Barranco, C., \& Lo Iacono Ferreira, V. (2011) Ecological Footprint and Carbon Footprint as an environmental indicator for universities. Case of study Polytechnic University of Valencia. GUNI 2010. 5th International Barcelona Conference on Higher Education.

Torres Martínez, A.J., Colomer Ferrandiz, J.V., Gallego Pérez, M.R., Pino Hernandez, E.M.; Ruiz Sánchez, T., Fiore, M.F. (2010) Plan de transporte para la Universidad Politécnica de Valencia. http://hdl.handle.net/10251/7301

Venetoulis, J. (2001) Assessing the ecological impact of a University. The ecological footprint for the University of Redlands. International Journal of Sustainability in Higher Education, 180-196. http://doi.org/10.1108/14676370110388381

Wackernagel, M., \& Rees, W. (1996) Our ecological footprint: reducing human impact on the earth. Gabriola Island, Canada: New Society Publishers 0-86571- 312-X. 